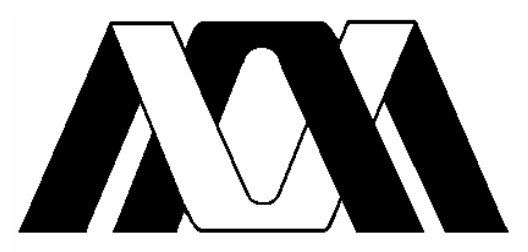

Casa abierta al tiempo

UNIVERSIDAD AUTÓNOMA METROPOLITANA

UNIDAD IZTAPALAPA

DIVISIÓN DE CIENCIAS SOCIALES Y HUMANIDADES

POSGRADO EN CIENCIAS ANTROPOLÓGICAS

Administración autónoma de la justicia y su relación con el estado.

El Sistema de Seguridad y Justicia Comunitaria de la

Costa - Montaña de Guerrero, México

Giovanna Gasparello

Tesis de Maestría en Ciencias Antropológicas

Directora: Dra. Alicia Castellanos Guerrero

Asesores: Dra. María Teresa Sierra Camacho

Dr. José Enrique González Ruiz

México, D.F.

Julio, 2007 


\title{
ADMINISTRACIÓN AUTÓNOMA DE LA JUSTICIA Y SU RELACIÓN CON EL ESTADO. EL SISTEMA DE SEGURIDAD Y JUSTICIA COMUNITARIA-POLICÍA COMUNITARIA DE LA COSTA-MONTAÑA DE GUERRERO, MÉXICO
}

\author{
Giovanna Gasparello
}

Tesis de Maestría en Ciencias Antropológicas Universidad Autónoma Metropolitana UAM Iztapalapa 


\section{ÍNDICE}

INTRODUCCIÓN

CAPÍTULO 1

DIVERSIDAD CULTURAL Y DERECHOS COLECTIVOS: ENTRE LA REIVINDICACIÓN Y LAS POLÍTICAS PÚBLICAS

1.1 Pueblos Indígenas, Nación y Estado en México: una constante relación de fuerza 10

Las políticas de Estado en las últimas tres décadas y el movimiento indígena en

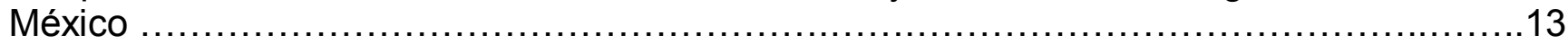

El multiculturalismo como actual política de Estado

\subsection{La realidad multicultural.}

Propuestas para el gobierno de la diversidad ..............................................

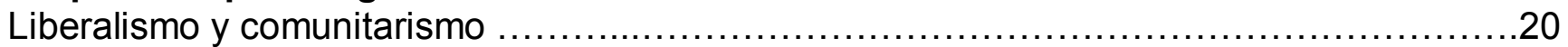

Luces y sombras del multiculturalismo: ¿a quiénes benefician los derechos culturales? ......22

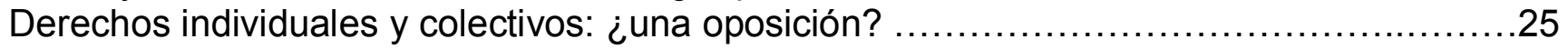

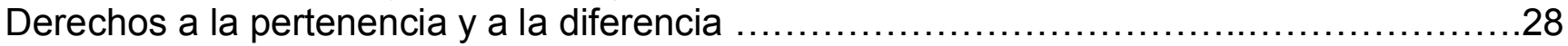

CAPÍTULO 2

AUTONOMÍA EN LA PRÁCTICA: DERECHOS Y DERECHO DE LOS PUEBLOS

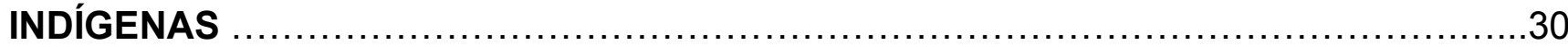

2.1 El derecho a la autonomía de los pueblos indígenas .............................. 30

¿Qué es la autonomía indígena? Elementos para una definición inacabada ..................30

La autonomía a debate: muchas experiencias, diferentes interpretaciones …...............33

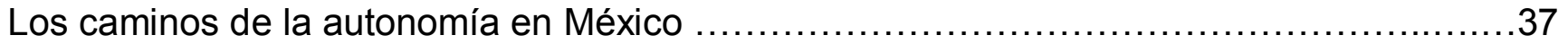

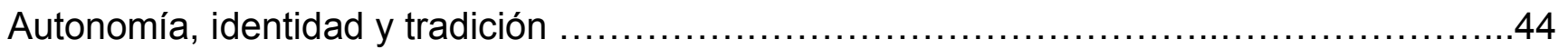

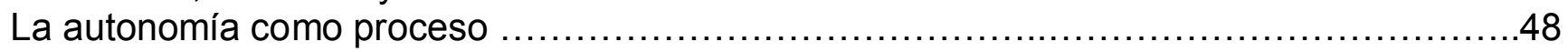

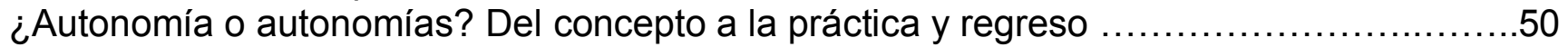

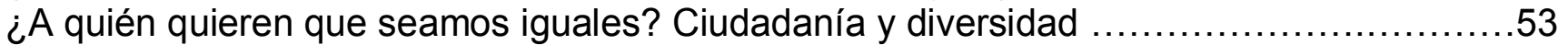

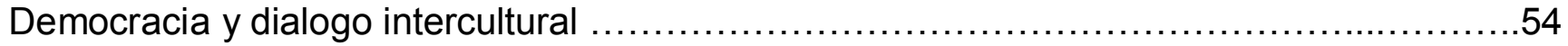

2.2 Los pueblos indígenas y el campo jurídico .......................................58

Algunos conceptos básicos: procesos jurídicos, pluralismo jurídico, interlegalidad ............58

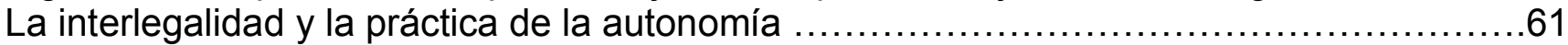

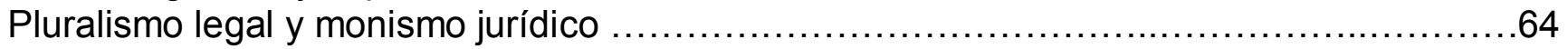

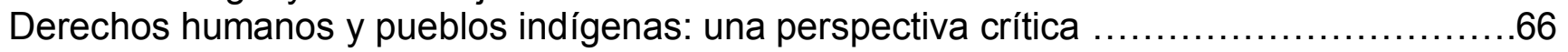

CAPÍTULO 3

LA COSTA-MONTAÑA DE GUERRERO: DE LA VIOLENCIA ESTRUCTURAL A LA

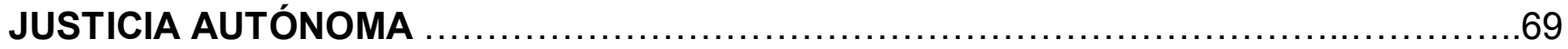

3.1 La región Costa-Montaña de Guerrero, violencia y seguridad ......................69

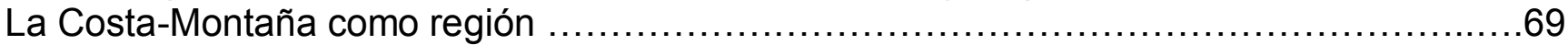

La Costa-Montaña en la encrucijada de la violencia. Violencia capilar y corrupción institucional 
Las instituciones judiciales y ministeriales en la Costa-Montaña:

¿donde quedó la justicia?

La construcción del espacio social en la Costa-Montaña: algunos sujetos y momentos determinantes

\subsection{El Sistema de Seguridad y Justicia Comunitaria- Policía Comunitaria de la Costa}

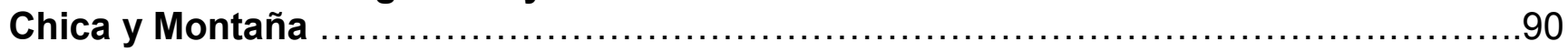

El contexto social en que se forma la Policía Comunitaria: testimonios de una

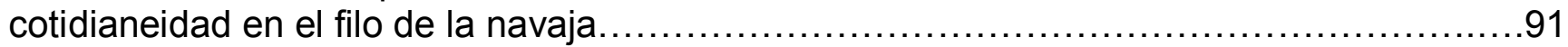

Las vertientes de la movilización: las organizaciones sociales y la Iglesia católica ...........92

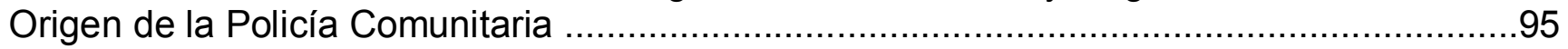

Estructura y funciones del Sistema de Seguridad y Justicia Comunitaria .......................99

El Reglamento Interno: la construcción del derecho comunitario ..........................104

El sistema normativo utilizado por el SSJC: la justicia según la Coordinadora Regional

de Autoridades Comunitarias................................................................. 105

Una institución comunitaria: persistencia e innovación ..................................107

¿Justicia comunitaria o usos y costumbres? La identidad indígena y el SSJC ..............110

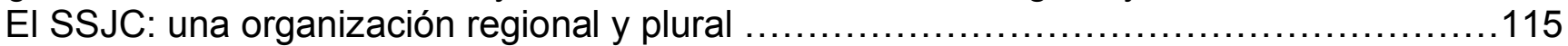

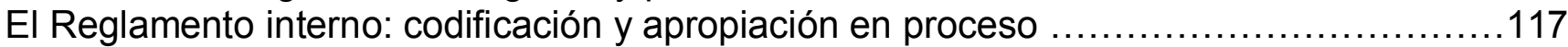

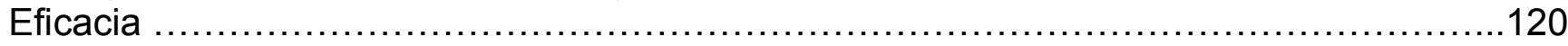

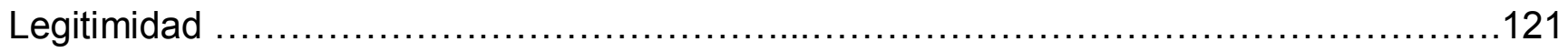

"Los Acuerdos de Horcacitas": reforma de la organización y zonificación del

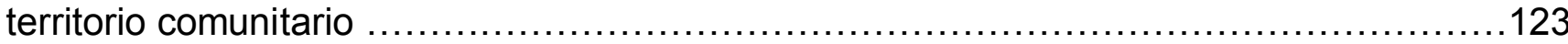

\subsection{La relación entre el Sistema de Seguridad y Justicia Comunitaria-Policía}

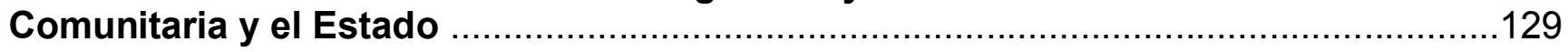

Encuentros y desencuentros: la relación del Sistema de Seguridad y Justicia

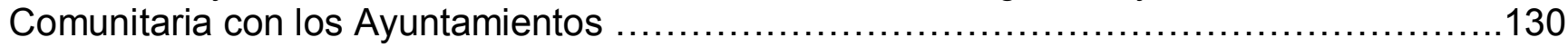

La relación entre el SSJC y la administración de justicia ...................................136

EI SSJC en la encrucijada de los "derechos humanos" ...................................139

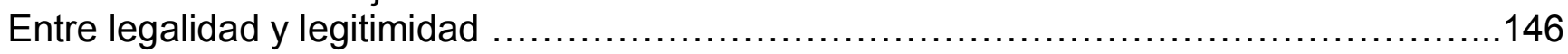

El discurso y la práctica: ¿autonomía, reconocimiento o respeto? ...................................148

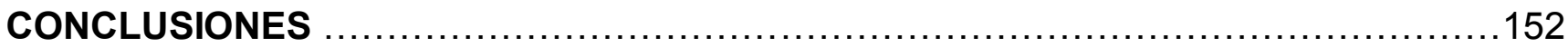

EI SSJC: hacia la reconstitución del tejido comunitario y regional ..........................153

Límites y alcances de la autonomía en el SSJC ..........................................156

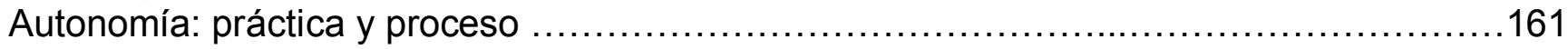

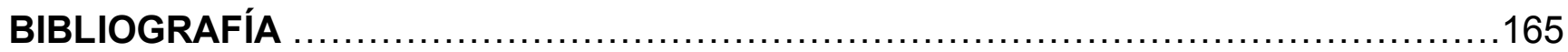

\section{ÍNDICE DE TABLAS}

Comunidades integradas al Sistema de Seguridad y Justicia Comunitaria por

pertenencia étnica

Municipios integrados al Sistema de Seguridad y Justicia Comunitaria: población,

$\%$ de indígenas, índice de marginación, comunidades integradas al SSJC ....................71

Violaciones a los derechos humanos en la Costa-Montaña ................................76

Sistema de Seguridad y Justicia Comunitaria: datos generales ............................ 98

Estructura y funciones del SSJC 1998/2006 ............................................. 103

Demandas atendidas por la CRAC 1998-2007 ........................................123 
Evaluación del SSJC.

\section{MAPAS}

Municipios integrados al Sistema de Seguridad y Justicia Comunitaria .89

Comunidades integradas al SSJC

\section{SIGLAS Y ABREVIACIONES}

SSJC: Sistema de Seguridad y Justicia Comunitaria

PC: Policía Comunitaria

CRAC: Coordinadora Regional de Autoridades Comunitarias

UNORCA: Unión Nacional de Organizaciones Regionales Campesinas Autónomas

CNOC: Coordinación Nacional de Organizaciones Cafetaleras

URC: Unión Regional Campesina

SSS: Sociedad de Solidaridad Social

Luz Mont: Unión de Ejidos Luz de la Montaña

CG 500 Años: Consejo Guerrerense 500 Años de Resistencia Indígena, Negra y Popular CAIN: Consejo de Autoridades Indígenas 


\section{INTRODUCCIÓN}

En este trabajo se analiza una de las muchas experiencias autonómicas presentes hoy día en el territorio mexicano: el Sistema de Seguridad y Justicia Comunitaria de la Costa Chica y Montaña de Guerrero, mejor conocido como Policía Comunitaria. Es quizás el más importante proceso autonómico (por su profundo arraigo en un territorio muy amplio, su eficacia y la legitimidad que tiene entre la población, por la complejidad de su estructura y la trascendencia de su función jurídica) activo en México después de la experiencia zapatista en Chiapas.

Me propongo demostrar, a partir de la revisión del debate sobre los derechos colectivos de los pueblos indígenas (entre ellos la autonomía) y sus sistemas jurídicos, que el SSJC es una práctica contrahegemónica que está construyendo autonomía a partir de las necesidades específicas de la población, lo que explica que hasta este momento se haya circunscrito a un solo ámbito de la vida social: mantener la seguridad en el territorio e impartir y administrar la justicia. Fundamento mi argumentación en el análisis de la estructura y las funciones del SSJC, así como de su relación con las instituciones ministeriales, judiciales y políticas (locales y municipales).

EI SSJC está construyendo una nueva legalidad, que a menudo entra en conflicto con el sistema jurídico formal; el arraigo de la nueva forma de expresión del derecho, basada en un sistema de practicas y valores distintos al dominante, determinará la pauta de la integración de las dos formas de entender lo jurídico, donde no se menoscaben los derechos colectivos de los pueblos ni los derechos fundamentales de la persona.

Todas las investigaciones realizadas hasta la fecha con la Policía Comunitaria tienen en común el entendimiento que esta experiencia representa un avance en la construcción de derechos y espacios democráticos para los pueblos indígenas; el debate sobre la necesidad del reconocimiento de la autonomía proporciona el marco en el cual se han desarrollado las investigaciones, aunque desde diversas perspectivas. Muchos trabajos se insertan en el campo de la Antropología Jurídica.

Si bien los debates que caracterizan dicha disciplina son importantes para la comprensión de la experiencia de la Policía Comunitaria, mi interés es insertar tal proceso en el marco de la autonomía como proyecto político de los pueblos indígenas; he tomado como referencia analítica la Antropología Jurídica pero no la he asumido como marco general. Así, tomo el SSJC como ejemplo de una forma de entender la autonomía que se concentra en la práctica y en el proceso. En el desarrollo de la investigación, donde el carácter procesual aparece 
como fundamental y común tanto al sistema jurídico indígena (elemento prioritario en la construcción y ejercicio de los derechos colectivos al interior de las sociedades indígenas) como a la práctica de la autonomía, de la cual es un ejemplo dicho sistema. Finalmente, el marco general propuesto para el respeto de la diversidad dentro del Estado, en el cual los pueblos se organizarían de acuerdo al principio de autonomía, es el diálogo intercultural, entendido como proceso constante de negociación en el cual se acuerdan los alcances y límites de derechos y obligaciones comunes a todos los miembros de la sociedad.

El Sistema de Seguridad y Justicia es la expresión de la autonomía en la experiencia analizada y constituye el objeto de estudio de mi investigación, aunque en esta etapa no me he propuesto documentar en detalle las prácticas jurídicas, objetivo que sí ha sido realizado en las tesis citadas. Mi horizonte se ha mantenido en términos más generales y privilegia el ámbito regional como espacio de construcción del proyecto autonómico.

La experiencia analizada es, a mi parecer y de acuerdo con diferentes autores, paradigmática para las nuevas luchas indígenas que caracterizan el México actual. Fue sobre todo a raíz del levantamiento zapatista en 1994 que las luchas indígenas, hasta entonces en muchos casos encubiertas, empezaron a buscar y encontrar las formas para hacerse patentes, ponerse en red entre ellas y con la sociedad a nivel mas amplio. Empecé a acercarme a las experiencias de resistencia indígena en ocasión de un momento tópico de abertura y encuentro entre los indígenas zapatistas y la sociedad civil: el Primer Encuentro Intergaláctico Por la Humanidad y Contra el Neoliberalismo realizado en 1996 en la comunidad chiapaneca de La Realidad. El discurso zapatista tuvo desde el primer momento un fuerte impacto entre los movimientos y las experiencias (auto)organizativas que, "desde abajo y a la izquierda", en diferentes rincones del mundo tratan de construir alternativas de participación ciudadana y nuevos derechos. En precedentes investigaciones $(2004,2005)$ he tratado de explicar el importante papel que tuvo el movimiento zapatista en la izquierda alternativa italiana y en el debate sobre autonomía y democracia participativa que se esta dando en algunos ámbitos de la izquierda institucional italiana.

Pues la trascendencia del debate sobre la autonomía me empujó a ahondar en la forma en como la estaban construyendo las mismas comunidades zapatistas, realizando sobre el tema mi tesis de licenciatura en Etnología en la Universidad de Padova, Italia. "L'autonomia possibile. Chiapas: la costruzione dell'autogoverno nelle comunità indigene della Selva Lacandona" es fruto de un trabajo de investigación de aproximadamente tres años. A raíz de mis repetidas estancias en las comunidades zapatistas ubicadas en Las Cañadas de Las 
Margaritas, fui conociendo con más profundidad el alcance de las reivindicaciones zapatistas y la importancia de la lucha indígena en México. Así, empecé a interesarme en otras experiencias autonómicas que están construyendo los pueblos indígenas mexicanos, con la preocupación de documentar los diferentes caminos posibles en la búsqueda de alternativas de convivencia entre los hombres, que sean respetuosas y sustentables.

Desde el 1994 a la fecha el movimiento indígena propuso y experimentó mucho, pero mi interés se fue focalizando en algunas situaciones paradigmáticas por su efectividad, cual es la Policía Comunitaria de la Costa Chica y Montaña de Guerrero. Entrar al Posgrado en Ciencias Antropológicas de la UAM me permitió concretizar tal interés en un proyecto de investigación. Mi primer acercamiento a la Policía Comunitaria ha sido en ocasión de su Décimo Aniversario, celebrado el 15 de octubre 2005 en la comunidad de Pueblo Hidalgo. Empecé el trabajo de campo sistemático para la elaboración de esta tesis en julio 2006; durante el último año realicé tres estancias de investigación, cada una de aproximadamente un mes de duración. Desde el momento de mi arribo a San Luís Acatlán he encontrado una enorme disponibilidad de las personas a ayudarme en la investigación; la confianza, el apoyo y la protección que la CRAC me ha otorgado han hecho mis estancias sumamente agradables y ha hecho posible la realización de esta tesis.

Las preciosas informaciones que aparecen en el texto me han sido ofrecidas por las mujeres y los hombres valientes que han dedicado y dedican sus vidas a la organización: los que han sido Coordinadores Regionales para la impartición de justicia, los que han ejercido los cargos de Comandantes Regionales, y muchos Policías Comunitarios que, durante los días de guardia a la oficina en San Luís Acatlán o en mi visitas a sus comunidades, compartieron conmigo su experiencia. Agradezco particularmente a algunos de los fundadores de la Policía Comunitaria, que me han dado su confianza y muchas horas de su tiempo para comentarme la "verdadera historia" de la organización, en el acuerdo que la información recogida se utilizará para una recopilación sobre la memoria histórica de la institución comunitaria (según ellos, de gran utilidad para la organización misma).

También se recogieron testimonios de los habitantes de algunas comunidades tlapanecas y mestizas de la Costa Chica y de la Montaña, así como de los habitantes de las ciudades de Tlapa y San Luís Acatlán. De gran utilidad para esclarecer la relación entre la institución autónoma y las formales, han sido las entrevistas que me otorgaron algunas autoridades ministeriales y judiciales (Ministerio Público, Fiscal Especial Para los Pueblos Indígenas, 
Juez de Paz y Juez Mixto de Primera Instancia,) y políticas (Presidentes y Síndicos Municipales) de las ciudades de San Luís Acatlán, Malinaltepec y Tlapa de Comonfort.

\section{Estructura de la tesis}

La tesis comienza con una parte propiamente teórica, donde se revisan debates antropológicos actuales tratando de enfocarlos de acuerdo a la especificidad del objeto de estudio (capítulos 1 y 2). Luego se exponen los datos empíricos, interpretándolos en base a los elementos conceptuales mencionados anteriormente y a otros que se introducen en el texto según la necesidad de análisis (capítulo 3).

El capítulo 1 es un panorama general de la relación entre los pueblos indígenas y el Estado en México. En particular, se centra sobre las actuales políticas de gobierno, evidenciando algunos nudos problemáticos del multiculturalismo. También propone una revisión del debate sobre los derechos individuales y colectivos.

En el capítulo 2 resumo el amplio debate alrededor de la autonomía indígena, evidenciando diversas concepciones a partir del breve análisis de algunas experiencias paradigmáticas. Propongo algunas críticas a las interpretaciones corrientes y avanzo una interpretación que se concentra en el carácter procesual de las autonomías, entendidas como procesos integrales pero también como prácticas contrahegemónicas.

Ya que la experiencia autonómica analizada actúa principalmente en el campo jurídico, en el siguiente apartado retomo algunos puntos de la actual discusión en Antropologia Jurídica que utilizo como herramientas para el análisis del Sistema de Seguridad y Justicia Comunitaria.

El primer apartado del capítulo 3 analiza brevemente el espacio social de la región CostaMontaña de Guerrero, que se caracteriza por una situación de violencia y constante violación de los derechos humanos, además que por una generalizada corrupción de las instancias de procuración e impartición de justicia. Menciono las principales experiencias organizativas de las últimas décadas, ya que tienen un importante papel en la constitución de la Policía Comunitaria.

El siguiente apartado estudia el origen, la estructura y las funciones del Sistema de Seguridad y Justicia Comunitaria, evidenciando los diversos elementos (prácticas jurídicas indígenas y estatales) que conforman el sistema jurídico aplicado a nivel regional. Dedico particular atención a los elementos innovativos que integran dicho sistema, así como a la 
relevancia de la identidad indígena. Demuestro la eficacia y la legitimidad de la institución autónoma, como prueba de su trascendencia.

El último apartado del capítulo 3 examina la relación entre el SSJC y las instituciones, en particular los Ayuntamientos y las instancias de procuración e impartición de justicia. También analizo el discurso utilizado por la organización hacia las instituciones para reivindicar su legitimidad.

Las conclusiones retoman las consideraciones sobre la importancia del SSJC como proceso de reconstitución del tejido comunitario y regional. Expongo los límites y los alcances de esta experiencia hacia la construcción de la autonomía, reafirmando su carácter de práctica autonómica que surge a partir de las necesidades especificas de la población. 


\section{CAPÍTULO 1 \\ DIVERSIDAD CULTURAL Y DERECHOS COLECTIVOS: \\ ENTRE LA REIVINDICACIÓN Y LAS POLÍTICAS PÚBLICAS}

\subsection{PUEBLOS INDÍGENAS, NACIÓN Y ESTADO EN MÉXICO: UNA CONSTANTE RELACIÓN DE FUERZA}

En el México actual la condición de las comunidades y pueblos indígenas, y la reivindicación compartida por los diferentes sujetos indígenas organizados, expresa la necesidad de que el poder central actúe con políticas concretas de reconocimiento, al interior de un nuevo pacto social, de una nueva relación entre el Estado y la sociedad, en donde éstos sean reconocidos como sujetos de derecho, y puedan ejercer la autonomía, como articulación interna de la libre determinación ${ }^{1}$.

Hasta fechas recientes, el proyecto nacional del Estado mexicano ha marcado la pauta de su relación con los muchos pueblos que viven al interior del territorio. La voluntad de aniquilar la fuerza cultural y política de los pueblos indígenas ha caracterizado a los gobiernos mexicanos a partir de la administración colonial, cuya estrategia fue fragmentar en comunidades y territorios discretos la unidad de los pueblos.

En el siglo XIX, a pesar de que la lucha por la Independencia rompía con el pasado colonial, el mismo proyecto nacionalizador liberal produjo un nuevo racismo sobre lo diverso, debido a que se pretendía una "igualdad" ciudadana retomada de las ideas de la Revolución francesa, que superara las divisiones estamentales que habían caracterizado la sociedad de la Colonia. Pero en un territorio donde había múltiples culturas, dicha idea implicaba la imposición de un solo pensamiento (el liberal y, más en general, el producido por la civilización occidental) y, por tanto, una intolerancia y negación de todo aquello que no promoviera la homogeneidad.

Según López y Rivas, "la nación es esta construcción histórico- social que por un lado dota de identidad al Estado pero lo desborda al estar constituida por sujetos cuya identidad es negada por la hegemonía de la consolidación estatal" (2004:63).

Pero en esta discusión debemos considerar que la relación entre las estructuras dominantes (administración colonial y, luego, Estado nacional) y los pueblos indígenas, siempre ha sido dialéctica, y que una lectura de tal relación que enfatice solamente los procesos de represión 
y dominación dejaría de lado los igualmente importantes procesos de resistencia y adaptacion que han protagonizado los pueblos. Precisamente en los términos de cómo los mismos pueblos indígenas han construido y siguen modificando su relación con el Estado, está la clave para entender la fuerza política de sus reivindicaciones y de las instituciones propias con las cuales se gobiernan. Con respecto al periodo colonial, Stern afirma que "el proceso de colonización «desde arriba» generó también una colonización «al revés». En ésta son los pueblos indígenas quienes van invadiendo el laberinto del Estado, la iglesia y los mercados coloniales, tratando de hacerlos suyos y así protegerse" (2000:77).

Los gobiernos liberales que siguieron a la Independencia de México, con más esmero se dedicaron a la tarea de constituir la "comunidad imaginada" nacional (Anderson: 1993) a costa de la desestructuración de las comunidades indígenas, reales y concretas. "La constitución liberal de 1857, al declarar ciudadanos iguales a todos los habitantes de la República, privó a los grupos étnicos del derecho consuetudinario que amparaba sus formas de vida comunitaria, los despojó de personalidad jurídica para defender su tierra y no proveyó ninguna legislación social en su favor" (Florescano 1996: 487). En el texto constitucional se destruía uno de los pilares de la organización de los pueblos, el territorio, que actualmente está al centro de todos proyectos politicos de autonomía y autodeterminación, quitando a los pueblos indígenas el derecho de propiedad sobre las tierras comunales.

Según Villoro, desde su constitución el Estado nacional mexicano ha sido marcado por la "contraposición entre dos corrientes que responden a ideas distintas de la nación: la construcción del Estado nación moderno, que había imaginado el grupo fundador; y la resistencia de las comunidades que no encajan en este proyecto" (Villoro: 1998).

La participación de los indígenas en la Revolución del 1910 se debe a la voluntad de cambiar tal situación de privación material y simbólica; la lucha agrarista encabezada por Emiliano Zapata planteaba de hecho la restitución de las tierras según los confines presentes en los títulos prehispánicos y amplias autonomías locales ${ }^{2}$. El Articulo 27 de la Constitución de 1917 retoma este espíritu y por varias décadas ha fungido como protección para la población campesina e indígena mexicana, hasta su modificación en sentido profundamente neoliberal durante el mandato presidencial de Carlos Salinas de Gortari, en 1992.

\footnotetext{
${ }_{1}^{1}$ Acuerdos de San Andrés, Documento 1, en Hernández Navarro y Vera: 1997.

${ }^{2}$ Ley Agraria de la Soberana Convención, Cuernavaca, 22 octubre 1915.
} 
En la historia reciente del país, el despojo de recursos y propiedades se unió a la voluntad de desaparecer la diferencia cultural de los pueblos indígenas: la misión homogeneizadora caracterizó las políticas sociales pos-revolucionarias dirigidas a los pueblos originarios, conocidas con el nombre de indigenismo. A nivel teórico y a nivel concreto, los esfuerzos para "mexicanizar el indio" más bien han ido haciendo más hondas las fracturas que caracterizan la sociedad mexicana, juntando nuevos argumentos a viejos racismos ${ }^{3}$. Ésta fue la pauta que marcó las políticas indigenistas mexicanas hasta más o menos los años sesenta del siglo XX, el llamado indigenismo "integracionista". El cambio de tendencia en la reflexión antropológica, y las profundas criticas al indigenismo que de esta provinieron, junto con el despertar de las movilizaciones indígenas, determinaron un cambio en la década de los setenta hacia lo que Oemichen llama indigenismo "de participación". Es en este contexto cultural y ideológico que se desarrolla con más fuerza el debate sobre la "cuestión étniconacional", empezándose a plantear posibles formas de interacción que reconocieran la diversidad cultural de la sociedad mexicana.

Intricadamente vinculados con la división clasista de las sociedades capitalistas, anclados en modo profundo en el pasado cultural, mezclados con desigualdades regionales [...], reclamos y propuestas de carácter y de origen étnicos se enfrentan a modelos de organización política de tipo "nación" y se tienen que articular con ellos. Tal enlace es de carácter altamente conflictivo, porque este modelo siempre pretende, en virtud de su propia naturaleza, reducir al máximo y, de ser posible, eliminar la diversidad en todas las esferas. [...] En América Latina, esta situación se agudiza por el pronunciado autoritarismo que, según algunos estudiosos, constituye una compensación característica de sistemas nacionales faltos de concentración de poder real (Krotz 1993: 20).

Siguiendo las sugerentes afirmaciones de Krotz, podemos considerar como, para el caso particular del Estado de Guerrero, la relación entre los pueblos indígenas y los poderes del Estado no ha sido marcada solamente por la actitud racista de este, sino que se ha articulado según lógicas "premodernas", con arreglos entre estructuras de poder locales (cacicazgos, latifundistas y sus "guardias blancas" o "bandoleros") que sustituían o suplantaban las instituciones estatales débiles o ausentes; y estas mismas instituciones reconocían y se apoyaban en dichas estructuras de poder para el gobierno de los territorios, aunque no ejercieran sobre éstos ninguna forma de control político, el cual estaba en las manos de los poderosos locales. Podemos afirmar que en las zonas rurales del estado de Guerrero, como la Costa-Montaña, el Estado ha sido en buena medida ausente en cuanto garante del bienestar y de los derechos básicos de los ciudadanos; pero no ha sido ausente

\footnotetext{
${ }^{3}$ Por un analisis de las políticas indigenistas véase Oemichen: 1999; Del Val: 2004.
} 
la estructura política corporativista que aseguraba la continuidad del sistema unipartidista del Partido Revolucionario Institucional ${ }^{4}$. Por estos motivos, los representantes de las instituciones generalmente han ejercido su función de forma autoritaria y corrupta, entendiendo su poder más en forma personal que como funcionarios públicos.

\section{Las políticas de Estado en las últimas tres décadas y el movimiento indígena en México}

El desarrollo del movimiento indígena que sobresalió en México al inicio de los años '90 debe verse en su continuidad con el fuerte movimiento agrarista, al interior del cual se fue progresivamente dando una reflexión y concientización sobre la identidad indígena de la gran mayoría de los sujetos campesinos mexicanos, y construyendo una propuesta política que no se limitara a las reivindicaciones agrarias sino que incluyera también las culturales y las sociales; es decir la apuesta política de autonomía. Es en la década de los '70 cuando se da el fuerte auge del movimiento campesino y al mismo tiempo se empieza a reflexionar sobre lo indígena como identidad cultural y también política (dos acontecimientos fundamentales en este sentido son el Congreso Indígena que tuvo lugar en 1974 en San Cristóbal de Las Casas, Chiapas, impulsado por la Iglesia Católica y el magisterio rural, que representó el primer momento público de discusión entre los pueblos indígenas a nivel regional; y el Congreso Nacional de los Pueblos Indígenas organizado en 1975 por el gobierno federal en Pátzcuaro, Michoacán, que a pesar de su marco oficialista fue momento de encuentro de representantes indígenas a nivel nacional). En este periodo se empieza a producir una ruptura con el integracionismo y a la vez el crecimiento de agrupaciones sin la tutela del Estado: son organizaciones campesinas de carácter regional y nacional, que plantean un discurso de autodeterminación propio de su práctica política, pero también surgido en los Congresos Indígenas de 1974 y 1975. En el desarrollo de las organizaciones campesinas durante los años '80 es importante la progresiva superación de la lucha comunal, local, y la creación de redes de movilización a nivel más amplio: sobre estas mismas redes se conformará y movilizará el movimiento indígena de la década siguiente.

Es así como la articulación de la lucha indígena se convierte en una apuesta política que madura al interior del movimiento campesino en la década de los setenta y ochenta ${ }^{5}$, en

\footnotetext{
${ }^{4}$ Como se destaca más adelante, siempre ha sido muy fuerte la presencia y la actividad de los partidos politicos en las zonas rurales de Guerrero, muchas veces con el resultado de fragmentar las instituciones comunitarias y los proyectos organizativos autónomos de los pueblos.

${ }^{5}$ La organización política regional de los '80 presenta la construcción de bases étnicas que darán fruto más adelante a la formación del movimiento indígena (Mattiace: 2002).
} 
tanto que articula y transforma la demanda por la tierra en la demanda por el territorio, termino que incluye también los derechos culturales y simbólicos y no sólo los económicos. Es aquí donde se traslapa el discurso desde lo campesino a lo indígena, con el impulso del debate que se estaba dando sobre la figura de "pueblo indígena", y las atribuciones de éste, en el marco del Grupo de Trabajo sobre Poblaciones Indígenas, parte de la Comisión de Derechos Humanos de las Naciones Unidas. Este grupo sirvió como tribuna para la discusión y la denuncia sobre la situación de los pueblos indígenas a nivel internacional, y trabajó por 22 años a la Declaración de Derechos de los Pueblos Indígenas que incorpora la autonomía como derecho fundamental de los pueblos.

El proceso de construcción del sujeto indígena y del análogo movimiento es acompañado por la gestación de una política pública de la diferencia que en México se inicia en los primeros años noventa con la reforma a dos artículos de la Constitución por iniciativa del gobierno encabezado por Carlos Salinas de Gortari. En 1992 se modificó el articulo 4 adecuándolo ${ }^{6}$ al Convenio 169 de la Organización Internacional del Trabajo, reconociendo a México, aunque sólo formalmente, como un país multiétnico y pluricultural ${ }^{7}$. La segunda reforma se aplicó al artículo 27, cancelando el reparto de tierras, abriendo las posibilidades para la mercantilización de las áreas comunales y ejidales. Ambas reformas responden a directrices impulsadas por organismos internacionales, como el Banco Interamericano de Desarrollo (BID) y el Banco Mundial (BM), que en los años 90 empezaron a concretizarse en especificas políticas del Estado hacia los pueblos indígenas ${ }^{8}$. En particular el BM implementó un programa de fondos directos que motivara a los gobiernos latinoamericanos a descentralizar sus sistemas politicos-administrativos para promover el desarrollo de las poblaciones marginales en los aspectos sociales, ecológicos, de género y étnicos. Este énfasis hacia el "desarrollo" y la relativa atención a la temática de la diversidad cultural van de la mano con proyectos y acciones siempre más fuertes de intervención del Estado y de las empresas en los territorios indígenas, en aras del aprovechamiento indiscriminado de los recursos naturales y estratégicos presentes en éstos. Por ejemplo, las políticas de "desarrollo" infraestructural, comercial y hasta turístico, mismas que en la mayoría de los casos no llevan a los pueblos ningún beneficio y tienen como consecuencia directa el

\footnotetext{
${ }^{6}$ En realidad tal adecuación no se logró por completo, como se vio en los reclamos indígenas manifestados durante los Diálogos de San Andrés.

${ }^{7}$ La reforma al artículo 4 se hizo según una visión universalista que apela al principio de igualdad ciudadana: veremos en el siguiente apartado los problemas que trae este enfoque a las políticas públicas que lo adoptan.
} 
aumento de la marginación y la migración en los territorios "beneficiados"9. Hasta donde es posible, el Estado trata de disfrazar como positivas tales acciones, pero cada vez que se encuentra con la resistencia de los pueblos para defender sus territorios y sus culturas, no titubea en utilizar contra ellos la amenaza, la cooptación y, frecuentemente, la represión violenta.

De contra a tal tendencia política del Estado, en los últimos 15 años el movimiento indígena ha ido desarrollándose, cobrando fuerza de organización y poder de negociación.

Un momento determinante fue la Campaña 500 Años de Resistencia Indígena, Negra y Popular, que en México representó un momento aglutinador para las organizaciones indígenas, que crearon redes de discusión y movilización a nivel nacional, y empezaron a articular una propuesta política común: la de autonomía.

El levantamiento zapatista de 1994 revitalizó estas redes organizativas y convirtió la discusión sobre los derechos de los pueblos indígenas en un debate político de relevancia nacional. La demanda de autonomía se volvió el proyecto político de los pueblos y organizaciones indígenas a nivel nacional, bandera del nuevo espacio de discusión y organización formado en 1996, el Congreso Nacional Indígena.

No obstante, los gobiernos que siguieron el levantamiento no supieron ni quisieron convertir en norma constitucional las demandas de reconocimiento de los derechos indígenas; las que han sido planteadas por el movimiento no en términos aislados, sino en el marco de una profunda reforma y democratización del Estado; y aunque la organización a nivel nacional aparece actualmente estancada o en un momento de reflujo, una observación atenta desmiente tal impresión. De hecho, estamos asistiendo a una reactivación de los movimientos indígenas: son innumerables las experiencias de resistencia, organización y construcción de espacios autonómicos a lo largo del país; una vertiente muy importante son las luchas para la defensa de los recursos naturales y territoriales contra la embestida gubernamental y del capital transnacional. Lo que destaca en todas estas experiencias locales es la visión según la cual llevan a la práctica derechos de los cuales conscientemente afirman la legitimidad, cada experiencia según su particular situación.

\footnotetext{
${ }^{8}$ Véase la compilación de Hernández, Paz y Sierra, El estado y los indígenas en tiempos del PAN, México, CIESAS -Porrúa 2004 donde se detallan las tendencias políticas que caracterizan al Estado mexicano en la ultima década.

${ }^{9}$ Ejemplos son innumerables; entre los que han destacado en lo que va del 2007 está el revivido Plan Puebla Panamá, cuyas nefastas consecuencias han sido advertidas por varios investigadores, como Harvey (2004); y el proyecto de la presa La Parota, en el estado de Guerrero, que ha aglutinado una fuerza resistencia de las comunidades indígenas y campesinas afectadas.
} 
El movimiento indígena y sus organizaciones, actuando en los espacios locales, no se encierran en ellos sino que inscriben su proyecto y sus reivindicaciones en el ámbito nacional, arena política donde se han de articular las diferentes experiencias y en la cual se han de dar las reformas sustanciales. De hecho, el movimiento indígena está creando y fortaleciendo una nueva identidad nacional, a partir de las transformadas relaciones de fuerza entre espacios locales, nacionales y supranacionales creadas por los procesos globalizantes. Los movimientos indígenas muestran saberse mover con agilidad en los diferentes contextos (reivindican la legitimidad de sus prácticas locales con base en el Derecho Internacional, y tienen una fuerte presencia en los foros y las instituciones internacionales) remarcando siempre su identidad, indígena y mexicana; a partir de su diferencia apuntan a la apertura de espacios democráticos -desde abajo- en la nación de la cual se reivindican parte integrante.

\section{El multiculturalismo como actual política de Estado}

La historia del siglo XX ha demostrado el fracaso de las políticas asimilacionistas, pero sigue más fuerte que nunca la voluntad de desactivar el poder que tienen los sujetos diferentes por excelencia, los pueblos originarios, o sea el poder de cuestionar la otrora utopía modernizadora-nacionalista, y hoy transnacional.

En la actualidad, tanto en México como en otros países de América Latina y del mundo, existe una nueva coyuntura política en la cual la ideología del multiculturalismo ${ }^{10}$ está ganando espacio y legitimidad. Esta nueva coyuntura incluye el reconocimiento por parte de

\footnotetext{
${ }^{10}$ Aunque aparezcan frecuentemente como sinónimos, hay una diferencia sustancial entre multiculturalidad y multiculturalismo. Hablamos de multiculturalidad "para referirnos a las situaciones de hecho en las que coexisten pueblos y culturas diversas"; el término por lo tanto tiene un valor descriptivo de la realidad que, actualmente, comparten la mayoría de los países del mundo. Consecuencia de la generalidad del fenómeno, es que no haya un único tipo de multiculturalidad, sino diferentes procesos de acuerdo al desarrollo histórico y politico de las sociedades. León Olivé individua al menos tres tipos de sociedades multiculturales: en un caso, las comunidades cuentan con territorio propio, como los quebequenses en Canadá, o los pueblos que integran España o el Reino Unido. Otro caso que se considera es principalmente el de Estados Unidos, donde las comunidades de inmigrantes de diferentes nacionalidades comparten espacios públicos y servicios con el resto de la población, y no hay una separación geográfica neta. Esta misma forma de articulación de la multiculturalidad es la que están experimentando los países europeos, meta siempre mayor de inmigrantes proveniente de variadas partes del mundo. Un tipo todavía diferente de multiculturalidad es la que se ha venido construyendo en los países latinoamericanos: aquí la mayoría de los pueblos indígenas comparten territorios con otros pueblos y con mestizos, aunque las zonas donde viven sean relativamente delimitadas y no compartan de hecho servicios y espacios públicos con otros sectores de la población (debido también a que frecuentemente son territorios que carecen de estructuras y servicios básicos).

A las diferentes articulaciones de la diversidad en las sociedades deberían corresponder diferentes modelos normativos. A esto se refiere el término de multiculturalismo, o sea a una política explicita, que podría aceptar y llevar adelante un Estado nacional, diversos integrantes de la nación u organismos internacionales, respecto a
} 
los Estados de la diversidad étnica y cultural y, como elemento de éste, la necesidad de otorgar algunos derechos específicos al respecto, lo que algunos autores llaman el nuevo constitucionalismo multicultural (Van Cott 2000a) favorecido por las agencias internacionales y el Derecho Internacional ${ }^{11}$.

Por más que en muchos casos el reconocimiento cultural formal no dé lugar a desarrollos efectivos y no se implemente políticamente, constituyendo lo que se ha denominado reconocimiento retórico del multiculturalismo (Van Cott 2000a), los instrumentos legales, tanto a nivel de los diferentes Estados como en el plano internacional, son en buena medida fruto de un potente proceso de movilización de los pueblos y las organizaciones indígenas. Estos logros han permitido que el "sujeto colectivo indígena" siguiera creciendo y articulara de forma cada vez más efectiva sus reivindicaciones.

Pese a la existencia de una gran distancia entre las declaraciones jurídicas y la implementación de políticas públicas que las actualicen, la presencia de derechos colectivos de base indígena comunitaria han permitido no solamente romper, por lo menos en ciertos ámbitos "formales" o "discursivos", con la lógica monocultural ${ }^{12}$ del Estado nación, sino también dotar de una base jurídica y política a las demandas de derechos culturales y lingüísticos, así como, lo que constituye un salto cualitativo, del derecho a la autonomía y autogobierno territorial. Al respecto, en México se ha distinguido entre una primera etapa (1992-1995) en la cual el movimiento indígena se formó y probó su fuerza a partir de demandas basadas en la reivindicación de la diversidad en cuanto pueblos, demandas centradas en el reconocimiento constitucional de los derechos culturales y educativos; y una segunda etapa (1996-1998) en la que la autonomía y la autodeterminación se convierten en las demandas centrales del movimiento indígena tras el impulso determinante del Ejército Zapatista de Liberación Nacional (Trejo 2000).

Actualmente, el termino multiculturalismo causa muchas polémicas. Será útil adelantar las dos más importantes: que el término ha sido elaborado principalmente a partir del contexto anglosajón, lo cual implica un modelo que responde a la particular realidad multicultural de Estados Unidos o de Canadá. En segundo lugar, se ha tendido a identificar este término con

las diversas culturas que integran un país o una región. Es decir, el multiculturalismo es un modelo propuesto para el gobierno de la multiculturalidad.

${ }^{11}$ Declaración de los Derechos de los Pueblos Indígenas de la ONU; borrador de una análoga declaración de la OEA; Convenio 169 de la OIT.

12 Un Estado = una nación = un pueblo = una cultura = una lengua. 
una corriente particular en la Filosofía, que ha orientado las formas de organización política y la relación entre el Estado y la sociedad, es decir el liberalismo ${ }^{13}$.

\footnotetext{
${ }^{13}$ El liberalismo, en su fundamento teórico, se rehúsa a formular juicios éticos con respecto a las elecciones que cada persona, en cuanto agente moral, pueda hacer para realizar su plan de vida de acuerdo a los valores elegidos. El ideal del modelo liberal es tratar a todos con igual respeto; de acuerdo con tal ideal, el Estado liberal mantiene una postura neutral frente a cualquier ideal ético, y no se inclina por ninguna formulación del bien común. Una crítica elemental que se puede avanzar a tal modelo es que, de hecho, las políticas liberales estrictas, con su empeño en no intervenir activamente en la corrección de desigualdades económicas y sociales, las han aumentado considerablemente (Villoro 1996:118). Según esta postura, el modelo liberal no debería promover ninguna discriminación hacia las diversidades políticas y culturales: en la práctica nunca ha sido así, por los principios de individualismo universal que sustentan tal modelo. La idea de fondo es que las sociedades son meras asociaciones de individuos, que gozan todos de iguales derechos y deberes.
} 


\subsection{LA REALIDAD MULTICULTURAL. PROPUESTAS PARA EL GOBIERNO DE LA DIVERSIDAD}

En el debate filosófico alrededor de la diversidad cultural se han definido por lo menos dos maneras de entender el multiculturalismo, que Olivé define como el "multiculturalismo liberal individualista" y el "multiculturalismo comunitarista", además de una tercera postura denominada "relativista"

Estas se diferencian por las concepciones que tienen alrededor de la propia diversidad cultural y de las relaciones entre las culturas, así como entre la colectividad y el individuo, y entre los grupos y el Estado. Estas posturas derivan en determinadas políticas públicas y sociales, aplicables en situaciones concretas por los Estados y los organismos internacionales, influenciando los documentos elaborados en los marcos jurídicos nacionales e internacionales.

Tal debate filosófico se articula sobre la posibilidad y la forma del reconocimiento de derechos colectivos a grupos que se diferencian sustancialmente de la cultura y la organización política dominante en una sociedad.

Las cuestiones centrales que animan el debate son, a mi entender, dos: la afirmación de valores universales vigentes en todas las culturas, o más bien la idea que cada cultura tiene una identidad inconmensurable (universalismo vs. relativismo), lo cual produce diferentes modelos para el reconocimiento. En segundo lugar hay quien afirma la legitimidad del reconocimiento de derechos colectivos y de grupo a los pueblos, objetando la idea que basta con los derechos otorgados por los regimenes liberales a todos los individuos (comunitarismo vs. liberalismo), lo que da forma a marcos jurídicos y políticas públicas estatales.

Propongo aquí un breve análisis de las dos posiciones y de su concepto clave, introductorio al tema central de este trabajo: los derechos colectivos y la autonomía de los pueblos indígenas. Se tratará de un análisis superficial y tal vez imperfecto, debido a la complejidad de la temática (en el sentido de la multiplicidad de puntos de vistas e interpretaciones diferentes aunque al interior de la misma corriente $)^{15}$.

\footnotetext{
${ }^{14}$ Olivé: 1996.
} 


\section{Liberalismo y comunitarismo}

La concepción liberal propone el derecho a la autonomía individual como valor universal, que tiene que ser reconocido en todas las sociedades. Bajo este supuesto universalista, o sea la prioridad de los individuos y la afirmación de una racionalidad universal ${ }^{16}$ que animaría las acciones de todos ellos, se admite la existencia de las diferencias siempre y cuando acaten las normas internacionales de protección de los derechos humanos, y se "respetan otras culturas porque y en la medida en que sirvan a valores verdaderos"17. El pensamiento liberal clásico, además, concibe como una superflua redundancia los derechos colectivos, en cuanto las garantías fundamentales estarían ya en los derechos individuales ${ }^{18}$, expresando una tajante subvaloración del ámbito colectivo.

Muchas veces se relaciona la postura relativista ${ }^{19}$ a lo que se define como "multiculturalismo comunitarista". Éste se diferencia del "liberal" porque se basa en la idea que el individuo no es previo a sus fines, sino que está constituido por ellos. Esta postura se conoce también como "política de la diferencia"; su planteamiento cultural central es que el reconocimiento a la identidad del grupo o del individuo se realiza marcando la diferencia entre éste y la sociedad mayoritaria; se defiende la forma de discriminación denominada "discriminación a la inversa" o "positiva" argumentando que se trata de medidas temporales cuyo objetivo es equilibrar las reglas del juego entre todos los grupos sociales, eliminando gradualmente cualquier forma de discriminación. El concepto de identidad fue central en el desarrollo de esta corriente, pues en "la política de la diferencia, lo que pedimos es la identidad única de este individuo o este grupo, el hecho que es distinto de todos los demás" (Taylor 1993:61).

\footnotetext{
${ }^{15}$ Por una discusión sobre el tema véase los trabajos citados de Olivé, Villoro, Clavero.

${ }^{16}$ La idea de la autonomía de los individuos tiene sus raíces en la filosofía kantiana. Consecuencia de esta idea, es la concepción kantiana de racionalidad, como una racionalidad universal (Olivé 1996:129).

17 Joseph Raz, "Multiculturalism: a liberal perspective", en Ethics in the public domain, Oxford, Clarendon Press, 1994, p.186 (citado en Olivé 1996:132). Sin embargo, ¿quién decide cuáles son los derechos humanos fundamentales y los valores verdaderos? Esta postura tiene un fuerte sesgo etnocéntrico, ya que los primeros hasta ahora son producto de la reflexión y la acción legal interna al mundo occidental, y los segundos, para ser tales, deberían ser fruto de una negociación global, idea bastante utópica.

${ }^{18}$ Los hechos han históricamente desmentido esta visión individualista de las sociedades; el modelo neoliberal ha venido enfrentándose a la reivindicación de derechos colectivos por parte de diferentes grupos que componen la sociedad. De ahí las teorías elaboradas por Kymlicka que apuntan a protecciones externas, para proteger la existencia y la identidad distintiva del grupo a través de limitar la influencia de las decisiones de la sociedad en general.

${ }^{19}$ En este enfoque, que trata escapar al etnocentrismo occidental, las diferentes culturas sólo pueden ser entendidas y valoradas a partir de sus normas y principios internos, y tienen todas igual valor y legitimidad. Esta perspectiva rechaza cualquier idea de valor transcultural o universal, remitiendo la validez de los principios a los contextos particulares. Los límites de esta postura han sido evidenciados por diferentes autores; lo que aquí nos interesa es destacar cómo las propuestas multiculturalistas que se han apoyado en el enfoque relativista han terminado por enfatizar el carácter esencialista de las identidades culturales, tratando las
} 
Sin embargo, así se pueden favorecer conductas de discriminación y racismo, pues reconociendo en estos términos la identidad de los pueblos indígenas y sus derechos, éstos tendrían la justificación si discriminaran a otras culturas con el afán de afirmar su identidad cultural.

Las dos posturas expuestas han sido objeto de críticas. En particular, el énfasis puesto por los comunitaristas en la identidad puede llevar a un manejo esencialista de la misma por parte de los pueblos objetos de políticas compensativas o de "discriminación positiva", lo cual más que a la armonización de la sociedad llevaría a una mayor fragmentación ${ }^{20}$. Es decir, políticas basadas en el reconocimiento de la diversidad cultural y orientadas a la reducción de la desigualdad política y económica, históricamente causada por la discriminación de la cual han sido objetos los grupos al interior de la sociedad dominante, podrían llevar a que tales grupos enfaticen su particularidad para acceder a los recursos especiales; el mismo Estado actuaría en este sentido implementando políticas intervencionistas orientadas a "preservar " las diferencias culturales. Como bien argumenta Villoro, "lo que destruye la identidad de un pueblo no es el cambio en sus formas de vida o de pensamiento, sino la negación de su capacidad para proyectar y realizar una imagen ideal de sí mismo, en la que el pasado se integre con la realidad actual" (1998:150) ${ }^{21}$.

culturas como un todo cerrado, impermeable al diálogo y a la transformación, y portadora de un sistema de valores inconmensurable con los demás.

${ }^{20}$ Al contrario, en mi interpretación, las identidades sociales y culturales son contextuales, modificables, múltiples. Refiriéndonos en general a los pueblos indígenas, la identidad colectiva se construye y se reconstruye constantemente en los intercambios sociales (Bartolomé 1997; Giménez 2000), o sea es un proceso dinámico. La interpretación esencialista de la identidad aparece todavía más desviante cuando se aplica a las identidades colectivas como son las de los pueblos indígenas. La identidad colectiva es por definición plural y múltiple, en cuanto expresión de innumerables singularidades y sujeta a diferentes interpretaciones tanto internas como externas. La interpretación de la identidad en términos esenciales/estáticos/objetivos/ substantivos también ha caracterizado muchos estudios antropológicos Schapera, Murdock, Nadel, Singer, Naroll, Caso, Aguirre Beltrán- que concebían a los grupos étnicos como entidades aisladas, objetivamente constituidas y definibles según un conjunto de rasgos y características culturales discretos. La interpretación esencialista abarca también los conceptos de cultura y tradición que, consideradas inmutables, sustentan la identidad; ésta adquiere valor sólo en cuanto expresión de una autenticidad ancestral. En América Latina la lucha política por el reconocimiento de los derechos indígenas ha favorecido, por parte de algunos antropólogos y activistas por los derechos indígenas, la valoración de un "esencialismo estratégico" para reivindicar el derecho a la diferencia cultural.

${ }^{21}$ En el mismo sentido, el autor propone una noción de "autenticidad" que difiere cabalmente de la de "peculiaridad": una cultura seria autentica "cuando está dirigida por proyectos que responden a necesidades y deseos colectivos básicos y cuando expresa efectivamente creencias, valoraciones y anhelos que comparten los miembros de esta cultura", pero también debe saber "responder en forma renovadas a necesidades variables que exigen a menudo tareas insólitas" (pp.75-77). 


\section{Luces y sombras del multiculturalismo: ¿a quiénes benefician los derechos culturales?}

Sin negar que la reivindicación de la diferencia ha sido un elemento madurado por la subalternidad como parte de la crisis del Estado-nación, lo cierto es que, al ser un significado social, en las últimas décadas los Estados se han apropiado de este capital simbólico y lo han puesto en el centro de lo que se considera políticamente correcto (Paz Patiño: 2004).

Sustentando su afirmación en una análisis de las políticas "de reconocimiento" en varios países de América Latina, las cuales identifica como políticas "neoindigenistas" nacidas de la crisis del modelo integracionista, Gros afirma que frecuentemente es el mismo Estado el que crea etnicidad y produce la necesidad de la autonomía, en aras de la institucionalización de la frontera étnica. Advierte que esto no pasa de forma igual en todos los países (México sería en parte una excepción), y menciona como "las nuevas políticas indigenistas bajo la voluntad de otorgar y reconocer la autonomía, lograrían de un modo 'perverso' controlarla, limitarla o, simplemente, negarla" (Gros 2000:183).

El meollo de esta última critica a las políticas multiculturalistas adoptada por varios Estados es que "el multiculturalismo se ocupa de la diversidad en cuanto diferencia 'cultural', mientras repudia o deja de lado las diferencias económicas o sociopolíticas que, de aparecer, tendrían como efecto marcar la disparidad respecto al liberalismo económico que está en su base" (Díaz-Polanco:2005). Esta critica se refiere ya no al multiculturalismo como postura teórica sino como política pública, y en su carácter de complemento sustantivo del modelo neoliberal. Speed y Sierra (2005) notan cómo, mientras el Estado define derechos colectivos estableciendo políticas multiculturales, lo ha hecho frecuentemente como manera de limitar las reivindicaciones más radicales de los movimientos indígenas. Aunque sin compartir completamente tales posiciones, encuentro algunos elementos validos en esta critica a las políticas multiculturalistas adoptadas por varios estados, que trataré de exponer brevemente.

Según el análisis de diferentes autores ${ }^{22}$, la globalización ${ }^{23}$ ha encontrado la manera de aprovechar la diversidad sociocultural a su favor, ya sin la necesidad de violentas políticas homogeneizadoras y abiertamente etnocidas, ni apelando exclusivamente a la igualdad de

\footnotetext{
${ }^{22}$ Hale: 2004; Hardt y Negri: 2002; Hardt y Negri: 2004; Díaz-Polanco: 2005, Slavoj Žižek, "Multiculturalismo o la lógica cultural del capitalismo multinacional", en Fredric Jameson/Slavoj Žižek, Estudios culturales. Reflexiones sobre el multiculturalismo, Paidós, Buenos Aires, 1998, p. 171 (citado en Polanco: 2005 y en Muñoz: 2004).

${ }^{23}$ Me parece pertinente la interpretación avanzada por García Canclini, quien afirma: "lo que suele llamarse globalización se presenta como un conjunto de procesos de homogeneización y, a la vez, de fraccionamiento articulado del mundo, que reordenan las diferencias y las desigualdades sin suprimirlas" (1999:49).
} 
deberes como medio para acceder a igualmente universales (y etnocéntricos) derechos democráticos. El modelo democrático neoliberal parece no imponer un estricto modelo cultural y de ciudadanía; aunque los aparentes espacios concedidos a los sujetos son condicionados a no contradecir los intereses imperantes del mercado (Hale: 2004). Para Hardt y Negri (2002), el momento diferencial "implica la afirmación de diferencias aceptadas dentro del espacio del imperio". Por lo regular, las diferencias exaltadas son las consideradas "culturales", no conflictivas ni peligrosas para el mantenimiento del (des)orden globalizado, cuanto aprovechables en diferentes términos (etnicidades "positivas", folclor) ${ }^{24}$ y “excitadas para incorporar al mercado [a] los disidentes" (García Canclini 2004:77). En el contexto mexicano, asistimos a la proliferación de organizaciones y grupos que tratan revivir hipotéticas tradiciones indígenas con fines comerciales (para incrementar el turismo, 0 vender productos artesanales), y que encuentran apreciación en diversos sectores de la sociedad $^{25}$.

Implícita en muchas de las "políticas de reconocimiento", la reducción de la autonomía formalmente reconocida a un nivel mínimo revela la renuencia de los gobiernos de reconocer verdaderamente las formas y estructuras del gobierno indígena.

En este sentido van las numerosas criticas avanzadas al multiculturalismo como política de Estado, entre ellas la formulada por Hale (2004) quien habla de multiculturalismo neoliberal. Este autor menciona como actualmente la tendencia de los Estados sea abrir espacios limitados y controlados (permitidos, en las palabras de Hale) de "autonomía", así como reconocer y hasta exaltar ciertos niveles de diferencia.

En el ámbito jurídico, la política "multiculturalista" se hace explicita en la relativa disponibilidad de los Estados en reconocer la legitimidad de los sistemas normativos indígenas, pero limitando su vigencia al ámbito interno al grupo indígena y acotando su alcance a los delitos menores.

Por otro lado, frente a organizaciones o grupos que salen del ámbito permitido reivindicando efectivamente la autonomía como facultad de autogobierno o de administración de la justicia, cuestionando las dinámicas políticas existentes (autonomías contrahegemónicas), la

\footnotetext{
${ }^{24}$ Según Žižek, el multiculturalismo es la forma ideal de ideología del capitalismo global, la cual establece una distancia eurocentrista condescendiente y/o respetuosa con las culturas locales, un "racismo con distancia", negado, que "respeta" la identidad del Otro, como una forma de reafirmar la propia superioridad.

${ }^{25}$ Un simple ejemplo. Una visita a Tepoztlán nos puede mostrar la comercialización para los turistas del baño de temascal, práctica higiénica y curativa usada desde siglos por los pueblos indígenas de la región. Pero los que se ofrecen a los turistas, juntos con "masajes mayas" en una zona nahua, y cursos de yoga, son temascales frecuentemente de forma cuadrada y construidos con bloques de concreto, que nada tienen que ver con el tradicional temascal redondo y de adobe.
} 
represión militar o policíaca es la estrategia prioritaria adoptada por el Estado. Sustento esta afirmación en la reflexión sobre lo acontecido a la Policía Comunitaria, que gozó de relativo apoyo y tolerancia política por parte del Estado mientras cumplía gratuitamente la función de policía auxiliar, entregando los delincuentes capturados al Ministerio Público. En el momento en que, a raíz de la ineficiencia del sistema formal, las comunidades decidieron formar un órgano propio y autónomo para la procuración e impartición de justicia (la Coordinadora Regional de Autoridades Comunitarias), empezaron las amenazas y las acciones represivas por parte del Estado y del sistema judicial.

El Estado mexicano ha seguido la tendencia multiculturalista de forma diferente a otros países latinoamericanos -en particular los andinos, como Venezuela, Colombia, Bolivia, Ecuador, Perú-, que han reformado sus constituciones reconociendo en términos bastantes amplios y específicos los derechos de los pueblos indígenas, aunque en muchos casos haya fuertes dificultades para traducir el reconocimiento desde el papel al nivel de los hechos.

En México se ha venido aplicando una versión limitada de la política del reconocimiento, cuyo ejemplo es la reforma constitucional en materia indígena aprobada por el gabinete del presidente Vicente Fox en 2001, en la cual se reconoce formalmente el derecho a la libre determinación pero se impide en los hechos su ejercicio por medio de limitantes y candados presentes en la misma ley. En la ultima década se observa en México la preferencia por una "retórica legal de la diversidad, que apunta a fortalecer un proyecto de nación excluyente, de minorías y acciones afirmativas y no fundado en el reconocimiento de los pueblos indígenas y sus autonomías". Esta perspectiva ha sido definida "neoindigenista" ya que "las viejas políticas integracionistas y modernizadoras se han revestido de un nuevo discurso que combina la exaltación de la diversidad cultural con programas para formar capital humano e impulsar el desarrollo empresarial de las comunidades indígenas" (Hernández, Paz y Sierra 2004: 10, 18).

Donde sí es muy presente la atención a la diferencia es en los discursos públicos de los funcionarios y de los políticos, que a cada momento se refieren al carácter multiétnico y multicultural de la nación mexicana, pero en términos puramente instrumentales, superficiales y erráticos (Guterrez Chong: 2004). En los mismos términos retóricos esta visión ha entrado en las acciones culturales, educativas y más directamente en las políticas del Estado. Para el caso que analizaremos, muestra de ello es la constante voluntad del Estado para incluir la Policía Comunitaria, institución autónoma de los pueblos de la Costa Montaña de Guerrero, en las estructuras policiales locales (en lo especifico, como Policías 
Auxiliares de los Municipios). Tal propuesta ha sido rechazada por la misma organización ya que, aunque les traería evidentes ventajas cesando la represión y el hostigamiento, acabaría también con la autonomía decisional de la organización misma. En segundo lugar, la inclusión de la Policía Comunitaria en el sistema policial, apunta a la desaparición del otro órgano, la Coordinadora Regional de Autoridades Comunitarias, que en realidad es el mayor logro de la organización de esos pueblos indígenas.

\section{Derechos individuales y colectivos: ¿una oposición?}

En el diálogo entre posiciones liberales y comunitaristas, un elemento central es el tema de los derechos colectivos, su relación con el sistema de los derechos individuales y la legitimidad de su reconocimiento.

Los derechos colectivos de los pueblos indígenas se diferencian de los derechos civiles y politicos, individuales por excelencia ${ }^{26}$, llamados de "primera generación"; y también de los de "segunda generación", económicos, sociales y culturales. Cuando se habla de derechos de "tercera generación" se hace referencia a derechos difusos ${ }^{27}$ y colectivos. La definición de derechos colectivos se relaciona con una amplia gama de conceptos como 'derechos de minorías', 'grupos de derechos diferenciados', 'derechos culturales', 'derechos consociativos',

etc., que encarnan diferentes visiones acerca de la diversidad. Un lugar especial en la caracterización de los derechos colectivos los ocupan los derechos de los pueblos indígenas, definidos por algunos autores como "derechos étnicos" (Thompson 1997; Kymlicka 1996).

En el debate filosófico, político y antropológico, los derechos colectivos han sido muchas veces puestos en oposición a los individuales. La principal critica avanzada en contra de los derechos colectivos es la llamada "teoría de la redundancia", que los define superfluos, ya que los derechos individuales colmarían todas las necesidades de libertad y justicia.

Otro argumento es que los derechos colectivos vendrían a poner en peligro el respeto a muchos derechos individuales, o en todo caso, al principio esencial de la igualdad. Al respecto, la primera interrogación que deberían hacerse los críticos es si y en qué medida,

\footnotetext{
${ }^{26}$ Gran conquista de la sociedad civil en los siglos XIX y XX.

${ }^{27}$ El Derecho Internacional de los Derechos Humanos considera que algunos derechos colectivos son el derecho al desarrollo, a la paz, al patrimonio artístico y cultural, a un medio ambiente sano, así como los derechos de los consumidores. Los derechos colectivos se distinguen de los difusos porque es relativamente posible determinar quienes concretamente pueden reclamarlos o son afectados por su violación, tendiendo a referirse a grupos más
} 
hasta la fecha, la presencia teórica de los derechos individuales ha beneficiado a la condición de los pueblos indígenas; para ello habría que tener una perspectiva histórica del problema, o sea un enfoque procesual. Cuando se habla de derechos colectivos como "redundancia", se considera implícita la conclusión de que los grupos y sujetos que reivindican los derechos colectivos están en un marco consolidado de derechos individuales, mientras en la realidad la proclamación teórica y constitucional de los mismos no ha sido garantía para su disfrute universal. Es más, los derechos individuales se han gozado en muchas ocasiones merced a la exclusión del otro o "lo otro".

Afirma Magdalena Gómez, con respecto a la coyuntura mexicana:

suele responderse a la demanda por el reconocimiento de derechos a los pueblos indígenas que la Carta Fundamental contiene un avanzado capítulo sobre garantías fundamentales para todos los individuos, incluidos, por supuesto, los indígenas. Por lo tanto, pedir reconocimiento de derechos diferentes es cuestionar el principio de universalidad, es crear inaceptables regímenes de excepción, derechos especiales, establecer discriminación positiva y, en última instancia, vulnerar uno de los pilares del orden jurídico. Todo ello sería valido si se plantearan derechos para los indígenas en cuanto personas. Sin embargo, se está buscando el reconocimiento constitucional a una realidad social que permanece a contrapelo de la pretensión de homogeneidad y de igualdad [cursivas mías]. Los pueblos indígenas persisten, han practicado y practican formas de organización social y política, y cuentan con culturas diferentes que por lo demás están en nuestras raíces como Nación. Ninguna de las llamadas garantías individuales permite la adaptación a estos derechos colectivos, a estos derechos de pueblo, a este nuevo sujeto jurídico (2002: 270-271).

En la interpretación que aquí se sostiene, el reconocimiento de los derechos de los pueblos indígenas en el ámbito estatal no debe ser subordinado a una precedente efectividad de los derechos individuales y a la provisión de acceso igualitario a los recursos. Estos tres elementos son derechos fundamentales de los pueblos indígenas y a la vez se les deben reconocer. Para que puedan disfrutar de los derechos individuales necesitan la reducción de la condición de desigualdad y el reconocimiento de sus derechos colectivos: todo este conjunto se puede resumir en el proyecto político de autonomía.

Con respecto a la discusión entre derechos colectivos e individuales, otro punto que angustia a muchos pensadores es éste: ¿los derechos colectivos preceden a los derechos individuales? ¿Cuál de los dos debería tener preeminencia? Se trata sustancialmente de la discusión entre liberales y comunitaristas esbozada al principio; una discusión que en mi forma de ver es bastante estéril, ya que considero los dos tipos de derechos como

específicos. Al revés, los derechos al desarrollo o a la paz son derechos difusos porque su violación nos afecta a todos pero no es posible determinar específicamente a quiénes. 
complementarios. De todos modos, esto no excluye la posibilidad de conflicto entre las dos definiciones de derechos.

Según Villoro "el Estado moderno nace con una tensión interna entre el poder central que intenta imponer la unidad y los pueblos diversos que componen una realidad social heterogénea; [...] nace a la vez del reconocimiento de la autonomía de los individuos y de la represión de las comunidades a las que los individuos pertenecen" (1998:80). El autor argumenta que el derecho de los pueblos a su autodeterminación es anterior a la constitución del Estado-nación, y en esto reside la necesidad de su reconocimiento incondicionado. Más adelante tal concepto viene matizado, pero se mantiene la idea de que los derechos colectivos en cierta forma preceden a los derechos individuales y por eso permiten el ejercicio de éstos.

En oposición a Villoro, Clavero (1994) sostiene que no debe presumirse y darse por sentado ningún derecho de la colectividad sobre el derecho de los individuos, y que son siempre los derechos individuales los que pueden originar los derechos colectivos.

Resuelve sencillamente esta contradicción un autor peruano, Montoya Rojas, afirmando que la prioridad atribuida a lo individual en desmedro de lo colectivo dentro de la órbita occidental capitalista, es un error comparable al que resulta de priorizar lo colectivo en desmedro de lo individual, que fue lo que ocurrió en el caso de los países del llamado socialismo realmente existente. Oponer lo individual a lo colectivo ha sido y sigue siendo un gravísimo error en la política occidental. No hay sociedad sin individuos ni individuos sin sociedad. Si se reconoce este hecho de la realidad es perfectamente posible fundar un derecho colectivo al lado y no en oposición del derecho individual" (1998: 56). 


\section{Derechos a la pertenencia y a la diferencia}

A pesar de que las posturas comunitaristas se orientan hacia la valorización de la colectividad, y pueden afirmar la supremacía de ésta respecto a los individuos (considerando que todo individuo es un ser social, a veces la importancia de los roles sociales y politicos rebasa la individualidad), se diferencian cabalmente del relativismo. Villoro, como otros autores (entre ellos Olivé), admite la necesidad de unos derechos fundamentales o derechos humanos básicos, que de ninguna forma pueden ser discutidos ${ }^{28}$. Entre los que Villoro presenta como derechos fundamentales o básicos está el de pertenencia a una comunidad cultural. Estoy de acuerdo con el autor en que "nadie puede elegir su plan de vida más que considerando el conjunto de fines y valores realizables a que puede tener acceso; este conjunto está dado por una cultura" (2002:222). Por lo tanto el derecho a la pertenencia (derecho colectivo y a la vez individual) puede estar en la base de cualquier derecho del individuo, ya que presupone la subsistencia del todo social al que pertenece; afirmar esto supone una actitud pragmática, que defiendo en mi argumentación. El derecho a la autonomía de las personas ${ }^{29}$, fundamento de los derechos humanos individuales, implica el derecho a la autonomía de las comunidades culturales a las que se pertenece: esto es, el derecho a la autodeterminación de los pueblos ${ }^{30}$, entendido entonces como derecho humano fundamental.

Con respecto al debate sobre la necesidad y la primacía entre los derechos individuales y los colectivos, Olivé propone un punto de vista diferente, introduciendo el concepto de derechos del grupo. Éstos se diferencian de los derechos colectivos (un ejemplo es el derecho a hablar un idioma particular), y son finalmente derechos de los individuos en cuanto

\footnotetext{
${ }^{28}$ Pero Villoro propone tales derechos como "necesidades y valores previos a la constitución de cualquier asociación política", la cual presupone la aceptación de tales valores básicos, "vedados" a la negociación y base de ésta. Los principios de autonomía, autenticidad, finalidad, eficacia, según Villoro pueden ser considerados universales en cuanto puramente formales, o sea que no tienen contenido. Serían de cierta forma los principios que permiten la organización y la permanencia de las culturas (1998:120). Tal posición, aunque lleve a un argumento muy sólido, como veremos después, mantiene una raíz universalista que no resulta útil a mi hipótesis. Encuentro más eficaz, aunque más difícil de trasladar al plano concreto, la propuesta avanzada por Olivé cuando llama al dialogo intercultural: también afirma la existencia de derechos humanos fundamentales, pero que tales principios se construyen en la interacción de los miembros de los diferentes pueblos que participan en la acción política. Se tratará de principios puestos sobre la mesa de discusión, cuya definición precisa debe determinarse en común y revisarse constantemente, aunque una vez establecidos no serán pasibles de violación por ninguno de los participantes al acuerdo. En lo que pertenece al argumento de los derechos humanos, esta propuesta me parece muy útil, debido a la necesidad que tales derechos sean construidos en un marco respetuoso de la diversidad, precisamente por su pretensión de validez universal.

${ }^{29}$ Para una exhaustiva discusión sobre el derecho a la autonomía individual y su relación de necesidad con la autonomía de los grupos, véase Villoro 1998; Olivé 2004.

${ }^{30}$ En el mismo sentido, De Sousa Santos afirma que "la falta de legitimidad cultural es una de las causas principales de las violaciones de los derechos humanos" (1998:219).
} 
pertenecen al grupo. El derecho a la diferencia es un derecho de los individuos. Según la definición del autor, "se trata del derecho de los miembros de cierto grupo social a ser reconocidos como tales y a gozar de determinados beneficios en favor de ello" (2004:82). Pero si hablamos del derecho de un pueblo a la autodeterminación, esto no se puede reducir a los derechos de los individuos, aunque surge de ellos. Cuando hablamos de derechos de grupo, nos estamos refiriendo a sujetos colectivos (en estos términos se refieren a los pueblos indígenas los tratados internacionales que les reconocen tales derechos, y también el texto de los Acuerdos de San Andrés), sujetos jurídicos y politicos, aunque no morales. En consecuencia, "el reconocimiento de un derecho de grupo podría dar lugar a que se otorgue una cierta prioridad a la comunidad, por encima de los individuos" ${ }^{\prime \prime 1}$ (2004:83). Finalmente, Olivé define los derechos del grupo como sobrevinientes, o sea que existen sólo en la medida que existen los individuos que componen el grupo: por lo tanto no se pueden reducir a los derechos de los individuos, aunque surgen de ellos. Las dos clases de derechos serían pues complementarias. Las conclusiones de Olivé en este argumento, recalcan las de Villoro: reconocer el derecho a la diferencia (comparable al derecho a la pertenencia de Villoro) en cuanto derecho colectivo de los individuos, conlleva la necesidad de reconocer el derecho del grupo a la autodeterminación o autonomía.

\footnotetext{
${ }^{31}$ Hay que considerar que no necesariamente las atribuciones de los derechos de grupo se superponen o substituyen los derechos individuales. También hay que valorar el hecho que muchas veces se observa en los pueblos indígenas una propensión o hábito a ceder parte de los derechos individuales a favor del buen funcionamiento de la vida comunitaria; esto no necesariamente es considerado una imposición o violación de los derechos del individuo, sino más bien un efecto positivo, que caracteriza la vida comunitaria. Por lo contrario, también hay muchos hábitos impositivos y que violan los derechos individuales, y algunos integrantes del grupo se rehúsan a seguir aceptándolos. Sobre esto hay una tensión que podría en parte resolverse adoptando la visión de dialogo intercultural, tal como se propone al final del siguiente capitulo.
} 


\section{CAPÍTULO 2}

\section{AUTONOMÍA EN LA PRÁCTICA: DERECHOS Y DERECHO DE LOS PUEBLOS INDÍGENAS}

\subsection{EL DERECHO A LA AUTONOMÍA DE LOS PUEBLOS INDÍGENAS}

\section{¿Qué es la autonomía indígena? Elementos para una definición inacabada}

El debate sobre el concepto de la autonomía indígena y la forma que debería tomar en la realidad cuenta con un sinnúmero de propuestas y posiciones diferentes, así como innumerables son las publicaciones sobre el tema. Aquí trataré de resumir los principales elementos que pueden conformar una definición de autonomía, adelantando algunos puntos de la reflexión que desarrollaré: que no es posible llegar a un concepto unitario de autotomía ya que ésta es un proceso en continua transformación y su forma depende de los diferentes contextos históricos, sociales, politicos y territoriales donde se desarrolla; y que debemos diferenciar entre la autonomía como régimen o propuesta de marco jurídico para el reconocimiento de las diferencias, y las autonomías como prácticas de los pueblos.

"Autonomía es un termino que proviene de la teoría ética. En ese campo se refiere a una voluntad que sigue las normas que ella misma dicta y no las promulgadas por otros. [...] Pero en el campo de las relaciones políticas [...] se refiere a un grupo social o una institución que tiene el derecho de dictar sus propias reglas, dentro de un ámbito limitado de competencia" (Villoro 1998: 94-95).

López y Rivas (1995) nota que un proyecto político común al movimiento indígena contemporáneo, en México como en muchos países latinoamericanos, es la reivindicación de la autonomía como expresión interna de su derecho a la libre determinación o autodeterminación. Tal derecho de los pueblos presupone tanto la facultad de decidir su propio destino en el marco de un Estado-nación, como el establecimiento de su propio Estado nacional.

Así entendida, la autonomía (como derecho colectivo e individual) implica la libertad de acción -económica, política, jurídica y social- de la colectividad al interior del Estado-nación, garantizando sus derechos de participación y representación, y no se debe confundir con los conceptos de independencia o de soberanía (de competencia exclusiva de los Estados).

Lo anterior ha sido expresado en los Acuerdos de San Andrés ${ }^{32}$ en la demanda de autonomía y autodeterminación territorial; entre los instrumentos del Derecho Internacional

\footnotetext{
${ }^{32}$ Acuerdos sobre Derechos y Cultura Indígena firmados por el Gobierno mexicano y el Ejercito Zapatista de Liberación Nacional en 1996.
} 
que garantizan tal derecho en estos términos, la referencia histórica es el Convenio 169 sobre Pueblos Indígenas y Tribales de la Organización Internacional del Trabajo, ratificado por el Estado mexicano en 1990. Un texto reciente que también sanciona el derecho a la autonomía es la Declaración de Derechos de los Pueblos Indígenas de las Naciones Unidas (2006).

No obstante tal reconocimiento en la normatividad internacional, uno de los argumentos utilizados por los gobiernos para descalificar las reivindicaciones autonómicas es acusarlas de separatistas, o sea de querer destruir la unidad nacional creando territorios completamente independientes. Al respecto, Olivé afirma que "hacer modificaciones estructurales en el Estado mexicano para que puedan ejercerse efectivamente estos derechos colectivos y estos derechos de grupo, no implica ninguna revolución en los fundamentos del Estado, sino tan sólo asumir las consecuencias propias de sus propios principios [liberales]" (2004:94). Las tradiciones políticas liberales han marcado la práctica de los pueblos indígenas, tanto que el concepto ${ }^{33}$ de autonomía tiene sus raíces en las tradiciones jurídicas occidentales; en este sentido no niega sino que afirma el pacto social como el modelo de convivencia ciudadana, pero sobre la base de la reconceptualización de los criterios que dan forma a la democracia, agregando a dichos criterios el de una identidad colectiva, cultural y política, con antecedentes históricos.

Independientemente de las formas muy diversas en las cuales los pueblos pueden entender y ejercer su autonomía, según López y Rivas la "esencia básica de la autonomía" sería que los pueblos indígenas puedan ser

reconocidos como sujetos de derechos politicos colectivos e individuales, con capacidad para definir sus propios procesos económicos, sus formas comunitarias y regionales de gobierno, su participación en los órganos de participación estatales y representación popular, el aprovechamiento de sus recursos naturales y la definición de sus políticas culturales y educativas (2005b: 63).

A estos elementos fundamentales, Esteva añade también el de un régimen agrario que responda a la forma específica de relación con la tierra y la organización social y, elemento que considero muy importante para el estudio que aquí se propone, la capacidad de autodefensa (1998: 310).

El reconocimiento del derecho a la autonomía implica la democratización del Estado, lo cual debería armonizar los derechos colectivos e individuales para satisfacer los intereses de todos sus integrantes, sean ellos sujetos individuales o colectivos (los pueblos, que son el sujeto de la autonomía). La autonomía, a través del reconocimiento de tales derechos, 
"organiza los mecanismos de participación de los autogobiernos indígenas en los espacios regionales y municipales; es decir, que distribuye las distintas formas en que se expresa la autoridad indígena sobre espacios tanto locales, como regionales y municipales" (López y Rivas 2004: 40).

Varios analistas han tratado de establecer los elementos formales de la autonomía: sin embargo, también en este aspecto es imposible tener una única formulación, ya que dichos arreglos formales reflejan las negociaciones que se logren entre los Estados y los pueblos indígenas, de acuerdo a las necesidades de éstos y la disposición a abrir espacios democráticos de aquéllos.

En términos generales, la autonomía puede ser entendida como "una distribución de competencias en los distintos niveles de la organización del gobierno [...] que permite definir formas de participación de etnias y pueblos dentro del actual Estado nacional en términos de programas sociales, politicos y económicos" (López y Rivas 2004: 39-40).

Cabe señalar aquí dos aspectos complementarios con respecto al papel y las obligaciones del Estado para con las autonomías. Por un lado éstas no se pueden reducir a una mera transferencia de competencias jurídicas o normativas, o sólo un arreglo administrativo para una región en el interior de un Estado-nación, ya que implican más bien la construcción de nuevas relaciones entre el Estado y los sujetos colectivos autónomos: nuevas relaciones políticas que replanteen las posiciones de poder en un nivel horizontal. Es decir que el cambio va más allá de la "descentralización", la cual en cierto sentido hasta podría aliviar el Estado de la obligación de atender a las demandas (sociales, políticas, de derechos y servicios básicos) de algunos sectores de la población, por lo regular los más desiguales que son los pueblos indígenas. Se trata pues de la construcción de "una nueva relación entre los pueblos indígenas, el Estado y la sociedad", la cual pasa por la transformación de la misma sociedad en términos ideológicos, politicos y éticos, hasta acabar con las marcas racistas y discriminatorias que están arraigadas no sólo en las estructuras políticas sino en las conciencias de muchos ciudadanos.

Por otro lado, la autonomía debe ser apoyada activamente por el Estado, el cual debería dotar las instituciones autónomas de recursos suficientes para garantizar su buen funcionamiento, satisfacer sus demandas y lograr sus objetivos. El Estado no puede limitarse a un reconocimiento formal de derechos (a esto se refiere la expresión ya mencionada del reconocimiento retórico del multiculturalismo), cuanto abrir espacios en su

\footnotetext{
${ }^{33}$ No así las prácticas, que residen en la historicidad de los pueblos.
} 
interior y dotar a las instituciones autónomas de recursos para el ejercicio concreto de tales derechos.

Finalmente, haciendo referencia a las políticas multiculturalistas mencionadas en los capítulos anteriores, a través de las cuales el Estado aparenta asumir las demandas avanzadas por los pueblos indígenas, López y Rivas señala acertadamente que

el establecimiento de la autonomía no puede ser entendido como una cuestión meramente administrativa o una mera declaración de principios politicos de respeto a las diferencias, especialmente en los aspectos culturales. Si así fuese, se estaría incurriendo en el reduccionismo culturalista que ha caracterizado el indigenismo desde que surgió. La autonomía supone una posición de poder político, sin la cual los procesos autonómicos derivarían en nuevas formas de dependencia y paternalismo (1995: xix).

\section{La autonomía a debate: muchas experiencias, diferentes interpretaciones}

El debate sobre la relación entre los pueblos indígenas y el Estado se ha venido desarrollando en contextos muy diferentes, tanto a nivel internacional -Latinoamérica y Europa- como en México. Las experiencias concretas se originan a partir de particulares contextos sociales, históricos, territoriales y politicos; implican disímiles relaciones entre el Estado y los pueblos indígenas, así como particulares discursos y prácticas políticas por parte de los sujetos colectivos indígenas de acuerdo a su nivel de organización y su relación con el conjunto de la sociedad nacional.

Por lo tanto, hay que considerar que son las diversas situaciones en las que se han venido construyendo procesos autonómicos las que determinan diferentes conceptualizaciones de la autonomía.

En este apartado trataré de resumir algunas propuestas de autonomía presentes en el debate académico y entre las mismas organizaciones indígenas, situándolas en los contextos que les dan origen, afirmando así la relacionalidad de la autonomía y la imposibilidad de elaborar un "modelo autonómico" universalmente valido.

Quizás la experiencia más trascendente, tanto en el plano concreto como por los elementos que sigue aportando al debate, es la de la Costa Atlántica de Nicaragua.

Tras una fuerte movilización de los pueblos afrocaribeños e indígenas (en particular los miskitos) que enfrentaron al gobierno sandinista reivindicando sus derechos históricos como pueblos, dicho gobierno se abrió al diálogo y promovió una amplia consulta nacional e internacional en la cual participaron tanto representantes indígenas, campesinos y 
sindicales, como expertos y académicos con experiencia sobre el tema ${ }^{34}$. Fue así que en 1987 se reformó la Constitución Política de la Republica de Nicaragua estableciendo los marcos para un régimen de autonomía regional para los pueblos indígenas (miskitos, sumomayangnas y ramas) y comunidades étnicas (creoles, garífunas y mestizos) de la región caribeña. Se formaron dos Regiones autónomas (Norte y Sur) de naturaleza pluriétnica que juntas cubren el $46 \%$ del territorio nacional. En el mismo año, se aprobó el Estatuto (o Ley) de Autonomía de las Regiones Autónomas de la Costa Atlántica de Nicaragua, que establece las atribuciones específicas de dichas regiones y define de forma detallada los procedimientos para la coordinación entre éstas y las instituciones del gobierno central. Asimismo, la Ley de Municipios establece a éstos como las entidades del Estado responsables de la administración y el gobierno del territorio municipal, definiendo los mecanismos de colaboración con los gobiernos regionales autónomos.

Las Regiones autónomas tienen la particularidad de coordinar decisiones y acciones de cuatro diferentes organismos: el gobierno nacional, el gobierno regional, el gobierno municipal y el gobierno comunal [...] es el único caso en que existen gobiernos regionales ubicados entre el gobierno central y el gobierno local, así como una nueva instancia de administración comunal ${ }^{35}$. En el resto del país sólo existe el gobierno nacional y los municipales" (Ortega Hegg 2005:228).

En Nicaragua se instauró un arreglo autonómico institucionalizado y detalladamente definido a nivel jurídico; se trata de un verdadero "régimen que establece una forma de gobierno específica que son los Consejos Autónomos con un Ejecutivo". Otra característica es el ser una autonomía de naturaleza territorial (López y Rivas 2002:118).

No obstante este reconocimiento institucional, el proceso de las Regiones Autónomas de la Costa Atlántica enfrenta problemas de gobernabilidad: en primer lugar la falta de voluntad política por parte del gobierno central para el reconocimiento y avance del régimen autonómico: "las políticas [del gobierno central] definitivamente buscan cómo negarle la participación a los gobiernos regionales en materias de fundamental importancia y de su competencia.[...] ésta es la posición del gobierno central: una posición que definitivamente es contraria a la autonomía”36. En segundo lugar está la falta de coordinación y los conflictos entre los distintos niveles institucionales operantes en las regiones, sobre todo la débil

\footnotetext{
${ }^{34}$ Entre ellos, los mexicanos Héctor Díaz-Polanco y Gilberto López y Rivas, que hicieron de la autonomía uno de sus temas privilegiados de investigación, aunque con enfoques diferentes.

${ }^{35}$ La Constitución nicaragüense reconoce a los territorios y comunidades indígenas en las regiones autónomas como sujetos de derecho publico, con competencias sobre administración de recursos naturales, ordenamiento territorial y planificación al desarrollo.

${ }^{36}$ Francisco Campbell (diputado ante el Parlamento Centroamericano y promotor de la Universidad de las Regiones Autónomas de la Costa Caribe Nicaragüense), en Díaz-Polanco: 1997a.
} 
institucionalidad de los gobiernos regionales y la falta de articulación de las autoridades tradicionales comunitarias. Otros problemas son la falta de compromiso con el proceso autonómico de las personas elegidas en los Consejos Regionales, la carencia de preparación de las mismas, y la insuficiente plataforma económica a disposición de las regiones autónomas. Estos desaciertos han provocado conflictos sociales como la fuerte migración y las rupturas inter-generacionales, que los gobiernos regionales no han sabido enfrentar de forma dinámica y positiva (Ortega Hegg 2005; PNUD: 2005; Díaz-Polanco 1997a). Es interesante notar cómo, aunque en una escala menor, encontramos dificultades en la organización interna muy parecidas en el Sistema de Seguridad y Justicia Comunitaria de la Costa-Montaña de Guerrero, lo que traza una conexión entre los diversos procesos autonómicos y los conflictos que éstos deben enfrentar en la construcción de la autonomía. La experiencia nicaragüense es un referente en el proceso de construcción de las autonomías, por sus importantes aciertos y avances (fortalecimiento de la identidad nacional y al mismo tiempo de la identidad indígena, construcción de instituciones autónomas de educación superior); al mismo tiempo sus dificultades nos hacen ver cómo tales procesos no pueden ser completamente exitosos si no combinan la institucionalización con la formación de conciencia autonómica desde la base; es decir, sin la construcción de un sujeto colectivo indígena. Regresaremos a estas consideraciones más adelante.

Otro contexto paradigmático para el debate sobre la autonomía en América Latina es el de Bolivia. Aquí las reivindicaciones "de un gobierno indígena por los indígenas y para los indígenas" (López y Rivas 2005:48) remontan por lo menos a 1952, año en que estalló la revolución animada por el movimiento aymara y pachacuti, y han marcado recurrentemente la historia reciente del país, hasta llegar al extraordinario levantamiento indígena, campesino y popular del 2004 y a la consiguiente elección del dirigente cocalero e indígena Evo Morales a la presidencia de la República. El actual gobierno boliviano enfrenta el reto histórico de refundar un Estado que se ha caracterizado por la continuidad de las estructuras coloniales, dando cabida a la diversidad de nacionalidades y culturas regionales que coexisten en el país.

Actualmente, el debate sobre la autonomía en Bolivia se encuentra polarizado entre dos posiciones encontradas: la que propone el movimiento indígena y la de "autonomías departamentales", abanderada por las élites políticas y empresariales de los departamentos orientales de Santa Cruz, Pando y Beni, donde se concentra el poder economico. En particular, el Comité Cívico Pro Santa Cruz ha avanzado una propuesta que se refiere a una 
descentralización política, administrativa y financiera. El objetivo es frenar la centralización estatal de los recursos estratégicos y atenuar la afirmación de los poderes locales de las poblaciones indígenas, impulsada por el gobierno con la integración de una nueva Asamblea Constituyente (en el caso del departamento de Santa Cruz, hay un fuerte conflicto entre el poder político-empresarial y el pueblo guaraní que reivindica derechos territoriales y autonómicos sobre la parte del territorio cruceño que ocupa ${ }^{37}$ ). En 2006, un fuerte conflicto político ha enfrentado el gobierno federal con los departamentos orientales, que en contra de los trabajos de la Asamblea Constituyente realizaron de propia iniciativa un referéndum que conferiría legitimidad a su autonomía, lo cual no fue reconocido por el gobierno central.

Contribuyen a complicar el debate las posiciones de los pueblos indígenas mayoritarios, que tratan de hegemonizar el planteamiento autonómico ${ }^{38}$.

Una de las voces que a mi entender resaltan por su autoridad y originalidad en la reflexión teórica es la de Álvaro García Linera, activista y catedrático, actual vicepresidente de la República. Para él, la refundación del Estado implica

diseñar una nueva estructura estatal capaz de integrar en todo el armazón institucional, en la distribución de poderes y en la normatividad, estas dos grandes dimensiones de la cualidad social boliviana: la diversidad étnico-cultural y la pluralidad civilizatoria de los regimenes simbólicos y técnico-procesuales de la organización del mundo colectivo. En términos de derechos ciudadanos y de prácticas democráticas, esto significaría la constitución de un Estado multinacional y multicivilizatorio (García Linera 2005: 281).

García Linera se basa en la análisis de la sociedad boliviana, cuyo $54 \%$ se identifica con algún pueblo originario, y donde hay pueblos que se consideran "comunidades nacionales" (como los quechuas y aymaras ${ }^{39}$, mayoritarios en la población indígena) y otros que no lo son. El primer paso para la

convivencia mediante la articulación de la pluralidad en una unidad política común [...] es la constitución de autonomías regionales por comunidades lingüísticas con distintos grados de autogobierno político. [...] Las características del autogobierno pueden variar según la extensión territorial de la identidad cultural, la densidad demográfica y los grados de politización étnica y nacionalizaría que han atravesado las distintas colectividades (2005: 283-284).

\footnotetext{
${ }^{37}$ Tal conflicto, que refleja también las dos opuestas concepciones autonómicas, se manifestó al interior del Seminario Internacional "Autonomía: nueva relación con el Estado", UE-IIS-UNAM, México D.F. 14/17 marzo 2006, en la discusión entre la presidenta de la Asamblea del Pueblo Guaraní, Nelly Romero López, y el representante del Comité Cívico de Santa Cruz, Juan Carlos Urenda, que se distinguió por la visión extremadamente racista y discriminatoria hacia la población indígena.

${ }^{38}$ Por ejemplo las declaraciones del secretario de la Confederación Sindical Unitaria de Trabajadores y Campesinos de Bolivia (CSUTCB), Felipe Quispe, quién planteó la separación del pueblo aymara del Estado boliviano.

${ }^{39}$ Los dos pueblos indígenas mayoritarios en Bolivia.
} 
El régimen autonómico (también regional) propuesto por Linera es de carácter intercultural, y va más allá de las "regiones pluriétnicas" propuestas por el caso mexicano, ya que reconoce la diferente densidad y desarrollo político de los sujetos colectivos indígenas, afirmando que "pertenecen a regimenes civilizatorios distintos, sus ritmos y tiempos históricos son heterogéneos, por lo que es necesario pensar en una sincronicidad puntual, por periodos cortos, a fin de que se incluya en la deliberación y acción global su presencia, fuerza, acción y decisión" (2005: 287-288).

Las experiencias expuestas de Nicaragua y Bolivia son solamente ejemplos del variado panorama latinoamericano, donde las reivindicaciones por derechos culturales, politicos, y económicos se presentan de tantas formas cuantos son los contextos sociales en que se desarrollan. En este contexto se tomaron brevemente en cuenta por lo que, en términos prácticos y teóricos, están aportando al debate sobre la relación entre el Estado nacional y las diferencias sociales que éste incluye.

\section{Los caminos de la autonomía en México}

En el contexto mexicano se presenta un debate de gran profundidad, que se ha complejizado más en los últimos quince años, principalmente a partir del levantamiento zapatista de 1994, aunque había empezado a sobresalir ya en los años ochenta en diferentes contextos.

Según Hernández Navarro, intelectual mexicano que cuenta con profunda experiencia sobre el tema, en esa época representaban una vertiente del debate

las organizaciones campesinas, cafetaleras, que entendían la autonomía básicamente como autogobierno, asociándola a la apropiación del proceso productivo. Planteábamos por eso la necesidad que las organizaciones campesinas crearan sus propios aparatos y empresas, de tal manera que los recursos, el excedente de lo que se venía produciendo se quedara en las comunidades permitiendo generar procesos de desarrollo autónomo. Había muchas organizaciones indígenas embarcadas en ese proceso, inclusas las que luego se convirtieron al zapatismo. Una segunda vertiente eran las organizaciones etnopolíticas que venían pensando la autonomía como recuperación de lo propio en cuestiones como la fiesta, la lengua, los sistemas normativos ("usos y costumbres"). En este ámbito ellos vinieron desarrollando experiencias prácticas. La tercera vertiente son las personas que se activaron en el 1992 alrededor de los 500 Años de Resistencia y se vincularon con la experiencia de autonomía que provenía básicamente de Nicaragua. En este ámbito fueron muy importantes las experiencias de algunos académicos que participaron en el proceso nicaragüense; algunos de ellos sobre el ejemplo de este proceso se encontraron con dirigentes indígenas para proponer al movimiento indígena la propuesta de las Regiones Autónomas Pluriétnicas. Aquí se entendía la autonomía como un régimen, la transferencia 
de un conjunto de facultades, competencias, funciones y recursos de una instancia oficial de gobierno a otra, los pueblos indígenas. El marco en que se entendían las autonomías era muy formal ${ }^{40}$.

Las dos últimas "vertientes" someramente mencionadas por Hernández Navarro representan los dos grandes ejes del debate mexicano, que comúnmente se identifican como "comunalista" y "regionalista". Las diferencias de visión y de postura no se limitan al debate teórico sino que han aparecido al interior del movimiento indígena mexicano y en éste se expresan, según algunos analistas, en la tensión establecida entre líderes oaxaqueños y chiapanecos, que tendrían distintas lecturas sobre lo indígena. Estas originan diferentes propuestas autonómicas, que se desarrollan a partir de: trayectorias diferenciadas de apropiación de lo étnico; tradiciones distintas de negociación con el Estado; desequilibrio de experiencias en el campo intelectual.

La diferencia fundamental entre las dos propuestas reside en la escala en la que se considera la autonomía y en consecuencia cuál es el sujeto de Derecho y su relación con el Estado. Con la advertencia que tal debate es muy amplio y delicado, trataré de resumirlo en sus puntos fundamentales, avanzando una disculpa por las imprecisiones de tal resumen.

La propuesta de autonomía regional empezó a ser planteada en México por el Frente Independiente de los Pueblos Indios $(\mathrm{FIPI})^{41}$ a partir de la homónima experiencia nicaragüense, recogiendo también el breve intento de instaurar una Región tojolabal en Chiapas, realizado en 1988. La autonomía regional se centra en la identificación de un territorio, adscribiendo a dicha región autónoma la cualidad de sujeto de Derecho: propone la implantación de un cuarto piso de gobierno en la organización político-territorial del Estado, el de la región como entidad política distintiva. El proyecto de autonomía regional, por como se ha venido elaborando en México, pone un énfasis particular en garantizar la representación de los pueblos indígenas en el sistema político y en la elección de sus representantes en los congresos estatales y en el federal, así como en la construcción de administraciones autónomos. Tal propuesta es criticada principalmente por representar una concepción demasiado formal de la autonomía, donde el "autogobierno" sería "un orden de gobierno especifico, constitutivo de un sistema de poderes verticales que conforma la organización del Estado" (Díaz-Polanco 1996:109), lo cual se limitaría a conceder facultades

\footnotetext{
40 Luís Hernández Navarro, entrevista realizada el 27 abril 2004. Es actualmente director de Opinión del periódico La Jornada, ha trabajado como asesor en la Coordinación Nacional de Organizaciones Cafetaleras (CNOC); ha sido asesor del EZLN en los Diálogos de San Andrés y cuenta con varias publicaciones sobre el tema de la autonomía indígena y el movimiento zapatista.

${ }^{41}$ EI FIPI se crea en 1988 y desparece luego del levantamiento zapatista.
} 
administrativas a la entidad regional ${ }^{42}$. Pero, como señala acertadamente Villoro, "establecer un nivel suplementario de gobierno exige una reforma constitucional radical y modificaciones en las leyes fundamentales de los estados con población indígena. Para ello se requieren circunstancias políticas precisas que son difíciles de prever, por lo menos en corto plazo"43 (Villoro 1998:97).

Más allá de esto, el reto en la actual lucha indígena en México no es sólo el reconocimiento constitucional de los derechos indígenas, sino la recreación del proyecto nacional y el establecimiento de un nuevo pacto social entre los pueblos indígenas y el Estado mexicano, reto que no se cumpliría solamente con la instauración de regimenes autonómicos aislados. La única tentativa de poner en práctica esta propuesta tuvo lugar en Chiapas, cuando el 12 octubre 1994 la AEPCH y el CEOIC ${ }^{44}$ proclamaron siete Regiones Autónomas Pluriétnicas (RAP) en el Estado, iniciativa que duró solo pocos meses ${ }^{45}$. El clima de movilización generalizada creado por el levantamiento zapatista explica la inicial adhesión al proyecto de las RAP, creado por una convergencia de organizaciones muy diferentes entre ellas, en un momento en que el proyecto de autonomía zapatista estaba en gestación, pero el debate sobre la autonomía a nivel nacional ya había adquirido mucha relevancia.

Se hizo vocera de la propuesta regionalista la Asamblea Nacional Indígena por la Autonomía (ANIPA), creada en 1995 también sobre la ola de atención a la cuestión indígena levantada por la insurrección del EZLN, organización en la cual convergieron muchos lideres indígenas que jugaron un papel importante en las movilizaciones del 1992 y en los circuitos internacionales. En los primeros años, la ANIPA tuvo bastante capacidad de convocatoria,

\footnotetext{
${ }^{42}$ Esteva distingue entre la descentralización, característica del self-government como tradición anglosajona y también de la administración colonial, que "tiene como premisa una noción del poder que lo centraliza en la cúspide, para delegar hacia abajo competencias" y el descentralismo, que sería característica de un real proceso autonómico y "busca retener el poder en mano de la gente, devolver escala humana a los cuerpos politicos y construir, de abajo hasta arriba, mecanismos que deleguen funciones limitadas en los espacios de concertación que regulen la convivencia de las unidades locales y cumplan para ellas y para el conjunto tareas especificas"

${ }^{43}$ Villoro escribía estas líneas en 1998. Los sucesos políticos siguientes (principalmente la reforma constitucional del 2001 que desconoce los Acuerdo de San Andrés), han demostrado la clara oposición de los actuales gobiernos a crear tales condiciones políticas.

${ }^{44}$ Asamblea Estatal del Pueblos Chiapaneco y Consejo Estatal de Organizaciones Indígenas y Campesinas.

${ }^{45} \mathrm{La}$ iniciativa tuvo bastante fuerza en la Zona Norte, donde el debate sobre la creación de instituciones de gobierno autónomas tenía ya por lo menos dos años, y la declaración de las RAP llevó a la ocupación de una docena de Municipios; pero a los pocos meses la capacidad operativas de las RAP, reconocidas informalmente por las instituciones oficiales (como el entonces Instituto Nacional Indigenista), disminuyó hasta su efectiva desaparición.
} 
aunque siempre haya representado una organización formal y con tendencia institucionalista, de corte tradicional y con estructura vertical ${ }^{46}$.

Mientras, como hemos visto, la propuesta "regionalista" toma ejemplo del proceso nicaragüense y se articula sobre las experiencias chiapanecas, la propuesta "comunalista" se origina principalmente en las experiencias presentes desde hace años en el Estado de Oaxaca. El comunalismo oaxaqueño es una de las corrientes protagónicas del movimiento indígena mexicano, por la capacidad de elaboración teórica, la preparación de sus lideres y los alcances logrados en la negociación con el Estado, con respecto al reconocimiento de sus formas de gobierno por "usos y costumbres" en la Constitución estatal ${ }^{47}$.

En esta propuesta la comunidad adquiere un papel central tanto en el ámbito simbólico como en el político y organizativo ${ }^{48}$; el proceso por el que se propone construir la autonomía no es la construcción de estructuras formales de gobierno, sino la "reconstitución de los pueblos" de acuerdo a unos principios básicos. En el estado de Oaxaca desde hace mucho tiempo la autonomía y el autogobierno en el ámbito comunitario son una realidad concreta: de aquí que la propuesta proponga la comunidad como elemento básico de la organización política indígena y que ésta sea el sujeto de Derecho a reconocerse; también que se plantee el reconocimiento de derecho del autogobierno que ya es realidad de hecho en las comunidades $^{49}$.

Analizando las propuestas autonómicas en correspondencia con los contextos en las cuales se plasman, podemos afirmar que, con respecto a las formas de relación con el Estado, los pueblos indígenas chiapanecos y oaxaqueños presentan trayectorias históricas diferenciadas, que muestran caminos de negociación (en el caso de los primeros) y de confrontación (en el caso de los segundos). La presencia de caciques indígenas capaces de negociar posesión de tierras y autoridad en Oaxaca es de larga data, llegando a construir relaciones de fuerza que las organizaciones campesinas e indígenas han sabido aprovechar.

\footnotetext{
${ }^{46}$ Muchos de sus integrantes cubren puestos en las instituciones gubernamentales y de representación política en el Congreso.

${ }^{47} \mathrm{La}$ Constitución del Estado de Oaxaca fue la primera a reconocer ciertos derechos colectivos de los pueblos indígenas, así como su Código Electoral, que a partir de 1992 empezó a reconocer en las elecciones para autoridades municipales como válidas legalmente la modalidad de nombramiento en asamblea, que fueron denominadas de Usos y Costumbres. Las elecciones del 1995, cuando 412 municipios eligieron sus autoridades de esta forma, fueron determinantes en la relación entre Estado y pueblos indios a nivel nacional y una referencia básica en las negociaciones de San Andrés (Hernández Navarro: 1997; Barabas: 2005).

${ }^{48}$ Como propuesta política organiza su acción en torno a cuatro principios básicos: la tierra y el territorio; el poder comunal (no centrado en el individuo sino en la comunidad) y la asamblea como poder constituyente; el trabajo comunal (como expresión de una relación diferente con la tierra), y la fiesta (como el espacio para recomponer el conflicto).
} 
Por el contrario, en amplias zonas de Chiapas no se consolidó una tenencia comunal de la tierra que permitiera el desarrollo de identidades comunitarias; la historia de los indígenas chiapanecos está marcada por los procesos migratorios que muy a menudo generaban confrontación con el Estado por la tenencia de la tierra, y por la condición de peonazgo en las grandes fincas. En este contexto de falta de negociación la rebelión parece representar la única salida; y el sujeto indígena que se constituye es más ligado a una reivindicación territorial amplia y pluriétnica que a una concepción comunitaria y como "pueblo".

Diversos analistas mencionan que el debate y la práctica de la autonomía indígena en México empiezan a cobrar importancia en ocasión de la movilización alrededor de la Campaña por los 500 Años de Resistencia Indígena, Negra y Popular de 1992 que, como otros Estados latinoamericanos, impulsa a la organización y movilización de los movimientos indígenas $^{50}$, y alcanzan trascender con el impulso y la apertura de espacios de discusión facilitados por el levantamiento zapatista de 1994.

Las dos posturas sobre la autonomía mencionadas entraron en conflicto en el contexto de los Diálogos de San Andrés ${ }^{51}$, donde la tarea para los asesores del EZLN fue redactar un texto que sirviera como base para una reforma constitucional sobre derechos indígenas. Para esto, había que definir la reivindicación central del movimiento indígena, la autonomía, de una forma que reflejara todas las demandas y las aspiraciones de los pueblos.

Quiero subrayar que la discusión que se dio durante los Diálogos de San Andrés puso en evidencia el carácter histórico y local de las formas de gobierno indígenas, ligadas a las identidades de los pueblos. De acuerdo con José del Val, "la diferencia cultural no constituye en sí misma un orden de procesos de carácter general o exclusivo, y deberemos de buscar siempre en situaciones concretas, especificas en tiempo, espacio y modalidad, las determinantes de cada relación" (2004:78). Por lo tanto no puede existir un modelo único de autonomía ni una cristalización de los sistemas políticos y jurídicos de gobierno presentes en los diferentes contextos indígenas. Tal imposibilidad se vio expresada en el marco de los Diálogos de San Andrés que llevaron a la redacción de los Acuerdos homónimos.

\footnotetext{
49 Una interesante critica al comunalismo en cuanto ideología política que idealiza estratégicamente la comunidad y el ámbito comunitario de ejercicio del poder se encuentra en Zarate: 2005.

${ }^{50}$ En Guerrero se formó en esta ocasión la más importante organización indígena a nivel estatal, el Consejo Guerrerense 500 Años de Resistencia Indígena, Negra y Popular.

${ }^{51}$ Proceso de negociación entre el EZLN y el gobierno federal, que se llevó a cabo entre octubre 1995 y febrero 1996 en la comunidad tzotzil de San Andrés Sakamch'en de los Pobres, cabecera del homónimo Municipio Autónomo Zapatista. Durante el Dialogo se llevó a cabo el Foro Nacional Indígena, importante convergencia de representantes indígenas y de la sociedad civil de todo el país, semilla de lo que será después el Congreso Nacional Indígena. Los Diálogos se concluyeron con la firma de los Acuerdos de San Andrés entre el EZLN y el gobierno federal.
} 
En el proceso de negociación se dio un duro debate entre los muchos intelectuales y representantes de organizaciones indígenas presentes como asesores del EZLN. Proviniendo de diferentes lugares del país, en donde las experiencias de autogobierno se han construido históricamente en términos distintos, cada quien reivindicaba la legitimidad de su práctica; el debate se dio sobre cuál debía considerarse el sujeto de la autonomía y a qué nivel reconocerse el "cuarto piso de gobierno", si comunidad, municipio o región. En esto, concuerdo con la opinión de Del Val (2004) de que los destinos de una cultura son asunto de los portadores de la misma; obligación de los Estados es establecer las leyes que fijen el derecho inalienable a su ejercicio, mientras tal ejercicio no contradiga los derechos humanos y las garantías individuales establecidas. Cabe señalar que esto significa no solamente un reconocimiento formal de la autonomía "cultural", sino garantizar las condiciones específicas para la vida de los pueblos (condiciones económicas y derechos sociales).

En relación con las propuestas de autonomía, creo que lo pactado en el texto de los Acuerdos de San Andrés es lo más útil para pensar las autonomías en un país con tanta diversidad cultural como México:

la autonomía es la expresión concreta del derecho a la libre determinación, expresada como un contexto que forma parte del Estado nacional. Los pueblos indígenas podrán, en consecuencia, decidir su propia forma de gobierno interna y sus propios modos de organizarse política, social y culturalmente. Al interior del nuevo contexto constitucional de autonomía se respetará el derecho a la libre determinación en cada uno de los ámbitos y niveles que lo hagan valer; pudiendo comprender uno o más pueblos indígenas, de acuerdo a las circunstancias particulares y especificas de cada entidad federativa ${ }^{52}$.

Un análisis interesante de la propuesta "regional" en oposición a la "comunitaria", que en mayor medida ha sido acogida en el texto de los Acuerdos de San Andrés, se encuentra en Villoro. Éste considera más viable que la comunidad, y no la región, sea reconocida como entidad de Derecho: "habría así una forma para llegar a regiones autónomas constituidas por un pueblo, sin necesidad de reformas legales radicales, planificadas desde arriba. Para ello, es menester reconocer el derecho de autodeterminación de los pueblos". Sobre la base de un marco general, se propone "no una reforma repentina, diseñada en el papel, sino un proceso paulatino, cuya progresión estaría marcada por las mismas comunidades indígenas" (Villoro 1998: 98).

Los acuerdos de San Andrés han sido definidos "acuerdos mínimos", ya que, en cuanto fruto de una negociación, no recogen satisfactoriamente algunas de las demandas del movimiento

\footnotetext{
${ }^{52}$ Acuerdos de San Andrés, Documento 2, Pág.2.
} 
indígena, como las que se refieren a la cuestión agraria y al reconocimiento de los sistemas jurídicos indígenas ${ }^{53}$. Los partidarios de la autonomía regional también los descartan como moderados, ya que su visión no se ve reflejada en ellos: según Díaz-Polanco, "por lo que respecta a la demanda de autonomía de los pueblos indios, es insatisfactorio lo que se avanza en los documentos que hemos examinado" (1997b: 213). Por otro lado, un comunalista como Esteva afirma que "en San Andrés se aceptó este alcance radical de la autonomía y se rechazó la propuesta que la mutila" (1998:314).

A pesar de los innegables límites, la propuesta autonómica forjada en los Acuerdos es suficientemente compleja y logra abarcar las demandas de los pueblos indígenas organizados que participaron en ella, ya que, como afirmamos, no tiene ninguna utilidad la pretensión de formular un modelo de régimen autonómico único válido para el conjunto de los pueblos indios del país. Hernández Navarro (1997) afirma acertadamente que el mérito de San Andrés fue poner la cuestión indígena en el centro de la agenda política nacional como nunca antes había estado. Por esto sigue siendo, a 11 años de su redacción y aunque se encuentre en algunos puntos rebasada por los acontecimientos recientes, la reivindicación que acomuna a todo el movimiento indígena mexicano. El proceso político que ha seguido a la firma de los Acuerdos ha visto, por un lado, el crecimiento y la estructuración del movimiento indígena, con la constitución del Congreso Nacional Indígena (CNI), espacio de discusión y organización a nivel nacional, hasta llegar a la excepcional movilización del 2001, con la Marcha zapatista que llevó a la tribuna parlamentaria representantes indígenas abogando por el reconocimiento constitucional de sus derechos. Por otro lado se ha demostrado la completa cerrazón del gobierno panista sobre el tema, con la aprobación de las reformas constitucionales en materia de Derechos y Cultura Indígenas ${ }^{54}$ que desconocen lo pactado en los Acuerdos y retomado en la propuesta de ley de la Cocopa, mientras ratifican la discriminación y la desigualdad. Ante esta realidad, la posición declarada por los integrantes el CNI ha sido que

sin reconocimiento o con reconocimiento legal seguirán impulsando el ejercicio de su autonomía y de sus derechos [...] Haremos efectivos los Acuerdos de San Andrés mediante el ejercicio cotidiano de la autonomía indígena, la construcción de autonomías comunales, municipales, regionales y la

\footnotetext{
53 "Punto y seguido", documento del CCRI-CG y asesores del EZLN al terminar la tercera fase de la mesa 1 de los Diálogos de San Andrés, en Ce Acatl n.78-79, 1996.

${ }^{54}$ Reforma Constitucional en Materia de Derechos y Cultura Indígenas, conocida también como Ley BartlettFernández, aprobada por el Congreso de la Unión el 28 de abril de 2001.
} 
reconstitución integral de nuestros pueblos. Impulsaremos la elaboración de estatutos comunales como instrumentos legales básicos para el reconocimiento del ejercicio de nuestra autonomía ${ }^{55}$.

En el México actual la experiencia autonomica más desarrollada quizás sea la que están construyendo en Chiapas los pueblos indígenas zapatistas. A partir de la declaración de más de 30 Municipios Autónomos Zapatistas en Rebeldía en el diciembre 1994, los pueblos zapatistas han sabido lograr la autonomía en muchos aspectos de la vida social: cuentan con gobiernos autónomos que se ocupan de cuestiones administrativas y agrarias, e imparten justicia; con sistemas educativos y sanitarios autónomos; con cooperativas de producción y una red de comercialización autónoma para los productos de las comunidades. Empezando a construir el autogobierno en los ámbitos municipales sobre la base de las prácticas de gobierno comunitarias (donde los cargos son rotativos y la máxima instancia decisional es el ámbito colectivo de la asamblea), han realizado un innovativo proceso de remunicipalización, reterritorializando los nuevos municipios autónomos de acuerdo a las exigencias prácticas y culturales de los pueblos. En 2003, otro paso cualitativo ha sido la regionalización de los gobiernos autónomos, por medio de las cinco Juntas de Buen Gobierno, instancias superiores de coordinación, dirección política e impartición de justicia a las cuales hacen referencia los Consejos Municipales Autónomos de cada región ${ }^{56}$.

\section{Autonomía, identidad y tradición}

Las autonomías, tal como las concebimos en nuestra América Latina, son procesos de resistencia mediante los cuales pueblos o etnias soterradas y negadas recuperan o fortalecen su identidad, a través de la reivindicación de su cultura, el ejercicio de derechos colectivos y el establecimiento de estructuras político-administrativas con diversas competencias, ámbitos y niveles de aplicación y una base material propia [...], respetando los usos y las costumbres que les dotan de identidad y les permiten resistir la hegemonía de un estado y un régimen político que los ha mantenido olvidados y marginados durante siglos (López y Rivas 2005: 33-34; 63).

Tenemos aquí una mención al valor de la identidad al interior de las reivindicaciones autonómicas. Esto se ha de entender no necesariamente en términos esencialistas, cuanto considerando la identidad como un elemento que concierne a los ámbitos de la pertenencia y de la diferencia, constantemente redefinidos por los procesos históricos y sociales, para hacerse siempre adecuada a las necesidades de quien se identifica con ella. Como bien

${ }^{55}$ Congreso Nacional Indígena, Declaración Final de la Octava Asamblea Nacional, México DF, 18-20 noviembre 2001.

${ }^{56}$ Son muchos los textos del mismo EZLN que explican el proceso y la forma de la autonomía en territorio zapatista, así como la bibliografía de autores mexicanos y extranjeros que analizan tal experiencia. He tratado de elaborar un analisis relativamente detallada en mi texto publicado en 2005. 
afirma Villoro, "la identidad así concebida no detiene necesariamente a una colectividad en la reiteración de sus formas de vida heredadas, sino que la obliga a reinterpretar continuamente el pasado para integrarlo en proyectos de vida colectivos" (1998:149).

$\mathrm{Si}$ las sociedades indígenas han podido resistir el embate de las acciones integradoras y desestructuradoras, es en parte gracias a la solidez y fuerza simbólica de su discurso. Si sus dinámicas sociales están más orientadas, desde nuestra perspectiva, a la recomposición que a la fragmentación, es también resultado de dichas estrategias identitarias, de las que los discursos son sólo una dimensión (Zúñiga: 2000).

Un debate interesante sobre el uso estratégico del discurso sobre la identidad y la tradición ha aparecido hace algunos años entre Sierra y Zúñiga. Sierra nos advierte sobre los riesgos que puede tener el discurso con tintes esencialistas y de idealización de su pasado que a veces utilizan los movimientos indígenas, como arma política y en respuesta al racismo también esencialista de muchos sectores de la sociedad mexicana. La autora propone como más valiosos los discursos que tratan de replantear las tradiciones de acuerdo a las nuevas necesidades y escuchando las voces calladas de algunas partes de las sociedades indígenas. En respuesta Zúñiga afirma que

el trabajo de María Teresa Sierra, abogando por un enfoque dinámico y situacional, con el que comulgamos, destina lo sustantivo de su análisis a desmentir el discurso indígena, intentando probar que los rasgos sustantivos y absolutizadores (la costumbre y la tradición) que transmite, no están vigentes, no corresponden a la realidad, sin interrogarse acerca de las funciones específicas que tienen este discurso y estos recursos argumentativos en el contexto de las luchas étnicas de las que son sólo una faceta (Zúñiga: 2000).

Siempre hay que considerar el discurso y la acción social en el contexto que los produce, de acuerdo a las funciones $\mathrm{y}$ a los fines que tienen: finalmente estamos hablando de herramientas que han permitido a los pueblos indígenas posicionarse en la arena política internacional, saliendo de la jaula particularista, y en cierto sentido racista, construida tanto por los Estados como por la academia.

Por lo anterior, "el respeto a la identidad de las otras culturas no conduce a la preservación de sus notas distintivas, sino a su mantenimiento irrestricto de su capacidad de decisión y de cambio" (Villoro 1998:150): es decir, a su existencia en un ámbito de autonomía.

Pero el discurso sobre la tradición y los usos y costumbres no sólo ha representado un arma estratégica para los movimientos indígenas; también ha sido utilizado por el Estado y sus intelectuales para descalificar a las culturas indígenas acusándolas de ser premodernas y antidemocráticas. Al estallar el levantamiento zapatista y el debate sobre la legitimidad de la 
reivindicación de derechos colectivos por parte de los pueblos indígenas mexicanos, el Estado mexicano, a través de los medios, desató una campaña dedicada a minar la legitimidad de tales reivindicaciones. En ella se pueden individuar dos principales directrices: "una abiertamente racista que presenta las culturas indígenas como primitivas y atrasadas, y una liberal que las presenta en términos de 'inauténticas', usando la historia para demostrar el origen colonial de las culturas indígenas" (Hernandez Castillo : 2002).

Este argumento, aunque más sutil, demuestra su debilidad ya que, en mi interpretación, la legitimidad de las culturas indígenas y los procesos autonómicos que éstas construyen no viene de su supuesto carácter "tradicional," sino de su capacidad de responder a las necesidades de los pueblos, respetando su visión y su cultura.

Un conocimiento, aunque somero, de la historia mexicana demuestra que tales reivindicaciones y prácticas autonómicas existen en forma más articulada por lo menos desde el siglo XIX. Como diría Beaucage,

la situación de los indígenas en México se encuentra actualmente en un proceso de rápido cambio y cualquier intento de balance resultaría fútil y rebasado por los acontecimientos. Sin embargo, se puede considerar que por la misma dinámica histórica, la autonomía local, aunque recortada por la injerencia de poderes superiores, constituye uno de los ejes más duraderos del proceso de resistencia y de afirmación identitaria de los indígenas de México. Los vastos movimientos agrarios, politicos y económicos de los años setenta y ochenta [del siglo $X X$ ] permanecen hasta hoy en la medida en que echaron raíces. A la vez, asistimos a la revitalización de instituciones que parecían caducadas, como los consejos de ancianos y la administración indígena de la justicia; las reivindicaciones actuales por la autonomía municipal, comunal, y la defensa del ejido, parecen inscribirse dentro del mismo proceso (2000:311-12).

La representación del sujeto indígena en la propuesta de autonomía es una evocación a la alteridad; es una reivindicación de los sentidos y los criterios de diferencia que a veces se concretan en nociones relacionadas con la "tradición" y "usos y costumbres". Sin embargo, la diferencia, al igual que la identidad y el sujeto, no está significando ningún sentido inmutable, ningún rasgo singular que ha persistido en el tiempo. Al contrario, la diferencia es una significacion social que está inscrita en un doble juego: designar alteridad (cuando es apropiada propositivamente por la subalternidad y construye resistencia) y excluir y discriminar al sujeto (cuando es apropiada por el poder).

En este caso, la diferencia reflejada en la reivindicación de "la tradición" o de "usos y costumbres", al ser alimentada desde el poder, ha generado formas específicas de articulación de los sujetos indígenas con un sistema de dominación local que se reconoce como caciquismo indígena y que tiene articulaciones regionales y nacionales. La referencia a "usos y costumbres", al apelar al carácter unificador de la comunidad, ha sido en algunos 
casos funcional a la ideología del corporativismo político mexicano, a la visión de filiación partidaria que se ha desenvuelto en los marcos del unipartidismo. Por otro lado, asistimos frecuentemente a un uso instrumental de la tradición por parte de estas "élites" indígenas para fines de acumulación de riqueza, prestigio o de exclusión política, actuando como mecanismos de discriminación, intolerancia y dominación hacia algunos sectores de la sociedad indígena (por ejemplo las mujeres o los jóvenes, que no gozan de iguales derechos).

No cabe duda que las sociedades indígenas siguen atravesadas por conflictos de orden economico, social y político. El autoritarismo de los caciques, las disputas por los linderos comunitarios y municipales, la discriminación religiosa y de género, marcan muchos territorios indígenas. En cierta medida, se puede sostener que tales conflictos y situaciones de desigualdad tienen su raíz en la relación sostenida con la sociedad dominante, que a partir de la Colonia ha actuado con mecanismos de dominación y despojo, minando las estructuras y los lazos comunitarios; ahora tales procesos son acelerados por la privatización de los recursos y las experiencias migratorias. Al respecto, propongo dos consideraciones: en primer lugar, las experiencias de autoorganización y autonomía indígena de facto no deben ser idealizadas; hay contextos más polarizados y también hay procesos que muestran la tentativa de replantear la organización social de forma más igualitaria, tratando de superar las situaciones de discriminación, a partir de una reflexión interna y considerando las influencias "externas". En segundo lugar, el reconocimiento de un marco de autonomía, aunado a procesos de empoderamiento y de construcción del sujeto autonómico $^{57}$, podría representar una oportunidad para el desarrollo de las sociedades indígenas. Esto es, permitiéndole elaborar estrategias sociales y económicas más adecuadas a las exigencias que las mismas perciben como prioritarias, garantizando el respeto de determinados derechos indígenas (como la propiedad colectiva, territorio propio etc.), dando la posibilidad de mantener y al mismo tiempo transformar instituciones tradicionales, abriendo la participación y acceso a cargos políticos a jóvenes y mujeres.

\footnotetext{
57“Las autonomías, reconocidas dentro del marco político-jurídico del Estado nacional, suponen fundamentalmente el establecimiento de un autogobierno que asuma las competencias y haga uso de los recursos públicos para el ejercicio de derechos reconocidos en la Constitución y en las leyes secundarias. Esto significa, y es el principal elemento constitutivo de un proceso de autonomía, la conformación de un sujeto autonómico, o sujeto colectivo de transformación social, con base territorial y con identidad socioétnica, no sólo
} 


\section{La autonomía como proceso}

En un texto reciente, López y Rivas (2005) expone lo que yo entiendo el carácter procesual de las autonomías en dos sentidos:

1. en primer lugar afirmando que el marco jurídico-constitucional de los Estados es un punto de partida y no de llegada, y que las autonomías constituyen también procesos permanentes de negociación, en los que la garantía de continuidad y desarrollo es la existencia o la construcción del sujeto autonómico. Es decir, no pueden existir autonomías exitosas caladas desde arriba o construidas en ámbitos ajenos a donde se implantarán; tampoco se puede pensar en construir instrumentos jurídicos que de una vez y para siempre establecerán alcances y competencias en términos fijos, como es el modo del derecho positivo. Este problema ha sido enfatizado por algunos autores con respecto a los sistemas normativos indígenas: Assies afirma que "lo que a menudo consideramos como 'justicia y derecho' coincide en la práctica con la mayor parte de la estructura social de las sociedades indígenas" (2000: 1). Pero con la necesidad de codificar en forma estricta los procedimientos y prácticas vivenciales que, con los años, han estado constantemente recreados, existe la tendencia a generalizar y homogeneizar la interpretación del "deber ser"; pues existe por un lado la posibilidad que la legalización fortalezca la burocratización, y por otro la contradicción que en codificar el derecho indígena se trasladaría una parte sustancial de las prácticas y normas indígenas al terreno de la cultura occidental y a la autoridad legal del Estado. Tales contradicciones no tienen fácil solución si se piensan las autonomías como un proyecto multicultural que se limite a añadir la diferencia cultural a la norma dominante existente, estableciendo derechos e instituciones aparte, sin repensar el proyecto estatal y nacional en su totalidad.

2. En segundo lugar, el carácter procesual de las autonomías destaca que cada pueblo tiene una historicidad propia, y las formas en que ha construido sus dinámicas de autogobierno y administración de la justicia son diferentes en los diversos lugres, además que cambian en respuesta a las particulares presiones y modificaciones del contexto político-social tanto interno como externo.

Al respecto, un destacado intelectual indígena escribía: "por higiene mental, la discusión de las autonomías no puede provenir solamente de disertaciones teóricas sino, y sobre todo, de

con la capacidad de representar por consenso los intereses de la colectividad, sino también para constituirse en un interlocutor legítimo implicado en el proceso de negociación y dialogo" (López y Rivas 2004:169). 
la reflexión de las realidades concretas en las cuales se matizan ciertas prácticas autonómicas, conservadas a pesar, y aun en contra, del Estado-nación dominante" ${ }^{\text {"58 }}$.

Por lo tanto será en la praxis concreta y a partir de ella, en medio de procesos de diálogo y negociación, en que se determinarán formas y modos de las autonomías, sin pretender un marco de universalidad en ellas ${ }^{59}$.

Esto no excluye la urgente necesidad de un marco constitucional que deberá establecer las competencias y los ámbitos generales de ejercicio de las facultades autonómicas; subrayando otra vez que tal marco general debe ser fruto de una negociación a nivel nacional y conllevar una profunda reforma del modelo estatal mismo.

En este sentido, la petición central de los Acuerdos de San Andrés, "la construcción de un nuevo pacto social constituyente una nueva relación entre los pueblos indígenas, la sociedad y el Estado"60 apunta a una reforma radical de toda la nación, en una redistribución de derechos, competencias y recursos para todos los sujetos de la sociedad. Por lo tanto, no concuerdo cuando Del Val afirma que "las autonomías aislarán definitivamente los pueblos indios del debate por la democracia nacional; [...] probablemente atentan contra la integridad de los pueblos indios y constitucionalizan su ubicación marginal en la disputa por la nación" (2004:211-12). Según la posición que aquí se expresa, autonomía no significa aislamiento sino participación igualitaria en el diálogo nacional a partir de una identidad social diferente, compartida: una identidad a la vez indígena, que implica el derecho a la diferencia, y mexicana, la cual significa derecho a la igualdad en el acceso a los recursos y participación ciudadana plena.

Uno de los principales temores a reconocer a las comunidades el derecho a su autodeterminación es el que sus prácticas normativas pueden ser lo suficientemente ajenas al Derecho estatal y a los derechos universales, llegando a ser degradantes de la personalidad individual. Estas argumentaciones a veces son fundamentadas en prácticas reales; otras veces son manipulaciones de los gobiernos para no tener que respetar los derechos de autonomía. Ahora bien, ninguna comunidad en la actualidad puede estar aislada de los derechos y obligaciones que imponen los estándares internacionales (por ejemplo el Convenio 169 de la OIT), y esto ocurriría aún más al ser reconocida la autonomía dentro del marco normativo general, que es la Constitución.

\footnotetext{
${ }^{58}$ Floriberto Díaz Gómez, "Comunidad y comunalidad” en La Jornada Semanal, 11 de marzo del 2001.

${ }^{59}$ Olivé propone que las autonomías sean fruto de una interacción transcultural (2004:103).

${ }^{60}$ Acuerdos de San Andrés, Documento 1.
} 
En los contextos donde los pueblos indígenas están construyendo procesos autonómicos, hay que poner énfasis en la constante reinvención y resignificación de las tradiciones, en un sentido que amplia la plataforma de los derechos sociales, nutriendo de sentido alternativo a las definiciones locales de democracia ${ }^{61}$. Para avanzar propuestas y diseñar políticas, es necesario tomar en cuenta los procesos internos a través de los cuales los sujetos autónomos negocian nuevos derechos, apropiándose de espacios hasta la fecha negados, a través del manejo de discursos políticos y sociales "ajenos" (en el sentido esencialista) a sus tradiciones culturales. El Sistema de Seguridad y Justicia Comunitaria de la Costa-Montaña de Guerrero y las Juntas de Buen Gobierno en el territorio autónomo zapatista en Chiapas, representan, junto con otras en el contexto nacional, experiencias sumamente interesantes por el nivel de relacionalidad que las prácticas tienen en los diferentes ámbitos de la sociedad y su aptitud para responder a los cambios (internos y externos), así como su capacidad de "autocrítica" (reflexión y poder de cambio sobre las prácticas mismas).

\section{¿Autonomía o autonomías? Del concepto a la práctica y regreso}

Hasta ahora las diferentes interpretaciones de la autonomía analizadas reflejan una idea de la autonomía como proceso, práctica o régimen que abarca todos los aspectos de la vida social. Se tiende a afirmar que una u otra experiencia organizativa de los pueblos indígenas está construyendo autonomía cuando la práctica autonómica influye en los aspectos fundamentales de la vida cotidiana: el gobierno y la vida política, la administración de justicia, el control del territorio y el aprovechamiento de los recursos, la educación, la salud, la economía. En la literatura sobre el tema, las experiencias analizadas e interpretadas como "autónomas" son las que abarcan de forma integral el todo social; esto depende de una particular forma de entender la autonomía que acomuna muchos estudiosos del tema, claramente expuesta por Barabas: "la autonomía debe entenderse como una totalidad multidimensional que tiene que ser reconocida y ejercida integral y no parcialmente" (2005:165). Esta posición puede ser aceptable como marco ideal al cual deberían apuntar los procesos autonómicos, o como marco jurídico no restrictivo o limitante para el reconocimiento de los derechos de los pueblos.

Pero la realidad es otra. Frente a contadas experiencias de autonomía "integral" (en México la más ejemplar en este sentido es la de las comunidades zapatistas en Chiapas)

${ }^{61}$ Ejemplo de esto es la Ley Revolucionaria de las Mujeres vigente en la zona zapatista: a través de una consulta, las mujeres de las diferentes regiones zapatistas han impuesto su papel en la construcción del 
observamos innumerables procesos organizativos que construyen y ejercen autonomía en ámbitos específicos de la vida social, sin alcanzar los otros aspectos que siguen funcionando según las reglas políticas y económicas del sistema dominante.

Encontrándonos frente a tales procesos, las conceptualizaciones corrientes quedan demasiada estrechas, o más bien demasiado anchas. Si pensamos en el Sistema de Seguridad y Justicia Comunitaria de la Costa Chica y Montaña de Guerrero, donde se observa un alto nivel de autonomía en los campos de produccion normativa, de administración y impartición de la justicia, y de control del territorio en términos de seguridad, pero en otros ámbitos organizativos no se vislumbran avances, la pregunta que problematiza el análisis es: ¿hay aquí autonomía?

Trataré de articular algunos elementos teóricos y metodológicos que pueden ser útiles para interpretar tales tipos de procesos, descartando la respuesta que niega tajantemente la posibilidad de definirlos como "autonomía"; más aún, sostengo que podemos hablar de autonomía, aunque en términos diversos a los planteados comúnmente.

En primer lugar, cabe recordar que cada experiencia de autonomía, en cuanto proceso en el cual los pueblos se apropian de partes o aspectos del poder político y decisional, nunca se da afuera o independientemente del contexto nacional (donde el ejercicio del poder, el uso de la fuerza, el control del territorio, de los procesos económicos y de las estructuras para el bienestar de la población, son competencia del Estado).

Como bien afirma Barabas, "no existe autonomía en un vacío de relaciones ni en el seno de relaciones de subordinación, por lo que su ejercicio se realiza no sólo al interior del ente autónomo, sino también en la articulación de los entes autónomos entre sí y con el Estado" (2005:165).

Puesto que cada proceso autonómico se desarrolla adentro del Estado y en una continua relación con éste, los logros y los alcances de la organización de los pueblos siempre se deben medir en correspondencia con las particulares políticas estatales, con la presión (política, militar, económica) que el Estado ejerce hacia el proceso y en el territorio, con el nivel de madurez y peso político que tiene la organización (lo que determina la calidad de la negociación).

Esta consideración también lleva a desglosar algunos aspectos de la autonomía hasta aquí no analizados. Considero insuficiente la postura que ve la autonomía principalmente como acciones de reconocimiento legal y transferencia de poderes, facultades y recursos desde el

proceso autonómico, imponiendo la valoración de los derechos de género en una tradición local discriminatoria. 
Estado hacia las instancias de gobierno autónomas. Esta posición olvida que dichas acciones deben ir de la mano con la construcción desde la base de dichas instancias de gobierno, que son expresión de un sujeto colectivo autónomo (pueblo, organización, municipio, región, etcétera). Ya que la autonomía siempre es fruto de una negociación, los avances en la construcción de las facultades autonómicas serán mayores en la medida en que este sujeto colectivo se fortalezca organizativamente y se desarrolle interiormente de acuerdo a sus necesidades, acumulando fuerza para presionar y gestionar hacia el Estado los espacios para el ejercicio del poder autónomo.

La autonomía pues se construye desde dentro a los procesos, sobre la base de problemas y exigencias concretas, cuya resolución por parte de los pueblos organizados constituye la fuerza de las instituciones autónomas. Tal fuerza la utilizarán en las negociaciones con el poder estatal, que se podrán dar en términos de diálogo o de conflicto, de acuerdo a la disposición del Estado.

La segunda consideración que quiero proponer se desprende de lo que he definido como el carácter procesual de las autonomías. Hablo de "autonomías" ya que "como no hay una cultura india ni un movimiento indio, no puede haber un tipo de autonomía que convenga a todos los pueblos indios ni a todos los países" (Becauge 2003: 317-318).

El mismo autor llega a una afirmación interesante, aunque parezca obvia, o sea que

el proceso real hacia la autonomía sigue caminos múltiples: las cientos de organizaciones de productores indígenas que buscan (y a menudo logran) procurar la subsistencia de sus miembros, las radios indígenas, los maestros bilingües que actúan como 'intelectuales orgánicos' de los pueblos, etcétera. Ahí me parece que están presentes los elementos que esbozan lo que podría ser una autonomía real, a nivel económico, político y cultural (2003:319).

Lo que acomuna todos estos "caminos autonómicos" es su calidad de procesos en continua construcción, no acabados; y el hecho que, aunque diferentes entre ellos, tienen como común denominador la apuesta hacia una nueva relación entre el Estado y los sujetos colectivos que conforman la sociedad nacional. Aunque sean procesos limitados a ámbitos específicos de la vida social, su calidad autonómica reside en que son sin duda acciones concretas en los ámbitos y formas que la sociedad local necesita, de acuerdo a sus problemáticas y exigencias. Así, la visión procesual imprime el carácter autonómico a todas estas que aparecen como prácticas aisladas.

Precedentemente he tratado de definir la autonomía en términos formales, como marco jurídico para el reconocimiento de derechos colectivos de los pueblos indígenas. Ésta es una de las formas en que se puede entender. 
Ahora bien, por el caso mexicano, en un contexto legal que ha visto al Estado aprobar en 2001, como resultado de una excepcional movilización indígena a nivel nacional, unas reformas constitucionales en materia de Derechos y Cultura Indígenas que ratifican la discriminación y la desigualdad, el ejercicio implica explicar cómo de manera particular en cada región, en cada municipio, los indígenas están tratando de construir sus propias razones de lo que entienden como sus derechos a partir de su historia y de sus experiencias.

Al propósito, se habla de autonomías de facto, o sea que existen aunque no exista un marco legal para su reconocimiento. Tal concepto es sugerente, aunque también se basa sobre una idea de la autonomía como integral.

Para el proceso que se analizará en los siguientes capítulos, creo más útil pensar a las autonomías como prácticas contrahegemónicas, procesos particulares que, en un espacio hegemonizado por las estructuras estatales, disputan a éstas competencias y facultades de acuerdo a los diferentes contextos y a las necesidades particulares de quienes habitan los territorios. Pueden ser procesos limitados a algunos ámbitos de la vida social, pero que tratan de construir otra relación ciudadana a partir de la apropiación y el ejercicio del poder desde abajo.

Para poder evaluar el significado y la trascendencia de estas prácticas autonómicas es necesario analizar atentamente las formas que asume la presencia del Estado en las regiones específicas, las acciones que impulsa tanto en términos positivos cuanto negativos (programas sociales, aprovechamiento de los recursos naturales, militarización, etcétera) así como la medida de sus ausencias, ya que en varios casos los procesos de organización autónoma surgen como respuesta a una efectiva ausencia del Estado, y representan caminos de construcción de "Estado" (entendido en términos de estructura social, política, de servicios básicos) desde abajo.

\section{¿A quién quieren que seamos iguales? Ciudadanía y diversidad}

"Los pueblos indígenas, en Indoamérica, plantean una doble exigencia: autonomía para decidir respecto de sus formas de vida y participación en la unidad del Estado" (Villoro 1998: 103); esto es, quieren ser diferentes y al mismo tiempo iguales. En estos términos, la propuesta de "ciudadanía diferenciada", avanzada en términos liberales por Kimlicka, aparece inadecuada para acoger la amplitud de esta reivindicación que desborda los límites de la simple afirmación de la diferencia cultural. No está demás reafirmar que otro límite de 
estas políticas es ser en cierta medida "caladas desde arriba" o fruto de una negociación parcial, que no incluye un diálogo amplio y una transformación radical de las estructuras estatales. Lo que plantean los pueblos indígenas es ser incluidos en la "ciudadanía común" pero en un marco que no incluya ningún derecho u obligación que ellos no reconozcan. Para pensar seriamente el derecho a la diferencia, es indispensable reconocer que los seres humanos no somos todos iguales, es decir que podemos ser iguales en muchas cosas diferentes en otras. Por eso necesitamos de una noción restringida de igualdad; o sea, restringir la universalidad de la noción de igualdad como condición para pensar el derecho a la diferencia. Asimismo, Villoro propone restringir el concepto de ciudadanía a términos compatibles a todos los grupos, a partir de una idea de igualdad que consiste en la atribución a todos de las mismas oportunidades para elegir su plan de vida y sus valores, aunque éstos difieran entre sí (1998:103-104). En este sentido, igualdad y diferencia, ciudadanía y autonomía, no serían contradictorias, sino coexistentes en el mismo razonamiento. Así el derecho a la diferencia puede ser contenido en el mismo principio universal de igualdad.

La consigna fundamental del discurso zapatista (unos de los más sugerentes movimientos politicos indígenas activos en México), el somos iguales porque somos diferentes, es espejo de un sentimiento que busca la interacción con los otros sujetos de la sociedad para construir un espacio de ciudadanía igualitaria, en que sea garantizado para todos el acceso a los recursos básicos, tanto materiales cuanto culturales. Ya estamos muy lejos de las concepciones multiculturalistas y diferencialistas: éste es, en mi interpretación, el espacio tan buscado de la interculturalidad, caracterizado por intercambio y comunicación, pero también donde los sujetos logren "ser incluidos, llegar a conectarse sin que se atropelle su diferencia ni se los condene a la desigualdad" (García Canclini 2004:53)

\section{Democracia y diálogo intercultural}

He tratado de moldear mis reflexiones de acuerdo a una visión que dé centralidad a las prácticas y los procesos, enfatizando la necesidad de construir los espacios politicos y los derechos a través de negociaciones.

Si hablamos de la necesidad del reconocimiento de derechos autonómicos, se trata de que se emprenda una profunda reforma, tanto de la estructura estatal como de la relación entre los sujetos que componen la "nación", reconociendo de cada uno su historia, su presente y su proyecto. Esto, a la luz de la realidad en que los sujetos construyen normatividades 
híbridas, que rompen con la dicotomía entre liberalismo individualista y tradiciones comunitarias que inhiben a las personas.

Los pueblos indígenas están planteando la necesidad de abrir el modelo "democrático" a nuevas definiciones de la democracia, que articulan prácticas innovadoras con las que históricamente han coexistido al lado de los modelos hegemónicos de la democracia representativa y liberal ${ }^{62}$.

Según Yashar (2005), actualmente en todo el continente latinoamericano los nuevos movimientos indígenas se están movilizando para redefinir los límites de la ciudadanía (quién es ciudadano) y su contenido (cuales derechos y prácticas contempla la ciudadanía), oponiéndose a la idea que existan una única cultura política abarcativa (sea nacional o cívica), una representación social unitaria, un modelo único de sistema legal, y que exista un único tipo de Estado que puede o podría regular las relaciones sociales. Lo que está en juego es superar las barreras políticas representadas por concepciones excluyentes y exclusivas de la diferencia y de la igualdad, y actuar hacia la interculturalidad. El concepto de la interculturalidad va más allá de la diversidad, el reconocimiento y la inclusión.

Quiero exponer brevemente la propuesta que Olivé llama pluralista o, también, diálogo intercultural, por ser la más sensata y abierta a un contexto práctico encontrada en la bibliografía revisada hasta ahora.

Olivé argumenta a partir del desacuerdo tanto con las posiciones universalistas como con las relativistas. Pero rescata de estas últimas la consideración de que, en los hechos, encontramos "diferentes conjuntos de creencias aceptadas por distintos grupos de seres humanos, que incluso pueden ser incompatibles, pero todas legítimas con base en diferentes estándares" (2004:143). Según una postura relativista, la base de tal legitimidad estaría en los sistemas de valores internos de cada cultura, lo que haría la legitimidad limitada al ámbito restringido de cada cultura. Lo que propone Olivé es la posibilidad de construir acuerdos razonables sobre normas de convivencia política que puedan ser consideradas como válidas por todos los sujetos, desde los distintos puntos de vista, y a partir de concepciones del mundo que incluyen diferentes normas y valores morales y cognoscitivos. Por lo tanto, la legitimidad provendría del contexto externo, es decir del proceso de negociación común -intercultural-, aunque después cada cultura encuentre

\footnotetext{
62 "Las comunidades locales, regionales y nacionales en diferentes partes del mundo emprenden experimentos e iniciativas democráticas basados en modelos alternativos de democracia, en los que las tensiones entre democracia y capitalismo, entre redistribución y reconocimiento, se avivan y se convierten en la energía
} 
internamente una diferente razón para reconocer que tal norma es legítima de acuerdo con sus principios y valores.

Lo que diferencia esta postura de una relativista, es reconocer la necesidad de unas "normas de convivencia política" ampliamente aceptadas, y la posibilidad de que la construcción compartida de tales normas permita el desarrollo de instituciones legítimas por las diversas partes (Olivé 2004:149). Por otra parte, la propuesta de Olivé se diferencia de las posiciones universalistas, que admiten la posibilidad de acuerdos a partir del diálogo pero sostienen que las normas de convivencia producidas por tal acuerdo serían aceptadas para todos por las mismas razones éticas de alcance universal.

El modelo de práctica política propuesto por Olivé es la negociación, la discusión, tanto de principios como de acciones sobre problemas comunes, en el marco de un proceso que mira a construir consenso alrededor del tema en la mesa de discusión, no a partir de los distintos supuestos o los sistemas de valores que caracterizan los participantes al diálogo. Se pone énfasis en la cooperación para la realización de acciones coordinadas, el éxito de las cuales es independiente de que haya un acuerdo total sobre lo que los diferentes actores consideran importante. Claro está que para que cualquier acción coordinada se pueda realizar, se requiere de algunos acuerdos mínimos, basados en la disposición al diálogo que deben compartir todos los participantes. Tales acuerdos mínimos son las normas de convivencia logradas mediante la negociación, de las cuales se hablaba antes. Vemos pues que la práctica de la negociación informa tanto el nivel de la construcción de las "normas básicas de procedimiento" necesarias para hacer posible el diálogo, cuanto el nivel sucesivo que se dedica a construir interacciones que interesen a todas las partes y a la resolución de problemas concretos. Estamos hablando de normas y acuerdos y no de principios universales, ya que no se requiere que sean completos y abarquen todos los asuntos de orden moral; eso sí, serían normas que una vez reconocidas por todos los actores, tendrían para ellos valor vinculante, o sea todos las deberían respetar.

Esta forma de construir ámbitos de consenso a través del diálogo tiene la ventaja de ajustarse a la realidad social, donde los sujetos, tanto individuales como colectivos, son insertados en contextos que se van transformando constantemente. Por eso, se manifiesta la necesidad de construir marcos normativos susceptibles de ser transformados, para incluir respuestas a los problemas que con el pasar del tiempo van emergiendo. Claro está que el

positiva que respalda los pactos sociales más justos y abarcadores, no importa que tan circunscritos sean por el momento" (Sousa Santos 2001: 61). 
sistema de valores sobre el cual se va construyendo el sistema normativo debería quedar firme en la aceptación de todos, confiriendo estabilidad y continuidad a las normas, mismas que evolucionarían de acuerdo a las situaciones.

La idea es un modelo de organización social basado en el respeto (antes que en el reconocimiento); ideal todavía lejano de la realidad, donde con frecuencia las relaciones entre las autoridades indígenas y las estatales son conflictivas, no respetando estas últimas el derecho a la libre determinación de los pueblos.

Una postura abierta a la negociación haría más sencilla la construcción de contextos politicos y jurídicos donde las competencias estatales se articulen con los espacios autónomos de los pueblos indígenas. Con respecto a la administración de justicia, sería el marco para reconocer la efectividad de los sistemas indígenas en cuanto legítimos para sus miembros, aunque puede que no respondan a las necesidades de otros sectores de la sociedad. Los sistemas jurídicos indígenas, así como sus instituciones políticas, tendrían el carácter de instituciones de gobierno, equiparadas y complementarias a los otros órdenes de la administración estatal; el respeto a la autonomía de sus sistemas normativos permitirá que las autoridades tradicionales no sean consideradas enemigas de las autoridades del Estado. Así, las relaciones entre los dos sistemas jurídicos deberán basarse en acuerdos de coordinación fundamentados en el respeto mutuo. En este marco se podrá establecer un criterio para el respeto de los derechos humanos como garantía de las personas: pero la definición precisa de éstos "debe determinarse en común y revisarse constantemente" (2004:152).

A manera de conclusión, quiero citar José del Val que, en un breve ensayo contenido en su obra más reciente, ha logrado sintetizar el espíritu que debería animar las nuevas relaciones entre el Estado y la sociedad en su conjunto y los pueblos indígenas: "la igualdad es posible, no como la erradicación o la tolerancia de la diferencia, sino como el ejercicio del respeto por lo que del otro no comprendo y no juzgo" (2004:85). 


\subsection{LOS PUEBLOS INDÍGENAS Y EL CAMPO JURÍDICO}

Uno de los puntos centrales del proyecto político de los pueblos indígenas, la autonomía, concierne a los sistemas normativos, en la demanda de que sea respetada por el Estado la efectividad y la legalidad de los sistemas de administración de justicia indígena, y las decisiones por ellos tomadas, como elemento constitutivo de la libre determinación.

El objeto de esta investigación, el Sistema de Seguridad y Justicia Comunitaria-Policía Comunitaria, representa una iniciativa de carácter autonómico, donde la práctica de la autonomía se concentra en el ámbito jurídico y de control del territorio; por tal especificad propongo en este apartado la reflexión sobre algunos conceptos elaborados en el campo de la Antropologia Jurídica, que ayudarán a analizar dicha experiencia organizativa.

\section{Algunos conceptos básicos: procesos jurídicos, pluralismo jurídico, interlegalidad}

El estudio de los sistemas jurídicos no estatales y los diálogos y articulación entre éstos y el sistema estatal, constituye uno de los principales campos de estudio de la Antropología Jurídica.

En el precedente apartado he atribuido a las autonomías un carácter procesual, que reside en ser procesos permanentes de negociación con el Estado y en su historicidad, ya que sus características particulares dependen del contexto y del papel activo de los sujetos que las construyen. De manera similar, quiero enfatizar también el carácter procesual de los sistemas jurídicos, atravesando someramente un debate antropológico que lleva ya varias décadas.

El llamado "paradigma procesual", en el cual se enmarcan varios estudios antropológicos realizados en México a partir de los años cincuenta del siglo XX (Nader, Collier), define los sistemas jurídicos como procesos, lo que en el campo de la Antropologia Jurídica significa enfatizar que tienen una relación de interdependencia con la vida social y la cultura, de las cuales son parte fundamental.

Más allá de esta perspectiva está la que Chenaut y Sierra (2002) Ilaman "de la historia y del poder". Esta perspectiva se vino desarrollando a partir de los años setenta, cuando se empezó a reflexionar en "cómo las instituciones jurídicas [formales] ayudan a las élites para mantener sus posiciones dominantes"63 (Collier 1995: 61).

\footnotetext{
${ }^{63}$ De la misma forma operan otras instituciones "legítimadoras", como por ejemplo las educativas; es conocido el papel de la escuela en la estrategia "integracionista" del indigenismo como política de Estado.
} 
Aquí los sistemas jurídicos se entienden como construcciones culturales cuya vigencia revela sin duda su eficacia para la regulación y el control social, además de su capacidad para adecuarse a los procesos sociales. Los sistemas jurídico-culturales indígenas, a pesar de ser definidos "sistemas", son más bien procesos contemporáneos, dinámicos, con una enorme capacidad para incorporar elementos nuevos, renovar y cambiar sus tradiciones. Se trata de normas "performativas", porque se van haciendo a la medida de los conflictos que se producen; y en esto probablemente reside su fuerza y su persistencia en contextos que van cambiando rápidamente.

El carácter dinámico de los sistemas normativos ha sido destacado, entre otros, por Starr y Collier $^{64}$ y por Moore ${ }^{65}$, quien muestra cómo los sistemas normativos indígenas en muchos aspectos son producto de procesos de resistencia y adaptación provocados por el colonialismo. "Una vez que los antropólogos jurídicos comenzaron a tratar el Derecho como construido y logrado a través del conflicto, buscaron explicaciones de sistemas existentes en luchas históricas por el poder" (Collier 1995:64).

El "derecho consuetudinario" nunca fue de hecho una tradición inmutable, sino más bien una construcción histórica formada y reformada por las fuerzas legales, políticas y económicas nacionales y globales. El trabajo de Moore documenta la creación constante de costumbres y tradiciones, lo que cuestiona una visión estática, atemporal y esencialista.

Los sistemas normativos indígenas han sido ampliamente criticados por su fuerte estructura discriminatoria hacia algunos sujetos sociales, las mujeres en particular. Pero tales críticas han de ser matizadas tomando en cuenta los procesos internos a través de los cuales los sujetos subordinados negocian nuevos derechos, apropiándose de espacios hasta la fecha negados a través del manejo de discursos politicos y sociales provenientes de otros órdenes culturales. La experiencia aquí analizada, donde observamos la creación de un sistema jurídico y su aplicación, es sumamente interesantes por el nivel de relacionalidad que las prácticas tienen con los diferentes ámbitos de la sociedad y su capacidad de responder a los cambios (internos y externos), así como su capacidad de "autocrítica" (reflexión y poder de cambio sobre las prácticas mismas).

Un paso sucesivo en la línea teórica que estamos resumiendo es la formulación del concepto de pluralismo jurídico (interacción de diferentes sistemas jurídicos en un mismo campo social) por Moore y otros autores.

\footnotetext{
64 June Starr y Jane Collier, History and power in the study of law, 1988.

${ }^{65}$ Sally Falk-Moore, Social Fact and Fabrication: Customary Law on Kilimanjaro, 1880-1980, 1986.
} 
La misma Moore define lo jurídico como "campo social semiautónomo" que "puede generar a su interior reglas, costumbres y símbolos, pero también es vulnerable a las reglas, decisiones y otras fuerzas que emanan del mundo más amplio que lo rodea" (Moore 1978:55). Partiendo de ese argumento, Merry argumentó que "el sistema legal externo penetra al campo pero no siempre lo domina pues allí existe espacio para la resistencia y la autonomía" (1988:878) y propone un análisis que advierte sobre el riesgo que conlleva la imagen del pluralismo jurídico si no es problematizada (llegando a describir un sistema de compresencia y convivencia armónica de diferentes sistemas jurídicos), mientras invita a analizar "la relación dialéctica y mutuamente constitutiva entre el derecho estatal y otros órdenes normativos" (Merry 1988:880).

En realidad, los sistemas normativos son producto de una historia de dominación ante la cual han debido responder, adaptarse o resistir, en interacción estrecha y conflictiva con el derecho estatal (Sousa Santos: 1998; Sierra: 2006). Para su análisis, hay que destacar la relación entre el derecho estatal y los otros sistemas normativos presentes en un determinado contexto social, los límites y los alcances de uno y otros; cómo el derecho estatal penetra y reconstruye, a partir de su posición hegemónica, los sistemas normativos no estatales y cómo el mismo viene modificado y constituido por éstos.

Asimismo, hay que poner atención en los conflictos internos, como los cuestionamientos de los individuos se relacionan con el sistema normativo: si la norma (y por lo tanto la sociedad) se modifica integrando nuevos derechos y necesidades, o bien reacciona de manera excluyente a tales cuestionamientos.

En esta perspectiva, de Sousa Santos propone el concepto de interlegalidad ${ }^{66}$ (1995), que va más allá del de pluralismo jurídico, representando "una concepción de diferentes espacios legales superimpuestos, impenetrados y mezclados" que dependen de órdenes de la vida en constante transformación y cambio, y de constantes relaciones de dominación y de resistencia a través de las cuales se van formando y construyendo los sistemas normativos subordinados.

\footnotetext{
${ }^{66}$ Actualmente utilizado por varios investigadores en México, como Sierra, Hernández, Chenaut.
} 


\section{La interlegalidad y la práctica de la autonomía}

Desde la Colonia, los pueblos indígenas han vivido en un contexto de interlegalidad, que los ha llevado a moverse entre el sistema jurídico impuesto a través de las relaciones de dominación y los sistemas jurídicos propios, conservados por siglos como elemento identitario y forma de resistencia. Mientras padecen la inequidad del sistema jurídico formal, también se han apropiado del mismo, desarrollando un conocimiento bastante profundo de normas, códigos y leyes, con el objetivo de defenderse de éstas y salvaguardar sus derechos, utilizando las leyes del Estado. Este proceso ha sido sin duda positivo, y en el mismo camino se sitúa el uso frecuente que hacen las organizaciones indígenas del derecho internacional, del cual tienen claras nociones por lo que este garantiza derechos colectivos que las leyes nacionales no reconocen. Gracias a la relación frecuente, alternada y creativa, y sin duda conflictiva, con la administración de justicia estatal, las comunidades originarias lograron mantener márgenes y límites entre ambas justicias y a la vez conectarlas. Es decir, no se puede pensar una justicia originaria excluyendo su relación con la justicia estatal, ya sea en la misma construcción local de la justicia, o en la conexión entre ambas. Pero, tampoco hay que suponer que esta relación es armónica e igualitaria, sino controversial y desequilibrada, lo cual motiva a las comunidades en hacer esfuerzos de independencia judicial frente a la justicia estatal.

Refiriéndose a este proceso de apropiación y uso del sistema jurídico formal, Stavenhagen afirma que "por lo demás, los grupos indígenas han aprendido bien a servirse de los mecanismos del sistema político nacional, es decir, no indígena, cuando advierten que las estructuras de gobierno internas no funcionan allende las fronteras de la comunidad o la tribu" (1992:103).

La experiencia de la Policía Comunitaria representa un proceso inverso a lo expuesto por Stavenhagen, y desmiente también las argumentaciones de quienes advierten que los integrantes de pueblos y comunidades indígenas frecuentemente se substraerían a sus autoridades y a sus sistemas jurídicos, ya que éstos operarían según una racionalidad contraria al respeto de los derechos humanos fundamentales, y les infligirían castigos profundamente lesivos de la dignidad humana. Claro está que situaciones de este tipo existen y hay que tomar neta distancia de ellas. Por lo tanto es cabal prestar atención y documentar los procesos que, aparentemente basados en los mismos presupuestos, representan caminos diferentes e innovadores. Será el estudio que permitirá marcar 
diferencias sin caer en el error de juzgar apriorísticamente las prácticas autónomas de administración de justicia, así como proponer ejemplos exitosos.

Así se puede observar que, inversamente a lo expuesto por Stavenhagen, en la CostaMontaña de Guerrero los pueblos indígenas han manifestado la inutilidad del sistema jurídico estatal, y han tenido que crear ex-novo un sistema autónomo que respondiera a sus exigencias y resolviera una situación de violencia que las instituciones simplemente no tenían interés en mejorar. La mayoría de los habitantes de la región han desertado las instancias oficiales participando directamente en la organización del nuevo sistema, u otorgándole su reconocimiento acudiendo a éste para la resolución de sus problemas en lugar que con el Ministerio Público.

Explica este proceso la argumentación de Van Cott con respecto a los que define como "sistemas legales informales", mismos que "se han desarrollado y han persistido dentro del vació de protección legal y el dominio de la ley del Estado que existen en América Latina" (2003). Los sistemas legales informales se caracterizarían, y en esto reside en gran medida su valor, precisamente por su informalidad -el hecho de que su autoridad se deriva de valores y significados locales que tienen gran autoridad, así como por la flexibilidad y el dinamismo que su estatus no codificado conlleva. Van Cott califica como "informales" los sistemas jurídicos indígenas; creo que la misma definición puede bien aplicarse al Sistema de Seguridad y Justicia Comunitaria, que tiene las características expuestas arriba y se origina precisamente para suplir a la ausencia de las instituciones formales.

Nosotros estamos aquí por necesidad pues, no porque queremos quitarle la autoridad al gobierno. Si el gobierno está, ¿para qué queremos armas pues? Pero la ausencia del gobierno nos obligó a hacer nosotros las cosas... ${ }^{67}$

"Los sistemas legales indígenas han sobrevivido [y se crean] por dos razones: (1) porque ayudan a perpetuar y defender la autonomía de las culturas indígenas, y (2) porque los sistemas legales del Estado o no son eficientes, o no son accesibles, o no son apropiados para su cultura". En consecuencia, "la preferencia por la justicia indígena varía dependiendo de la calidad y la accesibilidad relativa de los sistemas no indígenas" (Van Cott 2003). E análisis de la experiencia concreta de la Policía Comunitaria, su origen, su desarrollo y la actual relación con el sistema jurídico estatal, donde la administración autónoma demanda un mejor acceso a la justicia para los pueblos de la Costa-Montaña y lo proporciona frente a la impotencia de las autoridades estatales, me lleva a compartir plenamente tal enfoque.

${ }^{67}$ Entrevista a Don Francisco, Comisario de la CRAC 2001/2002, Pueblo Hidalgo, SLA, 25 julio 2006. 
Difiero por tanto de lo afirmado por Iturralde, quien argumenta que "los indígenas recurren a sus costumbres jurídicas -a su derecho consuetudinario- como una táctica para sustraer del régimen jurídico nacional algunos asuntos que consideran de su competencia exclusiva, o que quedan mejor protegidos al margen de tal régimen" (1990: 57). El SSJC no fue creado para sustraerse, sino para suplir a las faltas del sistema oficial, insuficiente para garantizar los derechos ciudadanos. Seguramente los conflictos penales y civiles de los que se ocupa la Coordinadora Regional de Autoridades Comunitarias quedan mejor protegidos al margen del sistema de justicia estatal, que para el caso de Guerrero alcanza extremos de corrupción y racismo ${ }^{68}$.

Los sistemas jurídicos indígenas se construyen, reconstruyen y actúan en contextos de interlegalidad, lo que los hace más o menos distinguibles de las categorías del derecho estatal. La realidad que se observa al analizar los sistemas jurídicos propios desmiente las interpretaciones esencialistas del "derecho consuetudinario" como aislado del contexto más amplio en el cual actúa, y cristalizado en unas normas ancestrales. Muchas veces los discursos de los mismos pueblos indígenas presentan las identidades y las prácticas jurídicas enraizadas en la tradición, como estrategia para demostrar la legitimidad de los sistemas normativos, para obviar la relación mutuamente constitutiva establecida entre las instituciones estatales y las prácticas indígenas ${ }^{69}$ (Sieder 2001). En realidad, la "autenticidad" de los sistemas jurídicos indígenas no deriva de su naturaleza milenaria, sino de su adopción en ausencia de un efectivo acceso a la justicia estatal (Van Cott 2000b: 212). EI SSJC difiere de esta tendencia ya que no usa un discurso esencialista; hace patente su interrelación y constante negociación con las estructuras políticas, ministeriales y judiciales del Estado, construyendo un discurso de coordinación, más no de dependencia. Reivindica por lo tanto la legitimidad del sistema jurídico autónomo, pero basándola en la práctica y en la eficacia, no en un discurso que apela a la diversidad cultural y a la tradición en que radicaría ésta.

Sobre la base de estas consideraciones, para el estudio de los sistemas jurídicos indígenas Sánchez Botero ${ }^{70}$ sugiere analizar la medida en que se distancian del derecho estatal (su

\footnotetext{
${ }^{68}$ Véase los informes del Centro de Derechos Humanos de la Montaña Tlachinollan, www.tlachinollan.org.

${ }^{69}$ Sieder se basa en el analisis del caso guatemalteco, donde el surgimiento del Movimiento Maya después de largas décadas de guerra de exterminio contra los pueblos indígenas ha llevado un proceso de esencialización de las identidades étnicas.

${ }^{70}$ Ponencia presentada en el Curso "Los grandes temas de la antropologia jurídica", organizado por la Red Latinoamericana de Antropologia Jurídica, México DF, 13 y 14 de octubre 2006.
} 
"gradiente de diferencialidad") y los elementos que a éste los acomunan: de esta forma analizaré más adelante el SSJC.

Con respecto a la práctica jurídica,

la ley indígena puede ser sustitutiva en comunidades donde la ley del Estado es esencialmente inexistente; donde las comunidades indígenas y campesinas están geográficamente distantes de las instituciones formales ${ }^{71}$ y son completamente responsables de la administración de justicia y la resolución de disputas. Puede ser complementaria donde hay más coordinación entre las autoridades indígenas y estatales (Van Cott 2003).

Frente a esta tipificación, Van Cott (2003) sugiere que las dos categorías no se vean como separadas, sino como dos polos de un continuum, en medio del cual "hay casos de instituciones informales de justicia, que coordinan su trabajo con los funcionarios estatales en la medida que sea necesario, dada la presencia de presión interna o externa y la disponibilidad de tales servicios". Entonces, un sistema de justicia informal puede moverse hacia el extremo sustitutivo o hacia el complementario, dependiendo de las condiciones particulares y de las relaciones de fuerza que se instauran con las instituciones formales en dado momento. En segundo lugar, hay que considerar que "un sistema legal indígena puede ser complementario con relación a ciertos aspectos (por ejemplo: la organización comunitaria interna) y competitivo con respecto a otros (por ejemplo: la ley penal)", pues las relaciones entre los sistemas no se dan de forma homogénea, ya que el desarrollo de las instituciones indígenas no se realiza uniformemente en todos los aspectos.

La ley indígena entonces puede ser también competitiva,

donde las autoridades tienen relaciones hostiles con las instituciones formales- particularmente en países donde no ha sido todavía formalmente reconocida. Aún más, la categoría de competitiva está abierta a la interpretación. Las sanciones indígenas que se interpreta violen la ley del Estado -como el castigo corporal o el trabajo comunitario forzado [o la encarcelación por dos o tres días] pueden ser interpretadas como no competitivas, si el intérprete evalúa dichas prácticas en el contexto de la cultura indígena (Van Cott 2003).

En este sentido, Sánchez Botero invita a analizar -en las prácticas- si el sistema jurídico indígena es alternativo ( $y$ en cual medida o nivel) o complementario, afirmando que mientras más es alternativo, más alto es el nivel de autonomía de facto en la sociedad.

\footnotetext{
${ }^{71}$ No necesariamente la lejanía de los centros del poder significa ausencia de control por parte del Estado. Las zonas periféricas siempre son relativamente aisladas, ya que el poder central puede ser ausente y a la vez manifestar su presencia en determinados ámbitos, o remarcar su autoridad en momentos o contextos
} 


\section{Pluralismo legal y monismo jurídico}

Impulsadas por el Derecho Internacional, varias constituciones latinoamericanas (Colombia, Ecuador, Bolivia, Perú y Venezuela de forma más profunda) se están modificando hacia el reconocimiento -más o menos amplio- de los derechos colectivos de los pueblos indígenas. En el campo jurídico, tal modelo pluralista implica:

1. el reconocimiento del derecho y la jurisdicción especial indígena autónoma dentro del ámbito territorial indígena;

2. derechos especiales de los indígenas ante la jurisdicción ordinaria en consideración de su cultura;

3. mecanismos consensuados de coordinación entre sistemas jurídicos para los conflictos de jurisdicción originados por la situación de interlegalidad.

En estos términos, las resistencias por parte del Estado se dan principalmente hacia el reconocimiento de las autoridades propias y su capacidad de autogobierno; del derecho indígena y su potestad de autorregulación; y finalmente de la jurisdicción especial entendida como capacidad de resolución de conflictos de acuerdo a la cultura y al derecho propio, no a la ley estatal o a la Constitución.

Observamos los tres tipos de conflictos al analizar la relación entre las instituciones formales y el Sistema de Seguridad y Justicia Comunitaria, que cuenta con un sistema jurídico propio sobre el cual las autoridades comunitarias imparten y administran justicia.

EI SSJC pone en discusión los pilares básicos del orden estatal: la idea de que la ley es una, igual para todos, y estrictamente codificada; y la que sostiene que la jurisdicción y el ejercicio de la acción penal son facultad exclusiva del Estado, lo que Yrigoyen (2000) define como la teoría monista del Derecho.

Si consideramos legítima la producción normativa de los pueblos indígenas, se produce una ruptura con la concepción clásica de que sólo el Poder Legislativo está legitimado para la producción de normas. Pero tal vez sea dentro del ámbito del sistema penal (principal campo de jurisdicción de la Coordinadora Regional de Autoridades Comunitarias), donde las diferencias y los conflictos se presentan más nítidamente. No sólo porque el derecho penal se encuentra fuertemente influenciado por determinadas valoraciones sociales (al tratarse de cosmovisiones diferentes, son estas valoraciones las que agudizan dichas diferencias), sino porque es uno de los ámbitos más sensibles del ordenamiento jurídico, en donde la

específicos (por ejemplo en las coyunturas electorales, o en las acciones represivas en ocasión de conflictos sociales). 
verdadera fuerza del Estado se hace ostensible, ya que éste se considera como la única instancia legitima para la imposición de las penas de acuerdo a las normas emitidas. Con respecto a la jurisdicción indígena, casi todas las constituciones latinoamericanas (incluida la mexicana) y el Derecho Internacional la reconocen, pero lo limitan a la resolución de conflictos menores, lo que a nivel epistemológico nos remite a la visión colonial, todavía presente, del indígena como inferior. En el sistema colonial, la ideología de la inferioridad natural de los indígenas estaba a la base del proyecto jurídico de la tutela; el mismo mecanismo ideológico parece funcionar ahora con el discurso de los derechos humanos, que se piensa deber imponer a las sociedades indígenas ya que estas no los comprenden y no los aplican ${ }^{72}$. Al contrario, observamos como la temática de los derechos humanos y los mecanismos para su protección, con más frecuencia están siendo incluidos en los sistemas jurídicos indígenas, en aras de una compatibilización con la justicia ordinaria; a partir de la reformulación interna que proviene de una autocrítica positiva.

\section{Derechos humanos y pueblos indígenas: una perspectiva crítica}

Según de Sousa Santos (1996), el discurso sobre los derechos humanos, aunque siga siendo abanderado por los movimientos de resistencia, fue apropiado por el Estado, que pretende ahora ser el garante de éstos. En el área de derechos humanos y de dignidad, la movilización social alrededor de estas reivindicaciones puede tener un valor emancipatorio sólo si se apropia de los contextos culturales locales: de no ser así, continuarán siendo políticas que reproponen el modelo de la "globalización desde arriba", como advierte Speed considerando que el discurso sobre los derechos humanos se ha ido difundiendo al mismo tiempo que el viraje hacia las políticas neoliberales de los Estados. En este contexto, los derechos humanos asumen una valencia regulatoria y hasta auto-regulatoria, siendo utilizado para obstruir o cooptar demandas políticas más radicales (Speed 2005).

Se necesita entonces que los principios y las formas, con base en las cuales se articulan las reivindicaciones por los derechos humanos, provengan del interior de las diferentes sociedades. Esto nos remite a la necesidad de la creación de marcos jurídicos que permitan ejercer libremente el derecho a la libre determinación en sus innumerables formas y a la necesidad de reconocer los procesos autonómicos ya en camino, que representan el sistema más viable de ejercer y garantizar los derechos que cada pueblo percibe como

\footnotetext{
${ }^{72}$ Raquel Irigoyen Fajardo, ponencia presentada en el Curso "Los grandes temas de la Antropologia Jurídica", organizado por la Red Latinoamericana de Antropologia Jurídica, México DF, 13 y 14 de octubre 2006.
} 
propios. Mientras debemos tomar distancia de los "usos y costumbres" que son lesivos a la dignidad humana de los sujetos (como las prácticas comunitarias que denigran a las mujeres), también es necesario poner énfasis en los procesos de resignificación de dichas "tradiciones", que amplían la plataforma de los derechos sociales.

Siguiendo el modelo procesual con el que he definido varios conceptos, puedo afirmar que tampoco los derechos humanos son algo fijo, sino que su forma y contenido son constantemente negociados en contextos sociales e históricos específicos. Como ha señalado Binion (1995), los derechos humanos no son derechos "naturales" universales, sino que son reclamos políticamente peleados que ganan fuerza y legitimidad precisamente porque están enmarcados en un lenguaje universal. En una literatura sugerente se está explorando cómo los distintos actores entienden, accionan y disputan los derechos humanos en contextos particulares (Pitarch 2001). Desde hace algunos años, las organizaciones indígenas demuestran su voluntad y capacidad de apropiarse del discurso sobre los derechos humanos como instrumento político, quitando al Estado y a las ONGs el monopolio de su defensa y construyendo un concepto más amplio y rico de derechos humanos.

Los procesos de autogobierno y de administración autónoma de la justicia, incluyendo en el sistema cultural indígena el discurso por los derechos humanos en una perspectiva propia y autodirecta, muestran su capacidad de valorar lo interno y construir nuevos derechos.

La indiferencia política de los gobiernos frente a los pueblos originarios se refleja en las condiciones materiales y sociales de marginación, pobreza, discriminación, falta de estructuras de salud y falta de acceso a la justicia de la población indígena. Problemas de ese tipo representan por sí mismos evidentes violaciones a los derechos humanos causadas por la falta de voluntad política para resolverlos en conjunto con la población. Además, llevan a la descomposición interna de las comunidades indígenas, mientras involucran estos sectores marginados en problemas más graves como la prostitución, el alcoholismo, la drogadicción, el narcotráfico, etcétera. Si se suman estos efectos con los problemas que están en la raíz, se produce una completa fragmentación social y la disolución de los vínculos comunitarios, que tienen como directa consecuencia las infracciones a la ley, la intervención indiscriminada de policía y Ejército y las violaciones a los derechos humanos.

Actualmente, el enfrentamiento de los indígenas ante la justicia revela el choque de sistemas jurídicos que el sistema legal muestra como contrapuestos. Las referencias culturales a partir de las cuales los indígenas dirimen cotidianamente sus controversias son 
sistemáticamente negadas durante el proceso judicial. Sus patrones de disputa, sus creencias y sistemas normativos, el sentido de lo justo y lo injusto, lo permitido y lo prohibido, no funcionan ya como referentes de validez para enfrentar el peso de la legalidad y la institución judicial. Se trata en efecto de una ruptura con sus esquemas de acción y representación, y el trasplante a una situación desconocida, lo que representa una evidente violación de los derechos humanos.

La defensa de los derechos humanos en las regiones indígenas ha abierto espacios importantes para canalizar injusticias ante el Estado u otras instancias, e incluso en el ámbito mismo de las comunidades. Dichas situaciones repercuten en los propios sistemas normativos que han debido actualizar sus formas de regulación. El ejemplo de los Policías Comunitarios de Guerrero, organización que surge con el fin de hacer frente a la violencia y la impunidad reinantes en comunidades indígenas de la Montaña de Guerrero, muestra cómo se dinamizan y actualizan sistemas normativos en relación con la práctica de la justicia, consiguiendo bajar de manera radical los índices delictivos en la región. Esa organización incorpora el tema de los derechos humanos en la justicia que administra, demostrando la capacidad de apropiarse de un discurso actualmente muy contundente, y también de instrumentarlo en el contexto que viven, caracterizado por continuas violaciones a todos los derechos humanos individuales y colectivos, como destacaré en el siguiente capítulo.

Esta experiencia, que por cierto no es la única en el país, revela una vez más la capacidad dinámica de los sistemas normativos y de las jurisdicciones indígenas. 


\section{CAPÍTULO 3}

\section{LA COSTA-MONTAÑA DE GUERRERO: DE LA VIOLENCIA ESTRUCTURAL A LA JUSTICIA AUTÓNOMA}

\subsection{LA REGIÓN COSTA-MONTAÑA DE GUERRERO, VIOLENCIA Y SEGURIDAD}

\section{La Costa-Montaña como región}

Actualmente el Sistema de Justicia y Seguridad Comunitaria de la Costa-Montaña de Guerrero está conformado por más de 60 comunidades na savi (mixtecas), me'phạa (tlapanecas), nahuas y mestizas que se ubican en los municipios de San Luís Acatlán y Marquelia (en la región Costa Chica), Malinaltepec, Metlatonoc, Atlamajalcingo del Monte, Cochoapa el Grande, Copanatoyac, Xalpatlahuac, Tlapa de Comonfort e lliatenco (todos en la región Montaña).

\begin{tabular}{|l|c|}
\hline Comunidades integradas al Sistema de Seguridad y Justicia Comunitaria por pertenencia étnica \\
\hline Mixtecos & 26 comunidades \\
\hline Tlapanecos & 27 comunidades \\
\hline Nahuas & 5 comunidades \\
\hline Mestizos & 7 comunidades \\
\hline
\end{tabular}

No obstante la zonificación socioeconómica del Estado de Guerrero divide estos municipios en dos regiones distintas, hay muchos elementos que las identifican y las relacionan entre ellas; los mismos habitantes de la zona se refieren a ésta como a la "Costa-Montaña". Varios trabajos que estudian la parte oriental de Guerrero lo hacen en una perspectiva regional $^{73}$, donde se entiende la región como una red dinámica de relaciones, que "se conforma por la presencia de distintos procesos sociales; se delimita de acuerdo con los intereses de los actores sociales que les dan direccionalidad a partir de sus proyectos, su memoria histórica y su visión del futuro" (Caníbal Cristiani 2001: 16). Expondré en este apartado algunos de los principales procesos sociales que en las últimas décadas han construido dicho espacio, para llegar a la experiencia más reciente y objeto de esta investigación, la de la Policía Comunitaria.

Tal experiencia, ejerciendo la función de control del territorio a partir de un proyecto político, es particularmente importante para la delimitación de tal espacio y su fortalecimiento a través de las estructuras organizativas regionales que ha creado.

\footnotetext{
${ }^{73}$ Dehouve; Canabal Cristiani; Sánchez Serrano, García Romano.
} 
En los trabajos consultados, hay diferentes conceptualizaciones del espacio regional en esta zona de Guerrero. La región más claramente delimitada es la de la Montaña, "definida por su espacio natural, economico y cultural" y que cuenta también con una identidad particular en la cual se reconocen sus habitantes, pues "hay un sentido de pertenencia socioterritorial o más bien de colectividad asentada en un territorio" (Caníbal Cristiani 2001: 19). Dicha región "sociocultural" (Giménez 2000) corresponde por otro lado a la zonificación oficial, que agrupa en la región Montaña 19 municipios, y hacia la región entendida como tal se dirigen las instituciones y las políticas públicas. También es un espacio que las organizaciones conciben como unitario y en sus acciones lo van fortaleciendo (por ejemplo, con la creación del Consejo Regional de la Montaña).

Pero tanto Canabal Cristiani (2001) como García (2000) individúan otra región "sociocultural": la Costa-Montaña, zona de transición entre la playa y los cerros, bisagra ecológica y comercial. García identifica tal región con los municipios de San Luís Acatlán, Azoyú $^{74}$, Malinaltepec y Tlacoapa. Dicha subregión, localizada al sureste del Estado de Guerrero, se extiende desde las playas de Marquelia hasta la Montaña; la Sierra de Malinaltepec, parte de la Sierra Madre del Sur, con sus numerosas ramificaciones atraviesa de oeste a este el municipio de ese nombre; en ella nacen, entre otros, los afluentes de los ríos de Ometepec y Omitlán (en términos generales, toda la zona está surcada por arroyos y pequeños ríos). En la subregión pueden delimitarse tres grandes zonas agroecológicas: la planicie costera de Marquelia, una zona de transición que comprende parte de los municipios de Marquelia y San Luís Acatlán, y la Montaña propiamente dicha, que comprende la parte norte de San Luís Acatlán y los demás municipios, dividiéndose en Montaña "baja" y "alta". Múltiples razones hacen de esta área geográfica una región: desde aspectos naturales como la subcuenca que forma el río Marquelia, pasando por aspectos culturales que remontan a la época prehispánica, hasta razones socioeconómicas, como el hecho de que San Luís Acatlán constituye el principal centro de intercambio comercial y de comunicación con el exterior ${ }^{75}$. Como expondré más adelante, los procesos organizativos de las últimas décadas han contribuido decididamente a construir y fortalecer el espacio regional de la "Costa- Montaña".

\footnotetext{
${ }_{75}^{74}$ Actualmente, una parte del territorio de Azoyú se ha constituido como nuevo municipio, Marquelia.

${ }^{75}$ García 2000.
} 
En particular, el proceso impulsado por la Policía Comunitaria crea un territorio compartido a partir de la pertenencia a la organización misma; un espacio social ${ }^{76}$ que se apoya en las precedentes regionalizaciones (Montaña y Costa-Montaña) y, a partir de éstas, crea nuevas perspectivas regionales (el "territorio comunitario" comprende municipios de las dos regiones $\mathrm{y}$, a pesar de las diversas problemáticas sociales que éstos presentan, los articula en un único proyecto organizativo, que estimula la creación de lazos de solidaridad y cooperación).

\begin{tabular}{|c|c|c|c|}
\hline \multicolumn{4}{|c|}{ Municipios integrados al Sistema de Seguridad y Justicia Comunitaria } \\
\hline $\begin{array}{lll}\text { Municipio y } & \text { núm. de } \\
\text { comunidades } & \text { integradas } \\
\text { al SSJC } & \end{array}$ & Población total & $\begin{array}{c}\text { Población indígena } \\
(\%)\end{array}$ & Grado de marginación \\
\hline $\begin{array}{l}\text { Atlamajalcingo del Monte } \\
\text { ( } 2 \text { comunidades) }\end{array}$ & 5080 & $\begin{array}{l}5052 \\
(99,4)\end{array}$ & Muy alto \\
\hline $\begin{array}{l}\text { Copanatoyac } \\
\text { ( } 5 \text { comunidades })\end{array}$ & 15753 & $\begin{array}{l}15149 \\
(96,2)\end{array}$ & Muy alto \\
\hline $\begin{array}{l}\text { Malinaltepec } \\
\text { (14 comunidades) }\end{array}$ & 34925 & $\begin{array}{l}34517 \\
(98,8)\end{array}$ & Muy alto \\
\hline $\begin{array}{l}\text { Metlatonoc } \\
\text { (12 comunidades) }\end{array}$ & 30039 & $\begin{array}{l}29829 \\
(99,3)\end{array}$ & Muy alto \\
\hline $\begin{array}{l}\text { San Luís Acatlán } \\
\text { ( } 21 \text { comunidades) }\end{array}$ & 36813 & $\begin{array}{l}24429 \\
(66,4)\end{array}$ & Alto \\
\hline $\begin{array}{l}\text { Tlapa de Comonfort (1 } \\
\text { comunidad) }\end{array}$ & 57346 & $\begin{array}{l}42377 \\
(73,9)\end{array}$ & Alto \\
\hline $\begin{array}{l}\text { Xalpatlahuac } \\
\text { (1 comunidad) }\end{array}$ & 11687 & $\begin{array}{l}11232 \\
(96,1)\end{array}$ & Muy alto \\
\hline $\begin{array}{l}\text { Cochoapa el Grande (3 } \\
\text { comunidades) }\end{array}$ & & & Muy alto \\
\hline \multicolumn{4}{|l|}{$\begin{array}{l}\text { Marquelia } \\
(2 \text { comunidades })^{*}\end{array}$} \\
\hline $\begin{array}{l}\text { lliatenco } \\
\text { (4 comunidades) }\end{array}$ & & & \\
\hline
\end{tabular}

Fuente: Índice de Desarrollo para los Pueblos Indígenas, CDI, 2000.

La principal actividad económica de los habitantes de las regiones Montaña y Costa Chica es la agricultura, con el cultivo de maíz y café, y la ganadería, aunque va en constante aumento el porcentaje de los que dejan los cultivos de temporal en las empinadas laderas de los cerros y las profundas cañadas (cultivo que llaman el tlacolol), y migran hacia las entidades del norte o los Estados Unidos.

\footnotetext{
${ }^{76}$ Entendido como un conjunto de prácticas sociales en ámbitos determinados, que expresan los intereses de los grupos en un espacio geográfico; estas prácticas generalmente están permeadas por una acción o una intención política y contienen una dimensión cultural (Sarmiento Silva, en Canabal Cristiani 2001: 14-15).

*Para estos tres municipios no hay datos ya que se constituyeron en 2005.
} 
En la Costa Chica hay una reducida actividad forestal; en las zonas medias de la sierra de esta región, la cafeticultura es la opción productiva para muchas familias. Aquí se localiza también una de las zonas de producción de jamaica más importantes del país; y es la zona de produccion de copra más extensa de Guerrero. Los pueblos que se encuentran alejados de la costa son los más afectados por la marginación, la pobreza extrema y la violencia. En la parte baja conviven mestizos y afromestizos; en la parte alta (municipios de Ayutla, San Luís Acatlán, Azoyú, Igualapa, Tlacoachistlahuaca y Xochistlahuaca), que es la más pobre, conviven amuzgos, mixtecos y tlapanecos.

La Montaña es habitada por pueblos mestizos, nahuas, mixtecos y tlapanecos. Los nahuas son el grupo con mayor número de hablantes, lo siguen los mixtecos y después los tlapanecos. Los indígenas representan el $62 \%$ de la población general de la Montaña, que es la región con el porcentaje indígena más alto del Estado (424.626 personas sobre un total estatal de 529.780 personas) $)^{77}$.

La vida de los pueblos indígenas de la Montaña está marcada por la marginación, la represión, la falta de acceso a la justicia y los conflictos políticos y agrarios. Todos estos problemas se agudizan insosteniblemente, ya que se encarnan en una situación de miseria extrema, agravada por la falta de expectativas y de oportunidades para el desarrollo.

Informes recientes denuncian la grave situación de rezago y marginalidad socioeconómica en que viven los pueblos de la Montaña, la poca cobertura asistencial de las dependencias de gobierno (municipal, estatal y federal) para atender las demandas, la elaboración e imposición de paquetes y programas productivos no acordes a las necesidades ni características de los pueblos $^{78}$. La Montaña se sigue colapsando por la destrucción incontenible de su hábitat: la explotación irracional del bosque es un negocio turbio que las autoridades federales y estatales siguen consintiendo, la tala clandestina es una práctica muy arraigada que no ha querido ser detenida ni castigada. A pesar de que en la Montaña existe una importante red hidrológica, las grandes corrientes de agua son desaprovechadas en la región. Lo paradójico es que estas aguas forman parte de los grandes cauces que alimentan el complejo siderúrgico Lázaro Cárdenas, el más grande de América Latina. En contrapartida, el $72 \%$ de las viviendas de la Montaña carece de agua entubada, siendo una de las demandas más sentidas de las comunidades indígenas.

\footnotetext{
77 Índice de Desarrollo para los Pueblos Indígenas, CDI, 2000.

${ }^{78}$ PAIR A.C. Conservación de la diversidad Biológica y desarrollo sustentable. Montaña de Guerrero. México, 1999.
} 
Los datos que se refieren a la marginalidad (CONAPO 2004) sitúan las regiones Montaña y Costa Chica entre las 36 "zonas prioritarias" del país, que tienen como común denominador la pobreza, el narcotráfico, la migración, la violencia y la militarización. De los 17 municipios de la región Montaña, 11 son catalogados como de "muy alta marginación", ubicándose 8 dentro de los primeros 50 más pobres a escala nacional. En 2007 el recién constituido municipio de Cochoapa el Grande ha sido declarado en el primer lugar por marginalidad a escala nacional, primacía anteriormente detentada por años por el colindante Metlatonoc.

Las enfermedades de la pobreza mezcladas con el problema de la insuficiencia alimentaria, que en buena medida se deriva de la baja productividad agrícola, muestran un cuadro alarmante en los niveles de desnutrición entre la población indígena: 5.7 de cada 10 niños de la región sufre de desnutrición severa.

En general, la mala alimentación es una de las principales causas de morbilidad en la Montaña, porque provoca que la población esté cada vez más expuesta a las enfermedades.

El alto índice de analfabetismo, que se eleva al 70\% en Metlatonoc, y la enorme deserción escolar, son las cifras del fracaso del modelo educativo implementado en la Montaña. La inapropiada educación bilingüe-bicultural ha segregado más a la población indígena, remarcando la desigualdad y la inequidad ${ }^{79}$.

La deficiente infraestructura de caminos es uno de los principales factores de aislamiento geográfico, causante a su vez precariedad económica y social, y que agrava el problema de la inseguridad en la región.

\section{La Costa-Montaña en la encrucijada de la violencia. Violencia capilar y corrupción institucional}

Guerrero bronco: despliegue de poderes discrecionales que chocan entre sí y se ejercen mediante la violencia ${ }^{80}$.

No es casualidad que un sistema autónomo para la seguridad y la impartición de la justicia haya nacido precisamente en esta región de Guerrero.

El mismo Estado se ha caracterizado históricamente por la impunidad y la arbitrariedad en el ejercicio del poder. Guerrero ha sido y sigue siendo una entidad violenta: "no tanto porque allí falle la ley, sino porque una de las normas no escritas de su cultura política es que no importa contar con la razón o el derecho sino con la fuerza" (Bartra 2000: 16). Esta cultura

\footnotetext{
${ }^{79}$ Fuente: Centro de Derechos Humanos Tlachinollan.

${ }^{80}$ Armando Bartra, Sur profundo, en Bartra 2000:15.
} 
política se caracteriza principalmente por el centralismo y el caciquismo: "se combinan los peores rasgos del centralismo presidencialista y del regionalismo conservador, gestando un sistema político tan autoritario como conflictivo; un orden patrimonialista donde la cosa pública es asunto privado que disputan de mala manera los hombres fuertes de la región" (Bartra 2000:15). Según Estrada Castañon (1994), esta situación se debe a que en Guerrero hay una escasa formalización del Estado o, más propiamente, de relaciones publicas regidas por un orden jurídico formal. Por lo tanto la relación entre el Estado y los poderes locales se da en términos "premodernos", sobre todo en las zonas rurales o indígenas, apoyándose el poder central en las estructuras de poder locales ya establecidas (los cacicazgos). Estos "feudatarios" suplantaban en las zonas rurales un Estado débil, y prácticamente ausente en sus funciones de garante del bienestar y de derechos básicos de los ciudadanos, que impone su presencia casi exclusivamente en las coyunturas electorales. Este tipo de relaciones clientelares no sólo constituye un soporte del caciquismo, sino que la estructura corporativa de lo que ha sido el partido oficial por décadas (PRI) se funda en el mismo tipo de relaciones ${ }^{81}$. El circulo se cierra si observamos que la estructura arraigada de cacicazgos locales, impidiendo el desarrollo de una sociedad civil fuerte, sustenta el centralismo, de modo que el Estado controla todas las vías de acceso al poder economico y político, aunque no tenga ningún control sobre los territorios rurales "gobernados" por los caciques. Por lo tanto,

los conflictos sociales que se manifiestan en Guerrero constituyen la expresión profunda de la insatisfacción social que priva a la entidad respecto a la estructura de poder. La muestra que estas políticas parecen haber llegado a su limite lo constituye no solamente la persistencia de la violencia y la inestabilidad política en el estado, sino también el agotamiento de las prácticas políticas clientelares que se expresa en los resultados electorales recientes ${ }^{82 " ~(R e n d o ́ n ~ A l a r c o ́ n ~ 2003: ~ 136-137) . ~}$

El estigma de "Guerrero bronco" se debe a que ha sido y sigue siendo una entidad violenta. Cifras oficiales del propio Instituto Nacional de Estadística, Geografía e Informática (INEGI), así como del Instituto para la Seguridad y la Democracia AC, establecen que Guerrero y la Ciudad de México son las dos entidades que presentan el mayor índice de homicidios. En efecto, en Guerrero el 30 por ciento o más de las muertes violentas durante 2003 tuvieron como causa el homicidio, siendo dicho porcentaje más alto incluso que el de estados fronterizos, que también se han caracterizado por la violencia en contexto de narcotráfico.

\footnotetext{
${ }^{81}$ Siempre ha sido muy fuerte la presencia y la actividad de los partidos politicos en las zonas rurales de Guerrero, muchas veces con el resultado de fragmentar las instituciones comunitarias y los proyectos organizativos autónomos de los pueblos.

${ }^{82}$ Muchos municipios y hasta al actual gobierno del Estado son gobernados por el PRD.
} 
Mientras en la entidad la violencia sigue creciendo, las regiones Costa Chica, Montaña y Tierra Caliente son las que cuentan con el índice delictivo más bajo ${ }^{83}$.

Pero cabe destacar que en Guerrero, además de la delincuencia organizada que se ha disparado en fechas recientes hasta niveles insostenibles, desde hace años se vive una situación de violencia generalizada.

Estrada Castañon concibe la violencia estructural que caracteriza al Estado como uno de los rasgos de la cultura política que están presentes desde un origen, y mantienen vigencia hasta el presente: caciquismo, caudillismo, autoritarismo, regionalismo y violencia (1994: 56). Según la autora, las relaciones clientelares y fundadas en la discriminación étnica, que con variantes predominan en la Costa Chica y la Montaña, han contribuido mayoritariamente a la imagen de violencia que tiene Guerrero. En su estudio sobre la violencia en Guerrero y Oaxaca publicado ya hace veinte años, Flanet (1985) afirmaba que la Costa Chica tenía fama de ser quizás la región más violenta de la Republica Mexicana.

"Puede afirmarse que ha sido la forma en que se ejerce el poder, la parcialidad del orden jurídico y las acciones represivas del gobierno, los principales factores que han hecho de la violencia un problema endémico y de la desconfianza a la ley una actitud comprensible de la ciudadanía" (Estrada Castañon 1994:65). En esta conexión entre poder autoritario, orden jurídico corrupto y represión, hay un actor que juega un papel central: las fuerzas policíacas.

Si en Guerrero la policía preventiva y la judicial son tan torvas y arbitrarias como las 'guardias blancas' es porque no son más que 'guardias blancas' embarnecidas e institucionales: transmutación en el plano estatal de los rústicos matones lugareños. Más que para combatir el delito, la fuerza pública de la entidad sirve para controlar a los guerrerenses rasos [...] (Bartra 2000:16).

Los datos proporcionados por las organizaciones humanitarias, cuales la Comisión de Defensa de los Derechos Humanos del Estado de Guerrero y el independiente Centro de Derechos Humanos de la Montaña Tlachinollan (que opera principalmente en esa región), confirman las afirmaciones de Bartra: la Policía Judicial (ahora Ministerial) se ubica en primer lugar como autoridad responsable de violar derechos humanos, seguida por la Policía Preventiva Municipal y los Agentes del Ministerio Público. En la Montaña, superan las violaciones cometidas por estos últimos las perpetradas por el Ejercito Mexicano.

\footnotetext{
${ }^{83}$ Estadísticas Criminales por Regiones Municipales enero-octubre 2005, Secretaria de Seguridad Publica y Protección Civil del Estado de Guerrero.
} 


\section{VIOLACIONES A LOS DERECHOS HUMANOS EN LA COSTA-MONTAÑA}

Principales autoridades responsables de violaciones a los derechos humanos en la Región Montaña, según el Centro de Derechos Humanos Tlachinollan 1994-2006

\begin{tabular}{|l|c|c|c|}
\hline Autoridad responsable & \multicolumn{3}{|c|}{ Numero de quejas } \\
\hline & $1994 / 2006$ & $2004 / 2005$ & $2005 / 2006$ \\
\hline Policía Judicial del Estado & 148 & 16 & 24 \\
\hline Policía Preventiva Municipal & 67 & 2 & 13 \\
\hline Ejercito Mexicano & 62 & 10 & 3 \\
\hline Agente del Ministerio Público & 46 & 0 & 3 \\
\hline Servidores SEG & & 17 & 0 \\
\hline
\end{tabular}

Principales autoridades responsables de violaciones a los derechos humanos para la Comisión de Defensa de los Derechos Humanos del Estado de Guerrero, años 2004 y 2006*

\begin{tabular}{|c|c|c|c|c|c|c|}
\hline \multirow[t]{3}{*}{ Autoridad responsable } & \multicolumn{6}{|c|}{ Numero de quejas } \\
\hline & \multirow{2}{*}{\multicolumn{2}{|c|}{$\begin{array}{lc}\text { Región Costa-Chica } \\
2006 & 2004\end{array}$}} & \multicolumn{2}{|c|}{ Región Montaña } & \multicolumn{2}{|c|}{ Total Estatal } \\
\hline & & & 20 & & 2006 & 2004 \\
\hline Policía Judicial del Estado & 20 & 26 & 3 & 10 & 165 & 262 \\
\hline Policía Preventiva Municipal & 26 & 22 & 12 & 15 & 175 & 177 \\
\hline Ejercito Mexicano & 0 & 0 & 0 & 0 & 0 & 15 \\
\hline Agente del Ministerio Público & 16 & 47 & 9 & 5 & 148 & 208 \\
\hline Servidores SEG & 11 & 8 & 4 & 4 & 104 & 88 \\
\hline
\end{tabular}

${ }^{*}$ Para el año 2005, la CODDEHUM-Guerrero no proporciona datos específicos para las diferentes regiones.

Más importantes tipos de violaciones a los derechos humanos según el Centro de Derechos Humanos Tlachinollan

\begin{tabular}{|l|l|l|}
\hline Violación & $2004 / 2005$ & $2005 / 2006$ \\
\hline Abuso de autoridad & 46 & 53 \\
\hline Detención arbitraria & 24 & 13 \\
\hline Privación de la libertad & 13 & 8 \\
\hline
\end{tabular}

Más importantes tipos de violaciones a los derechos humanos, según la Comisión de Defensa de los Derechos Humanos del Estado de Guerrero*

\begin{tabular}{|c|c|c|c|c|c|c|}
\hline \multirow{3}{*}{ Violación } & \multicolumn{6}{|c|}{ Numero de quejas } \\
\hline & Regic & Chica & Regi & aña & Total & atal \\
\hline & 2006 & 2004 & 2006 & 200 & 2006 & 2004 \\
\hline Ejercicio indebido de la función publica & 69 & 40 & 16 & 25 & 476 & 451 \\
\hline Detención arbitraria & 18 & 25 & 20 & 11 & 187 & 180 \\
\hline Lesiones & 10 & 12 & 4 & 13 & 122 & 135 \\
\hline
\end{tabular}

* Para el año 2005, la CODDEHUM-Guerrero no proporciona datos específicos para las diferentes regiones.

En los últimos años, la condición de vulnerabilidad de la población guerrerense y, en particular, de la región Montaña y Costa Montaña se ha agravado debido a la creciente militarización. El despliegue capilar del Ejército en las zonas rurales e indígenas representa en primer lugar la estrategia contrainsurgente aplicada por el Estado a raíz de la aparición de grupos armados, en lo específico el Ejercito Popular Revolucionario (EPR) y su principal escisión, el Ejercito Revolucionario del Pueblo Insurgente (ERPI). 
A principio de 1994, el Ejército incrementó dramáticamente su presencia en Guerrero, en particular en la sierra de Atoyac y en el Municipio de Metlatonoc en la Montaña, peinando las regiones en busca de "zapatistas". Con el surgimiento del EPR a fines de junio de 1996 (durante la celebración para el primer aniversario de la masacre de Aguas Blancas) la presencia militar y policíaca se redobló en algunas partes de Guerrero, aumentando exponencialmente la detención arbitraria de líderes de organizaciones y funcionarios del $\mathrm{PRD}^{84}$. En la Costa-Montaña, el municipio de Ayutla de Los Libres es el que más padece dicha estrategia, luego de la masacre perpetrada por el Ejército en la comunidad de El Charco en 1998, donde según fuentes oficiales se encontraba una unidad del ERPI. La sucesiva ocupación de ejidos y comunidades por parte de elementos militares ha encontrado la resistencia de la población de la región, que ha denunciado amenazas, detenciones arbitrarias, torturas y violaciones a mujeres indígenas ${ }^{85}$.

La otra motivación que aduce el gobierno para el despliegue militar, y que en la mayoría de los casos sirve para encubrir operaciones anti-guerrilla, es la lucha contra el narcotráfico, que desde el sexenio de Miguel de la Madrid se convirtió en una de las prioridades de seguridad nacional, coincidiendo con la política estadounidense de seguridad. En el tiempo de Salinas de Gortari, dicha tarea se amplió a otros temas de seguridad pública y contrainsurgencia, que se mantuvieron con Zedillo, Fox y ahora encuentran su apogeo con el gobierno de Calderón. Desde hace muchos años Guerrero padece la fuerte presencia del narcotráfico, y muchas zonas rurales son destinadas a la siembra de enervantes. Según el Informe 2006 del Centro de Derechos Humanos Tlachinollan, de la Montaña de Guerrero viene el 63 por ciento de la amapola producida en todo el país. Durante los últimos años, el combate a las drogas se ha traducido en una lucha frontal contra la población: se hostiga e intimida a los trabajadores del campo, se militarizan las regiones indígenas -consideradas como enclaves de mayor peligro para la seguridad nacional-, y aumentan los casos de violaciones graves de derechos humanos cometidos por el Ejército. Como se puede ver de los datos proporcionados por la CODDEHUM, las instancias oficiales no investigan en contra del Ejército, legitimando su impunidad.

En tiempos recientes el narcotráfico ha invadido el Estado, debido a que el puerto de Acapulco se ha convertido en una de las plazas más disputadas por los principales cárteles de la droga. Esto ya suscitó varios hechos de violencia que amenazan con generar un clima

\footnotetext{
${ }^{84}$ Informaciones detalladas sobre la presencia militar en la Montaña y las violaciones a los derechos humanos se encuentran en los Informes del CDH Tlachinollan y en Barrera Hernández y Sarmiento 2005: 690-698.
} 
de ingobernabilidad e incertidumbre generalizada. El Programa México Seguro, implementado desde el 2006 por el gobierno calderonista, no ha tenido efectos en la disminución de la narcoviolencia ${ }^{86}$, y ha creado una situación de mayor inseguridad para la población, aumentando aún más el numero de efectivos militares presentes en el Estado de Guerrero.

El poder de quien se dedica al cultivo y el comercio de amapola y marihuana en la región es muy grande, debido a su imbricación con el poder político y las fuerzas policiales, en particular la Policía Judicial Federal, como denuncian el CDH Tlachinollan y el mismo Bartra (2003:46). Se ha logrado crear una red regional dedicada al negocio del delito, que logra obtener información de primera mano en los Ministerios Públicos y Juzgados sobre hechos delictivos y acerca de las personas involucradas. La maquinaria de la extorsión funciona con la complicidad de abogados particulares y funcionarios del Ministerio Público y de la justicia penal. La ola de la delincuencia que ha cobrado centenares de vidas en la región, ha generado una crisis de gobernabilidad y entre la ciudadanía predomina un animo de desconfianza hacia las autoridades. Éstas no garantizan la seguridad, y con ello la población percibe un riesgo fundado de represalias, porque al hablar de violaciones a los derechos humanos es recurrente que los responsables del ilícito sean agentes policíacos o funcionarios que forman parte del aparato de gobierno ante quien hay que denunciar. De esta manera, resultan evidentes la parcialidad y los riesgos de dar parte a las autoridades. Un estudio realizado por el Centro de Investigación y Docencia Económica sobre índices delictivos revela que en el país aproximadamente el $60 \%$ de los delitos no son denunciados por el factor de falta de confianza y temor ciudadano frente a las fuerzas policíacas ${ }^{87}$.

\section{Las instituciones ministeriales y judiciales en la Costa-Montaña: ¿dónde quedó la justicia?}

Los motivos mencionados agravan la condición estructural de falta de acceso a la justicia que existe en Guerrero y en particular en la región de la Costa-Montaña, situación que padecen más los indígenas, que constituyen la mayoría de la población.

Los elementos que determinan esta condición son varios: en primer lugar la ausencia de instancias competentes para la atención de una población con un amplio grado de dispersión

\footnotetext{
${ }^{85}$ Véase los Informes del CDH Tlachinollan.

${ }^{86}$ Asesinatos y ejecuciones han crecido exponencialmente en el ultimo año. La Procuraduría General de Justicia del Estado informó que en el primer semestre del 2007 los homicidios en la entidad han aumentado del 40\% (Notimex /La Jornada On Line, 14 julio 2007).
} 
geográfica, ya que en los tres distritos judiciales (Morelos, Altamirano, La Montaña) en que se divide la región, hay sólo 9 agencias del Ministerio Público, tres con sede en Tlapa y las demás en las otras cabeceras municipales.

En la actuación de los agentes del Ministerio Publico, el principal vicio denunciado por la población es la arraigada costumbre de exigir y recibir dinero a cambio de la investigación y el ejercicio de la acción penal, lo cual beneficia a los adinerados (comerciantes o terratenientes) y discrimina profundamente a la mayoría de la población, excluida del sistema de procuración de justicia por su carencia económica. En las entrevistas realizadas, los habitantes de las comunidades mencionan que frecuentemente, a los que llegan a poner su denuncia ante el Ministerio Publico, se les pide que cubran el gasto de gasolina para que la Policía Ministerial vaya hasta el lugar de los hechos a realizar la investigación.

Al presentarse un indígena o campesino pobre en una agencia del Ministerio Público, se encuentra con la renuencia del Agente al abrir la averiguación previa, mostrándose generalmente indiferente a las denuncias o querellas que llegan a su conocimiento cuando no vislumbra perspectivas lucrativas. Es muy común que, en estos casos, los Agentes arreglen los problemas de forma rápida y según su arbitrio, rehusándose a buscar traductores cuando quien denuncia es hablante de alguna lengua indígena. Es opinión común que los indígenas en realidad entiendan muy bien el castellano: "los indígenas son tramposos, hacen como si no entendieran el español, para evadir las interrogaciones, saben que es difícil encontrar un traductor"88. Los órganos de procuración e impartición de justicia de la región, no obstante la mayoría de la población son indígenas, no cuentan con traductores propios, lo que implica que los tengan que solicitar y no haya una atención inmediata a la población indígena ${ }^{89}$.

En el caso que se acepte la denuncia, la población se encuentra otra vez expuesta a una fuerte violencia económica originada por procesos largos y costosos, ya que otro vicio de la justicia en la región es la dilación de los procesos judiciales. Los casos se tardan regularmente más de un año antes de llegar al juez, en burla a la ley que proclama el derecho ciudadano a una justicia pronta y expedita.

Finalmente, debido a que los conflictos comunitarios en la región se originan por problemas de naturaleza social, resulta inadecuada la actuación de las autoridades que se centran en la

\footnotetext{
${ }^{87} \mathrm{CDH}$ Tlachinollan, Decimo Informe, 2004.

${ }^{88}$ Entrevista a Alejandro Campos Blas, Agente del Ministerio Publico de San Luís Acatlán, noviembre 2006. También el Juez Mixto de Primera Instancia de la ciudad hizo afirmaciones parecidas, en la entrevista realizada en el mismo periodo.
} 
aplicación rígida de la ley, pues hace falta una instancia para la mediación de las controversias a través de la conciliación y que impulse las partes en conflicto a reciprocas concesiones. Cuando en un conflicto agrario, religioso, político o de otra índole social, surgen las órdenes de aprehensión, los desalojos y la mano dura, la consecuencia inmediata es el agravamiento del conflicto y la polarización de las partes. Sucede de esta manera porque la ley no contempla soluciones integrales a problemas complejos ${ }^{90}$.

Así, hay en la región una grave violación del derecho al acceso a la justicia, mismo que es fundamental para la vigencia de los derechos humanos.

Como han expresado una y otra vez las personas entrevistadas en las comunidades de la Montaña y la Costa Chica, las instituciones y las fuerzas policíacas no constituyen un referente de justicia para la ciudadanía. No solamente por la insensibilidad y la discriminación al realizar su trabajo, sino porque resulta evidente que los funcionarios encargados de hacer cumplir la ley son los primeros que están involucrados en ilícitos, debido a que aprovechan su posición de autoridad y de poder para lucrar con los problemas de la gente.

Estas consideraciones ayudan a entender la necesidad que está en el origen del sistema autónomo para la impartición y administración de justicia, cuyas autoridades son nombradas por los mismos pueblos y a ellos deben rendir cuentas sobre su actuación.

No estamos en contra del gobierno, pero si estamos en contra de la delincuencia, y pedimos que no nos deje abandonado el gobierno con la delincuencia, sufriendo. Sabemos que al gobierno no le hace falta dinero, tiene bastante para pagarle a sus empleados para que nos cuiden a nosotros, pero la corrupción está aquí abajo también, entre los policías judiciales, en las oficinas de seguridad, y de esto no podemos defendernos. Siempre los funcionarios nos prometen cosas, pero a la mera hora nadie nos protege. $Y$ tenemos así que vivir en el medio de la delincuencia, con el riesgo de volvernos delincuentes nosotros también ${ }^{91}$.

El esfuerzo de organización en una institución de justicia autónoma aparece aún más valioso, si tomamos en cuenta otro riesgo al que se enfrenta la población en estas condiciones, o sea la tentación a "hacerse justicia por su propia mano". Un trágico precedente en este sentido es lo acontecido en el municipio de Zapotitlán Tablas, ubicado en la Montaña y colindante con el territorio de acción de la Policía Comunitaria, donde en 1993 los habitantes de tres comunidades tlapanecas, luego de haber identificado y denunciado

\footnotetext{
${ }^{89}$ En San Luís Acatlán el Juzgado y el Ministerio Publico solicitan traductores al Ayuntamiento.

${ }^{90} \mathrm{CDH}$ Tlachinollan, Decimo Informe, 2004.

${ }^{91}$ Entrevista a Don Luís.
} 
inútilmente a la autoridad un grupo de asaltantes que actuaban en la región, se organizaron para agarrarlos y ajusticiarlos.

La organización de las comunidades en el Sistema de Seguridad y Justicia Comunitaria es una sorprendente respuesta al panorama de corrupción, impunidad y violencia esbozado en estos párrafos. En su función de control del territorio, ha logrado circunscribir la presencia militar en los lugares donde opera, protegiendo la población de sus nefastas consecuencias. Limita también la acción de la Policía Ministerial, evitando siquiera en parte su impunidad.

También es una respuesta al racismo profundo expresado por las instituciones hacia la población indígena, que muchas veces no se reconoce en ellas por el simple motivo de que las instituciones tampoco reconocen sus derechos ciudadanos (mucho menos sus derechos colectivos como pueblos indígenas).

\section{La construcción del espacio social en la Costa-Montaña: algunos sujetos y momentos determinantes}

La Policía Comunitaria representa quizás el proceso más reciente en una región, la CostaMontaña, donde desde hace décadas se han desarrollado con fuerza la organización popular y la resistencia colectiva. No es mi propósito exponer detalladamente la historia social reciente de la región, tarea ya realizada por algunos investigadores (García 2000, Sarmiento 2001, Barrera y Sarmiento 2006, Flores Felix 2004), sino proporcionar algunos elementos útiles para contextualizar y entender mejor el origen y desarrollo particular del SSJC-Policía Comunitaria.

Entre las experiencias organizativas que han moldeado el territorio y las sucesivas formas de acción colectiva de la gente, dejando una herencia aún viva, está la guerrilla de la Asociación Cívica Nacional Revolucionaria (ACNR) liderada por Genaro Vázquez Rojas, cuya ciudad de origen fue la misma San Luís Acatlán. Luego del fracaso electoral de la Asociación Cívica Guerrerense y la fuga de la cárcel en 1968, Genaro Vázquez escogió el territorio de la Costa-Montaña para reorganizar la lucha en términos ya armados y clandestinos. Con un grupo de compañeros se desplazó en esta región donde era menor la presencia militar y aquí tomó forma el proyecto de la Asociación Cívica Nacional Revolucionaria. Según testimonios directos de quienes integraron este grupo, la ACNR estuvo presente en la Costa Montaña entre 1968 y 1970, sin realizar acciones armadas sino de formación y sensibilización entre la población. Cuando la presión militar se hizo más fuerte, en particular en la zona baja, el núcleo guerrillero decidió desplazarse a la Sierra de 
Atoyac. La guerrilla tuvo una breve y limitada presencia en la Costa-Montaña, así que la represión militar no llegó a los excesos tristemente conocidos en la Sierra y Costa Grande; aunque sí hubo, en particular en la comunidad de Tlaxcalixtlahuaca, entre las más comprometidas con la ACNR (allí varias personas fueron asesinadas por el Ejército y otras desaparecidas).

En los siguientes años, se desarrolló en la región la organización campesina, sobretodo después de la mitad de los setenta, cuando comienza a disminuir de intensidad la guerra sucia contra los presuntos simpatizantes de Lucio Cabañas y Genaro Vázquez. Durante su presencia en la Costa-Montaña, el núcleo guerrillero cumplía acciones de formación y orientación política hacia la población, así como de asesoría a los campesinos para pedir apoyos al gobierno, sobretodo ayudas para el campo. Luego de su salida rumbo a la Costa Grande, varias personas ligadas a la ACNR quedaron en la región, continuando la actividad política de forma más abierta: su tarea fue impulsar la constitución de organizaciones campesinas y productivas, gestionando los créditos estatales (en el periodo, ofrecidos a través del programa COPLAMAR). Según testimonios, producto de este trabajo en la Costa Chica fueron los Campesinos Jamaiqueros Organizados en la región de Ayutla. En los años ochenta, cuando se fortalecen las organizaciones de base (por la favorable coyuntura de participación propiciada por las políticas legítimadoras del gobierno), la organización de productores de jamaica llegó a ser una de las más importantes. Según testimonios directos, al terminarse el programa COPLAMAR, el compromiso de la ACNR siguió en apoyar la gestión y organización del programa CONASUPO-Diconsa, para la construcción de los Consejos Comunitarios de Abasto.

Así, la red política tejida por la organización clandestina se extendió en el tiempo, fomentando muchos de los procesos organizativos que se dieron en la Costa-Montaña en las décadas de los setenta y ochenta; en el mismo periodo también se desarrollaron otras experiencias, principalmente campesinas, que surgen de otras tradiciones políticas.

En la zona de la Montaña, a partir de los años setenta, el Instituto Nacional Indigenista ${ }^{92}$ impulsó el cultivo comercial del café, apoyándose a otras instituciones federales, como la CONASUPO y el INMECAFÉ. A partir de ese entonces, el cultivo del café se volvió la principal opción productiva para los habitantes de la Montaña, y su comercialización el objetivo de las organizaciones campesinas emergentes.

${ }^{92}$ Que desde 1964 instaló el Centro Coordinador Indigenista en Tlapa. 
De las organizaciones con presencia nacional, en la Montaña tuvieron influencia la Central Independientes de Obreros Agrícolas y Campesinos (CIOAC, cercana al Partido Comunista Mexicano), cuya acción se concentraba en la defensa de los derechos de los trabajadores jornaleros y migrantes; y la Unión Nacional de Organizaciones Regionales Campesinas (UNORCA), que respaldaba a las organizaciones locales para el abasto y la comercialización de productos básicos. Éste era uno de los problemas que más afectaba a las comunidades de la Costa-Montaña, debido a los escasos recursos de que disponían y a la falta de vías de comunicación; así, una de las principales vertientes de organización se desarrolló para solucionar dicha situación. A través del programa gubernamental de Abasto Rural de Diconsa se instaló en 1985 en San Luís Acatlán el primer almacén comunitario; consecuentemente se constituyen los comités rurales de las tiendas y a nivel regional el Consejo Comunitario de Abasto. Para 1990 ya eran 52 las tiendas funcionantes en las comunidades. "A partir del abasto, la incipiente organización comunitaria transitó hacia el plano productivo y comercial, y colateralmente hacia el plano social y político" (García 2000:285). Organizadas para el abasto rural, las comunidades vieron que había otros problemas que rebasaban las atribuciones de Diconsa: para apoyar los procesos de producción y comercialización agrícola, asesorar las comunidades y gestionar obras sociales, se constituyó en 1989 la Sociedad de Solidaridad Social (SSS) Productores de Café y Maíz, integrada inicialmente por solo seis comunidades del municipio de San Luís Acatlán y que con los años se volvió el referente organizativo en la región.

La otra vertiente de organización campesina fue la Unión de Ejidos Luz de la Montaña, constituida en 1985 y enfocada específicamente a la produccion y comercialización de café. Actualmente integran esta organización alrededor de 4500 productores de café de 16 comunidades, principalmente de los municipios de San Luís Acatlán, Malinaltepec e lliatenco. Debido a divisiones internas, salieron de "Luz Mont" (así es llamada la organización por los habitantes de la región) algunas comunidades, que en 1991 dieron vida a la Unión Regional Campesina (URC). Recientemente la URC cambió su denominación en ARIC, y cuenta con alrededor 1500 productores pertenecientes a 18 comunidades.

Los años noventa representaron, para Guerrero como para todo el país, una nueva visión en los procesos organizativos. Es el fortalecimiento del movimiento indígena ${ }^{93}$, y el énfasis en la identidad indígena como fundamento de reivindicaciones políticas definidas, donde anteriormente era la identidad campesina la que animaba la organización colectiva.

${ }^{93}$ Que ya se venía configurando desde fines de la década de los ochenta. 
En realidad, la región ha sido escenario de una importante cantidad de acciones colectivas protagonizadas por actores indígenas, por lo menos en los últimos 20 años desde que el movimiento dirigido por el profesor Othón Salazar ganó la presidencia municipal de Alcozauca. A nivel nacional, en 1979, Alcozauca fue el primer municipio donde triunfó la oposición. Allí llegó a gobernar el Partido Comunista Mexicano que logró arraigarse entre la población mixteca como una expresión clara de rebeldía y protesta. Por esa razón, la región se ganó el nombre de "Montaña roja".

La década de los años setenta fue una época de ensayo por parte de los pueblos indígenas del estado de Guerrero. Animados por una nueva política indigenista mostraron su rostro y alzaron su voz a través de organizaciones que les fueron diseñadas e impuestas desde el gobierno y por el partido hegemónico de aquellos años. Fue de ensayo también desde diferentes posiciones políticas como la impulsada por el Partido Comunista Mexicano y sus organizaciones afines, como el Consejo de los Pueblos de la Montaña (CPM) y la Central Independiente de Obreros Agrícolas y Campesinos (CIOAC), y posteriormente la Unión Regional Agropecuaria, Forestal y de Agroindustrias de Ejidatarios Comuneros de la Montaña (URAFAECM). Una característica del CPM era que sus integrantes debían ser los pueblos de la región y otra era que compartieran los principios del movimiento comunista. Aún cuando el CPM se definía como conjunto de pueblos, poco aclaraba si se trataba de los pueblos mestizos o de los indígenas o de ambos. Los pueblos indígenas se dieron cuenta que no bastaba sentir que las organizaciones respondían a sus demandas sino que era necesario que los representaran desde su condición étnica (Sarmiento 2004).

Así, fue más de 10 años después cuando la población indígena de la región empezó a organizarse como sujeto político y a elaborar un proyecto político propio, que no dependiera necesariamente de las líneas o los discursos de los partidos politicos, aunque fueran de izquierda.

En Guerrero, el movimiento indígena se desarrolla a partir de la campaña que a nivel continental se oponía a las celebraciones para los "Quinientos años del descubrimiento de América". En ese contexto, diferentes experiencias ya activas en todo el Estado se aglutinaron en 1991 en el Consejo Guerrerense 500 Años de Resistencia Indígena, Negra y Popular. En sus orígenes coincidieron dos procesos locales como la lucha en contra de la presa en la región del Alto Balsas y el debilitamiento de las organizaciones campesinas. En su conformación coadyuvaron también intelectuales y miembros de la Iglesia local, que provenían de las mismas comunidades indígenas y eran influenciados por la corriente de la Teología de la Liberación. Experiencia casi única en México de organización indígena a nivel estatal, el CG 500 Años ha tenido un peso importante en la conformación de las demandas y la movilización indígena a nivel local. 
Pero, no obstante que los pueblos indígenas guerrerenses han protagonizado importantes batallas por el reconocimiento de sus derechos y formulado construcciones sociales que dieron vida a un movimiento social indígena de gran alcance, la entidad no cuenta con el marco jurídico más avanzado en lo que se refiere a los derechos de los pueblos indígenas. Es más, podemos decir que es uno de los estados más atrasados en el reconocimiento de sus derechos. El movimiento indígena que alcanzó dimensiones nacionales en los años noventa no fue suficiente para modificar el pacto social de la entidad que permitiera a los pueblos indígenas avanzar en el reconocimiento de su lucha ${ }^{94}$.

Estas dificultades en el proceso de interacción y negociación con el Estado no ha determinado el alto en la organización y la lucha de los pueblos, como testimonia la experiencia de la Policía Comunitaria.

En la Costa-Montaña el área de justicia de la SSS fue el antecedente de la nueva organización indígena, que logró desarrollarse con mucha fuerza integrando alrededor de 40 comunidades. La red precedentemente construida a partir de los Comités Rurales de Abasto, coordinados por el Consejo Comunitario de Abasto, será también la base de la que más adelante, el Consejo 500 Años de Resistencia se sustentará para hacerse de miembros.

Lamentablemente, luego de unos años de actividad política la dirigencia del CG 500 Años se volvió un coto de poder, y la organización se dejó involucrar en las contiendas políticas partidistas, estableciendo una estrecha relación de dependencia con el PRD, hasta que la misma corrupción de sus líderes lo llevó a la disolución en 1995.

En los años Noventa, una aguerrida lucha partidista se ha desatado en la región, logrando el PRD detentar actualmente (2007) casi la mitad de las presidencias municipales en la CostaMontaña. En las pasadas décadas, las organizaciones campesinas han entrado en la contienda por el poder político tratando de ganar puestos en el gobierno local; el avance de la oposición y la aparición de nuevos actores en el juego electoral ha causado fuertes resistencias por parte de los grupos que tradicionalmente han tenido el poder: los caciques y

\footnotetext{
${ }^{94}$ Los cambios a nivel de la estructura de gobierno estatal, como la institución de la Secretaria de Asuntos Indígenas, y los ligeros cambios en materia penal, en donde se reconoce el derecho a un traductor en lengua indígena cuando un indígena sea procesado, no significan un gran avance en el cambio constitucional que el estado requiere.
} 
el PRI. Se debe a este contexto la lucha de muchas zonas para constituirse en nuevos municipios y sustraerse a una estructura de poder estática e inamovible ${ }^{95}$.

Una institución relevante es el Centro de Derechos Humanos de la Montaña Tlachinollan, con sede en Tlapa de Comonfort y una dependencia en Ayutla de los Libres, constituido en 1994. Tlachinollan se ha convertido, a doce años de haber nacido, en una referencia obligada no sólo por su lucha en defensa de los derechos humanos de los pueblos indígenas, sino por compromiso con los procesos sociales que se han desarrollado tanto en la región como en el estado. El Centro no es sólo una oficina en donde están lo abogados para defender a los pobladores de la zona, sino que es también un espacio de confluencia de diversos esfuerzos que han permitido formular varias iniciativas sociales ${ }^{96}$.

Todas estas experiencias organizativas empezaron a constituir un espacio social y político que en los últimos 12 años se vino definiendo y estructurando a través de la presencia del Sistema de Seguridad y Justicia Comunitaria.

La Policía Comunitaria con su presencia y su acción ha estado formalizando y definiendo políticamente y simbólicamente una región, un espacio territorial donde se ejerce el poder y el gobierno de acuerdo a la peculiaridad cultural de sus miembros. Tal región ya se había venido construyendo a través de diferentes procesos sociales: la red de los Consejos Comunitarios de Abasto comparte el mismo territorio con la red de produccion y acopio del café de Luz de la Montaña y la URC; los procesos organizativos y territoriales impulsados por las parroquias se cruzan con estos dos y con la red de los integrantes y simpatizantes del Consejo Guerrerense 500 años. Por lo tanto podemos afirmar que la región se ha venido creando a partir de los diferentes procesos sociales que actúan en el territorio, entendido tanto como entidad concreta proveedora de recursos y riquezas, territorio para recorrer y proteger, pero sobre todo como espacio social donde se articulan los diferentes procesos que a su vez inciden y transforman la forma con la que los habitantes viven el territorio mismo (Flores Félix 2004:158-159).

Hasta aquí he bosquejado las experiencias organizativas que se desarrollaron al interior de la zona cuyas comunidades son parte del SSJC. En la región Costa-Montaña hay siquiera otros dos procesos colectivos recientes que colindan con el "territorio comunitario" y que tienen relaciones con la Policía Comunitaria.

En el extremo oriental del Estado de Guerrero se encuentra el municipio de Xochistlahuaca, cuyos habitantes por la mayoría pertenecen al pueblo amuzgo. En 1999 se organizó un

\footnotetext{
${ }^{95}$ Son ejemplos el proceso de lliatenco, constituido como municipio en 2005; Rancho Nuevo de la Democracia, que no logró independizarse; Xochistlahuaca, donde la organización popular declaró en 2002 un Municipio Autónomo.

${ }^{96}$ En la región, sus integrantes acompañan activamente el proceso de la Policía Comunitaria y la resistencia de los pueblos de Ayutla, y recientemente han asumido la defensa de los ejidatarios que luchan contra la construcción de la presa La Parota y contra la mina en El Carizalillo, en la región Centro del Estado.
} 
movimiento popular en contra de la presidenta municipal, exponente de una familia de caciques muy potente en la zona, que no quiso reconocer a los comisarios y a los delegados de las comunidades indígenas (elegidos por las asambleas comunitarias según el sistema tradicional indígena). La presidenta municipal nombró en su lugar a comisarios pertenecientes a su partido; en consecuencia, las comunidades ocuparon el Palacio Municipal. La resistencia en contra de la usurpación de los cargos duró hasta el 20 noviembre de 2002, cuando las comunidades indígenas del municipio, reunidas en asamblea general, declararon su autonomía y eligieron sus propias autoridades municipales autónomas, independientemente de los partidos y de acuerdo a los sistemas normativos internos. Hasta finales del 2005, el municipio estuvo gobernado por las autoridades tradicionales; las sucesivas elecciones determinaron el derrumbe de la experiencia de gobierno autónomo, ya que el PRD cooptó las autoridades tradicionales apropiándose en los hechos del espacio de poder generado por el proceso popular.

A pesar de su breve vida, la experiencia del Municipio Autónomo en Xochistlahuaca tuvo gran impacto a nivel nacional (fue el primer Municipio Autónomo que se declaraba fuera del territorio zapatista) y aún más a nivel local, demostrando que era posible oponerse al poder de los caciques y gobernarse de forma colectiva sin la ingerencia de los partidos politicos. Después de la descomposición del gobierno autónomo, el grupo que más había participado en el proceso se reorganizó como Colectivo en Rebeldía Suljaa' y dio vida a la radio comunitaria Ñomndaa (La Palabra del Agua), que desde 2004 realiza una importante labor de información y difusión en la zona.

Otra experiencia organizativa de los pueblos indígenas en la región es la Organización Independiente de los Pueblos Mixtecos y Tlapanecos, activa desde hace quince años en el municipio de Ayutla de los Libres, al oeste del "territorio comunitario". En años recientes, la organización ha sido blanco de una fuertísima represión militar y policial, siendo imputada de tener relaciones con el ERPI. La capilar militarización del territorio de Ayutla es posterior a los trágicos acontecimientos del 7 de junio 1998, cuando en la comunidad de El Charco, el Ejercito irrumpió en busca de guerrilleros y asesinó a once personas que estaban durmiendo en la escuela, ya que en el día se había realizado una reunión de varias comunidades para discutir algunos proyectos productivos. Como consecuencia de los hechos, las amenazas y los acosos a miembros de la Organización causaron un alto en su trabajo. Actualmente, los pueblos de la zona, cuya firme resistencia a la ocupación militar es tomada como ejemplo también por los mismos Policías Comunitarios, están levantando otra vez la Organización, 
que dividieron (para facilitar la comprensión en las asambleas) en Organización del Pueblo Indígena Tlapaneco (presente en 5 comunidades) y Organización Independiente del Pueblo Mixteco (presente en 40 comunidades).

En el último año se están desarrollando interesantes procesos de coordinación entre diversas organizaciones, con el objetivo de romper el círculo represión-resistencia que las tiene atrapadas. En fecha muy reciente (16 junio 2007), se ha constituido la Coordinación Estatal para la Defensa del Territorio, integrada por organizaciones populares, campesinas e indígenas de la Costa-Montaña y de la Costa Grande ${ }^{97}$.

${ }^{97}$ La Declaración del Foro Estatal Por Los Caminos de la Resistencia se encuentra en Ojarasca, suplemento de La Jornada, julio 2007. 


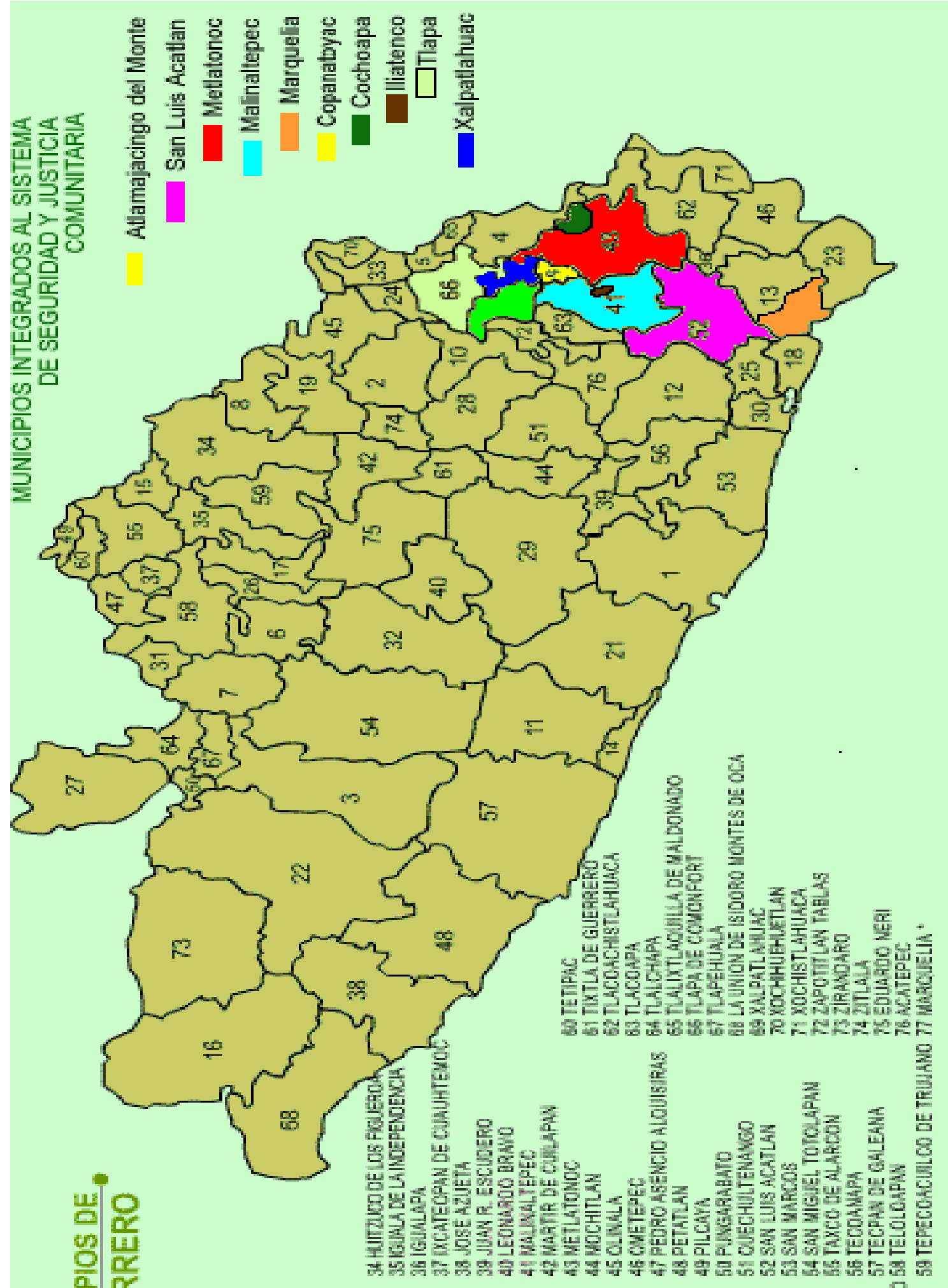

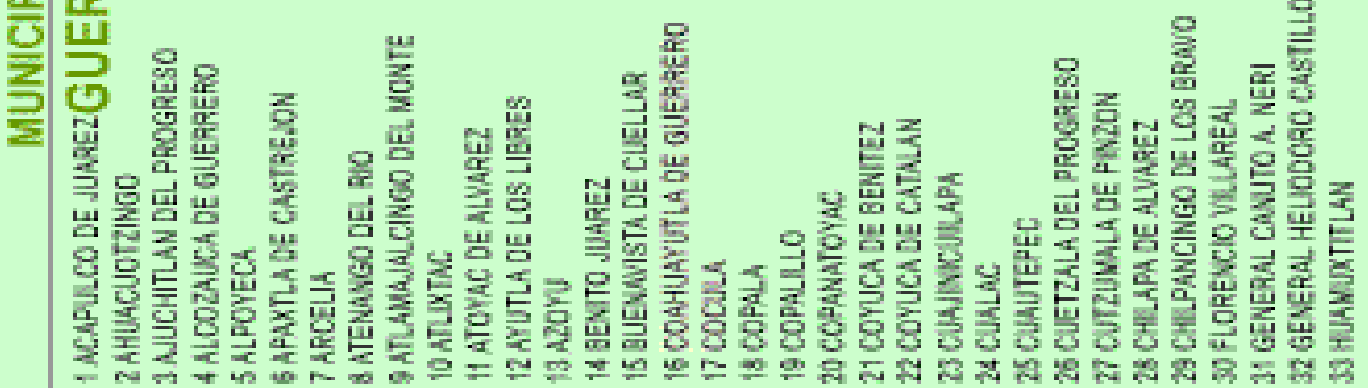




\subsection{EL SISTEMA DE SEGURIDAD Y JUSTICIA COMUNITARIA- POLICÍA COMUNITARIA DE LA COSTA CHICA Y MONTAÑA}

La experiencia de la Policía Comunitaria ha tenido mucha difusión en los últimos años, gracias al interés de periodistas e investigadores mexicanos. Quizás la primera publicación, que describe el origen y las funciones de la PC, es el de Martínez Sifuentes (2000).

Entre los antropólogos, hay que mencionar María Teresa Sierra, que en diversos artículos se ha ocupado del Sistema de Seguridad y Justicia Comunitaria a partir del enfoque de la Antropología Jurídica; documenta la construcción de jurisdicción autónoma prestando particular atención a los aspectos de los derechos humanos y de la mujer.

Otro trabajo interesante es la tesis doctoral del José Joaquín Flores Félix, quién recorre el proceso de formación del espacio social de la Montaña en los últimos años, utilizando la experiencia de la Policía Comunitaria como ejemplo de construcción local de la democracia. Me pareció trascendente la documentación que hizo de las diferentes "tradiciones organizativas" (la Iglesia, los partidos, las comunidades indígenas y las organizaciones sociales) que construyen el espacio social donde se desarrolla la Policía Comunitaria.

Evangelina Sánchez Serrano (2006) analiza la Policía Comunitaria a partir de la perspectiva de la sociología de la acción, que enfatiza el sentido de la acción colectiva y la generación de identidades políticas. Así, afirma que el SSJC se fortalece de la identidad indígena y construyendo un sujeto étnico; y que la pluralidad política se sustenta en las organizaciones productivas, políticas, religiosas. Serrano parte de la afirmación de la trascendencia de la identidad étnica y comunal en el proceso de la PC, matizando su posición en el curso de la investigación, que le muestra el proceso de construcción de un espacio intercultural y regional. Comparto tal afirmación y la confirmo con los hallazgos de mi investigación, aunque me parece que no sostiene con argumentaciones fuertes su tesis conclusiva, que finalmente no queda suficientemente esclarecida. A pesar de esto, considero dicho trabajo entre los más interesantes sobre el tema.

Sobre la práctica de impartición de justicia en una comunidad integrada al SSJC ha realizado su tesis de maestría Abigail Sandoval, quien propone un estudio de caso típico de la Antropologia Jurídica clásica. El importante trabajo etnográfico realizado por Sandoval, retrata la forma en que los habitantes mixtecos resuelven sus conflictos al interior de su comunidad apelando a la construcción de una justicia que recupera su vida cultural comunitaria; analiza en detalle algunos casos de disputa tejiendo la relación entre las practicas de resolución de conflictos a nivel comunitario y el sistema regional administrado 
por la CRAC. Martha Peral y Amor Ortega, que están realizando sus de licenciatura en Ciencias Políticas, analizan estructura y funciones del SSJC. Un resumen de su trabajo se encuentra en Ortega y Peral (2006). Los últimos tres trabajos citados abordan el proceso de construcción de una jurisdicción autónoma a partir del estudio más puntual de las practicas cotidianas en las cuales ésta se concretiza, tanto a nivel comunitario como a nivel regional. Además de las investigaciones concluidas, hay varias en curso. Entre ellas, la de Alma Megarito, estudiante de la Licenciatura en Derecho en la UNAM. Su tesis se centrará en la normatividad aplicada, para demostrar que se trata de un sistema jurídico.

\section{El contexto social en que se forma la Policía Comunitaria: testimonios de una cotidianeidad en el filo de la navaja}

El Sistema de Seguridad y Justicia Comunitaria se formó a partir de necesidades concretas, principalmente la de garantizar la incolumidad de los pobladores de la zona en los traslados entre las comunidades y las cabeceras municipales, en particular las de San Luís Acatlán y Malinaltepec. En las décadas que van desde el 1970 al 1990, la población padeció un aumento exponencial de la violencia en la zona, debido a la ineficiencia y a la corrupción del sistema de seguridad y de administración de la justicia del Estado. Esto originó una situación generalizada de violación de los derechos humanos más elementales, agraviada por la falta de acceso a la justicia para los habitantes indígenas, como quedó expuesto en el precedente capítulo.

Algunos extractos de las entrevistas realizadas son ejemplares en relatar tal situación.

Cuando yo tenía 14 o 15 años, la costumbre era de andar por el monte puro con bestia; en ese entonces sí había asaltos pero no tantos como hace unos anos. Ya en los setentas, '73 o '74 ya se asaltaba más, cada seis meses, o cada tres meses empezaban a asaltar. Después se fueron acostumbrando y se hizo más seguido, todos los sábados... porque la gente el sábado se va a comprar o vender a los otros pueblos, y le quitaban sus productos, la panela o lo que fuera, y el dinero... Se moría también la gente, por resistirse a dejar lo poco que tenía, los asaltantes los macheteaban y así se llevaban sus pertenencias.

Se puso muy fuerte en Horcacitas, porque es punto de paso para toda la gente que de los varios parajes se baja a comprar en San Luís, pero lo más peligroso era la carretera que va a Tlapa.

En los '80 ya no se contentaban con el dinero, empezaron a violar las mujeres. Las mujeres que se trasladaban escondían su dinero en los calzones, pero los asaltantes se los bajaban y después las violaban, y al final de los '80 eso ya pasaba casi diario ${ }^{98}$.

\footnotetext{
${ }^{98}$ Entrevista a don Francisco, tlapaneco, campesino, Coordinador en la CRAC 2001/2002, Pueblo Hidalgo, San Luís Acatlán, 25 julio 2006.
} 
Del '80 para atrás no había muchos problemas. Del ' 80 al '90 fue cuando la delincuencia se puso más fuerte; ya no era solamente el despojo de dinero, el robo de toda clase de animales; ya se empezaban a meter a las casas, gente de las mismas comunidades... después empezaron a matar y a violar mujeres. En 1993 y 1994 fue cuando se empezó a platicar sobre la Policía. En los tiempos anteriores, para nosotros no hubo gobierno; las autoridades competentes no nos dieron una justicia legal. El primer impulso vino de las organizaciones, LuzMont y 500 Años, ya que les robaban productos en el camino. Antes de esto, los delincuentes empezaron a robar mucho ganado. En 1993 y 1994 ya empezaron a asaltar en los caminos; eran caminos aislados, ya que antes no había tantas carreteras, eran caminos reales donde la gente iba caminando o con los burros o caballos ${ }^{99}$.

Para decir un ejemplo, venía en el camino un matrimonio: acostaron el hombre y en su lomo abusaron de la mujer... te imaginas... pero al final matan a ese matrimonio, así para tapar el ojo al macho, ya no podían denunciar a los delincuentes... hay gente que le sucedió lo mismo, incluso con sus hijas. Por eso nació este coraje de la gente, de los que vivieron esta situación; el que no lo vive te critica, de atribuirte un poder que no tienes, pero es una vil mentira... muchas veces un bien nace por un mal, y por ese mal nació la Policía Comunitaria, uniéndonos: como comunidades nos unimos, pensando que después nos iba a caer el Ejército, el gobierno, pero estábamos listos par a asumir el riesgo ${ }^{100}$.

Por muchos años, además de la marginación y la miseria, nuestros pueblos indígenas, mestizos o negros, han padecido la discriminación, la explotación de los caciques, y especialmente la crisis económica, la falta de empleos, un pedazo de tierra para producir, la falta de apoyos efectivos para el campesino, el analfabetismo, la drogadicción etc., ante lo cual, muchas veces las autoridades municipales y judiciales de esta región, no han actuado apegados a la ley y con responsabilidad para combatir a fondo esta situación ${ }^{101}$.

\section{Las vertientes de la movilización: las organizaciones sociales y la Iglesia católica}

Empezado en los primeros años noventa, para 1995 en la región Montaña y Costa Chica se había aglutinado un frente de organizaciones productivas y políticas, que movilizaba un amplio sector de la población. En tal movimiento participaba también la Iglesia local, representada por Mario Campos y Bernardo Valle, en aquel entonces párrocos respectivamente de El Rincón y Pascala del Oro. Las principales demandas consistían, en términos generales, en servicios y seguridad para la población e infraestructura para las organizaciones.

\footnotetext{
${ }^{99}$ Entrevista a don Juan, tlapaneco, campesino, comandante del grupo de Policía Comunitaria en su comunidad en 1995 y comandante regional en 1997; Camalotillo, San Luís Acatlán, 27 julio 2006.

${ }^{100}$ Entrevista a don Moisés, mestizo, Comisario de la CRAC en 2006; Capulín Chocolate, Marquelia, 4/08/2006.

101 Documento entregado a la Procuraduría General de Justicia del Estado, 6 noviembre 1995.
} 
La necesidad de servicios se refería principalmente a las vías de comunicación. Las peticiones eran que se rehabilitaran los caminos rurales dañados que comunicaban las comunidades, y que se abrieran nuevos, ya que la incomunicación de la zona agravaba la condición de pobreza, falta de acceso a los servicios como educación y salud, y hacía muy difícil el abastecimiento de los muchos productos necesarios en la vida cotidiana y que las comunidades tenían que traer de los centros más grandes. Sobre todo, se pedía la rehabilitación de los caminos ya su situación de abandono hacia más fácil que los asaltantes se apostaran y pararan los transportes públicos y los caminantes a lo largo de las brechas.

Para exigir la construcción de la carretera pavimentada Tlapa-Marquelia, eje vial que une la Costa con el principal centro de la Montaña, se dio un largo proceso de movilización popular, a través de asambleas comunitarias e intercomunitarias para sensibilizar e involucrar a toda la población, acompañado por la gestión de las organizaciones sociales.

De la movilización popular se habían hecho voceras y protagonistas las organizaciones presentes en la región: las que se ocupaban de produccion y comercialización de los productos agrícolas, cuales la Unión de Ejidos Luz de la Montaña, la Unión Regional Campesina (URC) $)^{102}$, la Sociedad de Solidaridad Social (SSS) de Productores de Café y Maíz; y el Consejo Guerrerense 500 Años de Resistencia.

He resumido en el precedente capítulo el proceso organizativo y la trascendencia de estas organizaciones en la región que posteriormente será el territorio de acción de la Policía Comunitaria. Hay otra experiencia organizativa, el Consejo de Autoridades Indígenas (CAIN), que no sobresalió pero, según testimonios, fue un antecedente importante para la formación de la Policía Comunitaria. El CAIN se constituye a finales de 1992 en el curato de la comunidad de Santa Cruz el Rincón, tras el impulso del párroco Mario Campos ${ }^{103}$, persona de fuerte carisma y compromiso social. Inicialmente participaron en el Consejo personas cercanas a la iglesia de la comunidad, pero sucesivamente se sumaron al CAIN las 28 comunidades de influencia de la parroquia del Rincón. A través de la integración al CAIN, paulatinamente, las comunidades de esta región se organizaron políticamente y avanzaron unas reivindicaciones fundamentales para la vida en la región: seguridad y servicios. La primera lucha que encabezaron las Autoridades Indígenas organizadas fue, de

\footnotetext{
${ }_{102}^{102}$ Ambas integrantes de la Coordinadora Nacional de Organizaciones Cafetaleras (CNOC).

${ }^{103}$ Mario Campos es un indígena mixteco que fue párroco de la iglesia de Santa Cruz del Rincón y, junto con el padre Bernardo Valle de Pascala del Oro, en 1995 fueron actores importantes al inicio del movimiento. Este doble papel, de sacerdote y dirigente, sumado a represalias del Gobierno del Estado provocó que sus superiores eclesiásticos lo reubicaran en otra parroquia, la de Xalpatlahuac, municipio cercano a Tlapa. Hoy día
} 
1992 a 1994, por la construcción de caminos, y en particular, de la carretera pavimentada de Tlapa a Marquelia. Posteriormente, el CAIN se concentró en las demandas educativas, promoviendo la instalación de una sede de la Universidad Pedagógica Nacional en la comunidad del Rincón. Finalmente, y junto con las otras organizaciones de la región, el CAIN demandaba seguridad y acceso a la justicia. Podemos afirmar que el proceso de organización de las autoridades indígenas que empezó allí, sentó las bases y confluyó en la estructura organizativa de la Policía Comunitaria.

Dicha movilización ciudadana en la zona de la Montaña y la Costa Chica se dio en una coyuntura de crisis del sistema de seguridad es, originada por la tristemente nota "matanza de Aguas Blancas" en la Costa Grande, acontecida el 28 junio 1995. Ese día un grupo de integrantes de la Organización Campesina Sierra del Sur (OCSS), que se dirigía a una marcha en Atoyac, fue victima de una emboscada en la que 11 personas perdieron la vida y 39 fueron detenidas. Responsables de la matanza fueron policías municipales, que apenas dos años después salieron de prisión, dejando exonerado de cualquiera responsabilidad al gobernador Rubén Figueroa. A raíz de esa masacre se generó una discusión sobre el deterioro de las instituciones encargadas de ejercer justicia en el estado de Guerrero. Como consecuencia de la deslegitimación del gobierno estatal en 1996 el gobernador dimitió y en su lugar fue designado, como interino por el periodo 1996/1999, Ángel H. Aguirre Rivero.

En los meses que siguieron a la matanza de Aguas Blancas, hubo una gran apertura y disponibilidad a la colaboración por parte de los funcionarios del gobierno estatal hacia las organizaciones sociales y productivas activas en la región, con el objetivo de distender el contexto social extremamente radicalizado, y tratar de contener la rabia contra las instituciones que en el Guerrero se percibía ya a flor de piel. En la zona de la Costa-Montaña había ya una estrecha interacción de las dos organizaciones de productores cafetaleros (Luz de la Montaña y URC), y a nivel más amplio entre varias organizaciones del Estado de Guerrero, con el objetivo de aprovechar de los varios programas de apoyo a la produccion de café implementados por las instancias de gobierno.

su participación se ha reducido prácticamente a la asistencia a eventos externos relacionados con el "Sistema", aunque fundamentalmente, a los aniversarios de la Policía Comunitaria. 


\section{Origen de la Policía Comunitaria}

A pesar de estas estrategias institucionales, lo que destaca en esto periodo es la fuerte movilización de las organizaciones alrededor de las reivindicaciones de servicios y seguridad.

Aquí producimos café, y yo participaba en la organización de productores Luz de la Montaña, así como en $500 \mathrm{Años}^{104}$. Los robos afectaban muchísimo también a las organizaciones productivas, ya que en los asaltos se iban muchas ganancias de las ventas del café. Fue así que los dirigentes de Luz Mont ${ }^{105}$, de 500 Años y otros empezaron a platicar cómo se podía hacer. Se empezaron a hacer asambleas donde participaba gente de los municipios de San Luís [Acatlán] y también de Malina[ltepec], porque allí vendemos nuestro café, así que fuimos todos sobre el producto que vendimos. Los que fueron más determinados son los de Luz Mont, que ponían el carro, juntaban gente ${ }^{106}$.

Paralelamente también las parroquias presididas por los padres Bernardo Valle y Mario Campos promovían reuniones y asambleas en que la gente discutía los mismos temas, en particular la necesidad de un sistema de seguridad pública que detuviera la escalada de violencia en la región. En el caso de las comunidades que pertenecían a la parroquia de Santa Cruz el Rincón, la movilización se dio a través del CAIN.

Los dos procesos de discusión y movilización, uno implementado por la dirigencia de las organizaciones sociales y otro por los párrocos, confluyeron en el verano de 1995, cuando organizaron conjuntamente la primera gran Asamblea Regional en Pascala del Oro, que "duró dos días y una noche, donde se elaboró un reclamo escrito y se mandó al gobierno ${ }^{107}$. En este momento ya era clara la necesidad de organizarse para garantizar la seguridad; las propuestas eran diversas, como la reorganización de los policías municipales, la formación de grupos de autodefensa comunitarios, hasta la justicia por propia mano.

Un segundo paso importante fue una asamblea pública convocada el 17 septiembre 1995 en San Luís Acatlán por las dirigencias de la Unión Regional Campesina, Luz de la Montaña y el Consejo Guerrerense 500 Años de Resistencia para discutir la cuestión de la seguridad. Fueron invitadas las autoridades municipales de San Luís Acatlán y Malinaltepec, pero participó solamente el asesor del presidente municipal de este último.

La discusión entre las organizaciones había llegado a la conclusión de que los problemas locales, de seguridad y servicios, de empleo e infraestructura, de participación política, había que atacarlos conjuntamente. Con este objetivo se formó la "Coordinación Provisional de

\footnotetext{
${ }^{104}$ Consejo Guerrerense 500 Años de Resistencia Indígena, Negra y Popular.

105 Unión de Ejidos y Comunidades Luz de la Montaña.

${ }^{106}$ Entrevista a don Francisco.

107 Entrevista a don Francisco.
} 
Organizaciones Sociales y Productivas" ${ }^{108}$. Uno de sus objetivos era aprovechar la coyuntura favorable para promover la participación en los Ayuntamientos, impulsar Consejos de Desarrollo Municipal (auspiciados por la Secretaria de Desarrollo Social-SEDESOL) y coordinar el trabajo de las organizaciones y de las instituciones locales. La Coordinación duró hasta finales de 1996, mientras esta tensión a la interacción con las instancias de gobierno municipales sigue caracterizando todo el proceso de organización de la Policía Comunitaria y de desarrollo del Sistema de Seguridad y Justicia Comunitaria. Ya desde entonces, había la convicción de que la organización a crear debía ser plural, participando en ella tanto los pueblos de las comunidades como sus autoridades, tanto las organizaciones sociales cuanto las instituciones locales.

El germen de la Policía Comunitaria ya existía no solamente en las discusiones, ya que los habitantes de varias comunidades del municipio de Malinaltepec habían formado, con el beneplácito del Ayuntamiento, un grupo que se encargaba de mantener la seguridad y patrullar los caminos, integrado por los Policías Municipales de los mismos pueblos, un cargo que existe tradicionalmente en las comunidades de la zona. En la asamblea convocada el 17 septiembre 1995 por las organizaciones, el asesor del presidente municipal de Malinaltepec se agregó a la demanda popular por la desaparición de la Policía Motorizada en el territorio, ya que eran resabidos sus nexos con los asaltantes.

La siguiente asamblea fue en Tlaxcalistlahuaca [el 24 septiembre 1995], y allí se consideró que, contrariamente a lo que se venia diciendo, los mañosos no son nada más de Horcacitas, sino son de todos los pueblos de la región. En Horcacitas se puso muy fuerte, porque es punto de paso para toda la gente que de los varios parajes se baja a comprar en San Luís. Ese día en Pascala hasta se había planteado de ir a quemar todo el pueblo de Horcacitas, pero el comisario de Horcacitas, supo guiar la asamblea hasta que se decidió que el 15 de octubre, se habría levantado un acta definitiva sobre las medidas a tomar contra los delincuentes, cómo agarrarlos, y qué hacerles: muchos decían que solamente matándolos se podía acabar con ellos ${ }^{109}$.

Resultado de estas dos primeras reuniones generales fueron unas actas de acuerdo que se enviaron a las autoridades, pero nunca hubo respuesta.

Cuando se realiza el "Foro sobre seguridad y servicios", el 2 de octubre en San Luís Acatlán, la formación de grupos de Policías Comunitarios, organizados entre ellos, ya era una propuesta precisa que algunas comunidades habían empezado a poner en práctica. Es decir que, antes de la fecha oficial de formación de la Policía Comunitaria, se habían integrado

\footnotetext{
${ }^{108}$ Animada principalmente por la SSS de Productores de Café y Maíz; Luz de la Montaña, la URC y el Consejo 500 Años.

${ }^{109}$ Entrevista a don Francisco.
} 
grupos de Policías por lo menos en dos comunidades: Horcacitas y Cuanacaxtitlán, los dos parajes más amenazados por la violencia. En ese foro hubo escasa participación de los funcionarios locales, mientras se incorporó otra organización, el Consejo Comunitario de Abasto. En ese momento, las organizaciones empezaron a presionar a los Comisarios Municipales, autoridades civiles de las comunidades, para que se responsabilizaran directamente en la organización de la seguridad comunitaria.

Finalmente, en la Asamblea Regional que tuvo lugar el 15 de octubre 1995 en la comunidad de Santa Cruz el Rincón se acordó formar la Policía Comunitaria en varias comunidades.

[...] Analizando la situación de inseguridad publica que padecen las comunidades de esta región, al transitar por el camino que los comunican con las poblaciones a las cuales acuden a hacer sus compras o ventas de subproductos, estudiantes que acuden a los centros de estudios o para recibir atención médica y viendo que esta situación ya es insoportable, pues con anterioridad centenas de veces ya se ha puesto la denuncia antes las autoridades correspondientes y al ver que no tenemos ninguna de ellas, y que a diario somos victimas de asaltos, violaciones sexuales, robos, lesiones y homicidios, nos vemos obligados a tomar el siguiente acuerdo:

Que en base a lo estipulado por el articulo $4^{\circ}$ constitucional, en cuanto a la autonomía y autodeterminación de las regiones indígenas, en base al Convenio 169 emitido por la OIT [...]

Decidimos que los grupos de policía comunitario de cada comunidad se avoquen el resguardo de los caminos principales en las rutas donde suceden frecuentemente los asaltos [...]

$Y$ que tienen que coordinarse entre los diferentes grupos de policía de las comunidades que se encuentren en las rutas en que suceden estos delitos.

Que el comisario tome acuerdo con su asamblea o policía si no cuentan con armamento, si los consiguen prestados, sólo que tendrá que elaborar una relación de armas con sus matriculas, que firmada y sellada por la autoridad municipal deberá portar que el comandante anexándola a la presente acta $[\ldots]^{110}$.

Juntos con Comisarios Municipales de diversas comunidades, firman el acta las organizaciones Unión de Ejidos y Comunidades Luz de la Montaña, el Consejo Guerrerense 500 Años de Resistencia, la Unión Regional Campesina, el Consejo de Abasto Indígena, la Coordinadora de Autoridades Indígenas (CAIN) y la SSS "Productores de café y maíz".

En el documento destacan varios elementos: principalmente las motivaciones que llevaron a la formación de la policía comunitaria; la legitimación de la organización con base en el derecho a la libre determinación y a la autonomía, fundamentado en la ley nacional e internacional; el intento de elaborar una nueva normatividad que dé legalidad a la posesión de armas por parte de civiles, basados en la autoridad del Comisario como representante del municipio, aunque formalmente los Comisarios no tengan tales facultades. 
El 6 de noviembre del mismo año, una comisión compuesta por autoridades comunitarias y representantes de las organizaciones sociales viajó a Chilpancingo para entregar una petición al Procurador General de Justicia del Estado. En el documento, donde se encuentra un listado de 44 casos precisos de asaltos y violencias padecidos en el periodo 1990/1995, además de "múltiples violaciones sexuales, por respeto no se mencionan nombres", se especifican las rutas más peligrosas, se subraya el reiterado desinterés de los órganos de procuración e impartición de justicia, y se denuncia que "además, también hemos vivido violaciones de las garantías constitucionales, por parte de la policía judicial y motorizada, como son: detenciones sin orden de aprehensión [...], tortura, allanamiento de morada, sobornos, asesinatos etc".

En el mismo documento se propone:

1. Desaparición de la policía motorizada, toda vez que es anticonstitucional y no nos garantiza seguridad a la sociedad civil de esta región, ya que son gentes extrañas que no conocen los problemas y costumbres de las comunidades.

2. Que en cada municipio se sustituya la policía motorizada por un grupo de policía comunitario de seguridad municipal, integrado por elementos de las diferentes comunidades del municipio [...].

3. Capacitación y equipamiento (armamento, uniforme, radio comunicación) y pago de honorarios a las policías locales o comunitarias.

Constituida la organización, la lucha se articuló en las formas para seguir gestionando el reconocimiento de estos Policías por parte de las instituciones; la dotación de equipo, la compensación y la capacitación. A falta de una representación formal de los Policías Comunitarios, los legitimaron las dirigencias de las organizaciones sociales que gestionaban las demandas ante los tres niveles de gobierno, de acuerdo con las decisiones tomadas en las Asambleas Regionales.

${ }^{110}$ Acta Constitutiva de la Policía Comunitaria. 


\begin{tabular}{|l|c|}
\hline \multicolumn{2}{|c|}{ SISTEMA DE SEGURIDAD Y JUSTICIA COMUNITARIA: DATOS GENERALES } \\
\hline Regiones de influencia & Montaña y Costa Chica, fundamentalmente en la zona cafetalera \\
\hline Municipios & $10 \begin{array}{l}\text { Región Costa Chica: San Luís Acatlán y Marquelia } \\
\text { Región Montaña: Malinaltepec, lliatenco, Metlatonoc, } \\
\text { Atlamajalcingo del Monte, Cochoapa el Grande, } \\
\text { Copanatoyac, Xalpatlahuac, Tlapa de Comonfort }\end{array}$ \\
\hline Comunidades Participantes & \multicolumn{1}{|c|}{65} \\
\hline Pueblos & Tlapanecos, Mixtecos, Náhuas y mestizos \\
\hline Actividades económicas & $\begin{array}{l}\text { Principalmente produccion de café (+ - 8.800 cafeticultores } \\
\text { minifundistas), jamaica, maíz }\end{array}$ \\
\hline $\begin{array}{l}\text { Número de Policías } \\
\text { Comunitarios }\end{array}$ & +-600 \\
\hline $\begin{array}{l}\text { Población beneficiaria } \\
\text { directa }\end{array}$ & +-100000 habitantes \\
\hline
\end{tabular}

\section{Estructura y funciones del Sistema de Seguridad y Justicia Comunitaria}

Actualmente las funciones de la organización son garantizar la seguridad en la zona, impartir justicia y administrar el proceso de reeducación; pero en su principio su competencia era mucho más limitada.

Cuando nació en 1995, la labor de la Policía Comunitaria era, en los hechos, coadyuvar el Ministerio Público y los cuerpos policíacos estatales, resguardando las camionetas pasajeras, patrullando a pie los caminos y reteniendo a los delincuentes, que después eran entregados a la autoridad ministerial.

Al principio la estructura de la organización era mínima: en las comunidades se iban formando grupos de Policías Comunitarios, integrados por un comandante, un segundo y un número variable de policías, entre seis y diez. La coordinación entre grupos de policías de comunidades cercanas era directa y ligada a necesidades especificas; no había un órgano de coordinación regional especifico para la seguridad, y las decisiones se discutían y ratificaban en las Asambleas Regionales, que se llevan a cabo periódicamente (cada dos o tres meses, cada vez en una comunidad diversa).

Esta autoridad asamblearia actualmente representa "la máxima instancia de dirección y mando del sistema comunitario de seguridad, justicia y reeducación; es la instancia de coordinación entre las comunidades integrantes del sistema, con los ayuntamientos y las instancias del gobierno estatal y federal"111. Cabe destacar que, antes del 1995, no se habían realizado asambleas de este tipo; de modo que en la organización de la seguridad, 
se origina un sistema articulado a nivel regional. Aunque en las Asambleas Regionales se tratan solamente temas relacionados con la Seguridad y la Justicia, su funcionamiento desde hace 11 años representa un gran avance con respecto a la coordinación a nivel amplio entre las comunidades. En este proceso se aprecia la construcción de un proyecto de autonomía compartido en lo que concierne al ámbito del control del territorio y la impartición de justicia. Tal proceso se enriquece en las diversidades (étnicas, culturales, de organización social y política, territoriales) de los pueblos y en las organizaciones que confluyen en la Asamblea Regional. De ellas resultan las normas a aplicar en la impartición de justicia y los procedimientos para la reeducación actualmente aplicados por las Autoridades Regionales. A las Asambleas Regionales puede asistir y participar cualquier ciudadana y ciudadano que lo decida, mientras las autoridades de las comunidades que pertenecen a la organización tienen el deber de asistir; por lo regular son invitadas las autoridades municipales, que no siempre asisten.

Los Policías y Comandantes comunitarios son elegidos en las asambleas generales de su comunidad, por lo regular a final de año o en los primeros días del nuevo año (según la costumbre de cada comunidad), en la misma asamblea en que se elige al comisario y al cuerpo de autoridades comunitarias. Mientras el cargo de éstas dura 1 año, los Policías Comunitarios duran 3 años; su trabajo no es retribuido, lo cual recalca la gratuidad de los cargos comunitarios.

En 1996 a la organización comunitaria de seguridad se agregó un órgano regional, el Comité Ejecutivo, compuesto por Comandantes Regionales (electos en la Asamblea Regional y con cargo rotativo; es la reproducción a nivel regional de las instancias comunitarias) que actualmente coordina el trabajo de los aproximadamente 500 policías distribuidos en las 65 comunidades de los municipios que integran el proyecto. El Comité Ejecutivo es el órgano máximo de dirección operativa de la policía comunitaria; se encarga de dirigir los operativos a nivel regional, llevar a cabo las investigaciones que les encarga la Coordinadora de Autoridades Regionales para la resolución de los casos que se están atendiendo, interrogar a los presos.

El año de 1997 representa un avance en la organización. Con la formación del Comité Ejecutivo se inicia la coordinación real y efectiva de los grupos, y se organizan operativos de mayor importancia: captura de abigeos, resguardo de fiestas tradicionales, patrullaje preventivo a colonias de San Luís Acatlán, resguardo de funcionarios de organizaciones y

${ }^{111}$ Reglamento Interno del SSJC, Articulo 6.II. 
Presidencias Municipales en reuniones importantes, recorrido a ríos, resguardo de valores de las Organizaciones. También se realizan algunos operativos coordinados con la Policía Motorizada y la Policía Judicial para establecer retenes.

En estas circunstancias se empezó a discutir el establecimiento de Rutas de Coordinación, para integrar los resguardos y recorridos de vigilancia de los grupos de policías de comunidades cercanas entre sí; los primeros operativos conjuntos se realizaron en mayo 1997. En la asamblea realizada el 20 julio 1997 en Yoloxochitl, municipio de San Luís Acatlán, los representantes de los policías de diferentes comunidades expusieron que estaban enfrentando problemas fuertes, los que requerían una coordinación entre comunidades vecinas; en la misma asamblea se formalizaron las primeras nueve Rutas de Coordinación que desde luego empezaron a funcionar.

Para financiar la organización, se propuso cobrar una cuota de 5 ó 10 pesos a los camiones de transporte pasajeros o de carga que transitaran en los caminos resguardados por los policías, y se acordó con los transportistas que en sus traslados por la zona los policías no pagarían el pasaje.

Al mismo tiempo se organizaron asambleas con la participación exclusiva de los Comandantes de los grupos de policías comunitarios; para fortalecer la operatividad a nivel regional, el 6 abril 1997 se nombró el Comité Ejecutivo, compuesto en ese entonces por 3 Comandantes de distintas comunidades.

Dejando mi cargo [Comisario en la comunidad], en 1996 me dediqué de lleno a formar el grupo de Policía, ya que la gente me pidió que fuera yo el Comandante Primero del grupo de mi pueblo. Entonces se convocó una asamblea de puros Policías y Comandantes, en la que se expresó la necesidad de tener un representante de la Policía; entonces se pensó nombrar Comandantes Regionales, como Comité Ejecutivo, que tuviera el control de todos los grupos. Entonces en la Asamblea Regional (1997) nos presentamos todos los comandantes de cada pueblo para que nos conociera la gente ${ }^{112}$.

Cuando nació en 1995, la labor de la Policía Comunitaria era coadyuvar el Ministerio Público y de los cuerpos policíacos estatales; sin embargo se hizo más patente la ineficiencia y la corrupción de las autoridades encargadas en administrar la justicia.

En noviembre 1997 se verificó el primer caso en que una persona retenida por la Policía Comunitaria fue sometida a "reeducación". Se trataba de un joven retenido por los policías comunitarios en la comunidad de Tuxtepec por traer una mínima cantidad de marihuana. Tal caso no había sido atendido por las autoridades competentes, que lo calificaron como una infracción tan pequeña que no era perseguible por la ley. Al revés, para las autoridades y el

${ }^{112}$ Entrevista a don Juan. 
pueblo de la comunidad, se trataba de una infracción muy grave, ya que rompe las normas internas y el equilibrio de la comunidad, proporcionando un pésimo ejemplo para los jóvenes. Así que las autoridades comunitarias de Tuxtepec (lugar de origen del joven) y los comandantes del Comité Ejecutivo, decidieron, en un acuerdo tomado a la presencia de sus familiares en la asamblea general del pueblo donde se le había retenido, sancionarlo como se usaba en algunas comunidades de la zona: "que el c. mencionado como castigo trabajara los trabajos sociales en cada comunidad después de haber cumplido este castigo la autoridad extenderá una constancia donde se ampare que si lo cumplió tal como se tomó el acuerdo"113. Desde este momento, los retenidos por la Policía Comunitaria ya no fueron entregados al Ministerio Público, y en las Asambleas Regionales que se realizaron la discusión se centró en qué hacer con los delincuentes atrapados. Hubo voces que llamaron a la ejecución, pero finalmente el debate se enfocó a articular un sistema donde hubiera autoridades que se encargaran de la impartición de justicia, de acuerdo a un procedimiento igual en toda la región para sancionar a los delincuentes.

En 1997 empezamos a preguntarnos si había otra forma de controlar los delincuentes, ya que si los entregábamos al Ministerio Público era lo mismo, los soltaban en pocos días y no había justicia. Entonces en la asamblea regional de San José Vista Hermosa (en ese tiempo sólo eran 3 municipios, San Luís, Malina y Azoyú) se consensó que los hubiéramos tenido nosotros. Y en 1998 se nombraron 6 comisarios $^{114}$.

Así, las comunidades que integraban la Policía Comunitaria decidieron, en $1998^{115}$, constituir la Coordinadora Regional de Autoridades Comunitarias (CRAC, que suple la función del Ministerio Público y de los Jueces), que se encarga de aplicar y administrar justicia "en base a los usos y costumbres" a aquellas personas que delinquen en el territorio donde opera la Policía. Hasta el año 2007 los que integran la Coordinadora Regional eran escogidos entre todos los que recibían el nombramiento como comisario en su propia comunidad. "Cuando es año nuevo, y todas las comunidades ya eligieron su comisario, entonces se convoca una reunión en la oficina y entre puros comisarios se proponen los seis que estarán en la coordinadora. Después se discuten y ratifican en la Asamblea Regional”116.

Es decir que cubrían dos cargos a la vez, de autoridad regional y comunitaria, ambos de la duración de un año. En los últimos años esto se volvió fuente de conflictos y quejas por parte de los mismos comisarios, que lamentaban la sobrecarga de responsabilidad y el estarse

\footnotetext{
${ }_{113}^{113}$ Acta de acuerdo, 7 noviembre 1997, Tuxtepec, Malinaltepec.

114 Entrevista a don Juan.

${ }^{115}$ En una asamblea realizada en febrero 1998, en la comunidad de Potrerillo Coapinole, San Luís Acatlán.
} 
desplazando constantemente entre su comunidad, la oficina de la CRAC en San Luís y los parajes donde son requeridos en su desempeño como autoridades regionales.

Frecuentemente, los que son designados como Coordinadores Regionales no tienen una idea precisa del trabajo a desempeñar, ni de cómo hacerlo. La organización les proporciona cursos eventuales de capacitación en materia legal, mientras el cuerpo de Consejeros se encarga de orientarlos en la tarea de impartición de justicia. Dichos Consejeros son todos los que han cumplido algún cargo regional en la organización, sea de Comandante Regional o Coordinador, y por esto tienen la función de compartir su experiencia y en base a ella orientar a los nuevos Comisarios. Últimamente, parece que los Asesores se han estado desentendiendo de su obligación, objetando que ellos ya sirvieron en el cargo y no pueden seguir dedicando tanto tiempo a la organización, lo que ha causado dificultades a los Comisaros nuevos y algunas deficiencias en la impartición de justicia.

Finalmente, el Comité de la Figura Jurídica, constituido como Asociación Civil (Coordinadora Regional de Autoridades Indígenas de la Costa Montaña A.C.), tiene la representación legal para la gestión de recursos ante instancias públicas y privadas, y promueve la formación y capacitación de los ciudadanos llamados a cumplir algún cargo en el sistema comunitario. Está integrado por tres personas y su duración es de tres años.

\section{ESTRUCTURA del SSJC 1998/2007}

\begin{tabular}{|c|c|c|}
\hline & COMUNIDAD & REGIÓN \\
\hline $\begin{array}{l}\text { TOMA DE DECISIONES/ } \\
\text { DISCUSIÓN POLÍTICA }\end{array}$ & Asamblea general comunitaria & Asamblea Regional \\
\hline $\begin{array}{l}\text { SEGURIDAD /INVESTIGACIONES } \\
\text { CONTROL DEL TERRITORIO }\end{array}$ & $\begin{array}{l}\text { 1995: grupos de Policías } \\
\text { Comunitarios (organizados a nivel } \\
\text { regional) }\end{array}$ & $\begin{array}{l}1997 \text { Comité Ejecutivo } \\
\text { (Comandantes Regionales) }\end{array}$ \\
\hline $\begin{array}{l}\text { IMPARTICIÓN Y ADMINISTRACIÓN } \\
\text { DE JUSTICIA } \\
\text { CONTROL SOCIAL } \\
\text { REPRESENTACIÓN POLÍTICA, } \\
\text { GESTIÓN Y ORGANIZACIÓN } \\
\text { (relaciones con los tres niveles de } \\
\text { las instancias de gobierno) }\end{array}$ & Comisario Municipal & $\begin{array}{l}1998 \text { Coordinadora Regional de } \\
\text { Autoridades Comunitarias } \\
\text { (CRAC) }\end{array}$ \\
\hline
\end{tabular}

${ }^{116}$ Entrevista a don Luís, tlapaneco, maestro, comisario de la CRAC en 2000, comunidad del Aserradero, lliatenco, julio 2006. 


\section{EI Reglamento Interno: la construcción del derecho comunitario}

Paralelamente al nombramiento de las Autoridades Regionales, en 1998 empezó el proceso de reflexión y elaboración del Reglamento Interno, para dar un sustento a la actuación de las autoridades, tanto las comunitarias como las regionales, y regular el proceso de reeducación ${ }^{117}$ En 1998 se formuló un primer borrador, que no reflejaba un trabajo muy profundo, limitándose a sistematizar prácticas que se estaban dando desde antes y acuerdos tomados en las precedentes Asambleas Regionales (donde se analizaban los casos más espinosos afrontados por los comisarios y se discutían formas y modos del proceso de reeducación, que se fue plasmando a través de estas periódicas discusiones, con los aportes de todos los presentes en las Asambleas).

De acuerdo a la necesidad de tener un instrumento más completo, en el 2002 se nombraron dos "Delegados del Reglamento" por cada comunidad. La tarea de éstos fue realizar repetidas asambleas generales en sus comunidades,

en las que, con el precioso aporte de los principales, las personas más ancianas o más reconocidas, y de los maestros, se discutió sobre los diferentes delitos que se cometían en las comunidades, los más comunes. Con ellos fuimos revisando parte por parte del reglamento que ya existía y le íbamos preguntando a toda la gente también qué opinaba, si estaba bien o mal; si estaba bien porqué, y si podían agregarle algo. Y si está mal, porque está mal, y como le modificamos. Algunas cosas entonces se fueron mejorando, otras añadiendo.

Cada 15 días teníamos reuniones en San Luís; los viernes y los sábados, con todos los delegados y los comisarios de la Coordinadora. Llegábamos a informar al licenciado que nos asesoraba [los asesores externos en este proceso eran tres: un representante del CDH Tlachinollan y dos abogados, relacionados con la $\mathrm{CDI}]^{118}$.

En el texto redactado por los "asesores externos", se consideraron las propuestas de cada comunidad. Con el aporte de éstos se integraron las prácticas jurídicas reconocidas por los pueblos en una estructura que refleja el derecho positivo (Código Civil y Penal), en la medida en que este es aplicado por los comisarios en las comunidades.

El Reglamento Interno proporciona un conjunto de normas generales tanto en la estructura de la organización y funciones de cada parte de ésta, cuanto en la impartición de justicia y la reeducación. Comprende los principales delitos juzgados por la Coordinadora y la duración de la reeducación respectiva, aunque no detalla casos específicos ni procedimientos,

\footnotetext{
117 "Esto es el machete con que los comisarios van a trabajar", definió dicho reglamento don Gerardo, que fue entre los delegados elegidos para sistematizarlo en 2002.

${ }_{118}$ Entrevista a don Gerardo, mestizo, campesino, Coordinador en la CRAC 2004, comunidad del Carmen, julio 2006.
} 
dejando amplio espacio al criterio de los Coordinadores y a la experiencia práctica adquirida por éstos y los Comandantes Regionales en la impartición de justicia y la averiguación.

Contraponiéndome a lo sostenido por las autoridades ministeriales y judiciales, afirmo que lo que es ha acuñado en el Reglamento Interno y se sigue forjando en la práctica cotidiana de la CRAC es un sistema jurídico, cuya característica de ser en constante evolución para poder responder a nuevos problemas no le quita su juridicidad. El sistema de valores comunitarios, que está a la base del Reglamento y que en ello ha sido formalizado como norma jurídica, queda establecido y representa el fundamento de los nuevos procedimientos que se van integrando.

Según Magdalena Gómez las características de un sistema jurídico indígena son: la existencia de órganos generalmente pluripersonales en cada pueblo, con facultades expresas y reconocidas por el propio pueblo; contar con reglas de conducta de cumplimiento obligatorio que han sufrido variaciones y adaptaciones, pero que son asumidas con cierto grado de consenso por los pueblos; contar con un sistema de sanciones que en general mantiene el objetivo de reconducir y reintegrar a la colectividad el individuo trasgresor de las normas comunitarias; aplicar normas cuya flexibilidad depende mucho de su naturaleza oral, que contienen principios generales sobre los que se resuelven conflictos concretos (Gómez 2002: 258). Aunque no definiré el sistema jurídico creado por el SSJC como propiamente indígena (retomaré esta discusión más adelante), considero útil la presente descripción para definir el que nos ocupa como un sistema jurídico, ya que coincide con ésta en términos generales, debido a la raíz indígena del sistema jurídico en cuestión. Una consideración aparte merecerá el carácter oral de las normas, ya que el Reglamento Interno está proponiendo un proceso de codificación que, aunque sin contradecirla, va más allá de esta característica.

\section{El sistema normativo utilizado por el SSJC: la justicia según la Coordinadora Regional de Autoridades Comunitarias}

Uno de los elementos a destacar es, como reconocen los Coordinadores Regionales, que la justicia que ellos administran no se limita a delitos menores, como otras experiencias de normatividad indígena, sino que abarca hasta los delitos de homicidio y violación, para los cuales es previsto como castigo un período mucho más largo de reeducación. El alcance que las autoridades comunitarias se han atribuido en la impartición de justicia es, en consecuencia, muy amplio, rebasando los límites de autonomía permitidos por el sistema 
institucional. Este es uno de los puntos alrededor de los cuales se dan los conflictos más ásperos con las instancias judiciales estatales, como comentaré más adelante.

Dado que nació y toma su fuerza de la Asamblea, la Coordinadora Regional se articula con ella de manera horizontal. Sus principios son: investigar antes que procesar, conciliar antes que dictar sentencia, reeducar antes que castigar, no hacer distinción de edad, sexo, color, religión o grupo social, impartir una justicia pronta y expedita (30 días máximo para sentenciar).

En general, una persona puede caer presa cuando la Policía Comunitaria o la autoridad comunitaria la encuentra en flagrancia de reato. En otros casos son terceras personas que llegan directamente a la Coordinadora a poner demanda, o denuncian ante la autoridad comunitaria que en casos de delitos graves decide turnarlos a la Coordinadora. En estos casos, la Coordinadora, actuando como segunda instancia, puede ordenar la aprehensión inmediata por parte de los Policías Comunitarios o previamente citar al inculpado y proceder a la investigación. En el primer caso, el preso permanece en la pequeña cárcel ubicada detrás de la oficina de la CRAC en San Luís Acatlán el tiempo necesario para que los Comandantes Regionales y los Coordinadores lleven a cabo las investigaciones que consideren oportunas, lo que puede llevar a veces semanas o hasta un mes.

Según las normas de la CRAC, el acusado no tiene derecho a un abogado, menos si trabaja gratuitamente, para asegurar que todos sean iguales delante de la justicia, no importando si tienen dinero o no. Puede estar defendido por su familia, o hacer él mismo su defensa.

Finalmente, procedimientos y prácticas son muy variados y dependen de los casos específicos, por lo que una sistematización se haría inoportuna en este contexto.

Eje central del Sistema de Seguridad, Justicia y Reeducación Comunitaria es el proceso de reeducación al cual son sometidos quienes son declarados culpables por la Coordinadora Regional, que consiste en cumplir con trabajo social a favor de la comunidad donde se encuentren. De acuerdo a la duración de la reeducación impuesta, los presos cumplen con 15 días de trabajo en una comunidad y después son trasladados a otra; esto hasta cumplir el tiempo señalado. En las comunidades son vigilados por los policías comunitarios, alimentados por la comunidad, mientras la población en general, y los principales en particular, se encargan de la reeducación, o sea de platicar con ellos para hacerlos reflexionar sobre su conducta. De acuerdo con esto, el proceso apunta hacia la reintegración de los individuos en la sociedad, donde los habitantes de las comunidades aprenden a aceptar quienes fallaron, y la presencia pública de los presos funciona como ejemplo para 
invitar a los demás a no cometer los mismos errores, y a fortalecer en la gente la conciencia que hay autoridad competente y justicia efectiva. Por lo tanto, es un disuasorio al ejercicio de la "justicia por propia mano".

Intentaré aquí una valoración del sistema jurídico utilizado por la CRAC, desarrollando el análisis con respecto a tres puntos:

-La articulación en dicho sistema jurídico entre formas de resolución de conflictos relacionadas con las culturas indígenas (lo que viene a veces definido como "derecho indígena") y las que se originan en el derecho "positivo"; los elementos que representan la continuidad con prácticas arraigadas y los que son respuestas inovativas a nuevos problemas.

-La eficacia de tal sistema jurídico para resolver los conflictos internos que enfrentan actualmente los miembros del contexto social analizado y los originados por actores externos.

- La legitimidad del sistema normativo autónomo, o sea en qué medida el sistema normativo es percibido como propio por la población, generando mecanismos de autoadscripción (por ejemplo, cuando una persona reconoce la autoridad comunitaria o autónoma y a ella recurre para la resolución de problemas, negando legitimidad a la instancia "oficial", lo que da fuerza al proyecto autonómico).

\section{Una institución comunitaria: persistencia e innovación}

El proceso a analizar no propone un discurso esencialista o "purista", ya que en la región no existe un verdadero sistema de derecho "tradicional" integral como sí se puede apreciar en otros pueblos, debido también a que se trata de una región "multiétnica", donde viven pueblos mixtecos, tlapanecos, nahuas y mestizos. Se retoman elementos del derecho positivo, "readaptados" según el uso que de ellos hacen las autoridades en las comunidades, juntos a otros elementos propios de las culturas indígenas presentes en la zona.

Las mismas autoridades de la CRAC ponen mucho énfasis en que el Reglamento para administrar la justicia es fruto de un proceso relacional entre los diversos actores presentes en la región, y que resulta de la elección de algunos elementos normativos sobre otros: es decir, no es la adopción integral de un supuesto sistema "tradicional". El sistema jurídico adoptado por la CRAC se basa en la organización social de los pueblos que viven en la región, fortaleciendo las competencias de las instancias comunitarias (asambleas, Comisarios, principales). Base de tal organización social es el ámbito colectivo para la toma 
de decisiones (la asamblea comunitaria), así como el principio de reciprocidad y ayuda mutua, principalmente por las labores agrícolas pero que se extiende a otros ámbitos de la vida social (principio que en la zona se conoce como el "cambio de brazo").

En algunas comunidades de la zona se utilizaba el trabajo comunitario (por tiempos breves) como pena para pequeños delitos que eran juzgados por el comisario; en las comunidades mixtecas todavía existe la práctica de exhibir públicamente a quienes ha cometido un delito, haciéndoles cargar, si es culpable de robo, el objeto robado, y acompañado por la banda obligarlo a recorrer toda la comunidad para que sirva de ejemplo; se trata de una práctica donde la pena para el culpable es, precisamente, la pena, la vergüenza.

La particularidad del sistema normativo que se aplica son los criterios para la resolución de conflictos: la constante práctica de la negociación y la búsqueda de la conciliación entre las partes, realizada a través de repetidos "careos"; la gratuidad de la justicia, donde no hay gastos para abogados ni para procesos, no hay fianzas ni multas, y los culpables pagan su pena con trabajo a favor de la sociedad ("la gratuidad de la justicia respeta nuestra cultura, y la condición de pobreza de nuestros pueblos"119), además de la reintegración a la sociedad de los delincuentes como objetivo del castigo. Otro elemento muy importante es la colectividad de la justicia, donde la asamblea de la comunidad o la Asamblea General tiene un papel fundamental en discutir las penas y el seguimiento en el proceso de reeducación.

Al interior de las comunidades, para los asuntos menores, es el Comisario Municipal quien se encarga de la resolución del conflicto, recibiendo la queja o denuncia, citando a las partes una y otra vez para que por medio del careo lleguen a la conciliación o a un acuerdo. Cuando esto no se logre, interviene con su autoridad e impone una sanción. Pero la autoridad que el comisario representa es más bien colectiva, ya que proviene de la asamblea que se la ha conferido y a la cual finalmente tiene que rendir cuenta. Así que, por lo menos en línea de tendencia (claro que hay muchos casos en que la persona llega a ejercer el poder de forma arbitraria e individual), en casos controvertidos el Comisario consulta a los principales o consejeros; y los conflictos de solución aún más difícil son llevados a la discusión en la asamblea de toda la comunidad, con la presencia de las partes en conflicto, para que expongan a la colectividad el problema y la resolución derive del acuerdo colectivo.

De forma análoga funciona el Sistema a nivel regional: los casos de mayor trascendencia para la vida colectiva, o de difícil solución, son discutidos en la Asamblea Regional, con la

${ }^{119}$ Entrevista a don Luís. 
presencia de los Consejeros de la organización y de vecinos y Comisarios de las varias comunidades. Asimismo, es práctica frecuente que para conflictos llevados a la CRAC y que involucran toda una comunidad, las autoridades regionales convoquen a la asamblea de la comunidad y participen en ella, para facilitar la solución del conflicto con un acuerdo interno de la comunidad. Un ejemplo de esta dinámica que pude presenciar, fue en la comunidad mestiza de Capulín Chocolate, municipio de San Luís Acatlán, en noviembre del 2006. Cuarenta y tres vecinos se presentaron a la Comisaría para firmar una denuncia contra un joven de la comunidad, acusándolo de repetidos asaltos contra personas externas y que allí se encontraban de paso. Por tratarse de delitos de gravedad, el Comisario Municipal turnó la denuncia a la CRAC, la cual detuvo el acusado alrededor de un mes mientras el Comité Ejecutivo desarrollaba las investigaciones. Debido a faltas de pruebas (los agraviados ya no se encontraban en la zona y no pudieron testimoniar) la CRAC no pudo emitir su fallo, pero tampoco consideró oportuno declarar inocente el acusado; por lo que decidió llevar la resolución del caso a la asamblea comunitaria. Las autoridades regionales dirigieron la discusión llamando los vecinos a participar; intervinieron el acusado mismo y sus familiares. La discusión entre estos y los vecinos se desarrolló en términos amigables y resaltó la voluntad de la misma comunidad de no castigar el joven, sino de llevarlo a comprender su error; finalmente se decidió que el joven no se fuera a reeducar y que la comunidad entera vigilara su conducta.

De este ejemplo podemos deducir el concepto de justicia que caracteriza el sistema comunitario. EI SSJC plantea que el delincuente no es la persona a 'eliminar' para que la comunidad pueda 'vivir en paz'. Cuando se comete un delito, todos son víctimas, no sólo el agraviado, sino también el delincuente (porque perdió lo más importante en la cosmovisión indígena: su honor, su palabra, lo que le hace hombre), así como la comunidad (porque 'no se dio cuenta que esta persona andaba en un mal camino' y 'no logró ponerlo otra vez en la buena dirección'). En esta visión, la justicia y la seguridad son responsabilidad de todos y se debe buscar maneras de restaurar la relación dañada, de restablecer el tejido social.

En las entrevistas realizadas, las autoridades de procuración e impartición de justicia estatales estigmatizan, entre otros elementos, el hecho de que los periodos de reeducación impuestos por la CRAC, frecuentemente son más breves que las sanciones atribuidas por el sistema penal por los mismos delitos, en particular por los delitos graves. Pero cabe aquí considerar el objetivo que tienen las dos instituciones: la formal en los hechos se limita a castigar; $y$, frecuentemente, las personas que salen de las dependencias penitenciarias se 
encuentran completamente desamparadas, rotos sus lazos sociales, estigmatizadas socialmente por la experiencia carcelaria vivida, con grandes dificultades para reiniciar su vida, ya que en general se carece de instituciones de reinserción social de los ex detenidos. Estos elementos, así como la vida al interior de la cárcel que no vehicula valores positivos sino la violencia y la mentira, son las causas de reincidencia ${ }^{120}$. Al contrario, el objetivo de la justicia comunitaria es sí castigar, pero para reinsertar el individuo en la sociedad; de allí que no se enfatice el aspecto del "castigo" sino el de la "reeducación".

Esto tiene que ver con una idea de que la sociedad que no es compuesta por individuos aislados, sino por redes sociales y colectividades; por esto la pena puede ser más corta pero el individuo se compromete a regresar a sus deberes familiares y comunitarios, reinsertándose en un contexto donde la comunidad toda seguirá vigilando su conducta. Así, el control (entendido en términos foucaultianos) no se limita a las instituciones represivas o carcelarias, sino es continuamente ejercido por toda la sociedad sobre los individuos que la conforman; de la misma manera en que dichas redes sociales sirven a que los individuos puedan hacer frente y superar sus problemas personales con la ayuda de los otros integrantes de la comunidad (reciprocidad).

\section{¿Justicia comunitaria o usos y costumbres? La identidad indígena y el SSJC}

Los criterios para la resolución de conflictos antes mencionados han sido definidos en varias entrevistas como los "usos y costumbres" que caracterizan las formas de toma de decisión y de resolución de conflictos al interior de las comunidades.

Este término es usado por los entrevistados frecuentemente pero en términos muy vagos, lo que demuestra que no haya una reflexión en términos "identitarios" sobre las prácticas de justicia, sino que el énfasis se pone en reivindicar la legitimidad de dichas prácticas a partir de su efectividad.

Usos y costumbres quiere decir que se busca el acuerdo entre el maleante y el agraviado: ellos deciden el monto de la reparación, económica antes de la comunitaria, y ahora también en días de trabajo. Las personas en el pueblo se van a platicar con el comisario, que la hace de mediador. Usos y costumbres también son nuestras formas de subir a los cerros para pedir agua, de rezar a la milpa: lo que es nuestra cultura $^{121}$.

${ }^{120}$ Estas afirmaciones derivan de la experiencia vivida directamente durante un año como voluntaria en el "comité editorial" de la revista Ristretti Orizzonti, escrita por detenidos de la cárcel "Due Palazzi" de la ciudad de Padova, Italia. El trabajo de reflexión, investigación y analisis sobre la experiencia carcelaria emprendido con los detenidos que trabajan para la revista sustenta la opinión propuesta sobre la institución carcelaria.

${ }^{121}$ Entrevista a don Francisco. 
También resaltan que es una justicia más cercana a los pueblos (indígenas), funcionando de acuerdo a sus prácticas sociales y a su cultura. Ejemplo de esto es el carácter de delito grave conferido por las autoridades comunitarias al consumo de enervantes, que crea conflictos y rupturas al interior de las comunidades, aunque para el sistema jurídico estatal el poseedor de pequeñas cantidades de estupefacientes no siempre es sancionado. Otro ejemplo son algunos "delitos ambientales", como la tala ilegal de árboles o la contaminación de los ríos, que también son sancionados como delitos graves. Finalmente, está la práctica de la brujería, bastante común en las comunidades mixtecas, que en más de una ocasión las Autoridades Regionales han enfrentado y sancionado.

Es una justicia particular, que responde a nuestra cultura indígena, porque hay delitos que la gente considera tales, pero que por las leyes oficiales no lo son. Por ejemplo la hechicería, que aquí los tlapanecos no practicamos mucho, y los nahuas tampoco, pero lo mixtecos si $^{122}$.

La "raíz indígena" y la conciencia de esta, es decir el conjunto de culturas y prácticas que orientan e imprimen una dirección y un sentido particular al actuar Público y privado de los pueblos, está presente con profundo arraigo en todos los aspectos sociales y políticos de la región. Los habitantes de las comunidades, ancianos y jóvenes, perciben y expresan con claridad su identidad tlapaneca o mixteca, reclamando la legitimidad de los saberes, las expresiones rituales y artísticas y las prácticas políticas que la pertenencia a tal cultura trae consigo.

Como mencioné, el sistema normativo elaborado para la aplicación a nivel regional se construye sobre una idea del Derecho, de la función de la justicia, y de las prácticas para su administración, que retoma e integra los valores, las normas y las prácticas vigentes en la sociedad indígena de la región.

Todos los integrantes activos del SSJC entrevistados (Policías y Comandantes Comunitarios; Coordinadores y Comandantes Regionales) mencionan, entre los elementos más importantes que confieren eficacia y legitimidad a la institución, su correspondencia a la cosmovisión y a la realidad social, política y normativa de los pueblos que conforman tal Sistema.

Lo mismo expresan quienes acuden a la Coordinadora Regional para la resolución de conflictos que los involucran, destacando que la que allí se imparte es una justicia que entienden y que sirve al interior del contexto social donde viven, mientras la "justicia oficial" aparece incomprensible, impositiva y corrupta.

${ }^{122}$ Entrevista a don Luís. 
En el funcionamiento interno del Sistema se confiere bastante importancia a la identidad étnica, tlapaneca o mixteca: se cuida que entre los Coordinadores Regionales haya igual representación de los dos pueblos, seguramente para evitar que unos puedan hegemonizar dentro de la organización, pero también para asegurar el igual acceso a la justicia de quienes hablan uno u otro idioma.

No obstante que esta conciencia identitaria indígena aparezca como una profunda raíz en los habitantes de la Costa- Montaña, emergiendo en todas las conversaciones que implicaron una reflexión y valoración sobre el SSJC sostenidas en las estancias de investigación, no se observa un uso político de la identidad, ni en términos "primordialistas o esencialistas", ni en términos "estratégicos" (Assies 1999:25). Se menciona -tanto en el Reglamento como en los documentos difundidos por la CRAC- la raíz indígena como un elemento básico de la justicia comunitaria y el mismo sistema de seguridad, pero no se hace mucho énfasis en ella para reivindicar la legitimidad del Sistema frente a los aparatos politicos y a la administración de justicia del Estado. Más bien se subraya que es un proceso que viene desde la necesidad de la población y por esta, "desde abajo", ha sido construido. Se hace residir la legitimidad de la institución en su ser "de los pueblos, para los pueblos y por los pueblos". Tal reflexión tiene qué ver con la interculturalidad de la organización misma ${ }^{123}$, pero también con el proceso que llevó a la formación de la organización, a la institución de un órgano para la procuración e impartición de justicia, y a la sistematización de un sistema jurídico propio. Esta "recuperación" y valoración de prácticas y valores relacionados al campo de la justicia, no ha acontecido como parte de un proceso "político" en el cual los pueblos indígenas de la Montaña reivindicaran sus derechos sobre la base de la reivindicación de una cultura propia. Fue una situación "contingente" (aunque la seguridad y el abuso policiaco se había vuelto más bien estructural en la región) la que movió los pueblos a la organización, sin tener mayor importancia su identidad; de la misma forma, fue la reiterada ineficacia e ineficiencia del sistema estatal de administración de justicia lo que los animó a crear un sistema alternativo. Y los pueblos buscaron los elementos para crear tal sistema en lo que conocen y les pertenece, su forma de vivir y gobernarse de acuerdo a su propia cultura.

${ }^{123}$ Al momento de su formación el órgano para la impartición y administración de justicia había sido denominado "Coordinadora Regional de Autoridades Indígenas", caracterización que luego fue sustituida por "Comunitarias" con la voluntad de que fueran igualmente representados los pueblos mestizos que participan en el sistema. 
Si preguntamos a las autoridades comunitarias y regionales, o a las personas que destacan en la estructura social (por ejemplo los maestros), como caracterizarían la justicia que imparte la CRAC, obtenemos respuestas heterogéneas y encontradas, pues no se maneja un discurso público homogéneo. Hay quiénes se refieren a una justicia que refleja "los usos y costumbres" o la "tradición de nuestros ancestros", pero en el sentido que éstas son prácticas y valores que han regido, y rigen todavía, la vida comunitaria, particularmente en las comunidades indígenas, y son percibidos como distintivos con respecto a la sociedad "de la ciudad", y a la "justicia" que allí se práctica. Otros hablan de "justicia comunitaria", un concepto que deriva específicamente de la práctica de la organización, y que se ajusta más a la interculturalidad presente en ésta; los entrevistados justifican el término considerando la importancia del ámbito colectivo para la resolución de los conflictos, y el hecho que el sistema jurídico que la CRAC aplica a nivel regional descansa y valora precisamente las estructuras comunitarias, armazón de la organización social de la región.

De los elementos que actualmente caracterizan el Sistema de Seguridad y Justicia Comunitaria y que son propios de la organización de las comunidades, podemos destacar la figura de los Policías Municipales o Suburbanos, un cargo que siempre ha estado presente en las comunidades indígenas de la zona.

La Policía Municipal nada más son mandaderos del comisario, van a traer la gente, a avisar cuándo hay una asamblea urgente; ellos se turnan cada mes, en la asamblea se nombran varios y después se turnan. Ese cargo en la comunidad siempre hubo desde que yo era niño ${ }^{124}$.

La Policía Municipal resguarda al interior de la comunidad, pero no los caminos, ya que los federales transitan mucho por aquí y les pueden crear problemas. Tampoco se podía hacer alianzas entre los policías municipales de varias comunidades ${ }^{125}$.

La Policía Comunitaria retoma la figura del Policía Municipal, ampliando sus competencias e insertándola en una organización a nivel más amplio.

La organización regional valoriza también las funciones de los Comisarios Municipales, apropiándose de esta figura de autoridad "institucionalizada" e insertándola en el sistema autónomo. El art. 94 de la Constitución Política del Estado de Guerrero prevé que en las localidades más importantes de cada municipio habrá "comisarios municipales de elección popular directa"; la Ley Orgánica del Municipio Libre y Soberano del Estado de Guerrero establece para los comisarios (electos por planilla y sin la intervención de los partidos politicos), entre otras funciones, las de cuidar el orden público de acuerdo al bando de

\footnotetext{
${ }^{124}$ Entrevista a don Francisco.
} 
policía y buen gobierno; actuar como auxiliar del Ministerio Público del Fuero Común; y aprehender los delincuentes en caso de flagrante delito y remitirlos a las autoridades competentes.

Entonces, los Comisarios siempre han resuelto los casos menores al interior de la comunidad, y siguen haciéndolo; anteriormente por lo regular resolvían los conflictos cobrando multas a favor de la comisaría, práctica que ahora ya no se utiliza.

En caso de delitos mayores, anteriormente los Comisarios de las comunidades remitían el asunto al Ministerio Público, mientras ahora lo turnan a la CRAC. En el Reglamento Interno se establecen las faltas que han de ser resueltas en las comunidades, para que los Coordinadores Regionales no tengan una sobrecarga de trabajo. No siempre esto funciona, ya que algunos casos, aunque leves, son de difícil solución, o la autoridad comunitaria no se encuentra en condición de imparcialidad (por estar emparentada con alguna de las partes en conflicto), o más aún por no querer el Comisario pronunciar un juicio que lo pondría en riesgo de venganzas.

El acuñado en el Reglamento Interno y en la práctica cotidiana de la Coordinadora Regional es un sistema jurídico extremadamente "híbrido", ya que junta elementos provenientes de las culturas de los pueblos indígenas que habitan la región, tlapanecos y mixtecos, en varios aspectos disímiles entre sí; retoma elementos del sistema político y jurídico estatal, sin percibirlos como muy ajenos, ya que varios cargos y normas comunitarias reflejan la organización estatal, pero su particularidad reside en cómo son apropiadas y resignificadas en el contexto indígena/campesino. Así, en la percepción de la gente, lo que hace "propio" este sistema normativo es la diferencia con el sistema jurídico y judicial "impuesto" por el Estado, que considera inapropiado para las necesidades culturales, ineficiente y corrupto.

Más aún, lo que caracteriza el sistema jurídico aplicado por la CRAC es que, además de retomar prácticas de resolución de conflictos utilizadas en la zona y de diverso origen, las adapta al contexto renovado y las enriquece con nuevos elementos: se está creando un sistema jurídico original e innovativo de acuerdo al proceso organizativo de los pueblos.

${ }^{125}$ Entrevista a don Mario, campesino, mestizo, Comandante Regional en 1998, comunidad de Horcasitas, San Luís Acatlán, julio 2006. 


\section{EI SSJC: una organización regional y plural}

Es novedosa y de gran interés la organización a nivel regional, que se refleja: a) en un ámbito regional de discusión y toma de decisiones (Asamblea Regional); b) en un cuerpo de autoridades con funciones jurídicas y políticas, ya que mantienen las relaciones con las instancias de gobierno en sus tres niveles (Coordinadora Regional de Autoridades Comunitarias); c) en una organización capilar en todas las comunidades (Policías Comunitarios) y con representación regional para el control del territorio y de la población que en éste vive (Comité Ejecutivo). Tal organización regional toma fuerza de lo que es el nivel inferior de organización político/social en la zona, o sea las comunidades, que cuentan también con un ámbito colectivo de toma de decisiones (Asamblea), autoridades facultadas para la impartición de justicia a nivel local (Comisarios), y policías para el resguardo de la comunidad (Policías Municipales) y su entorno.

Otro elemento sin duda alguna "nuevo" es la reeducación aplicada como medida de castigo y reinserción social de manera uniforme a nivel regional, que involucra todas las comunidades en el mismo proceso de organización. El Reglamento Interno, que codifica el sistema jurídico creado por la organización, es normativo para todas las comunidades integradas al Sistema, independientemente de su caracterización étnica. Así, donde había diferentes "usos y costumbres" se está creando un campo jurídico compartido, con normas aplicadas uniformemente, lo que hace más fuerte el Sistema al momento de defender su legitimidad y su autonomía frente al Estado.

Puedo afirmar que, mediante la creación del Sistema de Seguridad y Justicia Comunitaria, que implica organización intercomunitaria, control del territorio, conformación de un sistema jurídico y defensa de la estructura, se ha venido creando una identidad regional, ligada al sentido de pertenencia a la organización. Se trata de una identidad política y étnicamente plural, tal cual es la organización: integrada por diferentes culturas, diversa en su composición política. EI SSJC ha defendido su autonomía no alineándose con ningún partido, posición más valiosa si se considera que sus integrantes sí militan o son afiliados a diferentes partidos, y la estrecha relación con los ayuntamientos también implica la relación con los partidos.

En un espacio social como la Montaña y Costa Chica, fragmentado por la violencia criminal, por la represión y el control militar, por los conflictos intercomunitarios, por las divisiones políticas partidarias, el proceso autonómico reconstruye vínculos sociales y crea de nueva 
cuenta un tejido regional, a través de un proyecto que impulsa la seguridad y la justicia desde el punto de vista de los pueblos.

Un aspecto que necesitaría una investigación detallada es la participación de las mujeres ${ }^{126}$ tanto en la organización cuanto en la vida comunitaria en la región. En el contexto regional, la participación política de las mujeres es mínima, ya que en la mayoría de las comunidades visitadas no participan en la asamblea comunitaria, y donde lo hacen por lo regular no tienen derecho de palabra. Ha habido procesos organizativos de las mujeres, en particular ligados o impulsados por las organizaciones productivas, como los grupos de mujeres promovidos por la UNORCA y la URC a partir de 1996 o la organización campesina femenina Lucero de la Montaña; actualmente en las comunidades los espacios colectivos femeninos siguen ligados a los proyectos productivos. Por lo tanto, puedo afirmar que sí hay mujeres con formación política y experiencia organizativa, pero la organización de la Policía Comunitaria no ha sabido o no ha querido aprovechar en mayor medida de estas personas, algunas de las cuales por su voluntad y con gran esfuerzo, no siempre exitoso, han tratado de integrarse en la Comunitaria. Asimismo, la organización no ha aprovechado de los espacios organizativos femeninos preexistentes, quedándose como una institución paralela sin poder integrarlos a su interior.

Al interior del SSJC, se integró en 1998 la Comisión de Mujeres, con el fin de dar seguimiento a un caso de infanticidio. Se reclutaron para esta comisión personas que participaban en las organizaciones campesinas de la región, y se les dio las funciones de interrogar a las mujeres que eran acusadas de algún delito, y asesorar a la CRAC (integrada por puros hombres) en la resolución de los casos que implicaban mujeres. Pero esto no significó un mayor empoderamiento de las mujeres al interior de la organización, ya que los Coordinadores siguieron siendo hombres y, según el testimonio de unas mujeres que han participado en la organización, imparten justicia dando preferencia a las opiniones masculinas, por ejemplo en casos de conflictos intrafamiliares, esto es, con un sesgo machista que refleja la cultura arraigada en la región.

No obstante estas dificultades estructurales, el debate interno ha seguido empujando hacia una mayor participación femenina, y en 2005 , durante el foro realizado en ocasión del

${ }^{126}$ En los últimos años, varias investigaciones realizadas en México (Sierra, Hernández, Chenaut), han centrado su atención en la relación entre el genero y el campo jurídico-normativo en las sociedades indígenas, subrayando cómo estas sociedades y el campo jurídico en su interior son sujetos a continuas transformaciones bajo presiones o conflictos tanto externos como internos. En este contexto las mujeres están cuestionando desde el interior de sus propias culturas algunas prácticas "tradicionales" y replanteando su papel, en un proceso que reclama y construye nuevos ámbitos de derechos dentro de las sociedades indígenas. 
Décimo Aniversario de la Policía Comunitaria, se nombró la Comisión de Participación de la Mujer, integrada por dos personas que por el siguiente año coadyuvaron con el trabajo de los Coordinadores Regionales en la impartición de justicia, atendiendo las demandas junto con ellos, aunque no les fuera reconocido este papel. Al siguiente año, en ocasión del nombramiento de las nuevas autoridades y en el marco de una profunda reforma del SSJC, se logró que tres mujeres (de reconocido compromiso en la organización, ya que fueron entre las que integraron la primera Comisión en 1998) estuvieran nombradas como Coordinadoras Regionales, o sea como autoridades con el cargo de impartir y administrar justicia, a la par de los hombres nombrados para el mismo cargo.

Esto representa un gran avance en la inclusión de la visión de genero al interior de la justicia comunitaria, aunque necesariamente tenga que acompañarse con un empoderamiento de la mujer, y su concientización hacia la participación política activa, en toda la región, lo que pasa por un capilar trabajo de base que se vislumbra en las intenciones de la Comisión de Mujeres de la Policía Comunitaria pero que aún no ha sido realizado.

\section{El Reglamento interno: codificación y apropiación en proceso}

En el párrafo anterior he tratado de evidenciar los aspectos que hacen del SSJC una experiencia sumamente innovativa, tanto en términos organizativos como en lo que se refiere al sistema jurídico creado y puesto en práctica. En tal análisis, no puede faltar una mención al Reglamento Interno; propongo algunas consideraciones sobre su contenido y función.

Dicho Reglamento representa un esfuerzo interesante de sistematización de las funciones de las diferentes partes del SSJC, incluidas las que no nacen con el Sistema (asambleas comunitarias, Comisarios Municipales). También se trata de un primer intento de sistematizar, aún en términos generales, el sistema jurídico que el SSJC aplica: encontramos las acciones que constituyen delito, las penas correspondientes, las normas para la aplicación de la pena, los procedimientos para la resolución de conflictos con la conciliación.

Diversos autores han llamado la atención sobre los riesgos que implican los intentos de codificar el derecho indígena, sea por parte de las agencias del Estado a fin de asimilarlo a la normatividad positiva, o por los mismos pueblos indígenas en su intento por presentar sus sistemas jurídicos como un conjunto orgánico y digno de ser comparado con el derecho positivo, acción que frecuentemente presenta las tradiciones como la esencia inmutable del 
ser indígena. "Con la necesidad de normativizar y codificar en forma escrita los procedimientos y prácticas vivénciales que, con los años, han sido constantemente recreados, viene la tendencia de generalizar y homogeneizar la interpretación del deber ser" (Walsh 2002). Mientras subraya la procesualidad del orden jurídico ${ }^{127}$, Krotz considera como los estudiosos del derecho, en aras de la sistematización de los sistemas jurídicos indígenas, suelen caer en un etnocentrismo que deforma severamente lo estudiado. "La consecuencia es, en el nivel más fundamental del análisis, el fortalecimiento no probado de la suposición de que los estudiados ven, piensan y construyen prácticamente su mundo de acuerdo con exactamente la misma racionalidad que la sociedad del estudioso" (1995: 34950). Estas anotaciones son sin duda acertadas, aunque necesitan ser matizadas en su comparación con los procesos reales en los cuales los sistemas jurídicos indígenas se adaptan constantemente a circunstancias cambiantes, en sentidos muy diversos. Entonces nos encontramos frente a un intento de sistematización, pero no por parte de "estudiosos del derecho" ni de funcionarios del Estado, sino por los mismos pueblos. El procedimiento de consulta y discusión desde las bases, del cual es fruto el presente Reglamento, es una práctica para la toma de decisiones que está en la esencia de la vida comunitaria en toda la región. Este proceso de sistematización también responde a una tendencia de las autoridades indígenas a escribir [en papel] sus decisiones y a registrar y codificar sus normas, ya que esto otorgaría mayor legitimidad a los procedimientos y decisiones; esta tendencia se debe a la creciente influencia e interrelación de la ley del Estado con la ley indígena (Van Cott: 2003). Al respecto cabe mencionar que todos los asuntos atendidos por los Comisarios Municipales y por la CRAC son respaldados por documentos, citatorios y actas de acuerdo, recalcando en la forma el procedimiento utilizado por las instituciones.

La voluntad de sistematización del sistema jurídico autónomo tiene también la función de proteger las autoridades comunitarias de demandas legales. Para ellos, tener un reglamento escrito en base al cual las autoridades en toda la región actúan de la misma forma, serviría como respaldo frente a las acusaciones de actuar de forma arbitraria e ilegal. No obstante que dicho reglamento no tenga ningún reconocimiento legal, también ha sido redactado con la intención de sentar las bases de la legitimidad de la institución comunitaria, fundamentándolas en el derecho nacional e internacional (el Art. 2 apela a los derechos de los pueblos indígenas reconocidos el los artículos 2 y 39 de la Constitución mexicana, a los

\footnotetext{
${ }^{127}$ Véase capitulo 2.
} 
artículos 1-9 del Convenio 169 de la OIT, "y demás relativos y aplicables de las leyes nacionales e internacionales").

Mencionaba antes que, para algunos analistas, la codificación de las normas significa la cristalización de las prácticas, mientras uno de los elementos más positivos del derecho indígena sería su flexibilidad relacionada a su naturaleza oral. "Precisamente la falta de codificación y su naturaleza de principios generales ha permitido acumular una enorme experiencia y habilidad para aplicar y mantener las normas propias" (Gómez 2002:258).

El caso del Reglamento de la Policía Comunitaria desmiente en parte estas afirmaciones, ya que su característica peculiar es el estar en constante proceso de redefinición, para incluir respuestas a los problemas que con el pasar del tiempo van emergiendo. Un ejemplo interesante es lo que relativo a los "delitos ambientales", no sancionados antes por las autoridades de las comunidades "según usos y costumbres". Recientemente, han sido sancionadas personas por tala ilegal de árboles y contaminación del agua, y se están discutiendo los términos para incluir estos delitos en el Reglamento, así como para normar el uso de químicos en el campo y sancionar su uso excesivo, y lo mismo con respecto al cultivo de semillas transgénicas. Éstos representan problemas nuevos que las comunidades están enfrentando, y el esfuerzo para encontrar respuestas desde su interior desmiente cualquier tentativa de considerar sus sistemas normativos como inmutables. Después de su redacción, se han realizado periódicas reuniones de consejeros para la actualización del texto, de acuerdo a las problemáticas emergentes.

Hay que prestar particular atención a esta constante renovación del sistema normativo, y valorar cómo y en qué medida se transforma para incluir ámbitos de atención anteriormente no considerados; también habría que analizar cuales son los nuevos derechos que vienen incluidos (por los pronto puedo generalizar refiriéndome a los derechos humanos, en menor medida los derechos de la mujer, tal vez los derechos ambientales). Claro está que, en este proceso, el que no cambia es el sistema de valores que sustenta el sistema jurídico elaborado por la CRAC, constituido por las normas de convivencia que rigen en las comunidades de la región y que se inscriben en su patrimonio cultural y organizativo. 


\section{Eficacia}

Tanto los medios de comunicación ${ }^{128}$ como los encargados de la procuración de justicia en la región ${ }^{129}$ afirman que la delincuencia en la región donde opera la Policía Comunitaria ha bajado hasta el 95\% respecto al 1995 (año de su creación), y confirman que esto se debe a la actuación de la misma Comunitaria.

En 1994 yo era agente titular del Ministerio Público en San Luís Acatlán. Constantemente había denuncias de robo, abigeato, asalto, violación: cuatro delitos en su modalidad de graves. Cuando yo dejo esta ciudad en el 1995 era esto algo que no podía ir más allá ya; yo era impotente. La solución la trajo la propia Comunitaria. Por el '98 empezó a disminuir, hasta que hoy en San Luís, lliatenco y Malinaltepec ${ }^{130}$, casi no hay asaltos. Donde hay todavía es en Tlacoapa y Acatepec, que colindan con Ayutla, donde no está presente la Comunitaria ${ }^{131}$.

Lamentablemente, las autoridades ministeriales admiten no poder sustentar sus afirmaciones con datos estadísticos: "no hay estadística, pero también es cierto que ya no hay incidencia delictiva como antes, y te das cuentas porque andas con toda la libertad. Lo puedo asegurar de manera personal" ${ }^{132}$.

En la búsqueda de datos que pudieran comprobar la disminución del índice delictivo en los últimos 10 años para los municipios donde opera la Policía Comunitaria, me he encontrado con problemas de difícil solución. En primer lugar, la falta de información sistematizada en las instancias locales, cuales la Agencia del Ministerio Público y el Juzgado Mixto de Primera Instancia de San Luís Acatlán. La información proporcionada por el Tribunal Superior de Justicia del Estado, con respecto a los tres distritos judiciales que comprenden el territorio de acción de la Policía Comunitaria, es muy limitada, y además incluye municipios muy conflictivos (Ayutla de los Libres, y en general los de la Costa Chica), que no están integrados a la Policía Comunitaria. Informaciones detalladas por municipio, y referidas a las instancias ministeriales y judiciales, se encuentran en el Anuario Estadístico del INEGI; lamentablemente, este instituto ha empezado la sistematización en el ámbito de la "Seguridad y Orden Público" apenas en 2004, de modo que no se puede comparar la

\footnotetext{
${ }^{128}$ Rosa Rojas, La Jornada 29/09/2005; La Jornada 27/09/2005.

129 Agente del Ministerio Publico de San Luís Acatlán y Fiscal Especial para la Atención a los Pueblos Indígenas- Región Montaña de la Procuraduría General de la Republica, entrevistados respectivamente en julio del 2006 y marzo del 2007.

${ }^{130}$ Los tres municipios donde primero se formó la Policía Comunitaria y donde actualmente la organización es más fuerte.

131 Joaquín Juárez Solano, Fiscal Especial para la Atención a los Pueblos Indígenas- Región Montaña de la PGR, Tlapa, 20 marzo 2007.

132 Idem.
} 
situación actual (los últimos tres años muestran un índice estable) con la que se vivía antes de la formación de la Policía Comunitaria y en los primeros años de actividad.

Así, no me queda más que confiar en las afirmaciones de las autoridades, avaladas por los Presidentes Municipales de Malinaltepec e lliatenco. Los recorridos por las comunidades de la Montaña, que he realizado en el transporte público y muchas veces sola, me llevan a confirmar tal afirmación. Las mujeres, a veces muy jóvenes, viajan sin acompañantes y dicen no tener miedo. Los chóferes de las camionetas afirman sentirse mucho más seguros, y por esto realizan viajes en horarios impensables antes, ya muy entrada la tarde.

Al comparar el ambiente que se vive en los caminos de la Montaña con la imagen de Guerrero que proporcionan los medios de información, debo concluir que los pueblos que habitan el territorio están logrando cambiar sus condiciones de vida con sus mismas fuerzas y a través de su propia organización comunitaria.

\section{Legitimidad}

Entiendo la legitimidad del sistema jurídico autónomo como el reconocimiento que le viene conferido por a población que recurre a él para la resolución de problemas, decidiendo no acudir a la instancia "oficial" y negando así la legitimidad de las instituciones estatales, lo que da fuerza al proyecto autonómico a pesar de tratarse de una diferente y nueva legalidad. En el contexto analizado, la legitimidad implica también la medida en que el sistema jurídico es percibido como propio por la población, generando mecanismos de autoadscripción.

Durante la investigación, he podido entrevistar los habitantes de varias comunidades, tlapanecas y mestizas. Al expresar su opinión sobre la Policía Comunitaria y la CRAC, concordaron en considerar positivo su trabajo, y afirmaron que "es más fácil y efectivo obtener justicia para nosotros ahorita que hay la CRAC" ya que los procedimientos utilizados son más sencillos, expeditos y económicos que los del Ministerio Público. "Además podemos expresarnos en nuestra propia lengua, nos entendemos mejor porque las autoridades conocen cómo es la vida y los problemas en las comunidades". Entonces, la institución comunitaria facilita y ha mejorado el acceso a la justicia de los habitantes de la región, problema que afecta a todas las regiones indígenas del país.

Tal legitimidad se confirma al analizar las Actas de Acuerdo levantadas en cada comunidad integrada al Sistema durante la consulta realizada en marzo 2002 para evaluar la importancia de la Policía Comunitaria, a raíz del "ultimátum al desarme" expedido por el gobierno estatal. Con dicha consulta se ratificó el respaldo de las comunidades a la 
organización, contra la voluntad del gobierno de desaparecerla. Al interior de dicha consulta, la asamblea realizada en la comunidad de El Aserradero, el 12 marzo 2002, analizó las ventajas (y desventajas) que aportó la creación de la Policía Comunitaria en tres sectores de la vida comunitaria: social, de educación y de salud. En el primero, se destaca que anteriormente la población indígena era "pisoteada por los maleantes", que con los asaltos violaban diariamente sus derechos. En el sector de la educación, se recuerda cómo los alumnos padecían de inseguridad y asaltos al trasladarse para llegar a la escuela, lo que incrementaba el abandono escolar. En el sector de la salud se subraya que, a raíz de los frecuentes asaltos, hubo un sinnúmero de lesionados física y moralmente, violaciones con su consecuencia de abortos, embarazos no deseados, enfermedades sexuales, así como muchísimos problemas psicológicos.

Un elemento que vale la pena considerar es que el SSJC no solo tiene legitimidad para los habitantes de las comunidades: en entrevistas, vecinos y comerciantes de la cabecera municipal de San Luís Acatlán han valorado positivamente la existencia del Sistema, afirmando haber acudido a la CRAC para la resolución de algunos problemas, ya que según su valoración el Ministerio Público no los hubiera atendido, o hubiera actuado con demasiada lentitud, o su intervención hubiera comportado un gasto demasiado alto. Esto contradice las opiniones de las autoridades entrevistadas, que han llegado a reconocer cierta legitimidad a la Policía Comunitaria y a la justicia autónoma en las comunidades, pero oponiéndose tajantemente a que actúen en las ciudades: "para mi en lo personal la PC es excelente. Es una policía que ha sabido vigilar y guardar el respeto entre los hermanos

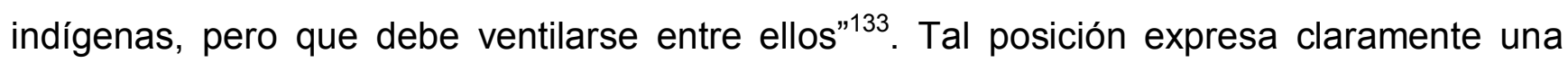
visión racista, en otras palabras "que los indios se gobiernen según sus costumbres bárbaras si quieren, pero que no se metan con nosotros los mestizos". Afortunadamente, la percepción que los habitantes de las cabeceras tienen del SSJC es otra, como lo demuestra el hecho de que los comerciantes del mercado municipal de San Luís Acatlán desde hace varios años solicitan el apoyo de Policías Comunitarios para el resguardo nocturno de la estructura, ya que numerosos robos se cometían no obstante la supuesta vigilancia de los policías municipales.

${ }^{133}$ Joaquín Juárez Solano, Fiscal Especial para la Atención a los Pueblos Indígenas- Región Montaña de la PGR, Tlapa, 20 marzo 2007. 
DEMANDAS ATENDIDAS POR LA CRAC 1998/2007

\begin{tabular}{|l|l|}
\hline $1998 / 200$ & 125, de las cuales 100 resueltas con conciliación y 25 con reeducación \\
\hline $2000 / 2001$ & 118 \\
\hline $2001 / 2002$ & 60, de las cuales 56 resueltas con conciliación y 4 con reeducación \\
\hline $2002 / 2003$ & 248 \\
\hline $2003 / 2004$ & 314 \\
\hline $2004 / 2005$ & 400, de los cuales 267 resueltos con conciliación y 74 con reeducación \\
\hline $2005 / 2006$ & 145, de las cuales 96 resueltas con conciliación y 49 con reeducación \\
\hline $2006 / 2007$ & 280, de las cuales 98 resueltas con conciliación y 34 con reeducación \\
\hline
\end{tabular}

TOTAL DE DEMANDAS ATENDIDAS: 1764.

RESUELTAS CON CONCILIACIÓN: 1301.

DETENIDOS PRÓFUGOS: 34.

POLICÍAS MUERTOS: 5.

Aunque no permiten una comparación con los atendidos por las instancias ministeriales e judiciales del Estado, estos datos muestran que una cantidad importante de personas han decidido acudir a la CRAC para la resolución de sus problemas, demostrando en los hechos la legitimidad del sistema comunitario.

\section{"Los Acuerdos de Horcacitas": reforma de la organización y zonificación del territorio comunitario}

Como se ha destacado en los párrafos anteriores, desde el momento de su constitución la organización ha tenido que enfrentar problemas diferentes y ha sabido resolverlos a través de su continua transformación.

En los últimos años, la evolución misma de la organización y el notable crecimiento del territorio donde opera, la han enfrentado con problemas profundos, cuya solución ha ocupado -y sigue ocupando- la organización desde por lo menos un año, lo que coincide aproximadamente con el periodo de trabajo de campo sistemático realizado para la investigación que aquí se presenta.

El primer problema tiene que ver con las autoridades encargadas de la impartición de justicia. Al constituirse la Coordinadora Regional de Autoridades Comunitarias, se decidió que los designados para impartir y administrar justicia a nivel regional debían ser al mismo tiempo Comisarios ${ }^{134}$ de su comunidad, en la convicción de que el fuero conferido a éstos

134 Que por ley actúan como Auxiliares del Ministerio Publico y tienen facultades para iniciar las primeras diligencias sobre los delitos cometidos en su comunidad. Los asuntos deben ser transferidos a la brevedad a la Agencia del Ministerio Publico competente, que abrirá la averiguación previa y dará seguimiento al caso. 
sirviera como garantía de legalidad para la actividad desempeñada en la CRAC. Los sucesos posteriores han demostrado que se trata de un argumento discutible, pues no ha servido como amparo ante las acusaciones de ilegalidad; además las funciones de la CRAC rebasan ampliamente las facultades asignadas a los Comisarios Comunales.

Parece que este método de elección de las autoridades regionales originó más problemas que beneficios. En primer lugar los comisarios son escogidos por la comunidad para que cumplan su cargo al interior de ésta; eso no significa necesariamente que tengan capacidades, aptitudes, o compromiso para impartir justicia a nivel regional.

En segundo lugar trajo problemas el hecho que los Coordinadores cumplan dos cargos a la vez, ya que es imposible desempeñar bien dos cargos de responsabilidad en dos lugares distintos al mismo tiempo. Es desgastante estarse desplazando continuamente entre su comunidad de origen y la oficina de la CRAC; además origina desatención en el trabajo de la CRAC.

Estos temas han sido objeto de discusión en varias reuniones internas, y llevados a la discusión abierta durante el Encuentro de Evaluación Interna realizado en la comunidad de Horcasitas del 24 al 26 de noviembre de 2006. En ese evento se acordó que las nuevas autoridades regionales que se nombrarían serían personas de capacidad y confianza, de reconocido compromiso con la organización, por haber ya cumplido algún cargo a su interior o por haber apoyado y aportado en otras formas. También se decidió que los que imparten justicia no han de ser al mismo tiempo comisarios de su comunidad, aunque así no tengan el fuero que les confiere ese cargo. Esto se suple porque el fuero y la autoridad para actuar en la organización lo otorga su nombramiento en la Asamblea Regional ${ }^{135}$. Se acordó que el cargo de los Coordinadores y de los Comandantes Regionales sería de tres años, igual que los Policías y Comandantes Comunitarios. Aún considerando el desgaste personal que implica ausentarse de la propia comunidad, del trabajo y de la familia por un periodo muy largo, sin adecuada compensación económica, se consideró necesaria esta medida para permitir a los encargados de impartir y administrar justicia adquirir cierta competencia en la materia y dar continuidad a la función jurídica.

Otro tema que se discutió en el Encuentro de Horcasitas fue cómo permitir a los habitantes de toda la zona donde está presente la Policía Comunitaria acudir fácilmente a la Coordinadora Regional para la resolución de sus problemas. Tal cuestión es importante, ya

\footnotetext{
${ }^{135}$ Propuestas aprobadas por la Asamblea en el Encuentro Regional de Evaluación Interna, Horcasitas, San Luís Acatlán, 24, 25 y 26 de noviembre del 2006.
} 
que en los últimos años el "territorio comunitario" se ha extendido enormemente, pasando de dos municipios en 1995 a 10 en la actualidad. Esto complicó la coordinación de los grupos de Policías Comunitarios de las comunidades más alejadas con el Comité Ejecutivo, cuya base quedaba en San Luís Acatlán; al mismo tiempo limitaba la participación a las Asambleas Regionales de los habitantes de tales zonas "periféricas", las que terminaban sin integrarse completamente al Sistema y sin asumir todas las reglas y el funcionamiento de éste. En segundo lugar, por lo que tiene qué ver con el acceso a la justicia comunitaria, resultaba que para quien vive en la parte alta de la Montaña (sobre todo en la zona mixteca) era más fácil, en términos de tiempo y dinero invertido en pasaje, acudir con los agentes del Ministerio Público (hay dos en el Municipio de Malinaltepec, uno en Metlatonoc, y dos en Tlapa) o con el Sindico en el Ayuntamiento, que trasladarse hasta la Coordinadora en San Luís Acatlán. Tal punto es de trascendental importancia, ya que su resolución implica una reflexión de la organización sobre su función, de acuerdo a las características del territorio en el cual actúa. Así, operativizar el trabajo jurídico comportaba necesariamente una descentralización de la función jurídica y también de la coordinación de seguridad; pero en esto emergieron las inconformidades de quienes, gracias a los cargos en la organización o a la influencia ejercida en las comunidades a través de la organización, habían logrado ocupar posiciones de poder en el territorio.

A pesar de esto, en el Encuentro de Evaluación Interna se empezó a discutir la propuesta de zonificación del territorio comunitario en tres zonas (baja, alta y mixteca), que reflejan tanto las características étnicas como las geográficas. Tal reterritorialización ha llevado casi un año e innumerables asambleas -regionales, de Comandantes, de Consejeros- para ser concordada, formulada detalladamente y llevada a cabo. Un proceso de discusión profunda en las zonas "periféricas", comunidad por comunidad, ha llevado a que se designaran las comunidades de Espino Blanco (en la zona de la Montaña Alta, de población mayoritariamente tlapaneca) y Zitlatepec (en la región oriental del territorio, habitada principalmente por mixtecos) como sedes de impartición de justicia, con funciones análogas a las de la oficina de San Luís Acatlán. Se planteó por lo tanto una tripartición del territorio: en cada sede operarán tres Coordinadores Regionales impartiendo la justicia y administrando la reeducación en el territorio de su competencia, así como tres Comandantes Regionales que coordinarán la acción de los grupos de Policías Comunitarios. 
El proceso de discusión ha implementado la participación activa y el compromiso de estas regiones, que empiezan a ver la posibilidad de un papel activo en la organización. Según las últimas informaciones, las dos nuevas sedes empezarán a operar en el verano del 2007. La subdivisión del territorio ha traído a la discusión otro punto débil de la organización regional, o sea las funciones que hasta la fecha cumplía la Coordinadora Regional de Autoridades Comunitarias. Esta, además de impartir y administrar justicia, también tenía las tareas de gestión de recursos y representación política ante las instancias de gobierno. En el Encuentro de Horcasitas se aprobó limitar las funciones de los Coordinadores Regionales al solo ámbito de la justicia, para que pudieran cumplir satisfactoriamente tal tarea, de por sí muy compleja, sin dispersarse en otros asuntos. Las funciones de gestión y representación quedaron a cargo del Comité Coordinador, que también coordinaría las acciones de las tres sedes de justicia, siendo integrado por un Coordinador Regional, un Comandante Regional, un representante del Comité de la Figura Jurídica y un consejero. Este Comité tendrá también la tarea de centralizar todos los recursos que llegan a la organización por parte de distintos proyectos y de los Ayuntamientos, y luego administrarlos repartiéndolos según las necesidades a las diversas zonas y a las partes de la estructura. Dicha instancia todavía no ha entrado en función.

La rezonificación representa, en el desarrollo de la organización, un momento importante de apropiación del territorio por parte de la institución regional, y de más profunda integración y vinculación con dicha institución regional por parte de muchas comunidades que hasta la fecha se habían quedado al "margen" del proceso organizativo. Pues aunque bajo diversos aspectos el Sistema de Seguridad y Justicia Comunitaria parezca actualmente atravesar un periodo de crisis estructural, la reterritorialización representa un proceso de crecimiento y fortalecimiento, que parte de asumir el cambio de las condiciones sociales y organizativas de la organización con respecto al momento de su formación. 
EVALUACIÓN DEL SISTEMA DE SEGURIDAD Y JUSTICIA COMUNITARIA

\begin{tabular}{|c|c|}
\hline $\begin{array}{l}\text { Razones para su } \\
\text { constitución }\end{array}$ & $\begin{array}{l}\text { Protección frente a robos, asaltos y violaciones; defensa de abusos } \\
\text { cometidos por policías municipal y estatal }\end{array}$ \\
\hline Actuales propósitos servidos & $\begin{array}{l}\text { Controlar el territorio; disuadir y castigar la delincuencia } \\
\text { Resolver conflictos } \\
\text { Proporcionar administración de justicia más eficiente y efectiva } \\
\text { Servir a necesidades comunitarias ad hoc }\end{array}$ \\
\hline $\begin{array}{l}\text { Alcance de asuntos } \\
\text { considerados }\end{array}$ & $\begin{array}{l}\text { Amplio: incluye asuntos penales y civiles, delitos menores } \\
\text { (Comisario comunidad) y mayores (CRAC) } \\
\text { y resolución de disputas inter e intracomunitarias }\end{array}$ \\
\hline $\begin{array}{l}\text { Métodos para resolución de } \\
\text { conflictos }\end{array}$ & $\begin{array}{l}\text {-Negociación-mediación/ careos: conciliación } \\
\text {-Adjudicación }\end{array}$ \\
\hline Sanciones típicas impuestas & $\begin{array}{l}\text {-Comunidad (delitos leves): restitución económica, detención breve, } \\
\text { trabajo comunitario breve } \\
\text {-CRAC (delitos graves): reeducación (trabajo comunitario de } \\
\text { duración variable) }\end{array}$ \\
\hline Discriminación de genero & $\begin{array}{l}\text { El rol de la mujer es reducido y subordinado, tanto a nivel } \\
\text { comunitario (participación en la toma de decisiones) como en la } \\
\text { organización regional. En este contexto, ha habido esfuerzos para } \\
\text { ampliar la participación (2005: Comisión de seguimiento de mujeres; } \\
\text { 2007: mujeres nombradas como Coordinadoras) que vislumbran un } \\
\text { creciente empoderamiento femenino. }\end{array}$ \\
\hline Relación con el sistema formal & $\begin{array}{l}\text { Funciones de seguridad, procuración e impartición de justicia no } \\
\text { reconocidas por el Estado. Amplia autonomía de facto. Relación } \\
\text { con el Estado (sistema político estatal, instancias ministeriales y } \\
\text { judiciales, cuerpos policíacos y militares) pasa del velado apoyo } \\
\text { (1995/98) al hostigamiento abierto (1998/2002) y a una tensa } \\
\text { tolerancia (2002-2007) } \\
\begin{array}{l}\text { Relación con instancias de poder local (Ayuntamientos): } \\
\text { apoyo/colaboración }\end{array}\end{array}$ \\
\hline
\end{tabular}




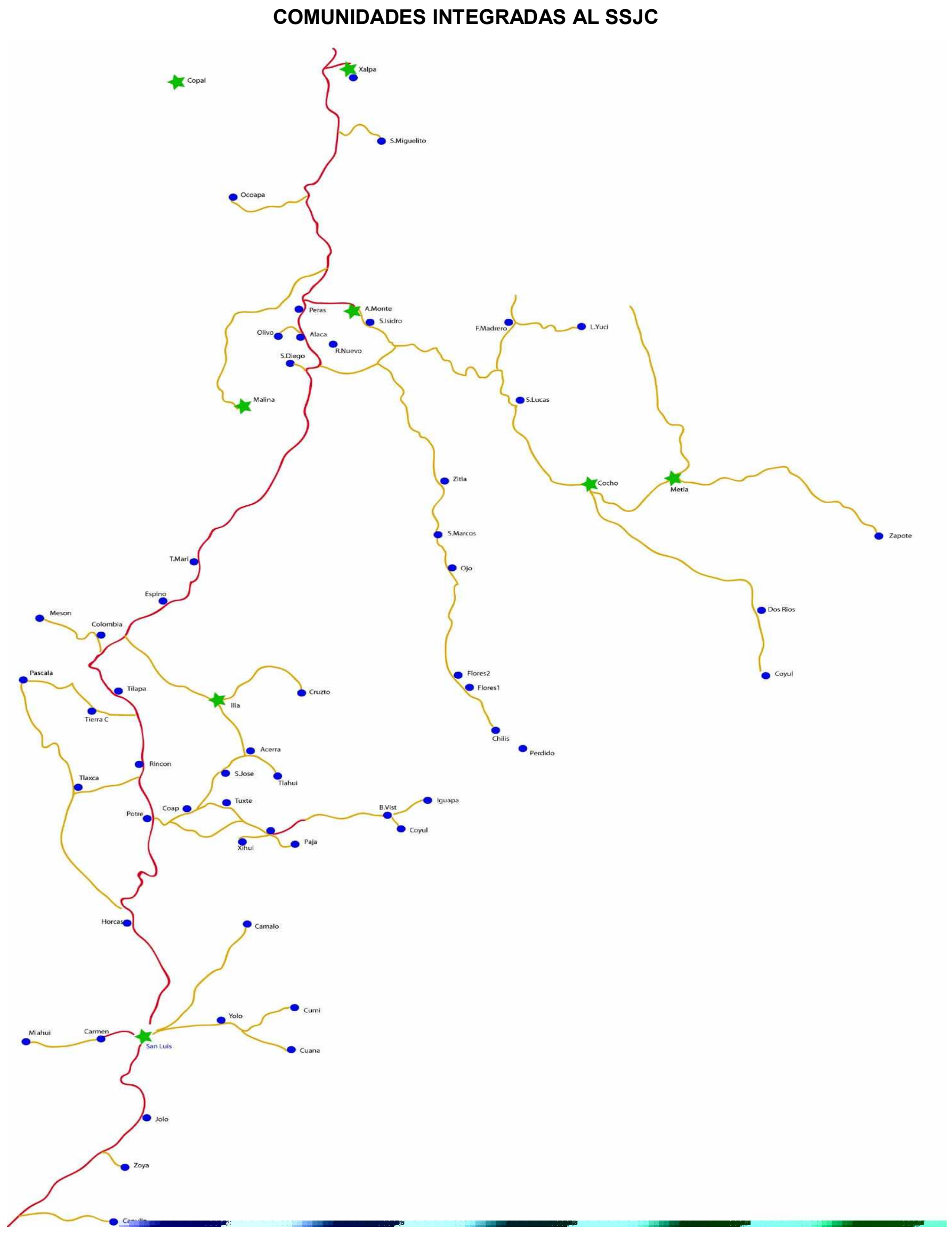




\subsection{LA RELACIÓN ENTRE EL SISTEMA DE SEGURIDAD Y JUSTICIA COMUNITARIA Y EL ESTADO}

El reconocimiento de la diversidad cultural y el pluralismo legal por el Convenio 169 de la OIT y la reforma constitucional del $2001^{136}$ plantea nuevos retos teóricos y políticos. Tal reconocimiento cuestiona los binomios Estado-Nación y Estado-Derecho, obligando a un replanteamiento de la relación Estado-derecho-sociedad. Ello supone trabajar en el plano del desarrollo normativo, la implementación institucional y la cultura legal; ámbitos en los cuales se observan fuertes resistencias de las instituciones estatales.

Hemos visto como el SSJC constituye una forma extendida de institución comunal e indígena que ejerce funciones de gobierno local, justicia, interlocución con el Estado y articulación supra-local. Analizando su origen he subrayado que es un proyecto nacido de las necesidades de los pueblos, los cuales encontraron las estrategias más adecuadas para resolver los problemas que padecían. Esto no significa que se haya decidido romper la relación con el Estado; se reivindica la fundamentación en el derecho nacional e internacional de la Policía Comunitaria, y se abren procesos de colaboración con los Ayuntamientos. Estos han sido conflictivos a lo largo de los años (se han alternado periodos de apoyo a periodos de represión y acoso por parte de los Gobiernos Municipales y de las instancias de gobierno hacia los Comisarios y Comandantes de la Policía Comunitaria). No obstante, la Coordinadora de Autoridades ha siempre puesto énfasis en su voluntad de buscar una colaboración abierta fundamentada sobre una relación de respeto mutuo.

Para un análisis de la articulación entre el SSJC y el Estado, hay que señalar que con las instituciones políticas municipales la relación ha sido de altibajas pero en lo general de coordinación y relativo apoyo, reconociendo en gran medida los Presidentes y Síndicos municipales la eficacia de la organización en garantizar la seguridad publica de la región, y en ciertos términos la legitimidad de la impartición autónoma de la justicia en cuanto derecho de los pueblos indígenas, aunque en lo general limitan tal derecho a los asuntos menores y intracomunitarios.

Los conflictos mayores han surgido en la relación con las instituciones de justicia, y con las estructuras estatales. Aquí se pueden distinguir tres "etapas": la primera (del 1995 al 1998) de "colaboración", mientras la Policía Comunitaria desempeñaba gratuitamente las funciones que debieran cumplir los cuerpos policíacos formales, y entregaba los delincuentes al

${ }^{136}$ En la cual se reconoce que "México es una nación multicultural". 
Ministerio Público. En tal momento, la función de la Policía Comunitaria era "complementaria" (según la definición de Van Cott expuesta en el capítulo 2.2). La segunda etapa va del 1999, cuando se constituye la Coordinadora Regional de Autoridades Comunitarias, al 2002, año en que todas las autoridades regionales fueron encarceladas. Esta etapa se caracteriza por un enfrentamiento directo entre las instituciones políticas y de justicia formales y la institución autónoma: esta había pasado a ser "competitiva". Desde 2003 al 2006 no hubo represión abierta pero tampoco reconocimiento: la CRAC trabajó de forma paralela y quizás "sustitutiva". En fechas recientes, el 7 agosto 2007, han sido notificadas órdenes de aprehensión contra muchos integrantes y ex integrantes de la CRAC, lo cual hace entrever una nueva embestida "legal" contra las autoridades autónomas.

\section{Encuentros y desencuentros: la relación del Sistema de Seguridad y Justicia Comunitaria con los Ayuntamientos}

En primer lugar, cabe destacar que la relación con las instancias de gobierno locales ha sido hasta ahora fundamental para la existencia del SSJC, debido a que la aprobación de los Ayuntamientos significa menor represión y mayores posibilidades organizativas; y también por el sustento material que éstos aportan al SSJC.

De hecho, la mayor parte de los financiamientos provienen de los Ayuntamientos ${ }^{137}$. Estos apoyos son utilizados como compensación para los Coordinadores Regionales que prestan servicio durante uno o más años en la oficina ubicada en San Luís Acatlán, dejando el trabajo en sus comunidades y que por lo tanto no tienen otra fuente de ingreso. También sirven para cubrir los gastos de la comida de los detenidos, de los Coordinadores, los Comandantes Regionales y los grupos de policías de guardia, que se encuentran diariamente en la oficina de la CRAC; y los gastos de la gasolina para las camionetas que se trasladan en el territorio para desarrollar operativos o investigaciones. Los Ayuntamientos tienen diferentes formas de sostener económicamente la organización, solventando gastos específicos u otorgando una determinada cantidad mensual (por ejemplo cubriendo la compensación de los Coordinadores y Comandantes Regionales que pertenecen a tal municipio). En el último periodo, los Ayuntamientos han empezado a desentenderse de este compromiso economico

${ }^{137}$ Otra parte de dichos recursos, utilizada para los cursos de capacitación a los Policías y Comandantes Comunitarios y para la organización de eventos, se obtiene desde hace unos años a través de proyectos financiados por la CDI estatal, y por algunos apoyos eventuales otorgados por la Secretaria de Asuntos Indígenas del Estado de Guerrero. 
iniciado hace unos años; hasta llegar al momento actual en el cual, debido a la poca capacidad de negociación de las autoridades pasadas y de las actuales, los apoyos han disminuido drásticamente, y no se cuenta con los recursos necesarios para garantizar el mejor funcionamiento del Sistema, lo cual no obstante sigue trabajando en el espíritu del servicio gratuito a las comunidades.

Desde el principio de la organización la gente es muy respetuosa de las instituciones, ya que no se plantea el surgimiento de la Policía Comunitaria en términos de enfrentamiento con las demás instituciones, con la Policía o con el Ejército, sino como una respuesta de las comunidades a una problemática concreta que era la falta de seguridad ${ }^{138}$.

Inmediatamente después de la institución de la Policía Comunitaria, en octubre 1995, una comisión de autoridades comunitarias viajó a Chilpancingo para ir a la Procuraduría de Justicia y dar a conocer la decisión de los pueblos. No obtuvieron ninguna forma de reconocimiento, informándoles las autoridades estatales que lo que estaban haciendo era ilegal. Sin embargo la comisión dijo que no lo iban a dejar ni iban a pedir permiso, pues eran portadores de los acuerdos que reflejaban la voluntad del pueblo.

Cuando se formó la Policía tratamos de dar al gobierno un conocimiento del porqué nos habíamos armado, y siempre con armas sencillas, no con las potentes que tiene el gobierno, porqué en este caso si estaríamos en error. Somos gente honesta y respetamos al gobierno. Como ejemplo de esto, es el deber de nosotros los comisarios hacer un listado de cuántos Policías Comunitarios hay en cada comunidad, y después llevarlo al Municipio. El Presidente Municipal, junto con el Síndico y el Director de Seguridad, pone firma y sello, así que de hecho hay un importante reconocimiento de la organización ${ }^{139}$.

Los primeros apoyos y reconocimientos en los hechos del trabajo que empezaba a desempeñar la Policía Comunitaria vinieron desde los Ayuntamientos municipales de Malinaltepec y San Luís Acatlán (en ese entonces, las 17 comunidades que primeramente integraron a la organización se encontraban en la jurisdicción de estos dos municipios).

En el periodo 1996/1999 ambos municipios fueron gobernados por el PRD. En particular el presidente municipal de San Luís Acatlán, Gerardo Reyes Ortega (que en su candidatura fue apoyado por la Coordinadora de Organizaciones Sociales), apoyaba y defendía la Policía Comunitaria; con frecuencia participaba a las Asambleas Regionales en las cuales era invitado. En 1998 dotó a la PC de un terreno en el centro de San Luís Acatlán completo de un edificio, de una sola planta, donde se encuentra la oficina de la CRAC y el cuartel general de la PC; de una camioneta y de un sistema de comunicación de banda civil que comunica

\footnotetext{
138 Valentin Hernandez Chapa, ponencia presentada en el taller de investigación "La Policía Comunitaria y la Coordinadora regional de Autoridades Comunitarias", realizado en el CIESAS, México D.F., 16 junio 2006.

139 Entrevista a don Moisés.
} 
los Comandantes de las diferentes localidades. Reyes Ortega empezó a otorgar credenciales a los Policías Comunitarios, incluyéndolos en 1996 en el Bando de Policía y Gobierno como "órgano auxiliar del ayuntamiento", función que en aquel entonces efectivamente cumplía ${ }^{140}$. Actualmente todos los Policías Comunitarios cuentan con credencial expedida por los respectivos Ayuntamientos.

En el primer periodo, fue importante el papel político de las organizaciones sociales y productivas, que integraron un Comité Técnico Regional (junto con funcionarios municipales) para dar seguimiento a las demandas de servicios y seguridad. Tal colaboración entre las organizaciones y los gobiernos locales con respecto a la temática social, se reflejó en el hecho que los Ayuntamientos empezaron a involucrarse y respaldar activamente la organización de la Policía Comunitaria.

El punto central para el funcionamiento de la organización era- y es- el economico: desde el principio se buscó el financiamiento directo con los Ayuntamientos. Estos lo otorgan aunque en medida diferente dependiendo de la disposición y la orientación dequienes lo encabezan; algunos han apoyado de forma consistente y con una cantidad de dinero fija cada mes; otros cubriendo gastos puntuales (gasolina); otros de forma eventual y discontinua.

El presidente de Malinaltepec en 1995 se llamaba Melquíades [Ramirez]: ese cabrón poco nos apoyó, muy a fuerza; el siguiente presidente, Teodoro, sí empezó a pagarle a sus policías, les pagaba un mes a los de un pueblo, otro mes a otro pueblo ${ }^{141}$.

Igualmente positiva fue, en esta primera fase, la relación con el gobierno del Estado y el Ejército. En un primer momento, el gobierno demostró cierta condescendencia. Atravesaba una profunda crisis política y para poder sustentar su resquebrajada legitimidad necesitaba mostrar su capacidad de enfrentar al Ejercito Popular Revolucionario (EPR) que hizo su aparición el 28 de junio de 1996 (primer aniversario de la masacre de Aguas Blancas), y que estaba presente en las zonas de la Sierra y de la Montaña.

Así que la PC, a un año de su creación, empezó a relacionarse positivamente con el gobernador interino Ángel Aguirre Rivero ${ }^{142}$, quien vio la eficacia en la disminución de los

\footnotetext{
${ }^{140}$ Al terminar su mandato, Gerardo Reyes se empleó en la Comisión Nacional para el Desarrollo de los Pueblos Indígenas (CDI) en Ometepec. En ese entonces fue juzgado por la CRAC y puesto a reeducación por haber engañado tanto a la Coordinadora cuanto a la familia de un hombre que se encontraba en proceso de reeducación y que fue con él a pedir ayuda. Reyes aseguró tener influencia en la Policía Comunitaria y que, soltándole la familia un buen dinero, él habría entregado este dinero para cubrir los gastos de la organización la cual, en cambio, hubiera soltado el preso. Pero la maniobra pronto fue descubierta por la CRAC la cual castigó justamente al ex Presidente municipal.

${ }^{141}$ Entrevista a don Francisco.

142 Gobernador de Guerrero por el periodo 1996/1999, y que sucede a Rubén Figueroa Alcocer.
} 
asaltos y en particular del robo de ganado, lo que beneficiaba también a los grandes ganaderos.

Para el otoño de 1996 eran 20 las comunidades que contaban con grupos de Policías Comunitarios. El 31 de octubre 1996 se realizó una reunión en el Palacio de Gobierno en Chilpancingo con los responsables de la seguridad publica del Estado ${ }^{143}$, quienes hicieron un reconocimiento a las primeras actividades de los Policías Comunitarios. Se invitó a las autoridades estatales a la Asamblea Regional que se llevó a cabo el 10 de noviembre de 1996 en Horcacitas, en la que participó entre otros, el comandante de la Policía Estatal. Éste se presentó en la asamblea para ratificar frente a la población reunida el acuerdo tomado el 31 de octubre, para dar fe de la relación de armas y matrículas que portaban los Policías Comunitarios, y para supervisar y dar fe de la integración de cuerpos policíacos por comunidad. Con respecto a éstos, el comandante admitió que la gran diferencia entre la actuación de la policía estatal y de los Comunitarios reside en el contacto directo con las comunidades. El oficial también propuso algunos lineamientos de operación: que se estableciera una base operativa en San Luís Acatlán (lo que se obtuvo en 1998, cuando el presidente municipal otorgó la oficina que actualmente es sede de la Coordinadora Regional de Autoridades Comunitarias); que se coordinaran los operativos con la Policía estatal; y que se diera identificación a los Policías Comunitarios, así como se registraran sus armas, operación posible en cualquier cuartel militar. Fue en este contexto que la Policía Comunitaria empezó a valorar la necesidad de elaborar un reglamento de operación. Finalmente, el oficial planteó la necesidad de obtener la Licencia Colectiva 110, que nunca se gestionó, ya que incorporaría la Policía Comunitaria a la Policía Federal Preventiva, lo que en ningún momento ha sido en el interés de la organización.

Fruto de la gestión de la Coordinación de Organizaciones Sociales fue un acercamiento entre los grupos de Policía Comunitaria y la SEDENA, a raíz de que en diciembre de 1996 se registraron alrededor de 50 armas, pertenecientes a 8 grupos de comunidades del municipio de San Luís, bajo el $48^{\circ}$ Batallón con sede en Cruz Grande.

En la primavera 1997 la Policía Estatal, la Secretaria Estatal de Protección y Vialidad, y el $48^{\circ}$ batallón impartieron talleres de capacitación sobre varios temas. Dichos talleres, representando en cierto sentido una legitimación política de la organización, fortalecieron la participación de la población en los grupos de policías comunitarios. Al mismo tiempo se

${ }^{143}$ Entre ellos el Secretario General de Gobierno, Humberto Salgado Gómez, el Subsecretario de Protección y Vialidad, general Vicente Osorio Hernández. 
reforzó la organización misma, sintiéndose con la confianza de moverse y actuar respaldados por las instancias militares y policíacas oficiales.

Por agosto de 1997, la organización empezó a redactar informes sobre sus actividades. Los grupos de policías comunitarios debían hacer un reporte semanal sobre los servicios realizados, avalado por la autoridad comunitaria, que sería entregado al Comité Ejecutivo y al Presidente Municipal. "El Comité y la presidencia, por su parte integrarán la información necesaria a efecto de que cada mes, al cierre, se elabore un parte informativo el cual deberá entregarse directamente al Gobernador, al Procurador General de Justicia, al Subsecretario de Protección y Transito, a la Secretaria General de Gobierno, al $48^{\circ}$ Batallón de Infantería y a malquiera otra instancia o institución que se juzgue conveniente" ${ }^{\text {"144. }}$.

En un acto Público realizado en San Luís Acatlán el 5 de mayo de 1997, con la presencia de más de 200 policías comunitarios, el gobernador Aguirre Rivero reconoció la importancia de la labor de la Policía entregando 100 uniformes. A raíz de este acto, en junio 1997 se propuso al gobernador participar en la cooperación para comprar armas para los grupos de policías comunitarios. Éste aceptó la petición y el 13 de julio 1990 entregó 20 escopetas "chaqueteras"; el gobierno estatal pidió al Ayuntamiento de San Luís, en tanto instancia oficial, que recibiera dicho armamento, el cual lo entregó en seguida a los responsables de la organización. Inmediatamente, las armas fueron repartidas entre los grupos de policías de 4 comunidades del mismo municipio. Este hecho, junto con el velado apoyo a través de los talleres de capacitación, parecía reconocer y favorecer la labor de seguridad regional a cargo de la organización indígena.

Abdías Acevedo Rojas fue presidente municipal de San Luís Acatlán en el periodo 1999/2003, por el PRI. Su relación con la Policía Comunitaria fue controvertida. Al principio apoyó decididamente la organización, aunque no reconociéndola en los discursos. En este periodo, como consecuencia de la creación de la CRAC, hubo por parte de los Comunitarios un notable esfuerzo organizativo y se presentaron propuestas similares a todos los Ayuntamientos de los municipios donde había Policía Comunitaria, para que apoyaran más concretamente la organización. El Ayuntamiento de San Luís apoyaba con 60 mil pesos mensuales.

Cuando era yo Comisario [de la CRAC] presionaba mucho a los Ayuntamientos. Hacemos una Asamblea Regional y los invito yo, y entonces empiezan a apoyarnos. Malina nos daba 10 mil pesos, pero pura gasolina; dice que a sus policías no les den de comer porque dice que él les está pagando. También

\footnotetext{
${ }^{144}$ Acta de acuerdos de la Asamblea Regional de la Policía Comunitaria, comunidad de Yoloxochitl, San Luís Acatlán, 20/07/1997.
} 
cuando era yo de la CRAC [2001] el INI nos dio 60 mil pesos, y Tlachinollan 4 mil. Pero hay que ir a presionar con mucha gente, no solos. El presidente de San Luís nunca le creó problemas a la PC, pero no quería que los Comunitarios se metieran en la cabecera; pero ellos les decían que si encontraban policías municipales que robaban, los hubieran matado o retenido, y si no le parece señor presidente, váyanse a la Asamblea Regional, a ver que te dice la gente ${ }^{145}$.

En 2003 ganó la presidencia Genaro Vázquez, hijo del conocido guerrillero, con el PRD. La relación con ese Ayuntamiento también fue buena, aunque al finalizar su mandato defraudó con las muchas esperanzas que la gente, y también la PC, habían puesto en él.

Cuando era yo comisario de la CRAC, los Ayuntamientos que nos apoyaban (económica y moralmente) eran San Luís Acatlán, Malinaltepec, Metlatonoc, Copanatoyac. Los que nos apoyaron sólo "moralmente" tenemos Marquelia y Amatlalcingo; estos lo único que hacían era autorizarle la credencial a los Policías. El Municipio de San Luís nos daba el dinero directamente a la organización (50 mil pesos mensuales), y a veces también a los mismos Policías; a veces también si una comunidad donde estaba la Policía iba a pedir apoyo se lo daba. El Municipio de Malinaltepec les daba directamente su viático a los policías, y 10 mil pesos tres veces al año para la organización. Metlatonoc nada más estuvo apoyando a su comandante con su pensión mensual, y a la organización sólo nos apoyó para el Aniversario. Copanatoyac nos daba para la gasolina, alimentación, y para pagar el hotel en Tlapa. El trato era directamente con el presidente ${ }^{146}$.

Además de representar el principal sustento de la organización, los Ayuntamientos reconocen en el plano general la legitimidad del SSJC. No es raro que personal de los Ayuntamientos, y a veces los mismos Presidentes Municipales, participen en las Asambleas Regionales. Entre las autoridades entrevistadas, quien criticó la función de la Policía Comunitaria fue el Jefe de Seguridad Publica de San Luís Acatlán; no obstante, admitió que más de una vez se han realizado operativos conjuntos; lo mismo afirmó el Presidente Municipal de Malinaltepec, que no duda en definir como "coordinación" la relación entre el Ayuntamiento y la Policía Comunitaria. Policías Municipales han revelado que en varias ocasiones han entregado a la CRAC personas detenidas por ellos, trás la petición de los mismos detenidos.

\footnotetext{
${ }^{145}$ Entrevista a don Francisco.

${ }^{146}$ Entrevista a don Gerardo.
} 


\section{La relación entre el SSJC y la administración de justicia}

En su trabajo sobre la administración de justicia informal comunitaria en América Latina, Van Cott (2003) evidencia tres tipos de conflictos que suelen emerger entre las instituciones estatales y las instituciones jurídicas informales.

En primer lugar, están los conflictos relacionados a los procesos o procedimientos de resolución de conflictos. Éstos se crean porque los sistemas indígenas son más flexibles y dinámicos que la justicia formalizada, preocupándose más de proporcionar la solución adecuada para un caso especifico que un precedente jurídico; y también porque los procedimientos pueden violar los estándares democráticos liberales de un debido proceso, tales como el derecho a un abogado, que frecuentemente no son parte de la cultura indígena.

Los conflictos de normas se deben a que los sistemas indígenas y occidentales pueden estar basados en distintos conjuntos de significados y valores culturales (Stavenhagen 1988:102).

Primero, hay transgresiones en la ley indígena que no son consideradas como delitos en la ley occidental -tales como el chisme, la brujería y el disenso religioso, todos los cuales son sancionados porque pueden quebrar el orden social del pueblo en cuestión, de la misma forma que acciones que para la racionalidad dominante representan una ruptura del orden social -por ejemplo el consumo de sustancias alucinógenas, no son consideradas de la misma forma en determinadas culturas. En segundo lugar, la ley indígena tiende a dar prioridad a la armonía de la comunidad sobre los derechos de los individuos. El trabajo comunitario, como forma de reeducación de los delincuentes adoptado por el SSJC, es considerado legítimo por los habitantes de las comunidades de la Costa-Montaña, ya que el valor atribuido a la comunidad en su conjunto los lleva en este caso a poner en un plano inferior los "derechos individuales". Esta consideración tiene qué ver también con los conflictos sobre el castigo; la sanción es seguramente uno de los elementos comunes a todos los sistemas normativos existentes en el mundo, pero la idea que se tiene sobre la sanción y las diversas formas que se usan para aplicarla, cambian de conformidad con los principios y valores que tiene cada sociedad.

El Estado interviene más frecuentemente cuando los defendidos y observadores reclaman que las sanciones impuestas violan los derechos humanos o constitucionales del defendido. Tales acusaciones han causado problemas a las organizaciones indígenas. La mayoría de ellas reconoce la autoridad de las convenciones internacionales sobre derechos humanos, y regularmente hacen reclamos basados en ellas. Las acusaciones han generado debates dentro de las comunidades, particularmente con respecto 
al rol de la mujer en los sistemas de autoridad indígena. En algunos casos, las prácticas que no han soportado un escrutinio han sido alteradas (Van Cott 2003).

La relación con el agente del Ministerio Público y el Juez de Primera Instancia de San Luís Acatlán parece variar, dependiendo de la capacidad política y de negociación de los que, cada año, son nombrados Comisarios de la Coordinadora. He subrayado anteriormente que la organización nació demostrando un fuerte sentimiento de desconfianza y condena a la forma de actuar del Ministerio Público y la Policía Judicial. En los primeros dos años, no hubieron motivos de roce, ya que los delincuentes eran simplemente atrapados por la Policía Comunitaria y entregados a la instancia oficial.

Al principio con el Agente del Ministerio Público no hubo muchos problemas, a parte que era un poco molesto con nosotros porque le quitamos su trabajo; para no tener conflictos siempre enviábamos una copia de las denuncias que nos presentaban la gente, o de los expedientes de los casos que estábamos atendiendo, para que estuvieran al tanto y no hubieran dobles investigaciones o quejas de personas inconformes con la CRAC. En 2001 el Juez estaba de acuerdo con nosotros, también decía ser feliz por tener poco trabajo, él nos invitó a pasarle una copia de la declaración, para evitar quejas eventuales en el Tribunal Federal.

Ahora esto ya no se hace, por esto ora tienen muchas demandas y amparos. Hay que platicar bien con el Juez y con el Ministerio Público, también me mandaban a llamar para recibir informaciones ${ }^{147}$.

Con el Estado, el Ejército y las autoridades ministeriales y judiciales la relación empeora a partir de 1998, el momento en que, a raíz de la ineficiencia del sistema formal, las comunidades decidieron formar un órgano propio y autónomo para la administración de la justicia, la Coordinadora Regional de Autoridades Comunitarias (CRAC). Así cuestionaron directamente la legitimidad de las funciones de gobierno, tocando uno de los pilares del orden jurídico, el que la jurisdicción y el ejercicio de la acción penal es facultad exclusiva del Estado $^{148}$.

Somos una institución paralela: obligamos el gobierno a modificar y corregir su estructura... ${ }^{149}$

Las autoridades de la CRAC y de la PC nunca hayan asumido una postura de abierta oposición a los gobiernos municipales y estatal. No obstante, al afirmar la legitimidad de la estructura autónoma de administración de justicia frente a la legalidad a que apela el Estado,

\footnotetext{
${ }^{147}$ Entrevista a don Francisco.

${ }^{148}$ Es lo que Yrigoyen (2000) define como la "teoría monista del derecho".

149 Cirino Plácido Valerio, mixteco, Comisario de la Coordinadora Regional de Autoridades Comunitarias, discurso por el $10^{\circ}$ Aniversario de la Policía Comunitaria, Pueblo Hidalgo, Malinaltepec, 15 octubre 2005.
} 
han salido del espacio permitido ${ }^{150}$ y funcional (de hecho en el primer momento cumplían gratuitamente las funciones de los policías estatales). Tal actitud ya no es fácilmente aceptable por los ámbitos de poder, que han cambiado su postura en abierta hostilidad.

Desde que empezó a funcionar este proyecto comunitario, hemos tenido en contra a la Policía Judicial, a los Agentes del Ministerio Público, al mismo Juez de Primera Instancia y demás autoridades estatales, municipales y federales, quienes nos han presionado para dejar de trabajar, parando a nuestros policías en los caminos y desarmándolos, avalando las denuncias injustas de delincuentes que han estado bajo nuestro cargo, integrando averiguaciones previas y girando órdenes de aprehensión en contra de los comisarios y comandantes de nuestra organización. Con las autoridades antes mencionadas se han tenido varias reuniones y por tiempos han disminuido el hostigamiento pero sin dejar de denostar y difamar a nuestra organización y nuestro trabajo. El ejemplo más claro de esto es que a partir de la detención del ganadero Emiliano González Navarrete quien ha sido la cabecilla de delincuentes abigeos en San Luís Acatlán, hemos tenido la presencia de miembros del Ejército Federal en los caminos y dentro de nuestros pueblos. Los pobladores tienen miedo de salir a sus labores libremente. Frecuentemente los militares nos visitan en la oficina de la CRAC para amenazarnos e interrogarnos, a reclamarnos del porque detenemos a gente que no es indígena, en clara defensa de ganaderos y caciques. También en fechas recientes el Ejército desarmó a un grupo de policías comunitarios de Pueblo Hidalgo, Pascala del Oro y Arroyo Mixtecolapa. Otros hechos ofensivos de los militares, por ejemplo, han sido su actitud violenta en contra de los ciudadanos $[\ldots]^{151}$.

Los hechos a los que se hace referencia son el desarme acontecido en Pueblo Hidalgo el 26 de marzo de 2000 , por mano del $49^{\circ}$ batallón de infantería del Ejercito Federal; y la detención, por parte de la Policía Judicial del Estado, del entonces párroco del Rincón, Mario Campos Hernández, acontecida el 9 de julio de 2000, con la acusación -después revelada sin fundamento- de allanamiento de morada. También se registra la detención por parte de la PJE de Bruno Plácido Valerio, uno de los fundadores de la organización, el 18 de septiembre de 2000. La acusación fue de violación de 4 mujeres mixtecas, las cuales después de unos días desmintieron el hecho, demostrando como la acusación había sido construida por la misma Policía Judicial aprovechando de la condición de analfabetismo de las mujeres. Finalmente, el 20 de octubre del mismo año, fue detenido Agustín Barrera Cosme, Comandante Regional de la Policía Comunitaria. Las investigaciones que siguieron tales aprensiones nunca encontraron pruebas contra los presuntos culpables, los cuales fueron liberados en unas semanas; aparece entonces la clara voluntad intimidatoria de la

\footnotetext{
${ }^{150}$ Según Hale (2004) "el centro del proyecto cultural neoliberal no es un individualismo radical, sino la creación de sujetos que se autogobiernen en acuerdo con los principios del capitalismo globalizado". Véase Capítulo 1.2 .

${ }^{151}$ Documento elaborado por la CRAC en ocasión de su décimo aniversario, 2001.
} 
Procuraduría de Justicia del Estado, que al mismo tiempo trata de desprestigiar la imagen de los Comunitarios.

Sucesivamente, se han realizado reuniones con el secretario particular de Gobierno, el encargado de Asuntos Indígenas y el representante de la Procuraduría General de Justicia, firmando minutas de acuerdos que nunca han llegado a concretarse en un serio compromiso por parte de las autoridades estatales.

\section{EI SSJC en la encrucijada de los "derechos humanos"}

Los indígenas guerrerenses han aprendido que el Ejército y las policías federal y estatal no están en sus comunidades para erradicar de raíz el narcotráfico sino para evitar, desalentar y combatir el enorme potencial que tienen como sujetos autónomos. Esto es, la fuerza pública está en sus comunidades no para combatir el crimen sino para atacar a las comunidades y a sus formas de autonomía (López y Rivas 2005:79).

Cuando empezó a funcionar el sistema autónomo para la impartición de justicia, empezaron también a abundar las órdenes de aprehensión en contra de Policías Comunitarios, Coordinadores Regionales y Comisarios Municipales por "privación ilegal de la libertad" y "abuso de poder", denuncias presentadas por algunos de los familiares o por los mismos detenidos a los que la CRAC sentenció la reeducación. Estos hechos, según el boletín de prensa difundido por la organización en junio 2001, manifiestan el "incumplimiento, por parte de la Procuraduría General de Justicia del Estado (PGJE), de un acuerdo firmado el 31 de julio del 2000 con la Policía Comunitaria, en el que se compromete a que, antes de iniciar una averiguación previa por asuntos relacionados con esta corporación indígena, el Ministerio Público deberá avisar al director de Asuntos Indígenas y a la Dirección General de Averiguaciones Previas "para que reciban instrucciones sobre el particular"152.

Mientras era yo Comisario, el Agente del Ministerio Público era muy accesible, nos coordinábamos en los trabajos; él mismo nos puso en contacto con el Fiscal Regional de Ometepec, y empezamos a comunicar con él también. El Ministerio Público solamente quería tener las informaciones de los casos que íbamos atendiendo, después no se metía con nosotros, no acogía eventuales quejas de familiares. Entonces a veces éstos se iban con [la Comisión de] Derechos Humanos en Ometepec, que sí retomaba la demanda. Pero nosotros le informábamos, les dábamos las actas, pero muchas veces con ellos teníamos choques. Pero por otro lado, teníamos [el centro de Derechos Humanos] Tlachinollan que nos ayudaba $^{153}$.

De acuerdo con Collier y Speed (2000), frecuentemente el discurso de los derechos humanos se utiliza instrumentalmente como un mecanismo de control por parte de los

152 “Denuncia la Policía Comunitaria agresiones del gobierno estatal”, El Sur, 5 de junio de 2001. 
gobiernos, con el fin de acusar a las autoridades indígenas de violaciones y limitar su legitimidad, y no para sancionar los abusos cometidos por las fuerzas policíacas y los poderes institucionales. Frecuentemente, cuando las autoridades indígenas actúan de acuerdo a su propio sistema jurídico y aplican las sanciones consecuentes, vienen acusadas de violación a los derechos humanos individuales. Es por ejemplo el caso de la práctica común a muchos pueblos de México de tener preso en la cárcel de la comunidad hasta por dos o tres días quien haya cometido una falta menor, como emborracharse (les toca una noche de cárcel) o un pequeño robo; esto por lo regular representa toda la pena, sin implicar más deberes para el acusado (pago de multas, etc.). Pero dicha práctica, reconocida por los pueblos, es considerada ilegal por las instituciones formales; que se apegan estrictamente a la "Ley" cuando quieren limitar el poder autónomo de algunas instituciones informales particularmente eficaces y "contrahegemónicas". Es el caso de los Municipios Autónomos Zapatistas relatado por Collier y Speed, o del mismo Sistema de Seguridad y Justicia Comunitaria, cuyas autoridades han sido demandadas por "violación de los derechos humanos". Se trata de lo que Van Cott define como los "conflictos sobre el castigo".

A esta situación se debe tal vez el cuidado que ponen las autoridades regionales en su actuación: "Hay casos en que las esposas vienen y denuncian a sus maridos que las maltratan; pero para actuar les pedimos que nos firmen un papel, para no tener problemas con derechos humanos"154. Se ve como el sistema autónomo se moldea para defenderse de un discurso ambivalente cual es el de los derechos humanos que, en este caso, viene utilizado en términos represivos, como se verá con lo acontecido en 2001. Pero también el sistema autónomo se transforma incluyendo elementos de normatividad que son ajenos a la práctica de los pueblos, y que éstos perciben como importantes y legítimadores. La frase "derechos humanos" se usa con mucha frecuencia, aunque haya una percepción bastante generalizada sobre qué son tales derechos: "Siempre tratamos también de garantizar los derechos humanos de los detenidos. El dispensario médico en San Luís es cerca de la oficina; cuando estuve de comisario yo, nos pusimos de acuerdo con el director del dispensario, nos propuso venir a atender a los enfermos en la oficina misma" ${ }^{155}$.

La elección como gobernador del Estado de Guerrero del priista René Cisneros marca un empeoramiento en la relaciones del gobierno con la organización, coincidiendo con el gobierno municipal del también priista Díaz Acevedo en San Luís Acatlán.

\footnotetext{
${ }^{153}$ Entrevista a don Gerardo.

${ }^{154}$ Entrevista a don Moisés.
} 
En ese momento se dio el más fuerte enfrentamiento entre el sistema de Seguridad y Justicia Comunitaria y las instancias de gobierno, que finalmente demostró las profundas raíces de la organización, la magnitud de su base de apoyo, su legitimidad y la decidida voluntad de los pueblos de defenderla, afirmando la legitimidad de la estructura autónoma de administración de justicia (en cuanto "nacida de los pueblos y por los pueblos" frente a la legalidad a que apela el Estado).

En el 2001 hubo en una familia un pleito por la herencia: había tres hermanos y la herencia era de una casa con una parcela. El hermano [Silvino Encarnación Gabino] a quién sólo le iba a tocar la parcela y no la casa, disparó a uno de sus dos hermanos, que se fue al hospital. Después disparó también al otro hermano, y trató de hacer lo mismo con su mamá. Entonces se mandó a llamar a la Policía Comunitaria del pueblo, la noticia llegó a la Coordinadora. El asesino huyó ${ }^{156}$. Se dice que era la esposa que lo empujaba a hacer lo que hizo, así que se le tomó presa en la cárcel hasta que apareciera su esposo. A las tres horas lo agarraron, pero la señora se fue al tribunal federal a Chilpancingo y metió una demanda $^{157}$. Nosotros juzgamos a ese amigo y le dimos 10 años de reeducación, pero ya lo sacaron. Quince días ante que acabara mi mandato, llegó el jefe de la Policía Municipal de San Luís y me avisó que había una orden de aprehensión para mí. Entonces llamé a una Asamblea Regional y comuniqué la noticia, y alerté la gente. Después fui a platicar con el Juez y el agente del Ministerio Público, los invité a comer. Vine a apartar dos chivatitos aquí [en Pueblo Hidalgo] para preparar una barbacoa e invitarlos. Pero sólo faltaban dos días para ese día cuando llegaron los judiciales sin ninguna orden de aprehensión o cateo, se metieron en la oficina de la Coordinadora. Llegaron con la señora que nos indicó, eran las 11 de la mañana, y nos llevaron al bote todos los Comisarios [de la CRAC] que estábamos alli ${ }^{158}$. A las dos horas que caímos en la cárcel empezó a concentrarse la gente afuera. En la noche, ya había más de 5 mil personas reunidas. También el Presidente Municipal de ese entonces no nos apoyaba. Pero la gente entró y tomó al Juez y al Agente ministerial; les impedía salir de la oficina del Ministerio Público ${ }^{159}$. También se enfrentaron cara a cara los policías y los Comunitarios, los dos con sus armas. Al día después nos dejaron libres. Pero a los tres días leímos en el periódico que iban a desarmar la Comunitaria: fue "el ultimátum". Entonces anduve platicando con los pueblos: "prepárense que ya el

\footnotetext{
${ }^{155}$ Entrevista a don Gerardo.

156 "Esta persona ya había sido denunciada en numerosas ocasiones en el Ayuntamiento Municipal, pero nunca fue detenido. En el momento de su detención se notificó al Ayuntamiento este hecho donde se les informó que se trataba de un sujeto de alta peligrosidad". CDH de la Montaña Tlachinollan, VIII Informe, 2004.

157 "A pesar de que la Policía Comunitaria actuó con base en la denuncia, investigación y comprobación de hechos, la señora Constantina Morán Ramírez, esposa del detenido interpuso una denuncia ante el Ministerio Público de San Luís Acatlán, por el delito de privación ilegal de la libertad en contra de integrantes de la Coordinadora Regional de Autoridades Indígenas". Ídem.

${ }^{158}$ Fueron detenidos cinco de los seis Coordinadores electos por el año 2001, que en ese mismo día habrían hecho formal entrega de sus facultades a las autoridades entrantes por el año 2002.

${ }^{159}$ La petición de la gente era que fueran tomadas las declaraciones a los Comisarios públicamente, lo que no aconteció.
} 
gobierno nos va a desarmar. Hay que convocar una marcha. Yo pasado mañana me voy a México a platicar con Xóchitl Gálvez ${ }^{160}$.

Luego de la liberación de los comisarios hubo una reunión entre una comisión de la Policía Comunitaria, el Delegado Regional de la Procuraduría de Justicia del Estado en Costa Chica y el Presidente Municipal de San Luís Acatlán, en la que se llegó a varios acuerdos, entre ellos la revisión de las acusaciones contra las autoridades indígenas y un pacto de colaboración entre la CRAC, el Ministerio Público, el Juez Mixto y la Presidencia Municipal, para agilizar la procuración de justicia en la entidad.

El 26 de febrero del 2002 una comisión de Autoridades de la Coordinadora fue citada a una reunión en el palacio de Gobierno de Chilpancingo, en la cual presenciaron los titulares de la Secretaría de Seguridad Pública y Protección Ciudadana, de la Procuraduría General de Justicia del Estado y los comandantes de la $9^{a}$ Región y de la 35 ${ }^{a}$ Zona Militar, la CRAC, representantes del Centro de Derechos Humanos de la Montaña Tlachinollan y del Consejo Guerrerense 500 Años de Resistencia Indígena. En un ambiente acusatorio y hostil, a la presencia de elementos del CISEN $^{161}$, el gobierno presentó un documento en que analizaba detenidamente el Reglamento sobre el que se sustenta la impartición de justicia operada por la CRAC, destruyendo cuidadosamente las argumentaciones en base a las cuales la PC reivindica su legitimidad, para afirmar finalmente la ilegalidad de la organización ${ }^{162}$.

Después de esto, fue comunicado a la comisión "el ultimátum", en que se exigía el inmediato desarme de la Policía Comunitaria, o la alternativa de incorporarse como policías preventivos municipales, al mando de los Ayuntamientos.

Los ayuntamientos más de una vez nos han pedido que la PC entrara a formar parte de la Policía Municipal, pero hemos rechazado estos ofrecimientos para no mancharnos de la mala reputación de corruptos que tienen los integrantes de este cuerpo de seguridad. Finalmente preferimos la independencia, trabajar a nuestro modo; de la otra forma seríamos sujetos a la autoridad municipal, y, como en los primeros años [de 1995 a 1998] nada más estaríamos entregando los maleantes al Ministerio Público, participando del sistema ineficaz donde el pago de una fianza te otorga la libertad a pesar de que se haya cometido un delito, más o menos grave. Además muchos de nosotros habitantes de los pueblos hemos sufrido los atropellos de los cuerpos uniformados, y el recuerdo de las mañas no lo podemos olvidar $^{163}$.

También para ser parte de la Policía Municipal hay muchos requisitos discriminatorios, que impedirian a todos participar: ser mayor de 18 años, saber leer y escribir, tener cartilla militar... nosotros pensamos

\footnotetext{
${ }^{160}$ Secretaria de la Comisión Nacional de Desarrollo para los Pueblos Indígenas (CDI). Entrevista a don Francisco.

${ }^{161}$ Entrevista a Cirino Placido Valerio, El Sur, 28 febrero 2002.

162 Documento fotocopiado, archivo personal de don Paco, San José Vista Hermosa, Malinaltepec.

${ }^{163}$ Entrevista a don Moisés.
} 
que para servir al pueblo no se necesita tanto, basta con se honesto y tener la voluntad de comprometerse. ${ }^{164}$

En ese momento, los integrantes de la Coordinadora remitieron la decisión a las comunidades que integran el Sistema, ya que las asambleas comunitarias son "el órgano básico y pilar fundamental del sistema ${ }^{165 " ~ y ~ d e ~ e l l a s ~ d e p e n d e n ~ t o d a s ~ l a s ~ a c c i o n e s ~ y ~ l a s ~}$ decisiones. Pidieron por lo tanto un plazo de treinta días para realizar consultas en las comunidades sobre la importancia y la efectividad de la Policía Comunitaria. El ejercicio fue de gran importancia para ratificar el respaldo unánime a la organización y fortalecer la participación de cada comunidad. Esto aparece en las Actas de Acuerdo levantadas en las Asambleas que se convocaron en cada comunidad para discutir el asunto; en todos destaca el rechazo al desarme ${ }^{166}$.

Durante una reunión con las organizaciones sociales, el 7 marzo 2002, se planteó la idea de organizar un encuentro abierto a la población y las autoridades, donde se platicara de la función y los alcances del Sistema de Justicia y Seguridad Comunitaria. Mientras tanto,

llegaron a la oficina en San Luís unos soldados del campo militar n.1 de México con un registro de armas perdidas, acusándonos de tenerlas nosotros, y por esto nos amenazó de desarmarnos. Dijo que "éstos no son policías, son gente que se organiza para entrar a una revolución" pero yo le dije que no, estamos en contra de la delincuencia no contra del gobierno. $Y$ como le comuniqué que iba a convocar a los comisarios y la gente de las comunidades, ya que la nuestra es una organización de los pueblos, para que decidieran ellos que hay que hacer, entonces el comandante casi casi se disculpó y se fue con su montón de soldados ${ }^{167}$.

Una gran marcha por las calles de San Luís Acatlán fue la respuesta de los pueblos que integran el Sistema de Justicia y Seguridad Comunitaria a las amenazas del Estado: el 21 de marzo 2002 más de 4 mil indígena bajaron de los parajes más alejados de la Montaña para pedir el respeto a su organización. En los días 21 y 22 de marzo se realizó en dicha cabecera municipal el Segundo Encuentro Regional por la Justicia y la Seguridad Comunitaria. En el evento, donde se reiteró la voluntad popular de defender la organización, participaron también algunos presidentes municipales de la región, que manifestaron su tardío- apoyo al Sistema.

"Seamos indígenas, seamos mestizos, necesitamos seguridad, el pueblos ya se cansó de tanta violencia, por eso es que se formo la Policía Comunitaria, que busca la paz y la tranquilidad" afirmó en su participación Teodoro Tomás Galeano, presidente de

\footnotetext{
${ }^{164}$ Entrevista a don Paco, tlapaneco, comunidad de San José Vista Hermosa, Malinaltepec, 30 julio 2006.

${ }^{165}$ Reglamento Interno de la Policía Comunitaria, art.6

${ }^{166}$ Dichas actas se encuentran en el Archivo Documental en la Oficina de la CRAC, San Luís Acatlán.
} 
Malinaltepec, mientras Abdías Acevedo Rojas, presidente de San Luís, aseguró: "el cabildo está presente, el cabildo ha aprobado esta Policía Comunitaria" ${ }^{\text {"168. }}$.

Unos días antes, el 11 de marzo, una comisión de autoridades y consejeros de la CRAC se había reunido con la Secretaria de la Comisión Nacional de Desarrollo para los Pueblos Indígenas (CDI), Xochitl Gálvez, en la Ciudad de México. "Entonces fuimos en una comisión de seis o siete personas al DF que explicamos cómo nació la Comunitaria, y subrayamos que el gobierno, ahora que ya hay control en la zona, nos quiere desarmar... Y entonces Xochitl Gálvez nos apoyó, 'para mi está a toda madre', dijo"169.

A partir del 2002 hasta el 2006 se vio una situación más de tolerancia, mientras la organización se ha visto obligada a afianzar sus alianzas con otras organizaciones. En base a la acusación de que la CRAC actúa según el criterio exclusivo de los que están al frente, se vio la necesidad de redactar un Reglamento Interno, que surge en esta tercera etapa.

No obstante que la relación ha sido menos tensa, ha continuado un cierto hostigamiento por parte de las autoridades, como una forma de desarticular esta organización en las comunidades. Ejemplos de eso fueron el desarme efectuado por el Ejército en Pueblo Hidalgo en el octubre de 2002, y la detención de dos Policías Comunitarios de la comunidad de Cuanacaxtitlán el 17 de enero de 2003 por portación de armas de uso exclusivo del Ejército cuando resguardaban una camioneta de pasajeros de Yoloxóchitl a Cuanacaxtitlán. Después de seis días, fueron liberados por falta de elementos para procesarlos. Entre las pruebas más sustantivas estuvieron los testimonios de las comunidades a través de dos representantes, quienes reconocieron a estos elementos como la policía electa por asamblea en la comunidad.

En el 2005, se realizó una mesa de trabajo con el Fiscal Regional de Ometepec, donde se discutió la coordinación de trabajo y el mutuo "reconocimiento" (aunque no en términos formales) de las dos instancias de procuración de justicia en la zona, la formalmente legal Agencia del Ministerio Público- y la legítima -CRAC-. En noviembre del mismo año, y después en mayo 2006, se han realizado encuentros en el mismo sentido con el Secretario de Seguridad Publica y el Procurador del Estado.

En 2006, el gobierno estatal elaboró una propuesta de Ley de Seguridad Publica, que plantea la inclusión de los grupos de Policías Comunitarios en los aparatos policiales estatales, como Policía Auxiliar. Bajo este término, la ley (Título Octavo) prevé la

${ }^{168}$ El Sur, 23 marzo 2002. 
reglamentación, por parte del Estado o de los Municipios, de los servicios de seguridad privada, equiparando éstos la Policía Comunitaria, cuya característica (implícita en el nombre) es ser una institución publica y colectiva.

La organización rechaza cabalmente esta postura, ya que trata de reglamentar y "reconocer" únicamente el trabajo de seguridad ejercido por los Comunitarios, y también contradice las otras importantes funciones que cumple la organización, o sea la impartición de justicia y la gestión del sistema de reeducación.

Otra vez, asistimos a la tentativa de encasillar este proceso autonómico adentro de los espacios del indio permitido ${ }^{170}$, o sea los que no cuestionan las dinámicas políticas existentes y las estructuras del poder constituido.

Al respecto, uno de los "líderes politicos" de la Policía Comunitaria, Cirino Placido Valerio, afirmó que

el gobierno nos ha propuesto la legalización de la Comunitaria, pero nosotros no lo queremos: ya tenemos la legitimidad que nos otorga el pueblo, que decide acudir a la CRAC y participar en la organización. $\mathrm{Y}$ aparte del reconocimiento del pueblo, también hay un reconocimiento de hecho por parte de las instancias de gobierno: nos llegan regularmente oficios y cartas oficiales dirigidos a la Coordinadora Regional de Autoridades Comunitarias, o del Comité Ejecutivo de la PC. Esto demuestra que son instancias reconocidas en los hechos como actores colectivos legítimos aunque no legales. Bueno, también es cierto que nos reconocen como autoridad cuando les conviene y cuando no, nos acusan de ilegales.

En este 2007, precisamente cuando el Estado -a través de dicha Ley de Seguridad- ha proporcionado, en sus términos, un "marco jurídico para el reconocimiento" de la institución comunitaria, los Ayuntamientos han disminuido tajantemente su aportación económica, fundamental para el funcionamiento del SSJC.

Ahora como ayuntamiento tenemos prohibido apoyar a la PC, ya que no hay una partida de dinero para ellos; para la seguridad pública ya tenemos a la Policía del Estado, etc. Ahora casi estamos desviando recursos para poder apoyarlos, y no se puede comprobar. Estamos actuando prácticamente fuera de lo legal; sin embargo por necesidad lo estamos haciendo, aunque de forma menor que en los otros años ${ }^{171}$. Este es un ejemplo claro de cómo a veces las políticas de reconocimiento, actuando de acuerdo a la racionalidad institucional y no representando una apertura real hacia los procesos autonómicos, representan un obstáculo más para éstos, cerrando espacios "informales" de relación y coordinación con las instituciones.

\footnotetext{
${ }^{169}$ Entrevista a don Francisco.

170 Hale 2004.

${ }^{171}$ Entrevista a Zotico Jerónimo García, Presidente Municipal de Malinaltepec 2005/2008, marzo 2007.
} 


\section{Entre legalidad y legitimidad}

"Los sistemas populares de justicia se forman en los espacios sociales que existen en las periferias de los órdenes legales dominantes y, como tales, la naturaleza y capacidad de su ordenamiento queda configurada dentro de la dinámica asimétrica de las relaciones de poder" (Sieder 2001:70).

En el amplio debate sobre la necesidad y las formas para el reconocimiento de los derechos y las instituciones indígenas, la tensión entre legalidad y legitimidad ocupa un lugar central. En el contexto que nos ocupa, es el núcleo del conflicto entre la institución comunitaria, que nace de las necesidades de los pueblos y se desarrolla en 12 años a través de la participación de la población en su conjunto, y la autoridad judicial y policíaca, cuyas faltas en el ejercicio de su función son al origen de la organización popular. No es de sobra recordar que

la existencia de un problema de fondo en el sistema de justicia penal en México se ve reflejado en el dato corroborado por los informes de 2002 de la mayoría de las comisiones estatales de derechos humanos y de la Comisión Nacional de los Derechos Humanos, que registran a las Procuradurías Generales de Justicia respectivas como las autoridades más frecuentemente señaladas como responsables de violaciones a los derechos humanos ${ }^{172}$.

El dato es ejemplificativo de una tendencia que no ha cambiado hasta la fecha, como demuestran los más recientes informes de la Comisión Estatal para los Derechos Humanos en el Estado de Guerrero y del Centro de Derechos Humanos de la Montaña Tlachinollan. El abuso de poder de las autoridades se hace más fuerte hacia los pueblos indígenas;

en este cuadro existe también la corrupción y la impunidad en el sistema de justicia, por lo que muchos indígenas desesperan de acudir a la procuraduría y a los tribunales, y aun a las instancias públicas de protección de los derechos humanos por carecer de confianza en los mismos. También se reportan casos de abusos o incluso delitos (ej. violaciones) cometidos por elementos del ejército contra la población civil indígena en zonas de conflicto o de agitación social ${ }^{173}$.

Entonces, son estas "autoridades" de procuración e impartición de justicia las que acusan a la Policía Comunitaria de ser una organización de "criminales" por estar "fuera de la Ley". Las acusaciones se centran principalmente en que "no actúan según todos los procedimientos judiciales; no son autoridades reconocidas y no tienen la facultad de detener a nadie" ${ }^{\prime 174}$. Contrariamente a lo que afirman las autoridades de la CRAC ${ }^{175}$, todas las

172 Diagnóstico sobre la Situación de los Derechos Humanos en México - Oficina del Alto Comisionado de las Naciones Unidas para los Derechos Humanos en México - 2003.

${ }^{173} \mathrm{ONU}$, Informe del Relator Especial sobre la situación de los derechos humanos y las libertades fundamentales de los indígenas, Misión a México, diciembre 2003.

${ }^{174}$ Alejandro Campos Blas, agente del Ministerio Público de San Luís Acatlán, entrevistado en noviembre 2006. 
autoridades administradoras de justicia entrevistadas ${ }^{176}$ dicen tener pocas o nulas relaciones con la institución comunitaria, que actuaría de forma paralela y sin coordinarse con ellas.

Una opinión de tajante condena del SSJC es la del Juez Mixto de Primera Instancia, quien recientemente ${ }^{177}$ ha denunciado la organización como violadora de los derechos humanos. Es dicha institución la que da seguimiento a las demandas por privación ilegal de la libertad y violación a los derechos humanos que aún tienen algunas Autoridades Comunitarias.

En las entrevistas realizadas, todos los funcionarios han revelado un fuerte racismo hacia los pueblos indígenas, una profunda ignorancia sobre sus culturas y sobre los instrumentos jurídicos (art. $2^{\circ}$ constitucional, Convenio 169 de la OIT) que garantizan algunos de sus derechos colectivos, no obstante que la mayoría de la población con la que trabajan sea indígena. Consideran que la justicia autónoma "está bien entre ellos"; con respecto al derecho a un interprete, lo cual frecuentemente es violado ${ }^{178}$, el agente del Ministerio Público de San Luís Acatlán afirma que "los indígenas son tramposos, hacen como si no entendieran el español, para evadir las interrogaciones, saben que es difícil encontrar un traductor".

Las acusaciones de ilegalidad no preocupan demasiado a las autoridades de la CRAC, quienes saben que cuentan con la legitimidad otorgada por los habitantes de la región que a ellas acuden. Con respecto a la tensión entre legalidad y legitimidad de los sistemas jurídicos autónomos, Habermas considera que no es el Derecho el que crea la legitimidad sino que es esa legitimidad la que crea el Derecho ${ }^{179}$. Es lo mismo que, con otras palabras, afirma uno de los fundadores de la Policía Comunitaria: "estamos fuera de la ley porque la Ley la hicieron otros; si la hubiéramos escrito también nosotros, claro está que nos hubiéramos incluido" ${ }^{180}$.

\footnotetext{
175 "Con el Ministerio Público hay una relación de respeto, reconocen la legitimidad de nuestro trabajo: una persona que viene juzgada por la CRAC no puede ser juzgada por el mismo delito también por el Ministerio Público. Parece que hay un convenio firmado", Entrevista a Don Abad Flores Herrera, Capulín Chocolate, Marquelia, 4 agosto 2006, Comisario de la CRAC

176 Agente del Ministerio Publico (San Luís Acatlán), Juzgado de Paz (San Luís Acatlán), Fiscalía Especializada para la Atención a Pueblos Indígenas- Región Montaña de la Procuraduría General de la Republica (Tlapa), Juzgado Mixto de Primera Instancia (San Luís Acatlán).

177 "Dice el juez de San Luís Acatlán que la Policía Comunitaria es la que más comete abusos", El Sur, 20 febrero 2007 (http://www.suracapulco.com.mx/nota1.php?id_nota=13768); "Niega la Policía Comunitaria que cometa abusos con los detenidos", El Sur, 26 febrero 2007

(http://www.suracapulco.com.mx/nota1.php?id_nota=14086).

${ }^{178}$ El Ministerio Publico de San Luís Acatlán, en cuyo territorio viven indígenas mixtecos y tlapanecos, no cuenta con intérpretes, sino que los solicita eventualmente al Ayuntamiento.

${ }^{179}$ Citado en Gómez 2002:244.

${ }^{180}$ Entrevista a don Juan.
} 


\section{El discurso y la práctica: ¿autonomía, reconocimiento o respeto?}

EI SSJC es sin duda una experiencia que muestra un complejo proceso de construcción de la autonomía en los hechos (tiene jurisdicción y territorio, los dos elemento fundamentales para la autonomía), pero sus bases no la reivindican abiertamente aunque la están ejerciendo.

Es decir, valorando la experiencia del Sistema de Seguridad y Justicia Comunitaria en términos de autonomía y libre determinación, hay que distinguir entre el nivel de los hechos y el nivel del discurso.

En los hechos hay un contexto organizado, con autoridades propias, jurisdicción y territorio. La reivindicación de la legitimidad de tal experiencia se puede sustentar en el derecho a la libre determinación, como es formulado en el Convenio 169 de la OIT, y a la autonomía como su expresión interna.

En el nivel del discurso, también hay que diferenciar entre el de algunos "líderes politicos" y el de las bases, o de los "líderes comunitarios".

La PC creció mucho seguramente en su fama, pero también se cometieron muchos errores. Al mismo tiempo hay mucha gente que no tiene estudios pero que se entregó con conciencia al pueblo ${ }^{181}$.

Estas figuras, más que líderes politicos, serían "líderes morales", que basan su autoridad al interior de la organización en un innato carisma y una reconocida integridad moral, y en décadas de servicio a sus comunidades más que en el activismo en las organizaciones. "Yo entré en la Comunitaria en 1995, y apenas el año pasado solté el arma. Participé 10 años... Mucha gente no quiere entrarle, porque le crea problemas, enemigos..." recuerda don Francisco.

En los discursos de estas autoridades, resalta la voluntad de construir una relación positiva con las instancias formales de gobierno y de administración de la justicia; nunca llaman a una ruptura, sino que reclaman las faltas y el olvido que han manifestado los gobiernos hasta la fecha (donde no reservan condenas es hacia los cuerpos policíacos).

"Nosotros que empezamos buscamos por todos lados las posibilidades para existir sin problemas. Pedimos que nos reconozcan y pedimos que nos respete el gobierno" afirma don Juan.

En la zona sur-oriental de Guerrero, la organización indígena que tuvo más relevancia fue el Consejo Guerrerense 500 Años de Resistencia, que comparte la reivindicación de autonomía como proyecto y discurso político; el aporte de esta organización fue

\footnotetext{
${ }^{181}$ Idem.
} 
fundamental en la construcción de la Policía Comunitaria, y muchas de las personas que participaron ( $\mathrm{y}$ participan) más activamente en la PC fueron miembros, más o menos destacados, de "500 Años" (como es llamada familiarmente la organización en la zona). En los años de militancia, algunos de ellos pudieron formarse políticamente y adquirir experiencia -tanto teórica como práctica- sobre las formas de lucha, así como la capacidad de articular un discurso político complejo. Llevando su experiencia a la nueva organización, para reivindicar su legitimidad insertaron el reclamo de seguridad, la organización desde las comunidades y la práctica de una justicia alternativa en el horizonte más amplio de la demanda del reconocimiento de la autonomía, que en los hechos se está ejerciendo en los ámbitos legal y de seguridad. Encontramos tal argumentación en el "discurso político" de la PC desde su inicio, en la Acta de Acuerdo del 15 octubre 1995 que ratifica su constitución:

[...] Analizando la situación de inseguridad pública que padecen las comunidades de esta región [...] nos vemos obligados por la necesidad de tomar el siguiente acuerdo: que en base a lo estipulado por el articulo $4^{\circ}$ constitucional, en cuanto a la autonomía y autodeterminación de las comunidades y regiones indígenas, en base al Convenio 169 emitido por la OIT y avalado por el gobierno de México, ley internacional que establece que las poblaciones indígenas y tribales tienen el derecho de hacer uso pleno de sus costumbres y tradiciones, y al impulso de su desarrollo y orden social de su integridad física y moral de sus sociedades con autonomía, haciendo uso de su autodeterminación y que los gobiernos están obligados a brindar todo el apoyo para que se respete este derecho: decidimos que los grupos de Policía comunitario de cada comunidad se avoquen el resguardo de los caminos principales[...]

La legitimidad de la organización se sustenta, en estos términos, en el derecho nacional e internacional; lo mismo encontramos en otro importante documento que sustenta el Sistema de Justicia Comunitario, el Reglamento Interno:

Articulo 2. En pleno uso y ejercicio que asiste a los pueblos y personas indígenas, con fundamento en los artículos 2 y 39 de la Constitución Política de los Estados Unidos Mexicanos, art. 1, 2, 3, 4, 5, 6, 7, 8, 9 del Convenio 169 de la OIT y demás relativos y aplicables de las leyes nacionales e internacionales vigentes en nuestro país, se instituye el sistema comunitario de seguridad, impartición de justicia y reeducación, en beneficio de la población de las comunidades integrantes de dicho sistema [...] fundándose en el respeto a su cultura, identidad y organización sociopolítica.

Parece que tal discurso autonómico es utilizado por parte de los "líderes" y sólo en determinadas circunstancias. Tengo la impresión, con base en la información recogida hasta ahora, de que aparece en ámbitos "formales" (documentos, foros, eventos) como discurso político hacia el "exterior", pero que no hay un proceso de politización de la gente; por lo tanto, no se usa el mismo discurso hacia el interior de la organización.

El discurso de los "líderes políticos" queda bastante lejos de la población (que en gran medida no se ha apropiado de tales términos y conceptos), y también de los "líderes 
morales". Éstos, en su discurso, reivindican la legitimidad de la organización en cuanto proviene "de los pueblos y por los pueblos", en que es producto de la misma gente, y en su carácter de justa respuesta a la situación de inseguridad y continuo acoso que la población padecía.

En el discurso de estas autoridades comunitarias hay mucho énfasis en que la organización no busca un conflicto con el gobierno. El maestro de una comunidad del municipio de Malinaltepec (muy reconocido por su militancia política) afirmó que, aunque es claro que en los hechos se está practicando la autonomía (aunque limitada a los ámbitos de control del territorio e impartición de justicia), se trata de no usar este discurso como estandarte, de no gritarlo muy fuerte para no ocasionar tensiones con el gobierno (estatal).

Ésta es otra visión del discurso autonómico: hay quien lo usa por su carácter universal (ya que crea inmediatamente relaciones y cercanías con los otros protagonistas del movimiento indígena, tanto en México como en el resto de Latinoamérica) y central entre las reivindicaciones políticas de tal movimiento. Por otro lado está el pueblo, que no se ha apropiado de tal discurso político. Finalmente, hay quien lo encuentra demasiado conflictivo y prefiere usar un discurso que se apegue estrictamente a los hechos, reivindicar la práctica jurídica y pedir seguridad, sin hablar de autonomía en un sentido político, tratando de mantener espacios de negociación con el gobierno. Este último discurso apela a problemas particulares sin implicaciones políticas, en el entendimiento que sean más efectivos y de fácil gestión.

No estamos en contra del gobierno, pero sí estamos en contra de la delincuencia, y pedimos que no nos deje abandonado el gobierno con la delincuencia, sufriendo. Al gobierno parece que le interesa quien tiene dinero, el más poderoso; a nosotros los indígenas nos trata como polvo del camino. Pero nosotros también tenemos derechos como personas de vivir en la patria nuestra.

Nuestra pregunta es: ¿ya que nos estamos cuidando de los ladrones, en qué le afectamos al gobierno con nuestra seguridad? Nada, sino que estamos defendiendo nuestros derechos, asegurando nuestra vida. Pero el gobierno no está de acuerdo, y nosotros los indígenas nos preguntamos porqué el gobierno no apoya este trabajo que estamos haciendo, ya que no le estamos pidiendo mucho dinero, solo para los gastos, ya que los policías no ganan, su trabajo es gratuito.

Nosotros pedimos principalmente que nos dejen de perseguir, porque cuando nos persiguen sentimos que el gobierno es como el hermano de los delincuentes ${ }^{182}$.

La reflexión que emerge de éstas consideraciones es que el de autonomía es un concepto, y un discurso, maleable y que es usado por los actores sociales de acuerdo con sus necesidades y en forma diversa en los diferentes momentos de un mismo proceso social. 
Podemos encontrar contextos en que se reivindica la autonomía pero en la práctica no hay un real proceso autonómico; y situaciones donde hay procesos concretos de construcción de la autonomía aunque ésta no sea abiertamente reivindicada.

En los últimos años, las autoridades del SSJC han utilizado, para reivindicar su posición con respecto a las instituciones estatales, un discurso donde rechazan el "reconocimiento" y en su lugar piden el "respeto". Con esto, se posicionan concientemente fuera del ámbito "permitido", y así sustentan su negativa a ser incluidos en los cuerpos policíacos formales; argumentan que el reconocimiento no es posible mientras no haya una reforma profunda de las instituciones que abra espacios para la inclusión integral de las experiencias comunitarias y de jurisdicción autónoma, rechazando a acoplarse a los estrechos espacios de "reconocimiento" consentido por la actual legislación mexicana. En este discurso, respeto significa coordinación positiva con las instituciones mientras éstas no traten de reprimir o impedir el libre funcionamiento y desarrollo del SSJC.

${ }^{182}$ Entrevista a Don Luís. 


\section{CONCLUSIONES}

A manera de conclusión, quiero avanzar algunas consideraciones que emergen del análisis, más o menos detallado, realizado sobre el Sistema de Seguridad y Justicia Comunitaria, a la luz de los elementos conceptuales esbozados en los primeros dos capítulos. Trataré de valorar algunos puntos trascendentes de la experiencia analizada, así como los que parecen, según mi punto de vista, los límites de la organización hacia el fortalecimiento de su autonomía.

La herramienta para dicho analisis conclusivo la tomo en préstamo del Proyecto LATAUTONOMY, un reciente estudio realizado en varios países latinoamericanos y europeos, cuya hipótesis central es "Autonomías multiculturales en América Latina: una condición necesaria para el desarrollo sostenible"183. El marco analítico y teórico elaborado por los investigadores del proyecto es muy profundo: los estudios analizan los sujetos autonómicos a lo largo de cuatro ejes principales (autonomía, cultura, desarrollo y sostenibilidad, que representa el eje articulador), llegando a una definición del sujeto autonómico como "una red de comunidades basada en una identidad étnica y/o cultural que está luchando en determinadas regiones para el establecimiento o la conservación de un espacio vital común y autodeterminado". En un segundo momento, se analizaron los factores internos y externos que contribuyen, de manera positiva o negativa, en el desarrollo de los procesos autonómicos, llegando a elaborar un modelo teórico comparativo para la investigación y el analisis de diversos procesos autonómicos.

Considero sumamente interesante tal enfoque teórico; aunque en esta etapa no ha sido el marco sustantivo de mi investigación, utilizaré en parte las "10 hipótesis" que constituyen el modelo comparativo general del proyecto para tratar de evaluar, aunque someramente, el alcance de la autonomía en el SSJC. 


\section{EI SSJC: hacia la reconstitución del tejido comunitario y regional}

El Sistema de Seguridad y Justicia Comunitaria, como advierte su mismo nombre, pone un fuerte énfasis en lo "comunitario", lo que se explica a partir del análisis de su estructura, donde el eje articulador son precisamente las comunidades que lo integran.

EI SSJC nace de la organización de algunas comunidades, a partir de prácticas y valores reconocidos como sustantivos de la vida comunitaria: los cargos gratuitos que se fundan en la idea de servicio a la colectividad como parte de las obligaciones de quienes pertenecen al ámbito comunitario, y que son también fuente de prestigio y reconocimiento personal. Este valor del servicio es en la actualidad a veces fuente de conflictos (con más frecuencia las personas se niegan a las obligaciones y los cargos comunitarios), pero sin duda representa una fortaleza al momento de generar un proceso organizativo como el que estamos analizando, ya que el cargo de Policía Comunitario surge de una figura similar que ya existía en las comunidades. Estas observaciones se pueden extender también a las autoridades que integran la Coordinadora Regional de Autoridades Comunitarias, cuyo difícil cargo no recibe retribución ni es utilizado para crecer en la carrera política.

Las primeras comunidades se organizaron interiormente para su propia defensa y seguridad, creando en breve tiempo conexiones con otras comunidades cercanas, hasta llegar -en la actualidad- a integrar una red que abarca y constituye el espacio de la región CostaMontaña, cuyos nudos y articulaciones son precisamente las comunidades que la integran. Destaca entonces la capacidad de fundir el sentido comunitario con la construcción de estructuras y espacios regionales; donde el sentido comunitario tiene su raíz en la comunidad pero no coincide con su espacio limitado. En la acepción que encarna el SSJC, lo comunitario no significa comunal, más bien se refiere al espacio colectivo y a la acción colegiada que a partir de las comunidades se difunde a todo el espacio regional.

El debate sobre la comunidad y la ideología comunalista (o comunitarista) ha sido y sigue siendo muy vivo en las ciencias sociales, levantando fuertes pasiones tanto entre sus partidarios como entre sus detractores. Con respecto al análisis que estamos desarrollando, considero muy útil la revisión critica que de dicho debate hace Zárate, quien sostiene que "el comunalismo como ideología política busca redefinir una ideología cultural sobre nuevas bases y no, como lo señalan algunos autores, mantener los valores esenciales e inalterables

\footnotetext{
${ }^{183}$ El proyecto cuenta con una pagina web (www.latautonomy.org) y varias publicaciones. En castellano ha sido editado por Leo Gabriel y Gilberto López y Rivas Autonomías Indígenas en América Latina. Nuevas formas de
} 
del comunalismo transhistorico" (2005: 64).

Sin querer idealizar el ámbito comunitario, frecuentemente sede de conflictos, ni los valores comunitarios, que a veces encierran fuertes contradicciones, Zárate afirma que tal ideología tiene una gran fuerza ya que "la idea de comunidad le ha dado coherencia y solidez a la organización de varias comunidades, la posibilidad de emprender acciones conjuntas, trascender las disputas faccionales (y en ocasiones familiares) y desarrollar proyectos productivos o culturales que requieren la concurrencia de diversos grupos" (2005: 81). Podemos observar este proceso en el contexto analizado, donde no se propone un discurso sobre lo comunitario como ámbito idealizado de pertenencia y libre de conflictos; más bien se está construyendo una nueva visión de las relaciones políticas y sociales que se opone a los valores que Estrada Castañon (1994) identificaba como característicos de la cultura política guerrerense: violencia, corrupción, caciquismo.

El proceso de revaloración de prácticas y valores comunitarios coincide con la extensión de tales fundamentos organizativos al nivel regional: se recrea comunidad y a la vez se crea un territorio compartido, la región. El SSJC valoriza las diversas culturas de los pueblos presentes en la región ${ }^{184}$, juntándolos en un proyecto común en el cual se pueden expresar (el sistema de impartición y administración de justicia respeta las prácticas de cada comunidad e integra las diferencias jurídicas en el Reglamento Interno, producto de la discusión y el consenso entre todas las comunidades y los pueblos). También está fortaleciendo las identidades étnicas pero en términos dialécticos y no excluyentes, poniéndolas en relación con las otras identidades que comparten el espacio organizativo y afirmando la legitimidad de sus sistemas políticos y jurídicos ${ }^{185}$.

La construcción de una nueva jurisdicción y un espacio regional compartido puede entenderse como un ejemplo de ese dialogo intercultural propuesto por Olivé como un modelo de practica política y de organización social, basado en el respeto y la interacción de las diversidades, analizado en el capítulo 2.1.

Se puede hablar de un proceso, aunque muy joven, de reconstitución de unidades multiétnicas, base del desarrollo de la autonomía en un territorio definido, la región CostaMontaña. Con estas consideraciones quiero demostrar que también en éste aspecto el

convivencia política.

${ }_{184}^{184}$ Mixtecos, tlapanecos, nahuas, mestizos.

185“La identidad se construye en la diferencia no sólo excluyente del otro, sino en la que logra alimentarse y enriquecerse de la alteridad. La realidad no se agota en la cerrazón que muestra la defensa del estado de derecho gubernamental, los caminos pueden ser múltiples como [los pueblos indígenas] lo han mostrado en su largo caminar" (Canabal Cristiani 2001:285). 
Sistema de Seguridad y Justicia Comunitaria está avanzando en el proceso de construcción y fortalecimiento de su autonomía, ya que "cuanto mayor es el grado de multi- o interculturalidad, mayor es la posibilidad del sujeto autonómico de consolidarse como fuerza pluriétnica y de conseguir la autonomía político-jurídica por vía de la negociación con el Estado nacional” ${ }^{186}$.

Con respecto a este proceso de construcción y reconstrucción el sentido identitario y comunitario en la Montaña, retomo las reflexiones de Canabal Cristiani:

La desventajosa relación con un mundo de relaciones externas, generalmente de dominio, explotación y exclusión cultural, ha llevado a los pueblos montañeros a querer ser conductores de su propio destino acotando su territorio para generar certezas, ya sea el comunal o el municipal, y regenerar así su capacidad de reagruparse en espacios más amplios como el de la región. Ha habido sin duda una atomización de los asentamientos y un constante reacomodo de los gobiernos locales, especialmente de los municipios, pero que ha permitido a la vez la recreación de los pueblos y de las identidades que van dibujando de nuevo a la región. [...] La reproducción de la comunidad obliga a construirla cotidianamente en cada nivel de la vida.

La revaloración de las estructuras comunitarias, sobretodo las asambleas que construyen su fuerza política a través de la búsqueda del consenso, aunado a la constitución de un proyecto hegemónico, que permita articular los distintos discursos, voces e intereses ${ }^{187}$, pone el Sistema de Seguridad y Justicia Comunitaria al centro de lo que Sarmiento llama un proceso de reconstitución. En oposición a los procesos de desestructuración, que fracturan y debilitan las estructuras de los pueblos, los procesos de reconstitución

tienen como propósito no sólo restaurar las estructuras fracturadas sino también reinventarlas cuando han sido sumamente dañadas o cuando han sido puestas al servicio de los grupos de poder. Como los procesos desestructuradores, los de reconstitución también son el resultado de fuerzas exógenas y endógenas a los pueblos, aunque la diferencia con ellos es que se desarrollan en un medio hostil que busca por todos los medios acabar con la diversidad (Sarmiento 2001: 249-250).

En suma, la experiencia que nos ocupa, a pesar de sus límites y dificultades, representa un proceso que apunta a la reconstitución de un tejido social fragmentado por la violencia y la distribución desigual del poder y los recursos, favoreciendo la organización colectiva para enfrentar las necesidades de la población, reinventando las estructuras y el sentimiento comunitario.

\footnotetext{
${ }^{186}$ LATAUTONOMY, Hipótesis de la Interculturalidad.

${ }^{187}$ Lo cual no significa que al interior de las comunidades dejen de existir las diferencias, "en el que no son precisamente los ancianos que dirigen las asambleas, sino los nuevos actores forjados en las luchas sociales extracomunitarias o los "exitosos" empresarios, profesionistas o migrantes" (Zárate 2005:71).
} 
Tal proceso aparece más importante si consideramos que no se desarrolla solamente al interior de las comunidades sino que está re-creando el tejido social en términos regionales, "vinculando el nivel de las comunidades locales con una estructura regional de manera horizontal e interactiva"; ésta, según el enfoque de LATAUTONOMY, es una de las características que confieren sostenibilidad a un sistema autonómico. De hecho, el proceso de integración regional representa uno de los mayores logros del SSJC, que determina su fuerza en la negociación con el Estado.

\section{Límites y alcances de la autonomía en el SSJC}

Varios investigadores resaltan positivamente, en las actuales experiencias de organización indígena, la capacidad que están demostrando de apropiarse de elementos del discurso dominante (por ejemplo los derechos humanos, el discurso de género, la salvaguardia al medioambiente, o los argumentos que enfatizan el desarrollo y la participación), para respaldar un discurso propio, otra práctica de justicia (lo que Sieder llama framing, o sea enmarcación ${ }^{188}$ ).

Algunos trabajos realizados sobre la Policía Comunitaria analizan la presencia y el alcance de este tipo de proceso en dicha organización, en particular en lo que atañe a la preocupación para el respeto de los derechos humanos y la inclusión de las mujeres en la estructura organizativa. En mi investigación he observado de forma esporádica tales intenciones en la práctica jurídica de la CRAC. El uso de estos conceptos aparece quizás en las declaraciones públicas de las autoridades, pero en el discurso cotidiano tales preocupaciones emergen de manera casual, sin demostrar ser índice de una reflexión y conscientización sobre las temáticas. Puedo aseverar que sí hay algunas personas, que cubren o han cubierto cargos en la organización, que se han sensibilizado sobre las temáticas de los derechos humanos y la necesidad de una mayor participación de las mujeres en la organización, pero todavía tienen mucho trabajo de difusión y formación hacia la base para hacer. Se observa una tendencia hacia la inclusión de dichas temáticas en la vida cotidiana y en la práctica jurídica, pero también se observan resistencias y jaloneos a la modificación de costumbres arraigadas, tanto en las comunidades cuanto al interno de las estructuras de la organización. En particular, la atención hacia la temática de los derechos de la persona en la impartición de justicia de la CRAC me parece muy importante, ya que,

${ }^{188}$ Rachel Sieder, intervención en el V Congreso Latinoamericano de Antropologia Jurídica, Oaxtepec, México, 16-20 octubre 2006. 
incluyendo en el sistema cultural indígena el discurso por los derechos humanos (frecuentemente usado por el Estado con fines represivos) en una perspectiva propia y autodirecta, muestra la voluntad de valorar lo interno y construir nuevos derechos. En el curso de la investigación he podido constatar como el discurso de los derechos humanos, aunque en ciernes, tiene cierta legitimidad en la CRAC, que centra su debate interno en las formas posibles para integrar la practica jurídica autónoma con el marco universal de los derechos de la persona. Quizás esto suceda debido a que la represión contra la institución autónoma frecuentemente se fundamenta en que ésta viola los derechos humanos de los detenidos, ya que estos se encentrarían "ilegalmente privados de su libertad", según el marco jurídico constitucional.

Por otro lado, como también subrayan otros estudios ${ }^{189}$, el tema de género y de los derechos de la mujer desata mucho interés pero todavía no ha sido asumida como una problemática central en la práctica jurídica de la CRAC, ni en la vida de las comunidades. El trabajo de Sandoval, analizando unos casos de disputa que involucran mujeres, documenta los prejuicios machistas que orientan la administración de la justicia en las comunidades.

También en este aspecto, como en muchos otros, hay que poner atención al proceso y a los debates internos, sin pretender encontrar aciertos o logros consolidados, ya que la transformación de un contexto social siempre es paulatina y muchas veces conflictiva.

Dicha falta de claridad alrededor de las temáticas de los derechos humanos y de la mujer se puede insertar en una reflexión más general, o sea que uno de los límites más importantes del SSJC-PC es la falta de un discurso político coherente y elaborado acerca de la función que cumple, sus alcances actuales y los que podría tener en el futuro. Se pone gran énfasis en la práctica, en lo que hace la institución autónoma y en la legitimidad ganada entre los habitantes de la región, pero hay una innegable dificultad en dotarse de una visión política y de más amplio alcance, que podría fortalecer la posición de la organización con respecto a las instituciones, y también posicionarla en el contexto del movimiento indígena regional y nacional. De hecho, en los 12 años de su existencia, la organización, a pesar de haberse dado a conocer en ámbitos académicos por su particularidad y éxito, no ha logrado estrechar relaciones y alianzas fuertes con otras organizaciones, manteniéndose relativamente aislada.

\footnotetext{
${ }^{189}$ En un artículo comparativo con otras experiencias de jurisdicción indígena, Sierra documenta los límites de la inclusión de las mujeres en el proceso de la Policía Comunitaria (2006).
} 
En el tiempo transcurrido desde mi acercamiento a la Policía Comunitaria (en el 2005) he observado importantes esfuerzos de apertura y vinculación con los otros sectores de la sociedad civil, tanto a nivel regional como nacional. En primer lugar la celebración de los Aniversarios como eventos públicos que incluyen la realización de mesas de discusión y debate; en segundo lugar, la participación en La Otra Campaña promovida por el Ejercito Zapatista de Liberación Nacional a partir del 2006, lo cual ha significado en cierto sentido el posicionamiento de la Policía Comunitaria en la arena de los movimientos politicos nacionales. La adhesión a La Otra Campaña ha determinado también el fortalecimiento de relaciones con otras organizaciones y movimientos activos en Guerrero, ya que entre los que conforman "La Otra Guerrero" se realizan periódicas reuniones de discusión y coordinación. Aunque muy importante para el posicionamiento político de la PC, cabe destacar que la adhesión a la Otra Campaña no ha sido unánime ni libre de discusiones al interior de la organización, debido a la diversidad de opiniones políticas y a los intereses en juego en la región.

La capacidad de estrechar relaciones con otras experiencias, así como la de negociar con las instituciones en términos igualitarios y no en posición de inferioridad, es una medida de la sostenibilidad de un sistema autonómico. En éste, "a través de un proceso de integración desde abajo se deben crear estructuras políticas participativas que se articulan tanto al interior de la autonomías multiculturales cuanto hacia afuera generando un proyecto de sociedad alternativa”190. En México, la experiencia del Ejercito Zapatista de Liberación Nacional muestra la importancia de abrirse hacia otras experiencias y articular un discurso político fuerte a partir de la propia realidad, pero al mismo tiempo amplio y compartido.

En el caso de la Policía Comunitaria, la falta de un discurso político coherente, que imprima la dirección a las acciones de la organización, ha tenido consecuencias negativas no solo hacia lo exterior, sino también hacia el ámbito interno de la misma, que se han manifestado en los últimos dos años.

En primer lugar se ha verificado un proceso de relajamiento en el compromiso de las comunidades y sus autoridades con la organización, debido principalmente al hecho de que la delincuencia ha bajado considerablemente y por lo tanto ha desaparecido el motivo que hace 12 años movió a la población a organizarse; asimismo los fundadores de la institución comunitaria, por el desgaste que la actividad ininterrumpida comporta, se han alejado o han

${ }^{190}$ LATAUTONOMY, Hipótesis de la Red. 
disminuido su participación activa, dejando un vacío que no ha sido ocupado efectivamente por personas más jóvenes.

Esto que podemos llamar "mística del servicio y de la participación", muy fuerte en quienes empezaron la organización, se ha ido diluyendo en la medida en que no se ha sabido fortalecer el sentido de pertenencia de las comunidades, así como no se han realizado actividades para revivir la memoria histórica de las necesidades que originaron la organización, y de la participación de las comunidades en la misma. Se pudo observar por lo tanto una crisis de liderazgos que en cierto momento ha debilitado la misma organización, aunque observamos un decidido esfuerzo por parte de algunos grupos al interno de la organización para avanzar en este sentido.

Un paso importante hacia el desarrollo en otros ámbitos de la vida social, más allá de la impartición de justicia y la seguridad, es el impulso que en la primavera del 2007 se ha dado a la formación de un "Equipo de Comunicación Comunitaria", integrado por jóvenes de las comunidades que pertenecen al SSJC y que apunta hacia la instalación de una radio a nivel regional, así como al mantenimiento de la pagina de Internet de la organización creada en el mismo periodo ${ }^{191}$.

Estas consideraciones sobre el discurso político y su relación con los aciertos y las dificultades del proceso analizado, nos remiten a las advertencias de López y Rivas sobre la necesidad de la conformación de un sujeto autonómico para el éxito de cualquier proceso de autonomía. Éste, entendido como "sujeto colectivo de transformación social, con base territorial y con identidad socioétnica, [deberá contar] no sólo con la capacidad de representar por consenso los intereses de la colectividad, sino también para constituirse en un interlocutor legítimo implicado en el proceso de negociación y diálogo" (2004: 169).

Es decir, además de la capacidad de organización, que tiene qué ver con el ámbito de la práctica, muy fuerte en el proceso de la Policía Comunitaria, es fundamental que se desarrolle la "capacidad de propuesta y de formas de luchas efectivas y generadoras de consenso", lo que atañe al ámbito del discurso, de la creación de imaginario y de cohesión alrededor de un proyecto político.

A pesar de estas debilidades a nivel discursivo, es innegable la fuerza que el SSJC tiene en los ámbitos de acción en que se ha avocado, o sea el control del territorio para garantizar la seguridad, y la impartición y administración de justicia. En este campo, se da alto nivel de 
autonomía: todos los procedimientos se desarrollan de forma independiente del sistema oficial, hasta proponer un sistema completamente original de castigo (la reeducación por medio del trabajo comunitario). Además, se trata de un sistema jurídico que ha definido para sí mismo un alcance mucho más amplio de lo previsto por las leyes del Estado, ya que abarca todos tipos de asuntos civiles y penales (más no agrarios), hasta los delitos graves (como el homicidio y la violación). El sistema jurídico utilizado deriva en buena parte de las leyes y procedimientos formales, aunque reinterpretados y entretejidos con prácticas locales de resolución de conflictos, que reflejan la organización social y cultural de los pueblos que habitan la región. Esto determina la pauta y la especificidad de su autonomía en la práctica jurídica.

Es cierto que el SSJC se limita a ejercer el poder autónomo en el campo jurídico, pero también cabe destacar que éste es un campo de suma importancia al interior de la vida de cualquier grupo social. Asimismo es un ámbito clave para el Estado, ya que a través de las normas y del uso legítimo de la fuerza ejerce el control sobre los ciudadanos: de aquí que surjan fuertes conflictos cuando se pone en discusión la legitimidad de las instituciones en el aspecto normativo y represivo. Según el análisis de LATAUTONOMY,

cuanto más eficientes son los mecanismos de solución de conflictos aplicando el derecho consuetudinario en ámbito local y regional, mayor es la sostenibilidad política de un sistema. Porque la gobernabilidad democrática en el sentido de la good governance depende en gran medida si los sujetos autonómicos logran consolidar su sistema jurídico interno. O dicho de otra manera: cuanto más fuerte es la influencia del sistema del Estado nacional, menor es la sostenibilidad política y económica y más débil la autonomía ${ }^{192}$.

Demuestran la trascendencia de la autonomía la eficacia de la institución autónoma en la reducción de la delincuencia en la región, y la legitimidad de la que goza entre la población de las comunidades y de las ciudades.

También se puede afirmar que la CRAC ejerce una relevante fuerza política y de presión en otros procesos y luchas sociales de la zona. Asimismo he observado que cubrir cargos en la CRAC o en el Comité Ejecutivo de la PC, y desempeñarlos con éxito, confiere autoridad a las personas y espacios de poder en las comunidades.

Por lo tanto, el SSJC crea poder autónomo y lo ejerce, aunque siga siendo dependiente de las instituciones municipales para su funcionamiento. En el ámbito economico, los recursos

\footnotetext{
${ }^{191}$ www.policiacomunitaria.org. Un analisis de este proceso se encuentra en el articulo "La Policía Comunitaria de Guerrero explora otra comunicación", Ojarasca, La Jornada, julio 2007, www.jornada.unam.mx/2007/07/16/oja123-guerrero.html

192 Hipótesis de Gobernabilidad.
} 
necesarios al desarrollo de su función, tanto la jurídica como la de seguridad, provienen enteramente de aportaciones externas, esencialmente de instancias gubernamentales, en primer lugar los Ayuntamientos y también de la delegación regional de la Comisión para el Desarrollo de los Pueblos Indígenas. Tal situación de dependencia limita fuertemente la sostenibilidad del proceso y por lo tanto su autonomía, de acuerdo con el análisis de LATAUTONOMY donde se afirma que "un proceso autonómico se caracteriza por una interdependencia permanente entre la dimensión política y la dimensión económica". Esto se debe a que se trata de una experiencia autonomica que no abarca todos los ámbitos de la vida social, y por lo tanto no puede sostenerse por sí misma. En este aspecto, me parece interesante el esfuerzo de los últimos meses para conferir a la organización competencias en otros ámbitos de la vida social, como la constitución del Equipo de Comunicación, formado por jóvenes de las comunidades integradas al Sistema ${ }^{193}$.

\section{Autonomía: práctica y proceso}

Según la interpretación propuesta por el estudio LATAUTONOMY,

En un sistema autonómico, que es un proceso social del cual emerge un nuevo sujeto político, debe existir un equilibrio entre la dimensión política-jurídica, la dimensión cultural-intercultural y la dimensión económica-ecológica. Si un proceso autonómico tiene carencias de una de estas

dimensiones (por la sobre dimensión de otra), existe el peligro que actores externos (Estado nacional, terratenientes, compañías transnacionales etc.) penetren el sistema, lo subviertan desde adentro y lo destruyan $^{194}$.

En la experiencia analizada, como he expuesto a lo largo del texto, no hay equilibrio entre las varias dimensiones (en particular no se han desarrollado los aspectos económico y ecológico) lo cual sin duda representa una debilidad para la institución autónoma. Hasta ahora ésta ha resistido a través de la constante negociación con las instituciones formales de sus espacios de acción, conquistando amplia libertad en el campo jurídico a partir de la incontestada legitimidad que tiene.

Como argumentaba en el capítulo 2.1, muchas iniciativas de los pueblos son prácticas donde se ejerce la autonomía pero parcialmente, lo cual no le quita su carácter autonómico. Se trata sin duda de procesos que abren espacios de democracia más horizontal, aunque

\footnotetext{
${ }^{193}$ Con este nuevo proyecto la CRAC trata de acercar y dar un papel activo al interno de la organización a las nuevas generaciones, que no han participado en la fundación del Sistema y se han apropiado de la institución autónoma de forma marginal. En segundo lugar, el compromiso hacia la comunicación refleja la voluntad de mayor intercambio entre las estructuras regionales y las comunidades, así como la necesidad de vincularse con otras experiencias en la región y afuera de ella.

${ }^{194}$ LATAUTONOMY, Hipótesis del Equilibrio.
} 
limitados a determinados aspectos de la organización social, que son los campos donde en cada contexto especifico se han manifestado con más fuerza las carencias de las instituciones formales y las necesidades particulares o diferenciadas de los pueblos.

Puedo definir la acción del SSJC una práctica contrahegemónica, afirmando que está construyendo autonomía en el campo jurídico y de la seguridad, espacios anteriormente hegemonizados por las instituciones formales. También puedo afirmar que la experiencia analizada es un proceso autonómico, entendiendo el proceso como un trayecto, donde las debilidades y los límites evidenciados pueden representar los eslabones de una escalera que aún se tienen que subir hacia la construcción integral de la autonomía, la cual se desarrolla por etapas y de acuerdo a las condiciones, internas y externas, en continua modificación.

Esta, como otras experiencias similares de prácticas autonómicas circunscritas a aspectos específicos de la vida social, podrá completarse si se avanza en la construcción del sujeto autonómico que involucre de forma activa, y según sus especificidades, todos los actores sociales presentes en la zona, alrededor de un proyecto político incluyente. 


\begin{tabular}{|c|c|c|c|c|c|}
\hline \multicolumn{6}{|c|}{ PERFIL DE LOS ENTREVISTADOS } \\
\hline \multicolumn{6}{|c|}{ SISTEMA DE SEGURIDAD Y JUSTICIA COMUNITARIA } \\
\hline EDAD & $\begin{array}{l}\text { SEXO } \\
M\end{array}$ & INDÍGENA & $\begin{array}{l}\text { NO } \\
\text { INDIGENA }\end{array}$ & OCUPACIÓN & $\begin{array}{ll}\text { CARGO EN } & \text { LA } \\
\text { ORGANIZACIÓN } & \\
\text { (ACTUAL } & \text { O } \\
\text { PRECEDENTE) } & \end{array}$ \\
\hline $40+/-$ & & tlapaneca & & Ama de casa & $\begin{array}{l}\text { Comisión de Mujeres } \\
1998 \\
\text { Coord. CRAC } 2007 \\
\end{array}$ \\
\hline 35 & & & $x$ & Abogado & Asesor externo PC \\
\hline $50+/-$ & & & $\mathrm{x}$ & Campesino & $\begin{array}{ll}\text { Comandante } & \text { Regional } \\
\text { PC } 1998 & \\
\end{array}$ \\
\hline $40+/-$ & & & $x$ & Campesino & Coord. CRAC 2004 \\
\hline $65+/-$ & & tlapaneco & & Campesino & $\begin{array}{l}\text { Comandante Region. PC } \\
2000 \text {; Coord. CRAC } \\
2002\end{array}$ \\
\hline $65+/-$ & & tlapaneco & & Campesino & $\begin{array}{l}\text { Comandante PC 1995; } \\
\text { Comandante Region. PC } \\
1997\end{array}$ \\
\hline 65 & & tlapaneco & & Campesino & Comandante PC 1995 \\
\hline 60 & & tlapaneco & & Maestro & Coord.CRAC 2002 \\
\hline 57 & & tlapaneco & & Maestro & Consejero CRAC \\
\hline 61 & & & $\mathrm{x}$ & Campesino & Coord. CRAC 2006 \\
\hline 38 & & tlapaneca & & Empleada CECAFE & $\begin{array}{l}\text { Comisión de Mujeres } \\
1998 / 2006\end{array}$ \\
\hline 30 & & tlapaneca & & $\begin{array}{l}\text { Coord.Nacional Mujeres } \\
\text { Indígenas }\end{array}$ & $\begin{array}{l}\text { Comisión de Mujeres } \\
2006\end{array}$ \\
\hline $50+/-$ & & tlapaneco & & campesino & Comandante PC \\
\hline $60+/-$ & & & $\mathrm{x}$ & campesino & Comandante Reg. PC \\
\hline \multicolumn{6}{|c|}{ OTROS } \\
\hline 41 & & & $\mathrm{x}$ & $\begin{array}{l}\text { Campesino } \\
\text { Comisario Municipal } \\
2006\end{array}$ & Comisario Municipal \\
\hline $50+/-$ & & & $x$ & parroco & \\
\hline 45 & & & $\mathrm{x}$ & parroco & \\
\hline 44 & & tlapaneco & & $\begin{array}{llll}\text { Dirigente } & \text { Luz } & \text { de } & \text { la } \\
\text { Montaña } & & & \\
\end{array}$ & \\
\hline \multicolumn{6}{|c|}{ AUTORIDADES } \\
\hline 51 & & tlapaneco & & $\begin{array}{lr}\text { Presidente } & \text { Municipal } \\
\text { Malinaltepec } & 2005 / 2005\end{array}$ & \\
\hline 45 & & tlapaneco & & $\begin{array}{lr}\text { Sindico } & \text { Municipal } \\
\text { Malinaltepec } & \text { (antes: } \\
\text { dirigente URC) } & \\
\end{array}$ & \\
\hline $65+/-$ & & & $\mathrm{x}$ & $\begin{array}{l}\text { Fiscalia especializada } \\
\text { para la atención a } \\
\text { pueblos indígenas y } \\
\text { regional- PGR }\end{array}$ & \\
\hline 55 & & & $\mathrm{x}$ & $\begin{array}{l}\text { Director } \\
\text { Publica }\end{array}$ & \\
\hline 46 & & & $\mathrm{x}$ & $\begin{array}{ll}\text { Agente } & \text { Ministerio } \\
\text { Publico } & \\
\end{array}$ & \\
\hline 35 & & & $\mathrm{X}$ & Juez Mixto de Paz & \\
\hline 47 & & & $x$ & $\begin{array}{l}\text { Juez Mixto de Primera } \\
\text { Instancia }\end{array}$ & \\
\hline
\end{tabular}




\begin{tabular}{|l|l|l|c|l|l|}
\hline \multicolumn{9}{|c|}{ OTRAS ORGANIZACIONES } \\
\hline EDAD & $\begin{array}{l}\text { SEXO } \\
\text { M }\end{array}$ & INDIGENA & $\begin{array}{l}\text { NO } \\
\text { INDIGENA }\end{array}$ & OCUPACIÓN & $\begin{array}{l}\text { CARGO EN LA ORGANIZACIÓN } \\
\text { (ACTUAL O PRECEDENTE) }\end{array}$ \\
\hline 68 & $\mathrm{x}$ & & $\mathrm{x}$ & Empleado UAG & Ex Integrante ACNR \\
\hline 36 & $\mathrm{x}$ & amuzgo & & Campesino & $\begin{array}{l}\text { Coordinador Radio Nomnadaa } \\
\text { (Xochistlahuaca) }\end{array}$ \\
\hline 51 & $\mathrm{x}$ & & $\mathrm{x}$ & $\begin{array}{l}\text { Presidente Org. Pueblo Indígena } \\
\text { Tlapaneco } \\
\text { (Ayutla de los Libres) }\end{array}$ \\
\hline 67 & $\mathrm{x}$ & & $\mathrm{x}$ & Campesino & Ex integrante ACNR \\
\hline 65 & $\mathrm{x}$ & & $\mathrm{x}$ & $\begin{array}{l}\text { Profesor } \\
\text { universitario }\end{array}$ & Integrante ACNR \\
\hline
\end{tabular}




\section{BIBLIOGRAFÍA}

\section{AA.VV.:}

-2002 Moviendo Montañas...Transformando la geografía del poder en el sur de México, México, El Colegio de Guerrero A.C.

Anderson, Benedict:

-1993 Comunidades imaginadas. Reflexión sobre el origen y la difusión del nacionalismo, México, FCE

Assies, Willem:

-2000 “La oficialización de lo no oficial: ¿Re-encuentro de dos mundos?”, en www.alertanet.org

-1999 "Pueblos indígenas y reforma del Estado en América Latina", en W. Assies, G. Van der Haar y A. Hoekema, (eds.), El reto de la diversidad. Pueblos indígenas y reforma del estado en América Latina, México, COLMICH

Barrera Hernández, Abel y Sarmiento, Sergio:

-2006 "De la Montaña Roja a la Policía Comunitaria: violencia y militarización en la Montaña de Guerrero", en V. Oikón Solano y M. E. García Ugarte (coords.) Movimientos armados en México: siglo $X X$, Zamora, El Colegio de Michoacán-CIESAS

Bartolomè, Miguel:

-1995 "Movimientos etnopoliticos y autonomías indígenas en México", en G.Gruberg (coord.) Articulación de la diversidad. Pluralidad étnica, autonomías y democratización en América Latina, Quito, Abya-Yala, pag.227-256

-1997 Gente de costumbre y gente de razón, México, Siglo XXI

-y Varese, Stefano:

1986 “Un modelo procesal para la dinámica de la pluralidad cultural”, en A. Barabas y M. Bartolomé (coords.) Etnicidad y pluralismo cultural: la dinámica étnica en Oaxaca, México, Instituto Nacional de Antropología e Historia- Colección Centros Regionales.

-y Barabas, Alicia (coord):

-1998 Autonomía étnica y estados nacionales, México, CONACULTA-INAH

Bartra, Armando:

-1996 Federalismo y democracia. El papel de los municipios en el desarrollo social, México, Instituto de Estudios para el Desarrollo Rural Maya

-1996 Guerrero bronco. Campesinos, ciudadanos y guerrilleros en la Costa Grande México, ERA

-2000 (compilador) Crónicas del Sur. Utopías campesinas en Guerrero, México, ERA

Becauge, Pierre:

-2000 "Más allá de lo jurídico. Reflexiones sobre procesos autonómicos indígenas en América", en L. Reina(coord.) Los Retos de la etnicidad en los estados nación del siglo XXI, México, CIESAS-INI-Porrúa, pp. 299-321

Binion, Gale:

-1995 "Human Rights: A feminist perspectiva", en Human Rights Quarterly, vol. 17, pp 509-526

Buruguete Cal y Mayor, Araceli (coord.):

-1999, México: experiencias de autonomía indígena, Guatemala, IWGIA Calvo García, Manuel:

-2002 Identidades culturales y derechos humanos, Madrid, Dykinson

Canabal Cristiani, Beatriz:

-2001 "Introducción general", "Estrategias de sobrevivencia y el contorno regional", "Conclusiones" en B. Canabal Cristiani (coord.) Los caminos de la Montaña. formas de reproducción social en la montaña de Guerrero, México, UAM-CIESAS-Porrúa, pp.15-62; pp.281-289

-y Flores Felix, Joaquim (coords.):

- 2004 Montañeros: Actores sociales en la Montaña de Guerrero, México, UAM-Universidad de Chapingo

Carlsen, Laura:

-1999 “Autonomía indígena y usos y costumbres", en Chiapas 7, pp.45-70, México, ERA-UNAM

Castellanos Guerrero, Alicia:

-2000 Racismo, multietnicidad y democracia en América Latina, Nueva Antropología. Revista de Ciencias Sociales, №. 58, México, pp. 1-17

-2003 "Tolerancia, racismo y pueblos indios de México", en América Indígena, Vol. LIX Número 3, Jul.Sept. 2000

Clavero, Bartolomé:

-1994 Derecho indígena y cultura constitucional en América, México, Siglo XXI

Collier, Jane:

-1995 "Problemas teórico-metodológicos en la antropología jurídica", en V. Cheanut, y M. T. Sierra (coords.), Pueblos Indígenas ante el derecho, México, CIESAS-CEMCA, pagg. 45-78 
-y Speed, Shannon:

-2000 "Autonomía indígena, el discurso de los derechos humanos y el Estado: dos casos en Chiapas", en Cemos Memoria n.139, México, pp.5-11

Cordero Avendaño de Duran, Carmen:

-1997 Contribución al estudio del derecho consuetudinario triqui, México, Instituto de Administración Publica de Oaxaca

Dehouuve, Danièle:

-2001 Ensayo de geopolítica indígena. Los municipios tlapanecos, México, CIESAS-Porrúa

-2002 Cuando los banqueros eran santos. Historia económica y social de la provincia de Tlapa, Guerrero; México, UAG-Fomento Universitas

-y Pellottier, Victor F.; Hemond, Aline (coords.):

-2006 Multipartidismo y poder en la Montaña de Guerrero, México, CIESAS-Universidad Autónoma de Guerrero

Del Val, José:

-2004 México: identidad y nación, México, UNAM

Díaz-Polanco, Héctor:

-1996 Autonomía regional. La autodeterminación de los pueblos indígenas, México, Siglo XXI

-1997a Nicaragua: Diez años de autonomía en Nicaragua, en ALAl, América Latina en Movimiento n.258, $17 / 09 / 1997$

-1997b La rebelión zapatista y la autonomía, México, Siglo XXI

-2005 "Etnofagía y multiculturalismo", en Cemos-Memoria n.2000, septiembre 2005

-y Sánchez, Consuelo:

-2002 México Diverso. El debate por la autonomía, México, Siglo XXI

Esteva, Gustavo:

-1995 “Autonomía convivial”, en P. González Casanova (coord.) Etnicidad, democracia y autonomía, México, UNAM-CHIMEC

-1998 "Autonomía y democracia radical: el transito de la tolerancia a la hospitalidad", en M. Bartolomé y

A. Barabas, Autonomía étnica y estados nacionales, México, CONACULTA-INAH, pp 307-333.

Estrada Castañon, Maria Teresa:

-1994 Guerrero: sociedad, economia, política y cultura, México, UNAM

Estrada Martínez, Rosa Isabel y González Guerra, Gisela (coords.):

-1997 Tradiciones y costumbres jurídicas en comunidades indígenas de México, México, CND

Fatiné, Eela:

-2001 Construyendo el pluralismo jurídico, Guatemala, Defensoría Maya

Flanet, Veronique:

-1985 La madre muerte. Violencia en México

Flores Félix, José Joaquín:

-2004 Reinventando la ciudadanía: la construcción social de la democracia en la región Costa Montaña de Guerrero, Tesis de Doctorado en Antropologia, CIESAS, México D.F.

Florescano, Enrique:

-1996 Etnia, estado y nación. Ensayo sobre las identidades colectivas en México, México, Aguilar

García, Carlos:

2000 "De la Costa a la Montaña", en A. Bartra (compil.) Crónicas del Sur. Utopías Campesinas en Guerrero, ERA, México, pp. 275-320

García Canclini, Néstor:

-1999 La globalización imaginada, México, Paidós

-2004 Diferentes, desiguales y desconectados, Barcelona, Gedisa

García Leyva, Jaime:

-1999 La lucha social en la Montaña de Guerrero: la Unión Obrera Campesina Emiliano Zapata (1991/1998), Tesis de Licenciatura en Historia, Universidad Autónoma de Guerrero, Chilpancingo

\section{García Linera, Álvaro:}

-2005 “Autonomías indígenas", en F. Escárzaga y R. Gutiérrez, Movimiento indígena en América Latina: resistencia y proyecto alternativo, México, GDF-JP-UAP-UNAM-UACM, pp.273-290

\section{García Romano, Gerardo:}

-1999 El ejercicio del poder político en la Montaña de Guerrero (1980-1998), Tesis de Licenciatura, México, Universidad de Chapingo

\section{Gasparello, Giovanna:}

-2005 L'autonomia possibile. Chiapas: la costruzione dell'autogoverno nelle comunità indigene della Selva Lacandona, Venezia, Editoria Universitaria 
-2007 "Costruendo nuovi diritti: amministrazione autonoma della giustizia nella Costa-Montaña del Guerrero, Messico", Quaderni di Thule VI, Actas del XXVIII Congreso Internacional de Americanistica (Perugia 3-7 maggio 2006 / Mérida 25-29 ottobre 2006), Argo, pp. 959-964

Giménez, Gilberto:

-2000, "Territorio, cultura e identidades. La región sociocultural", en Cultura y Región, Bogotá, CesUniversidad Nacional-Mincultura.

Gómez, Magdalena:

-2002 "Derecho indígena y constitucionalidad", en E. Krotz (ed.) Antropología Jurídica: perspectivas socioculturales en el estudio del derecho, Barcelona, Anthropos/UAM-I, pp.235-277

González Galván, Jorge Alberto (coord,):

-2002 Constitución y derechos indígenas, México, UNAM-IIJ

Gros, Christian:

-2000 "Ser diferente para ser moderno, o las paradojas de la identidad. Algunas reflexiones sobre la construcción de la frontera étnica en América Latina", en L. Reina(coord.) Los Retos de la etnicidad en Ios estados nación del siglo XXI, México, CIESAS-INI-Porrúa, pp. 171-195

Gutiérrez Ávila, Miguel Ángel (coord.)

-1997 Derecho consuetudinario y derecho positivo entre los mixtecos, amuzgos y afromestizos de la Costa Chica de Guerrero, México, CNDH-UAG

Gutiérrez Chong, Natividad:

-2004 "Mercadotecnia en el indigenismo de Vicente Fox", en R. A. Hernández, S. Paz y M. T. Sierra (coords.), El estado y los indígenas en tiempos del PAN: neoindigenismo, legalidad, identidad, México, CIESAS -Porrúa, pp.27-52.

Hale, Charles:

-2004a "Rethinking indigenous politics in the age of the 'indio permitido', NACLA Report of Americas, vol. $38(2)$

$-2004 \mathrm{~b}$ "Neoliberal Multiculturalism: the remaking of cultural rights and racial dominance in Central America", en PoLAR: Political and Legal Anthropology Review, Vol. 28, No. 1, pp. 10-28, AAA-California University Press

-2006 “¿En contra del reconocimiento? Gobierno plural y análisis social ante la diferencia cultural”, ponencia presentada en el V Congreso de la Red Latinoamericana de Antropología Jurídica, 16 a 20 de Octubre 2006, Oaxtepec, México.

Hardt, Michael y Negri, Antonio:

-2002 Imperio, Buenos Aíres, Paidós

-2004 Moltitudine. Guerra e democrazia nell'ordine imperiale, Milano, Rizzoli

Harvey, Neil:

-2004 "Disputando el desarrollo: el Plan Puebla Panamá y los derechos indígenas", en R. A. Hernández, S. Paz y M. T. Sierra (coords.), El estado y los indígenas en tiempos del PAN: neoindigenismo, legalidad, identidad, México, CIESAS -Porrúa, pp. 115-135

Hernández Navarro, Luís:

-1992 "Las convulsiones sociales", en J. Moguel, C. Botey y L. Hernández (coords.), Autonomía y nuevos sujetos sociales en el desarrollo rural, México, Siglo XXI

-1998 Chiapas: la guerra y la paz, México, ADN

-"La autonomía indígena como ideal. Notas a La rebelión zapatista y la autonomía de Héctor Díaz-

Polanco", Chiapas, n. 2, Era, México, marzo de 1997, pp. 119-132.

-y Vera, Ramón:

-1997 Los Acuerdos de San Andrés, México, ERA

Hernández Castillo, Rosalva Aída:

-2001, La otra frontera. Identidades multiples en el Chiapas postcolonial, México, Porrua-CIESAS.

-2002 "Indigenous Law and Identity Politics in Mexico: Indigenous Men's and Women's Struggles for a

Multicultural Nation", en PoLAR, Political and Legal Anthropology Review: Vol. 25, No. 1 May 2002 pp.90110

-y Paz Patiño, Sarela; Sierra, Maria Teresa (coords.):

-2004 El estado y los indígenas en tiempos del PAN: neoindigenismo, legalidad, identidad, México, CIESAS -Porrúa.

Krotz, Esteban:

-1993 "Introducción: identidades culturales profundas y alternativa civilizatoria", en G. Bonfil Batalla, (coord.) Hacia nuevos modelos de relaciones interculturales, México, CNCA

-1995 "Ordenes jurídicos, antropologia del derecho, utopía. Elementos para el estudio antropológico de lo jurídico", en V. Chenaut y M. T. Sierra (coords.), Pueblos indígenas ante el derecho, México, CIESASCEMCA, pp.345-354 
Kymlicka, Will:

-1996 Ciudadanía multicultural, España, Paídos

Iturralde, Diego:

-1990 "Movimiento indio, costumbre jurídica y uso de la ley", en D. Iturralde y R. Stavenhagen (coords.), Entre la Ley y la Costumbre. El Derecho Consuetudinario Indígena en América Latina, México, Instituto Indigenista Interamericano- Instituto Interamericano de Derechos Humanos, pp.47-63

León Pasquel, Lourdes (coord.):

-2001 Costumbres, leyes y movimiento indio en Oaxaca y Chiapas, México, CIESAS- Porrúa

López Bárcenas, Francisco:

-2004 "La lucha por la autonomía indígena: un reto al pluralismo", en R. A. Hernández, S. Paz y M. T. Sierra (coords.) El estado y los indígenas en tiempos del PAN: neoindigenismo, legalidad, identidad. México: CIESAS -Porrúa. pp. 207 -232

-2005[2002] Autonomía y derechos indígenas en México, México, CEIICH/UNAM-Ediciones Coyoacán

López y Rivas, Gilberto:

-1995 Nación y pueblos indios en el neoliberalismo, México, Plaza y Valdés-Universidad Iberoamericana -2002 "Las autonomías indígenas", en J. A. González Galván (coord.), Constitución y derechos indígenas, México, UNAM-IIJ, pp.113-120

-2004 Autonomía, Democracia o Contrainsurgencia, México, ERA

-2005a "Introducción. Algunos referentes teóricos", en G. López y Rivas y L. Gabriel (coords.) Autonomías indígenas en América Latina, México, Plaza y Valdés, pp.29-46

-2005b "México: las autonomías de los pueblos indios en el ámbito nacional”, en G. López y Rivas, y L. Gabriel, (coords), Autonomías indígenas en América Latina, México, Plaza y Valdés, pp-47-112

-2007 "Pueblos indígenas: entre agresiones y resistencias", en La Jornada, 20 abril 2007

Martínez Sifuentes Esteban:

-2000, La Policía Comunitaria: un sistema de seguridad pública comunitaria indígena del estado de Guerrero, México, INI

Matías Alonso, Marcos:

-1997 La agricultura indígena en la Montaña de Guerrero, México, DDV-PACMYC-Plaza y Valdés

Mattiace, Shannan:

-2002 Tierra, Libertad y Autonomía: impactos regionales del zapatismo en Chiapas, S. Mattiace, R. A. Hernández e J. Rus (coords), México, CIESAS-IWGIA.

Merry, Sally Engle:

-1988 Legal Pluralism, en Law and Society Review, Vol. 22, pp. 869-96.

Montoya Rojas, Rodrigo:

-1998 Derechos indígenas, ciudadanos y humanos, Lima, Ediciones SUR

Muñoz Cruz, Héctor:

-2004 “Interculturalidad en la educación, multiculturalismo en la sociedad: ¿paralelos o convergentes?”, http://interbilingue. ajusco.upn.mx/modules.php?name=News\&file=article\&sid=99

Oemichen Bazán, Cristina:

-1999 Reforma del estado. Política social e indigenismo en México (1988-1996), México, UNAM, Instituto

Olivé, León: de Investigaciones Antropológicas

-1993 Ética y diversidad cultural, México, UNAM-FCE

-1996 "Multiculturalismo: ni universalismo, ni relativismo", en L. Villoro y L. Olivé (eds.), Filosofía moral, educación e historia. Homenaje a Fernando Salmerón, UNAM, Mexico

-1999 Multiculturalismo y pluralismo, México, Paídos-UNAM

-2004 Interculturalismo y justicia social, México, UNAM

Ordoñez Cifuentes (coord.)

-2005 Pluralismo Jurídico y pueblos indígenas. XIII Jornadas Lascasianas internacionales, México, IIJUNAM

Ortega, Amor, y Peral, Martha:

-2006 "Seguridad e impartición de justicia comunitaria regional en la Costa Montaña de Guerrero: La Policía Comunitaria", ponencia presentada en el V Congreso de la Red Latinoamericana de Antropologia Jurídica, México 2006.

Paz Patiño, Sarela:

-2004 "Pensando la diferencia en su posibilidad política", en R. A. Hernández, S. Paz y M. T. Sierra (coords.), El estado y los indígenas en tiempos del PAN: neoindigenismo, legalidad, identidad, México, CIESAS -Porrúa, pp. 357-384 
Pitarch, Pedro (ed.):

-2001, Representaciones y usos del concepto de Derechos Humanos en el Área Maya, Madrid, Universidad Complutense

Programa de las Naciones Unidas para el Desarrollo- Nicaragua:

-2005 Informe de desarrollo humano. Las regiones autónomas de la Costa Caribe. ¿Nicaragua asume su diversidad?, Managua, PNUD

Regíno Montes, Adelfo:

-1996 "La autonomía: una forma concreta de ejercicio del derecho a la libre determinación y sus alcance"s, ponencia presentada en nombre de Servicios del Pueblo Mixe A.C., en el Foro Nacional Indígena, San Cristóbal de las Casas, enero 1996 [en Chiapas 2 , México, ERA]

-1999 "Los pueblos indígenas: realidades, derechos y reconstitución", documento revisado para el Diplomado de Antropologia Aplicada para el Etnodesarrollo del CIESAS-Istmo

Rendón Alarcón, Jorge:

-2003 Sociedad y conflicto en el estado de Guerrero, 1991-1995, México, Plaza y Valdés

Reygadas, Luís:

-2005 "La desigualdad después del multiculturalismo", en Varios Autores, A donde va la antropología, México, UAM (en prensa)

Ribeiro, Lins:

-2003 Postimperialismo. Cultura y política en el mundo contemporáneo. Barcelona, Gedisa

Román Román, Salvador:

-2001 Revuelta cívica en Guerrero (1957/60), México, INHERM

Salgado Judith (comp.):

-2002 Justicia Indígena. Aportes para un debate, Abya Yala, Quito

Sánchez Serrano, Evangelina:

-2006 El proceso de construcción de la identidad política y la creación de la Policía Comunitaria en la Costa-Montaña de Guerrero, Tesis de doctorado en Sociología, México, UNAM

Sandoval, Abigail:

-2005 No es lo mismo la teoría que la práctica: el ejercicio de la justicia comunitaria desde la cotidianeidad de los mixtecos de Buena Vista, municipio de San Luís Acatlán, Tesis de Maestría en Antropología Social, México CIESAS

Sandoval Forero, Eduardo Andrés:

-2001, La ley de las costumbres en las indígenas mazahuas, México, UACM

Sarmiento Silva, Sergio:

-1991 "Movimientos indígenas y participación política", en A. Warman e A. Argueta (coord.) Nuevos enfoques para el estudio de las etnias indígenas en México, México, Centro de Investigaciones Interdisciplinarias en Humanidades- UNAM

-1996 "Movimiento indio, autonomía y agenda nacional", en H.C. de Grammond (coord.) Neoliberalismo y organización social en el campo mexicano, UNAM-Plaza y Valdés

-1998 Voces indias y V centenario, México, CONACULTA-INAH

-2001 "Procesos y movimientos sociales en la montaña de Guerrero. Entre el corporativismo y la violencia", en B. Canabal Cristiani (coord.) Los caminos de la Montaña. formas de reproducción social en la montaña de Guerrero, México, UAM-CIESAS-Porrúa, pp.239-256

-2004 "El movimiento indígena de Guerrero en el umbral del nuevo milenio", en Décimo Informe, Centro de Derechos Humanos Tlachinollan, www.tlachinollan.org

-y Bustamante Álvarez, T.:

-2001 El Sur en Movimiento. La reinvención de Guerrero en el siglo XXI, Ed. Laguna, México

Sieder, Rachel:

-2002 Multiculturalism in Latin America. Indigenous Rights, Diversity and Democracy, Palgrave-MacMillan -y Witchell, Jessica:

-2001 "Impulsando los derechos indígenas a través de la ley”, en Pedro Pitarch y Julian López (coords.), Los derechos humanos en tierras mayas, Sociedad Española de Estudios Mayas, pp.55-82.

Sierra, Maria Teresa:

-2001 "Conflicto cultural y derechos humanos: en torno al reconocimiento de los sistemas normativos

indígenas", en Cemos-Memoria, Revista de Cultura y Política n. 147, México

-1997 "Esencialismo y autonomía: paradojas de las reivindicaciones indígenas", en Alteridades n. 14, México, UAM-Iztapalapa

-2004 (coord.) Haciendo justicia. Interlegalidad, derecho y genero en regiones indígenas, México, CIESAS-Porrua 
-2005 "The revival of indigenous justice in México: challenge for human rights and the state", en PoLAR Political and Legal Anthropology Review, vol.28, No.1, pp.52-72

-2006 "La renovación de la justicia indígena en tiempos de derechos: etnicidad, genero y diversidad", en R. Stanley (coord.), Estado, violencia, ciudadanía en América Latina, Frankfurt/Madrid, Vervuert

-y Speed, Shannon:

2005 "Critical perspectives of human rights and multiculturalism in neoliberal Latin America", en PoLAR Political and Legal Anthropology Review, Vol. 28 No.1

\section{Sousa Santos, Boaventura:}

-1996 "Toward a Multicultural conception of human rights", Working paper series-Global studies program, Unyversity of Winsconsin-Madison

-1998 La globalización del derecho. Los nuevos caminos de la regulación y la emancipación, Bogotá, Universidad Nacional de Colombia-UNIBIBLOS

-2001 "Nuestra América: para reinventar un paradigma subalterno de reconocimiento y redistribución", en Chiapas No.12, México, IIE-UNAM

Speed, Shannon:

-2005 "Dangerous discourse: Human rights and multiculturalism in neoliberal Mexico", en PoLAR Political and Legal Anthropology Review, Vol. 28 No.1

Stavenhagen, Rodolfo:

-1988 Derecho indígena y derechos humanos en América Latina, México, El Colegio de México-Instituto Interamericano de Derechos Humanos

-1992 "Pueblos y derechos indígenas", en America Indígena, México, 1-2-1992

-e Iturralde, Diego (comp.):

-1990 Entre la Ley y la Costumbre. El Derecho Consuetudinario Indígena en América Latina, México, Instituto Indigenista Interamericano- Instituto Interamericano de Derechos Humanos

Stern, Steve:

-2000 "La construcción histórica: los indígenas como colonizadores", en L. Reina (coord.) Los retos de la etnicidad, México, CIESAS-INI-Porrua, pp.73-91

Taylor, Charles:

-1993 El multiculturalismo y "la política del reconocimiento", México, Fondo de Cultura Económica

Thompson, Richard:

-1997 "Ethnic minorities and the case for collective rights", en American Anthropologist, Vol.99, No.4

Trejo, Guillermo:

-2000 "Etnicidad y movilización social. Una revisión teórica con aplicaciones a la cuarta ola de movilizaciones indígenas en América Latina", en Política y Gobierno, Vol. VII, 1 pp. 205-250

Van Cott, Donna Lee:

-2000a The Friendly Liquidation of The Past. The Politics of Diversity in Latin America, Pittsburgh University Press

-2000b "A political analysis of legal pluralism in Bolivia and Colombia", en Journal of Latin American Studies, vol. 32 (1), pp. 207-234

-2005 "Pluralismo Legal y administración de la justicia comunitaria en América Latina", conferencia "Instituciones informales y política latinoamericana", Universidad de Notre Dame, Indiana, 24-25 abril 2005

Villoro, Luís:

-1996 "Igualdad y diferencia: un dilema político", en L. Villoro y L. Olivé (eds.), Filosofía moral, educación e historia. Homenaje a Fernando Salmerón, México, UNAM

-1998 Estado plural, pluralidad de culturas, México, Paídos-UNAM

-2002a "Multiculturalismo y derecho", en E. Krotz (ed.), Antropologia jurídica: perspectivas socioculturales en el estudio del derecho, Barcelona, Anthropos/UAM

-2002b “El Estado-nación y las autonomías indígenas", en J. A. González Galván (coord,), Constitución y derechos indígenas, México, UNAM-IIJ

Yashar, Deborah:

-2005 Contesting citizenship in Latin America, Cambridge University Press

Yrigoyen, Raquel:

-2000 Pautas de coordinación entre el derecho indígena y el derecho estatal, Guatemala, Fundación Myrna Mack, $1^{\text {a }}$ edición

Walsh, Catherine:

-2002 "Interculturalidad, reformás constitucionales y pluralismo jurídico", en http://icci.nativeweb.org/boletin/36/walsh.html 


\section{Zarate Hernández, Eduardo:}

-2005 "La comunidad imposible. Alcances y paradojas del moderno comunalismo", en M. Lisbona Guillen (coord.), La comunidad a debate. Reflexiones sobre el concepto de comunidad en el México contemporáneo, Zamora, COLMICH-UNICACH

\section{Zuñiga, Gerardo:}

-2000 "La dimensión discursiva de las luchas étnicas. Acerca de un artículo de María Teresa Sierra", en Alteridades n.19, México, UAM-I 
ADMINISTRACION AUTONOMA DE LA JUSTICIA Y SU RELACION CON EL ESTADO. EL SISTEMA DE SEGURIDAD Y JUSTICIA COMUNITARIA DE LA

COSTA-MONTAÑA DE GUERRERO, MEXICO
En México, D.F.. se presentaron a las 11:00 horas del día 30 del mes de agosto del año 2007 en la Unidad Iztapalapa de la Universidad Autónoma Metropolitana, los suscritos miembros del jurado:

DRA. ALICIA CASTELLANOS GUERRERO

DR. JOSE ENRIQUE GONZALEZ RUIZ

DRA. MARIA TERESA SIERRA CAMACHO

Bajo la Presidencia de la primera $y$ con carácter de Secretaria la última, se reunieron a la presentación de la

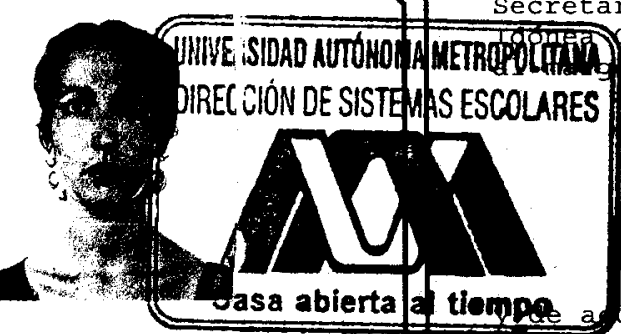
Comunicación de Resultados cuya denominación aparece n, para la obtención del grado de:

MAESTRA EN CIENCIAS ANTROPOLOGICAS

DE: GIOVANNA GASPARELLO
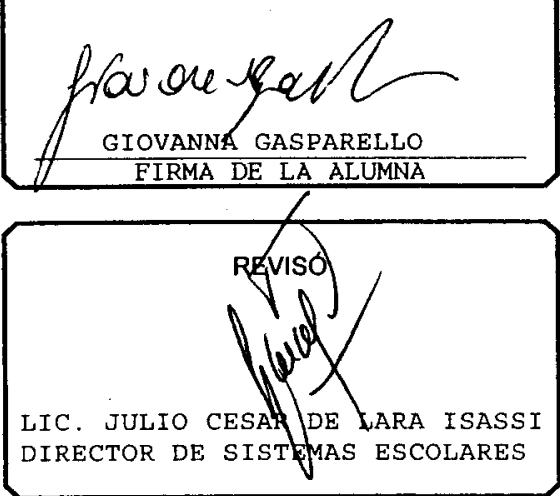

Metropolitana, los miembros del jurado resolvieron:
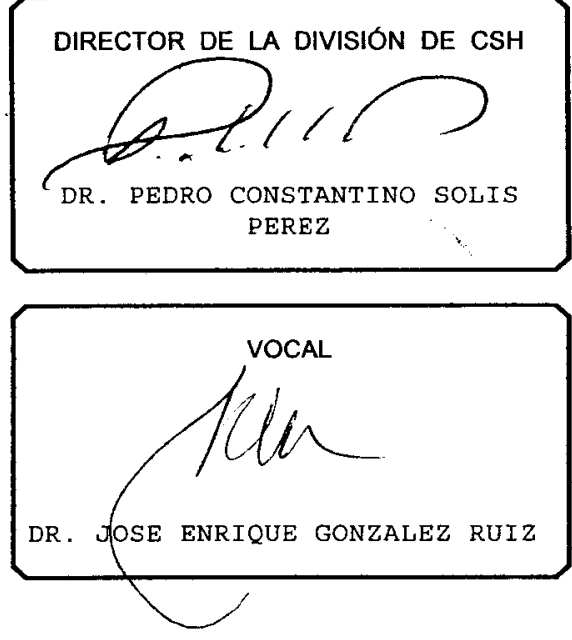

PRESIDENTA

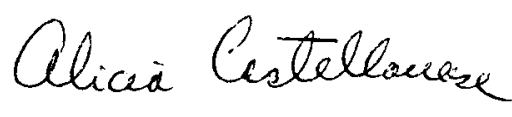

DRA. ALICIA CASTELLANOS GUERRERO

Acto continuo, la presidenta del jurado comunicó a la aprobatorio, le fue tomada la protesta.

\section{APROBAR}

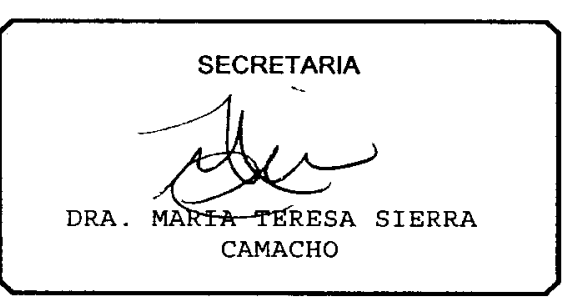

